A YEAR IN SCIENCE

WECKBL AND TTALMAN 


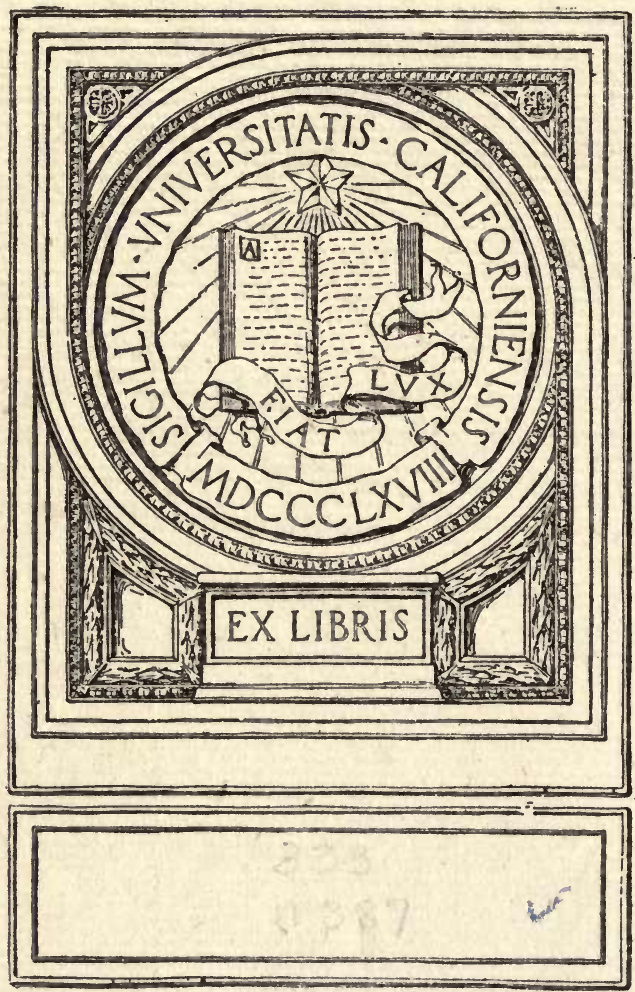





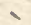




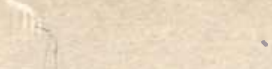


?

$$
\text { - }
$$




\section{A YEAR IN SCIENCE}

\section{A TEXT-BOOK FOR FIRST YEAR IN HIGH SCHOOLS}

ADA L. WECKEL, M.S.

- HEAD OF BIOLOGY DEPARTMENT, OAK PARK AND RIVER FOREST TOWNSHIP HIGH SCHOOL, OAK PARK, ILLINOIS

AND

JOSEPH L. THALMAN, A.M.

FORMER HEAD OF BIOLOGY DEPARTMENT, OAK PARK AND RIVER FOREST TOWNSHIP HIGH SCHOOL; PRINCIPAL OF HIGII SCHOOL, NEW CASTLE, PA. 
Copyright, 1916 ROW, PETERSON AND COMPANY

$$
\because \because \quad \because 3 \vdots \vdots
$$




\section{PREFACE}

The history of the many attempts to fit the different special sciences into the first year of the high school is too well known to require comment. As a result of these experiences, the conviction is becoming general that no one science is adequate for an introductory course. In the last few years the effort to present to the pupil subject matter of interest to him, adapted to his stage of mental development, and at the same time of educative value, has resulted in the development of many courses in general science. These courses vary somewhat in the organization of subject matter and in the method of presentation, but all of them are based upon the conviction that the first year of science should be fundamental to all the sciences.

In presenting this course we feel that it meets these fundamental requirements, first, in providing. a ground work in physies, chemistry, botany, zoology, physiology, and physical geography; and second, that it has stood the test of time. It has been carried through about fifteen years of experimentation in which frequent changes in material as well as eliminations and additions have been made, until it has now become fairly well established.

The course has for its purpose not so much the development of the subject alone as the consideration of that most important factor in teaching, namely, the develop- 
ment of the pupil. We hope that the scientific information will enable him to appreciate better the natural phenomena going on around him. The scientific training should enable him to observe more accurately, to interpret more sanely, to understand the vital importance of every day affairs, and, perhaps most important, to train him to apply acquired knowledge to useful ends and thus become a better eitizen of his community.

We wish to express our sincere appreciation to $\mathrm{Mr}$. J. C. Hanna, High School Supervisor for the State of Illinois, formerly principal of the Oak Park, Illinois, High School, for writing the Introduction and for his untiring inspiration and advice during the seven years in which we have been developing this course. It is due to Mr. Hanna's firm belief in the general science idea that this work has become a reality.

We wish also to express our appreciation for the advice and criticisms given us by the teachers who have been associated with us in the teaching of this course, especially for the valuable suggestions and assistance in proof reading by Miss Rachel Ott and Miss Ruth Williston of the Oak Park High School, and by Mr. F. L. Orth, Head of the Science Department of the New Castle, Pa., High School.

To all who have in any way contributed in the preparation of this work, we hereby make grateful acknowledgment.

$$
\begin{aligned}
& \text { A. L. W. } \\
& \text { J. L. T. }
\end{aligned}
$$




\section{INTRODUCTION}

Many sincere and intelligent persons have criticized the public school as an institution that clings too closely to obsolete aims and outworn methods.

Some text books, instead of ignoring this eriticism or indignantly resenting it, have attempted to meet it and to correct such tendencies as are really faults.

This publication by Mr. Thalman and Miss Weckel seems to the writer to be one of the most earnest and carefully prepared of the books made with that aim. This fact, as being distinctly related to the most far-reaching administrative problems, may justify the preparation of this introduction by one who is not a scientist.

Among the faults that have been observed in highschool science teaching, two have seemed conspicuous and at the same time possible to remedy. The writer is therefore glad to commend what appears to him to be a thoroughgoing and workable plan for eliminating those faults.

First, the material presented to beginners was too difficult for them and was not well adapted to their need and their stage of development. Second, the attention of the beginners was for a year confined to the narrow limits of one or another of the fields into which scientific phenomena are for many purposes very properly grouped. 
These faults have tended to make first year science courses inadequate, unfair, and likely to duill the edge of interest.

Surely the youth on the borderland of the New World, standing on the pinnacle of his fresh enthusiasm, has the right to a "look over" of the field, a general survey, before he takes up chain and transit for a detailed survey, has a right to a "bird's eye view" before he begins confining his attention to a "toad's eye view" in some particular section of the garden of nature.

The course here presented is the outcome of the desire suggested above, and of continued experimentation extending over more than fifteen years, to realize a course for first year pupils that should fill the following conditions :

1. A course that should introduce the pupil to the observing of natural phenomena and the recognizing of natural laws in a manner adapted to the stage of his maturity, and likely to hold and maintain his interest and stimulate his growth.

2. A course that should serve the purpose of training him, not only to observe with accuracy, but to think to just conclusion from the data thus gathered.

3. A course that should furnish him, in this process, with information which he is likely to find useful in his daily life and which he may thus have stored in his memory, or which he may thus be trained, as he needs it, to go and get, with pleasure and ease and success, by further study or by consulting references. 
4. A course that should prepare the way for any further systematic science study that may attract him or be needful.

5. A course that should conform to the Illinois state law which requires that all pupils below the second year of the high school and above the third year of school work shall study physiology and hygiene (including the nature of alcoholic drinks and other narcotics) for not less than four lessons a week for ten or more weeks of each year.

Though several text books in General Science have preceded the present one in date of publication, the present course was in successful operation for several years before any of them appeared.

The original idea was that of the present writer, but the credit for the work done belongs, of course, to the zeal, loyalty, patience, and skill of the several specialists who, from 1899 to the present time set themselves to the solution of the problem set forth above. While several instructors did much in the earlier years to clear the ground, the book itself, as it stands, is the work of the authors named on the title page. They are abundantly entitled to the credit that will be given them for making real a vague idea which was in the mind of another when they were little children.

The test of actual class-room experience with from ten to nineteen classes a year has only confirmed all concerned in these beliefs:

1. That certain preliminary science study of some 
sort should be done in the high school before the regularly accepted laboratory courses in physics, chemistry, botany, zoology, and physiography are taken up;

2. That such elementary studies are advisable for all pupils, whether the more advanced laboratory work is taken up later or not;

3. That, aside from the training value in such studies, consideration should be given to the matter of content with reference to the practical usefulness of the actual knowledge acquired; such consideration will demand the study of elementary truths that might be classified under several different heads, as physies, chemistry, physiology, botany ;

4. That useful familiarity may thus be acquired with simple laboratory methods and apparatus which will save time in the pursuance of more advanced courses;

5. That some familiarity with the scientific method of attack thus acquired in dealing with experiments under several heads, as physics, physiology, botany, etc., will tend to develop early the "scientific" habit which will be of use in every department of study;

6. That this, and the other aims enumerated, may be reached better by such a course than by any course confined to the facts and problems of any one of the fields of study named above.

It has been said, in the preface to a late text in highschool physies, that the presentation of that subject in the secondary school "should be the expansion of the every-day life of the pupil into the broader experience or 
observation of those whose lives have been devoted to the study."

This might be set forth as the guiding principle for the study, not merely of "physies", but for the study of the material phenomena of nature, of that which we call Science.

General Science in some form, as the introductory unit, has come to stay. It will last longer than will its timid opponents. The somewhat noisy war over the "project plan" will subside.

A thoughtful examination of the course as presented in this book and the laboratory manual which accompanies it, and above all experiment with it, will show whether it is a working out of that plan of framing a course, but what is of far greater importance, such trial of it will show whether it supplies a real need in the first high school year, and whether it helps to drown the many voiced criticism of secondary school instruction as being unrelated to "real life."

\section{John Calvin Hanna.}

Illinois State Supervisor of High Schools, Springfield, Illinois. 



\section{CONTENTS}

Chapter I. Matter........................ 1

What we understand by Science; Definition of matter; Is air matter; Three forms of matter.

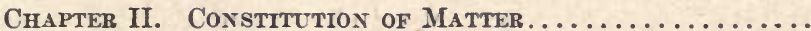

Introduction; Some common observations; Molecular theory; Molecules in solids; Molecules in liquids; Molecules in gases; Molecules in different states; Different sizes of molecules and inter-molecular spaces.

Chapter III. Effect of Heat ox Matter..............

Effect of heat on solids; Effect of heat on liquids; An exception to the rule; The effect of a change of temperature upon gases.

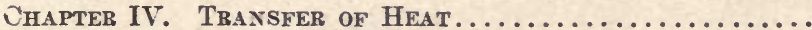

Conduction; Fireless cookers; Explanation of conduction; Convection; Convection due to displacement of molecules.

Chapter V. Measurement of Temperature; Thermometry. Introduction; Galileo's thermometer; Mercury thermometers; Fahrenheit; Centigrade; Construction of centigrade thermometer; Determination of freezing and boiling points; Value of a centigrade degree in terms of Fahrenheit and vice-versa; Range of mercury thermometer; Unit of heat measure.

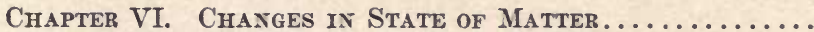

Three states of matter; Change from solid to liquid, and liquid to gas; Quantity of heat necessary to change ice to water; Heat necessary to dissolve a substance; Heat given off when liquids become solids; Melting points; Boiling points; Distillation; Effect of change of pressure on boiling point; Quantity of heat used in changing water to steam; Heat withdrawn in evaporation of liquids; Artificial ice; Heat given off in condensation; Change in volume resulting from change in state; Molecular changes resulting from change in state. 
Chapter VII. Physical and Chemical Changes Physical change; Chemical change.

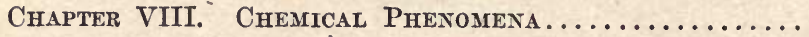
Physical and chemical properties; Classification of matter; Mechanical mixtures; Chemical compounds; Elements; Number of elements; Chemical synthesis; Chemical analy-; sis; Chemical affinity.

Chapter IX. Carbon

Introduction; Charcoal; Uses of charcoal; Lampblack; Coal; Graphite; Diamond; Carbon dioxide $=\mathrm{CO}_{2}$; Preparation and test for carbon dioxide; Balance of carbon dioxide maintained; Commercial uses of carbon dioxide.

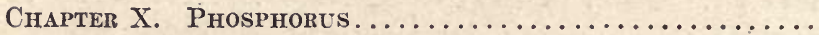

Introduction; Preparation; Properties; Uses of phosphorus; Friction match; Safety match; Dangers of friction match.

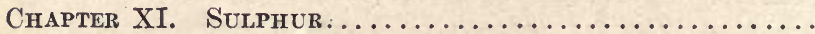

Occurrence; Preparation; Physical properties; Chemical properties; Uses.

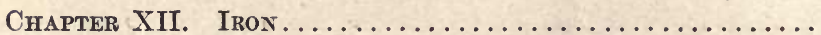

Introduction; Occurrence; Preparation from ore; Three forms of iron.

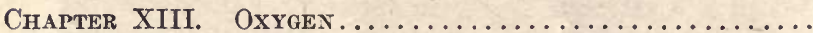

Introduction; Preparation; Properties; Oxidation; Uses; Source.

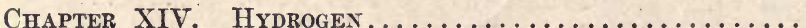

$\checkmark$ Occurrence; Preparation; Properties; Uses.

Chapter XV. Nitrogen.

Occurrence; Preparation; Properties; Uses.

Chapter XVI. Acids, Bases, and Neutral Substances... 105 Introduction; Acids; Characteristics of acids; Bases; Characteristics of bases; Neutralization; Salts.

Chapter XVII. Water..................... 110

Introduction; Composition; Properties and uses; Hard and soft water; Plant and animal life dependent upon water; Dangers in water. 
Chapter XVIIT. Atmosphere.................... 120

Introduction; Composition; Properties and uses; Moisture in atmosphere; Dew point; Dew and frost; Fog and clouds; Rain; Snow and hail.

Chapter XIX. Atmospheric Pressure.............. 129

Introduction; Air presses in all directions; Column of mercury held by air pressure; Variations in pressure due to elevation; Barometer; Uses of the barometer.

Chapter XX. Winds and Storms................. 137

Winds; Cause of winds; General effect of unequal heating; Land and sea breezes; Cyclones; Thunderstorms; Tornadoes; Effect of winds on rainfall.

Chapter XXI. Weather and Climate............... 149

Weather; Climate; Effect of temperature on climate; Day and night; Seasons; Weather maps; Explanation of a weather map.

Chapter XXII. The Surface of the Earth.......... 160

Continents and oceans; Mountains, plateaus, and plains; Minor land forms; Effect of the atmosphere on the earth's surface; Effect of change of temperature on rocks; Chemical; Work of rain in causing relief.

Chapter XXIII. Streams axd Their Work........... 172

Introduction; Streams and stream erosion; Stream development; Maturity; Old Age; Accidents to stream development; Streams as factors in human activities.

Chapter XXIV. Soll....................... 186

Introduction; Origin; Kinds; Clay; Sand.

Chapter XXV. Introduction to Plants.............. 193

Importance of plants; Plants are composed of cells; Composition of protoplasm; Properties of protoplasm; Comparison of plants and animals.

Chapter XXVI. Leaves...................... 200

Structure of leaves; Chlorophyll; Food making; Food storage; Other foods manufactured by plants; Uses of food; Transpiration; Disadvantages of transpiration; Advantages to plant; Habitat dependent on water supply; Protection against loss of water; Respiration; Air storage. 


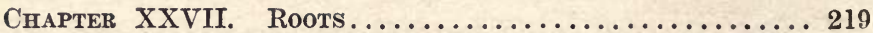

Function; Structure; Absorption of water and solutes; Anchorage.

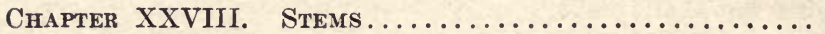

Functions; Kinds; Structure.

Chapter XXIX. Reproduction................ 232

Reproduction and nutrition; Flowers; Formation of seeds; Pollination; Seed dispersal.

Chapter XXX. Importance of Plants to Man..........

Economic importance; Bacteria; Conditions for growth of bacteria; Bacteria and disease; Decay; Useful bacteria.

Chapter XXXI. Axmmals.................... 249

Distribution; Means of distribution; Factors determining distribution;: Barriers to distribution; Animals can not maintain their ground; Change due to new conditions; Adaptation.

Chapter XXXII. Groups of Aximals...............

General statement; Mammals; Birds; Reptiles; Amphibians; Fishes; Arthropods; Mollusks; Worms; Echinoderms; Coelenterates; Porifera; Protozoa.

Chapter XXXiII. Life Processes in Animal. ......... Ameba; Complex animals; Tissues, organs, and systems; Animal functions; Digestion; Respiration; Circulation; Excretion; Motion; Sensitiveness; Reproduction.

Chapter XXXIV. Relation of Animals to Man........ 286 General statement; Animals useful to man; Domesticated animals; Food-supplying animals; Animals supplying clothing; Animals injurious to man; Diseases produced and carried by animals; Animals injurious to crops.

Chapter XXXV. Man's Place in Nature............ 294 Classification; Differences between man and other primates; Age and races of man; The human body.

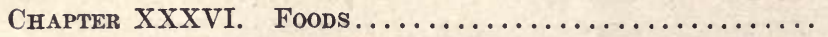

Introduction; Elements in food; Use of food; Foodstuffs; Proteins; Test of protein; Carbohydrates; Starch; Test for starch; Sugar; Test for sugar; Fats and oils; Test for fats and oils; Mineral salts or inorganic foods; Water. 
Chapter XXXViI. Composition of Foods.......... 304

Content of foods; Use of foodstuffs; Building material; Fuel; Quantity and kind of food; Selection of food; Adulteration; Cooking.

Chapter XXXvili. Digestive System............ 310

Introduction; Alimentary canal;. Digestive glands; The mouth; Teeth; Structure of tooth; Care of the teeth; The tongue; Salivary glands; Throat or pharynx; Esophagus; Stomach; Intestines; Liver; Pancreas; Peritoneum and mesentery.

Chapter XXXix. Digestion.................. 321

Introduction; Necessity of digestion; Action upon food; Digestion in mouth; Digestion in stomach; Digestion in intestine; Large intestine; Absorption.

Chapter Xl. Narcotics and Stimulants............. 328

Characteristics; Stimulants; Tobacco; Opium and other narcoties; Alcohol; Conclusion.

Chapter Xli. Circulatory System.............. 334

Introduction; Blood; Lymph; Red corpuscles; White corpuscles; Coagulation; Amount of blood; The heart structure; Action of heart; Beat; Blood and lymph vessels; Lymph vessels.

Chapter XliI. Respiratory System............. 345

Need of air; Oxidation; Internal and external respiration; Organs of respiration; Nose eavity; Larynx; The lungs; The pleura; Mechanism of breathing; Comparison of inhaled and exhaled air; Necessity of ventilation; Methods of ventilation; Diseases of the respiratory organs; Adenoids; Tonsils; Pleurisy; Contagious diseases.

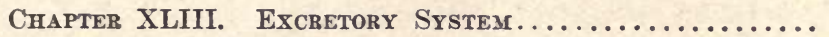

General; The kidneys; The skin; Structure; Sweat glands; The hair; The nails; Temperature of the body; Source of heat; Cooling the body; Clothing; Care of the skin.

Chapter Xliv. Ductless Glands...................... 367

Introduction; Lymph glands; Adrenal bodies; Thyroid glands; The spleen; The pancreas. 
Chapter XLV. Skeletal System.............. 370

General; Regions of the skeleton; The head; The trunk; Ribs and sternum; Bones of limbs; Composition of bone; Growth of bone; Joints; Hygiene of the skeleton.

Chapter Xlvi. Muscular System.............. 378 Importance; Structure; Blood and nerve supply; Action of muscles; Results of muscular action; Exercise.

Chapter XlviI. Nervous System............... 383

Introduction; Parts of nervous system; The nerve cell; Nerves; The brain; Functions of brain; Spinal cord; Sympathetic nervous system; Action of nervous system; Reflex actions; Voluntary action; Habits; Education; Care of nervous system.

Chapter XlviII. The Spechal Senses............ 397

General; Touch; Temperature; Taste; Smell; Eye; Structure; Light; Iuenses; Images; Focusing; Defects of the eye; Care of the eyes; The ear; Structure of the ear; Action of ear; Care of ears.

Chapter Xlix. Health and Disease............ 411

Importance of health; Health and disease; Cause of disease; How germs enter the body; Growth of germs; How the body destroys germs; Treatment of disease; Serums; Vaccines; Medicines; Immunity.

Chapter L. Sanitation.

Importance; Preventable diseases; Destruction of germs; Disinfection; Fumigation; Quarantine; Food; Insects and disease; Milk; Water; The Board of Health. 


\section{A YEAR IN SCIENCE}

CHAPTER I

\section{MATTER}

What we understand by Science. The subject with which we are about to deal in this study is Science. To many this is a new study, and, no doubt, ideas of its meaning differ widely. However, we shall learn, as we proceed with this work, that we are dealing with very common things and common changes that are going on about us daily.

Some of the subjects we shall study, perhaps we feel we know from our daily observations. All of us know that water flows down hill and not up; that a stone thrown into the air returns to the earth again. Have we stopped to learn why? To answer these and similar questions is the work of science. It deals with seeking truths concerning nature.

The field of science is usually sub-divided into the natural sciences and the physical sciences. The natural sciences deal with living material, plants and animals. To the study of plants the name Botany is given, to the study of animals, Zoology.

The physical sciences deal with inanimate material in 
all its forms and with the changes and processes to which it is subject. Some of the physical sciences are Chemistry, Physics, and Physical Geography. Chemistry deals with changes in substances which result in the formation of new substances. For instance, the burning of wood is a chemical process. Physics treats of changes and processes that do not result in the formation of other substances. In Physical Geography a study is made of weather, climate, and land forms, and their relation to man.

Definition of matter. For the substance dealt with

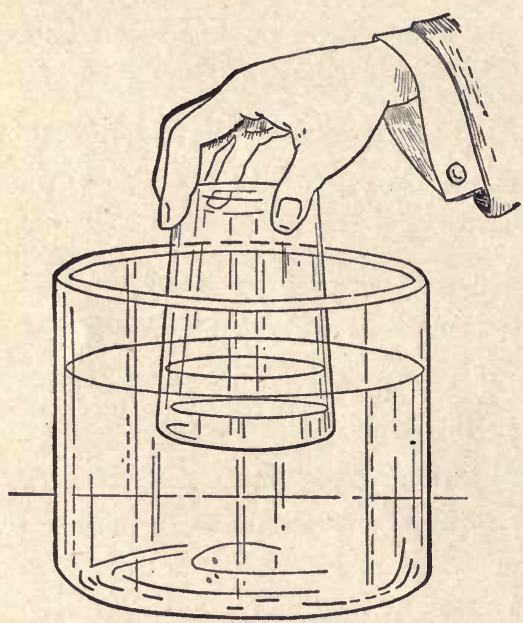

Fig. 1. If an inverted tumbler is pushed mouth downward into water, the air within the tumbler keeps the water from entering it. in this general science the term matter is used. According to most authors, matter is anything which occupies space or has weight. Thus it will be seen at once that wood is matter, and that water is matter. Matter, however, does not exist in visible form only, for gases, too, are matter.

Is air matter? An empty tumbler, that is, a tumbler which does not contain anything that can be seen, is pushed mouth downward half under the surface of the water in 
a glass jar. The water rises in the tumbler only about $\frac{1}{16}$ of an inch. Evidently there is something within . the tumbler which prevents the water from rising to fill it. The tumbler is then tilted sidewise until the mouth comes just above the surface of the water. Bubbles of air escape. If the tumbler is then again pushed into the water, the water will rise into it. Evidently, in the first instance, it was air that kept the water from rising into the tumbler. Since the water rose higher in the tumbler

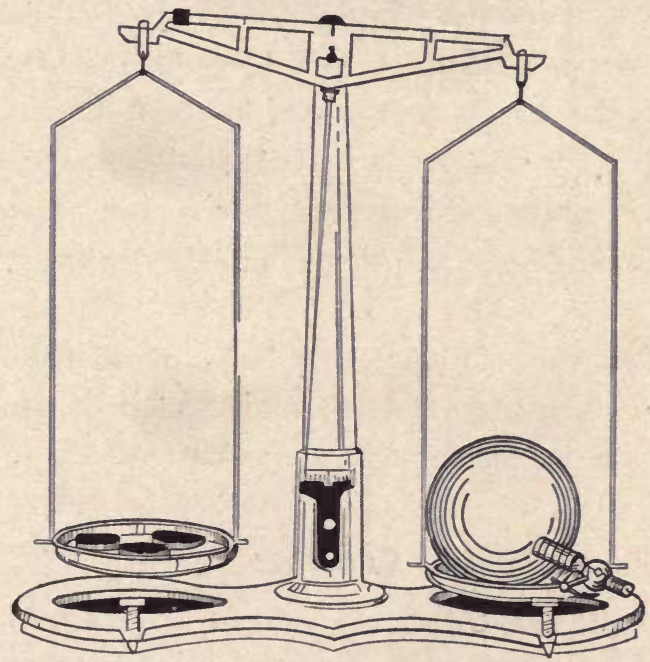

Fig. 2. A globe was balanced after part of the air was pumped from it. It was found to be heavier after the air was again allowed to enter it.

after the air had escaped, this experiment proves that air occupies space. In fact, air is present usually in spaces which appear empty.

A hollow brass globe fitted with a stop cock is accu- 
rately weighed. With an air pump the air is exhausted from the globe and the stop cock is closed. The globe is again weighed. It is found to weigh more when filled with air than it does after the air has been exhausted. Air therefore has weight.

Since air occupies space and also has weight, according to the definition of matter, air is matter. Air is a gas, so we have proved that a gas is matter.

Three forms of matter. All material exists in one of three forms : solid, liquid, and gas. If a substance has definite size and shape, we eall it a solid. The shape of a solid can not be changed except by some external force. If the size of a substance is definite, but the shape depends upon the containing vessel, it is a liquid. Gases have neither definite size nor shape, and they expand without limit.

The behavior of these three forms of matter, and the changes which they undergo under different conditions, will be studied in the following chapters.

\section{Questions}

1. With what does the subject of science deal?

2. Into what two divisions is science naturally divided?

3. What is meant by the words animate and inanimate?

4. Name the two natural sciences. How do they differ from each other?

5. Name three physical sciences. Of what does each treat? 
6. State the definition of matter.

7. In what three forms does matter exist?

8. Define solid, liquid, gas.

9. Name three solids, three liquids, and three gases.

10. Is it possible for a substance in the form of a solid to be changed to a liquid? To a gas? Give examples to prove your answers.

11. Does matter exist only in a visible form? Give two examples illustrating your answer.

12. Why do gases have to be kept in closed vessels ?

13. How can you prove that air is matter?

14. If a tumbler is filled with air, how do you account for the fact that water can be poured into it?

15. State three reasons why you think it is important for you to know something about science. 


\section{CONSTITUTION OF MATTER}

Introduction. We have learned in Chapter I that everything in nature, whether solid, liquid, or gas, is matter. We know, too, from observation that under different conditions of temperature the same substance may be successively a solid, a liquid, and a gas. In other words, with a sufficiently great change in temperature most substances may be changed from one state of matter into another. As an example take water. Below $32^{\circ} \mathrm{F}$. it passes into the solid state ; between $32^{\circ} \mathrm{F}$. and $212^{\circ} \mathrm{F}$. it is a liquid, and when heated to $212^{\circ} \mathrm{F}$. it passes into a vapor or a gaseous state.

Some common observations. Many ideas regarding things in nature, commonly accepted by most people as self-evident, are found by scientists to be entirely at variance with the facts. A glass filled with water is commonly thought to have all the space in the glass occupied, yet with care one is able to put a teaspoonful or more of sugar into the glass without increasing the volume of the water. The sugar disappears and yet the volume of water does not increase. A more striking phenomenon occurs if fifty cubic centimeters of alcohol are carefully poured into a burette containing fifty 
cubic centimeters of distilled water. The combined amounts of the two liquids is one hundred cubic centimeters. But if the burette is closed and the two liquids thoroughly mixed there will be found but about ninety-eight cubic centimeters of the mixture. From observations such as these, scientists were led to investigate the constitution of matter. If a mixture of equal quantities of two substances is less than their combined amounts, surely the substances must have gone into each other. To do this, however, the substances must have particles and spaces, and the particles of one must have moved into the spaces of the other. So reasoned the early scientists, and the result of their reasoning is the "Molecular Theory of Matter," which explains the constitution of matter.

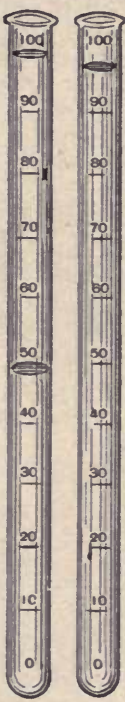

Fig. 3. If water and alcohol are mixed, the two liquids occupy less space than wh e $\mathrm{n}$ they are kept separate.

Molecular theory. According to this theory everything in nature is composed of very tiny particles with spaces between them. The particles are called molecules and the spaces between the molecules are called inter-molecular spaces. The molecules are conceived as being in constant motion back and forth in the intermolecular spaces. In the same substance, all molecules 
are of equal size, but they are of different sizes in different substances. The same is true of the intermolecular spaces. All molecules of water are of equal size, but they differ in size from those of mercury. Molecules are so small that they cannot be seen even through the most powerful microscope. The smallest particles that can be detected with our best microscopes have a diameter of $1 / 100,000$ of an inch. The
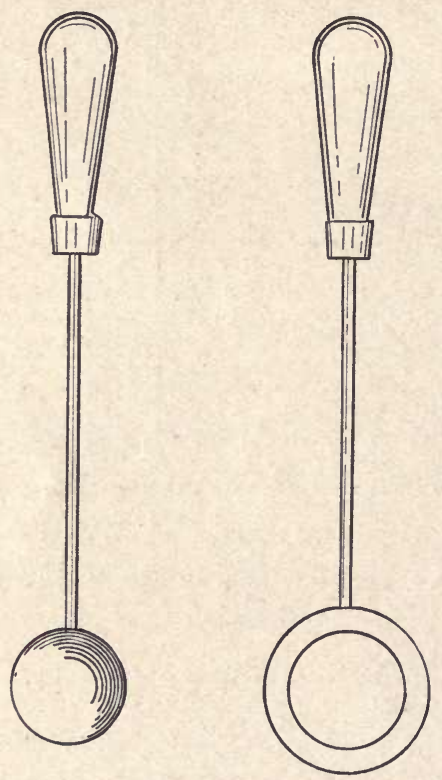
average diameter of molecules has been computed by some authorities to be about $1 / 62,500,000$ of an inch.

Another statement has been made to the effect that if a cubic inch of molecules of air tightly packed together could be so controlled that $100,000,000$ of them could escape each second, it would take over 100,000 years for all to escape.

\section{Molecules in solids. For}

Fig. 4. Metal ball and ring. proof that solids are composed of molecules we need only to recall the experiment of the ball and the ring. With both the ball and the ring at the same temperature, the ring just slips 
over the ball, but when the ball is heated, it no longer passes through the ring.

Thus we say, solids expand with heat and contract with cold. This statement means, speaking in terms of the Molecular Theory, that the motion of the molecules is accelerated by an increase in temperature and, moving more rapidly and with greater force, they collide, strike one another harder, and rebound from one another a greater distance. The inter-molecular spaces are thus enlarged and the whole object takes up more space.

On the other hand, when heat is withdrawn, the motion of the molecules is retarded; they are drawn more closely together, the inter-molecular spaces become smaller, and the object takes up less space.

Thus, we see that a change in temperature produces a pronounced change in the activity of molecules and consequently in the size of the inter-molecular spaces.

What has been said of the effect of the change of temperature upon solids is equally true for most liquids and gases.

Molecules in liquids. In liquids the molecules are farther apart than in solids and have greater freedom of movement. This is shown by the fact that liquids can be poured, while solids, as we know, can not. In pouring a liquid, the molecules glide over each other with freedom and ease. The greater freedom of molecules in liquids is shown in diffusion. Diffusion is the 
intermingling or gradual mixing of two substances. Thus if two liquids of different density or weight are placed in contact with each other with the heavier

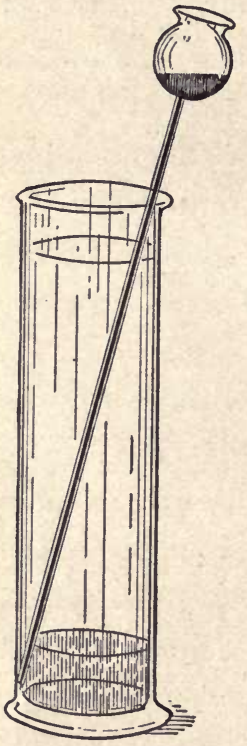

Fig. 5. If two liquids of different densities are placed in contact, they will gradually mix. liquid on the bottom and left undisturbed, it will be found in a few days that the heavier solution is gradually rising into the lighter substance. This phenomenon could not occur unless the substances were composed of moving particles with spaces between. Solids will diffuse also if left in contact with each other, but at a very much slower rate, because of the much slower movement of their molecules. If a brick of lead and a brick of gold with planed surfaces are placed together, after a few months small particles of each will be found in the other.

Molecules in gases. In gases the molecules are much farther apart than in solids and liquids, and consequently they move very much more rapidly than in either of the latter.

If two bottles of gas of different density are placed mouth to mouth, with the bottle of heavier gas on the bottom, and left in that position for a few minutes, a large portion of the heavier gas will be found in the upper bottle. Again, if a bottle of perfumery is opened in a corner of a room in which the air seems perfectly 
still, in a very few minutes the perfume may be detected in the opposite corner of the room. Thus gases diffuse very rapidly, which shows the great freedom of movement of their molecules within their larger inter-molecular spaces.

Molecules in different states. We have learned that the molecules in gases move much more rapidly than those in liquids, and the molecules in liquids move more rapidly than those in solids. Likewise, the intermolecular spaces in gases are much larger than those in liquids and those in liquids are larger than those in solids.

Different sizes of molecules and inter-molecular spaces. In the ex-

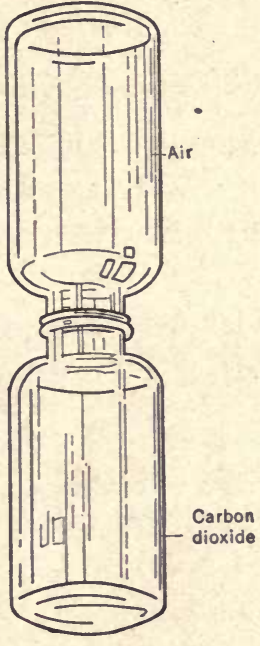

Fig. 6. Carbon dioxide is heavier than air, but it gradually diffuses in to the upper bottle. periment already referred to, in which 50 c.c. of distilled water were placed in a burette and 50 c.c. of alcohol poured carefully on top, the two thoroughly mixed were found to occupy but 98 e.c. The 2 c.c. had not been lost, but are accounted for by the fact that the molecules and inter-molecular spaces of one liquid are larger than those of the other and the smaller molecules of the one were crowded into the inter-molecular spaces of the other. This is the only way in which this phenomenon can be explained. 


\section{Questions}

1. How do you account for the fact that you can place a teaspoonful or more of sugar in a glass apparently already full of water, without causing the water to overflow the sides of the glass?

2. What does question 1 show concerning the structure of a liquid?

3. What do you conclude concerning the structure of a gas after a liter of oxygen has been squeezed into half a liter space?

4. What does the experiment of the ball and the ring tell you about the structure of a solid?

5. What is a molecule?

6. What do you mean by inter-molecular space?

7. Are molecules of different substances of the same size?

8. Are the inter-molecular spaces in different substances of the same size?

9. Are the molecules in steam, water, and ice of the same size?

10. Are the inter-molecular spaces in steam, water, and ice of the same size?

11. What is the effect of an increase of temperature on the molecules of a substanee? Of a decrease in temperature?

12. What is the effect of an increase of temperature on the inter-molecular spaces of a substance? Of a decrease of temperature? 


\section{EFFECT OF HEAT ON MATTER}

Effect of heat on solids. One of the best known effects of heat is the change which it causes in the size of a substance. As stated in the preceding chapter a metal ball, which, when cool, slips through a metal ring, will not do so when heated. The ball increases in size when heated. If the ring be correspondingly heated, it becomes so enlarged that the heated ball will pass through it.

If the ring is cooled, the ball will not pass through it. The ring has decreased in size. If the ball is sufficiently cooled, it will pass through the ring as it did in the beginning of the experiment.

Telegraph and telephone wires, which in winter are stretched taut from pole to pole, sag in summer, because they become longer. If the wires were stretched taut in the summer, they would snap and break in the winter, because there would not be sufficient slack to allow them to contract when cooled.

When railroad and street car rails are laid in winter, allowance must be made for their expansion in the summer.

The tire of a wagon wheel is made slightly smaller than the wheel. It is then put into a very hot furnace 
and heated until it expands sufficiently to slip on the wheel. When it cools it contracts, and then fits the wheel closely.

In construction work, when two pieces of steel are riveted together, the rivets are used red hot. When they cool they contract and thus draw the two pieces of steel closer together.

While we generally notice the expansion of a body in

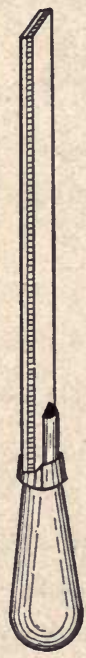

Fig. 7. A b a r which is, made of two different metals, bends when it is heated, because one of the metals idly than the other. expands more rapone direction only, that is in its length, it must not be forgotten that a body expands in three dimensions.

The increase in length of a substance is known as its linear expansion. The expansion or contraction of different substances is not equal for the same change in temperature.

If a bar, made of two different metals tightly welded or riveted together lengthwise, is heated, it bends. This is because one of the metals is expanding more rapidly than the other. If the bar is then cooled, it again becomes straight. In this instance the one side is contracting faster than the other.

A steel wire which measures $1 / 4$ mile on a cold winter day will gain 25 inches in length an a warm summer day. Under the same conditions an aluminum wire would gain about 50 inches. 
Effect of heat on liquids. Not only are solids affected by heat and cold, but liquids behave similarly with changes in temperature. Everyone knows that if a tea kettle is filled with cold water and heat applied, the water will soon overflow.

The expansion of water can easily be shown by heating a test tube filled with water and closed by a rubber stopper through which a piece of glass tubing passes. When the water is heated it expands and rises in the small tube. If the water in the test tube is cooled by running cold water over it, the water in the tube contracts, falls, and finally reaches its original level. If mercury is used in place of water, the expansion and contraction will not be so great, for the volume of mercury does not change so rapidly.

The action of a thermometer depends upon the fact that mercury

Fig. 8. Experiment to show the effects of a change of temperature on the volume of a liquid.

expands when heated and contracts when cooled. In some thermometers alcohol is used in place of mercury, but the principle involved is the same. 
An exception to the rule. Water shows an exception to the rule that heated bodies expand and cooled bodies contract. We all know that ice floats. In order to float it must, of course, be lighter than water. Ice is frozen water, so evidently in freezing the water has expanded. If two bottles filled with water are very securely sealed, and then one is heated and the other allowed to freeze, both bottles will break. This shows that in each case the water has expanded. It has been found that, if water is heated above $4^{\circ} \mathrm{C}$. or cooled below that temperature, it expands in both cases.

A few other substances show a similar disobedience to the general rule for expansion and contraction.

If water contracted in freezing, ice would be heavier than water and would sink in ponds and lakes as fast as it was formed. As a result, the entire pond or stream would become a solid mass of ice, killing all animal and plant life. It is a well known fact that even in the most severe winter, the deep lakes do not become solid masses of ice, and that fish and some other animals remain alive in the water beneath the ice.

Freezing water exerts a very great influence on the character of the land around us. Water is everywhere present in the ground, in crevices, and even within many rocks. When winter approaches this water freezes, and then it expands about one-eleventh of its volume. The rock is then broken into countless pieces, for the expansive power of freezing water is almost 
irresistible. This effect is most conspicuous in rocky or mountainous regions. Here massive rocks are sometimes pried out of position, and large and small particles of rock are broken off. This is the origin of a large part of the debris brought down the mountain slopes by the spring rains.

Water pipes, in cold places, are burst in a similar fashion. Parts of cement walks are sometimes dis-

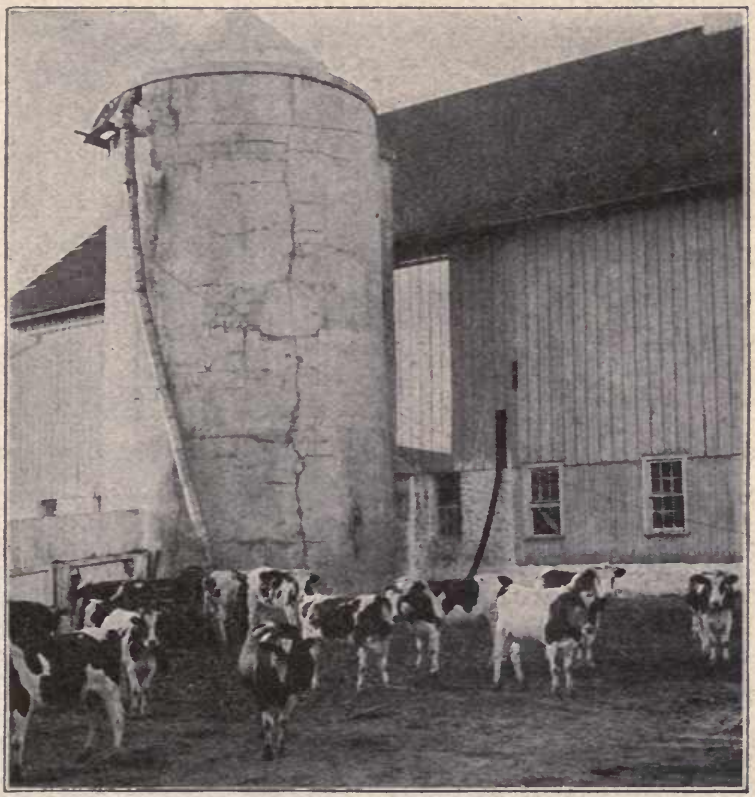

Fig. 9. A solid concrete silo cracked by uneven contraction and expansion caused by extreme cold and extreme heat.

placed, bricks and even fence posts are likewise frequently pushed out of place by the action of freezing water in the soil. 
The effect of a change of temperature upon gases. A change in the volume of gases is not so readily observed as it is in solids or liquids, because gases are invisible. With the same increase or decrease in tem-

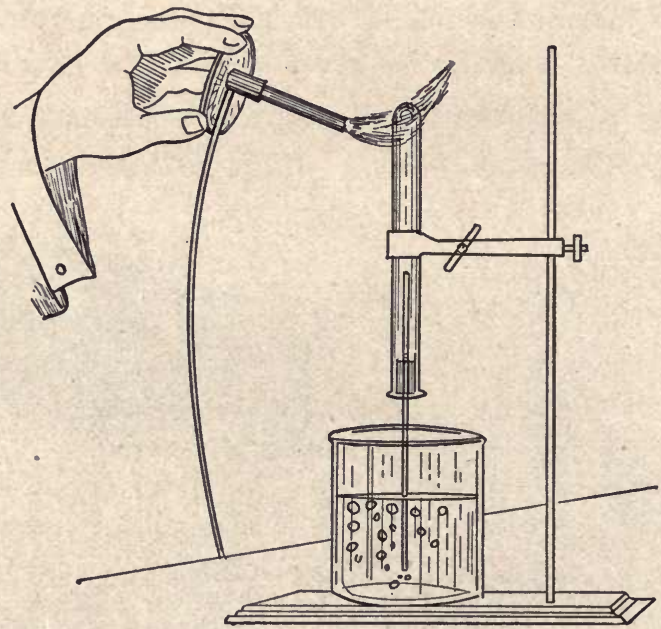

Fig. 10. When heated, the air in the test tube expands and bubbles of air appear in the water at the open end of the tube.

perature, gases expand or decrease much more than liquids or solids. This fact is taken advantage of in the construction of thermometers which are to be used to register very slight changes in temperature. In such thermometers air is used.

Automobile and bicycle tires are not filled with so much air on a hot summer day as they are on a cold winter day. Allowance is made for the expansion of the air in the tire.

All gases expand at the same rate for the same 
increase of temperature, but the rate of expansion of different liquids and solids varies considerably.

\section{Questions}

1. What effect does an increase in temperature have on the size of a solid?

2. Does a decrease in temperature have the same effect?

3. Why do telegraph wires which are taut in winter sag in the summer?

4. If street car rails are laid in the winter with the ends touching, why won't the cars run smoothly over them during the summer?

5. What is meant by linear expansion?

6. Name two metals which do not expand at the same rate.

7. With a change of temperature do liquids and gases behave the same as solids?

- 8. What happens to a bottle of milk if it is allowed to freeze? How do you account for this result?

9. If water did not expand when it froze, could we use our present methods for obtaining the water supply for cities? For removing sewage?

10. Why is it necessary to lay water pipes below the frost line?

11. Why does concrete frequently crack in the winter?

12. Why are air thermometers sometimes used? 
CHAPTER IV

\section{TRANSFER OF HEAT}

Heat may be transferred from one substance to another in three different ways: conduction, convection, and radiation. We shall consider only the first two of these ways.

Conduction. If one end of an iron rod is held in the hand and the other end is placed in a flame, the end held in the hand soon becomes hot. Evidently the heat from the fire travels along the rod from the flame to the hand.

When heat travels from one body to another, with which it is in contact, or from one part of a body to another, the process is called conduction. Heat flows from a warmer to a cooler part. Coldness is merely absence of heat.

A body which allows the heat to travel through it is called a conductor. There is a great difference in conductors, some being very good, others so poor as to seem to allow no heat to pass through them. "Most metals are very good conductors of heat. Different metals, however, vary greatly in the rapidity with which they conduct heat. Copper conducts heat about four 
times as rapidly as iron. A flat iron placed on a stove becomes heated throughout; cooking utensils become very hot; stoves heat quickly from the burning fuel within them; ete.

If a test tube full of water is held in a flame so that the water boils at the top, it will be some time before the tube will be hot enough to pain the hand by which it is being held. A bar of metal of the same size would be hot before the tube of water even felt warm. As compared with metals, water is a poor conductor of heat.

Iron utensils frequently. have wooden handles because wood is a poor conductor and does not allow heat to pass quickly through to the hand. Asbestos is another poor conductor. It is frequently used

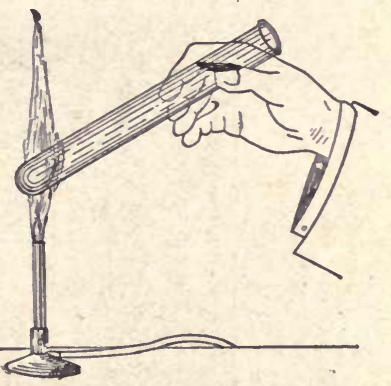
to wrap hot water pipes and steam pipes in order that the heat may not escape.

If the hand is placed in water, which is the temperature of the air around it, the water seems much colder than the air. This is because water is a better conductor than air and so takes the heat out of the hand more rapidly.

Fireless cookers. The fireless cooker depends upon the principle of non-conduction. One vessel is placed inside another. The space between the two is filled 
with sawdust, asbestos, excelsior, or some other poor conducting material. Foods are heated to a high temperature and then placed in the inner vessel. This heat remains in the food, and slowly cooks it, because the non-conducting material prevents the heat from escaping.

Explanation of conduction. When a body is heated the molecules in the part in contact with the heat move

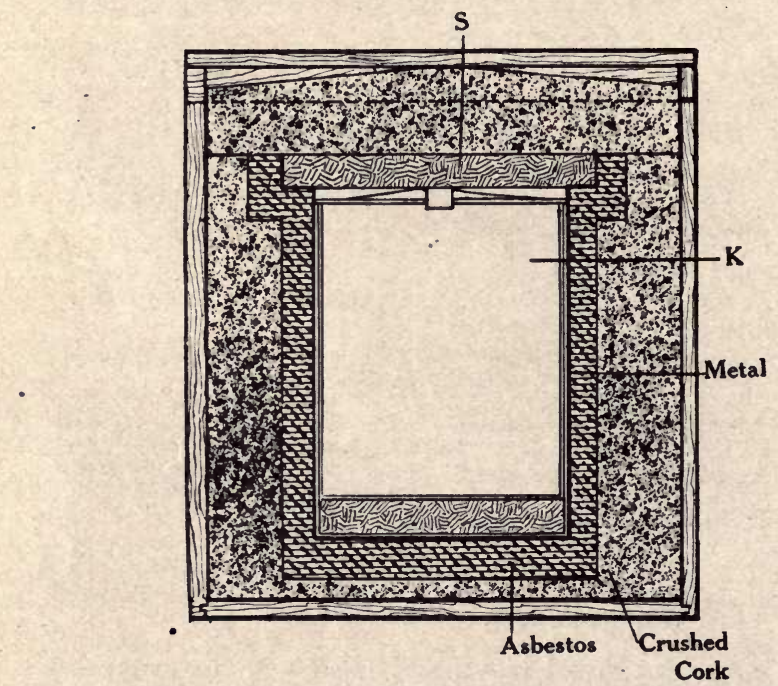

Fig. 12. Section of a fireless cooker; $s$, soapstone; $k$, kettle.

more rapidly. In their movement they strike harder and faster upon those next to them, so that these in turn move as rapidly as the first ones. In this way the motion is carried from one group of molecules to another.

Convection. Notwithstanding the fact that air and 
water are poor conductors, heat is readily communicated from one part of a liquid to another, or from one part of a room to another. The air in a cold room becomes warm very quickly if a hot fire is built.

The explanation for this is simple. When a liquid or a gas is heated, it expands. The same volume of it will then weigh less, and in consequence, it rises. The cooler substance around it, being heavier, sinks beneath the lighter part and forces it up. This process is called convection.

A kettle of water on a stove is heated in this manner. The water at the bottom of

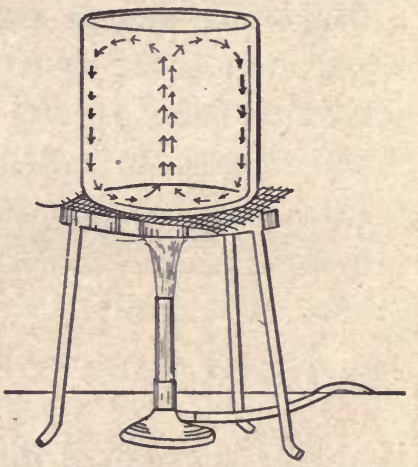

Fig. 13. Currents are produced in tea kettles or coffee pots when placed over a fire. The heated water expands and becomes lighter. The colder water above is heavier and is drawn down beneath the warm water which in consequence is forced upward.

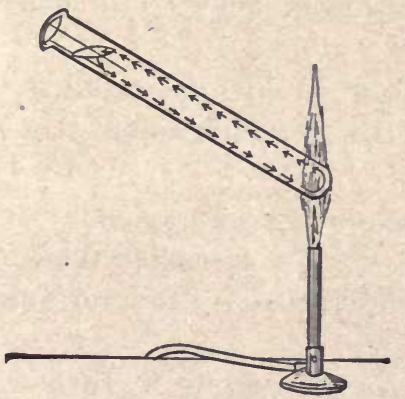

Fig. 14. If fine saw dust is placed in a test tube full of water, a continuous current can be easily seen when the water is heated. the kettle expands and becomes lighter. The colder water gravitates downward, causing it to rise. The colder water soon becomes heated, and in turn rises. In this way all the water is soon heated.

In the same manner all the air in a room becomes heated. The air immediately around 
a radiator or a register becomes heated and rises, as the colder air above it sinks and in turn becomes heated. In any room the air near the ceiling is warmer than that near the floor.

Convection due to displacement of molecules. In liquids and gases the molecules in contact with the source of heat are set in violent vibration. These rapidly vibrating molecules rise and the cooler ones then come in contact with the source of heat. This process continues until the liquid or gas is uniformly heated throughout.

\section{Questions}

1. Name three ways in which heat can be transferred from one substance to another.

2. Give a definition for conduction.

3. Name two good conductors of heat. Two poor conductors.

4. Do all metals conduct heat with equal rapidity?

5. From your observation, how do solids, liquids, and gases compare as conductors?

6. If you place your hand on a piece of metal or a piece of marble, does it feel warmer or colder than a piece of wood of the same temperature? How do you explain this?

7. Why are the pipes leading from a furnace wrapped with asbestos?

8. Why are stove pokers and flat irons usually provided with wooden handles? 
9. Will water at $70^{\circ} \mathrm{F}$. feel warm or cold? Why?

10. What is the structure of a fireless cooker? Of a thermos bottle?

11. How do you account for the fact that a thermos bottle may be used to keep a liquid either hot or cold?

12. Why do we wear woolen clothing in the winter and cotton clothing in the summer?

13. On cold nights in early fall or late spring, plants are sometimes covered with paper. Why does this keep them from freezing?

14. How does heat travel through a substance by conduction?

15. What is meant by convection?

16. Explain how the water in a tea kettle becomes heated throughout.

17. Is the air near the ceiling of a room warmer or cooler than that near the floor? Why?

18. How is heat transferred from a stove or a radiator to all parts of a room?

19. How is any body cooled? By what means is this usually done? 


\section{MEASUREMENT OF TEMPERATURE- THERMOMETRY}

Introduction. Some very common expressions frequently heard are, "it's as cold as ice" or "it's boiling hot." Such expressions are relative and compare the temperature of a substance with the known temperature of ice or boiling water. Thus it will be seen that by temperature is meant how hot or how cold a given substance is.

Galileo's thermometer. To-day we are supplied with

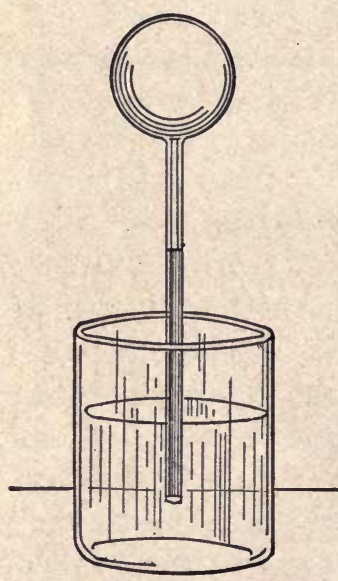
instruments by which the hotness or coldness of a substance may be definitely determined. But such was not always the case. In fact, the earliest attempt to measure temperature was made the latter part of the sixteenth century (1592) by Galileo, an Italian scientist.

His instrument was known as the gas or air thermometer. He had observed and knew well that subFig. 15. Air thermom-stances change in volume with a
ter made by Galileo. 
change of temperature. He knew, too, that gases respond far more rapidly to change of temperature than liquids and solids and was thus led to his air thermometer. This consisted of a glass tube of narrow bore, open at one end and enlarged into a bulb at the other. The open end of the tube was placed in a jar of liquid and the bulb slightly heated. As the gas in the bulb cooled, the liquid rose in the tube. Thus the relative temperature of the surrounding air could be told by the height of the liquid in the tube.

Mercury thermometers; Fahrenheit. Early in the. eighteenth century, 1714, Fahrenheit, of Danzig, Germany, gave to the world his mercury thermometer which is still used very extensively throughout the United States and England.

For the temperature of melting ice he marked $32^{\circ}$ and that of boiling water $212^{\circ}$. The intervening distance he divided into 180 parts or degrees.

Centigrade. In 1742 Celsius, of Upsala, Sweden, devised the thermometer known as the centigrade thermometer. This thermometer is used almost exclusively for scientific work in all countries, and also for other purposes in countries using the metric system. As the word centigrade (centum : $100+$ gradus : mark or grade) suggests, the stem of this

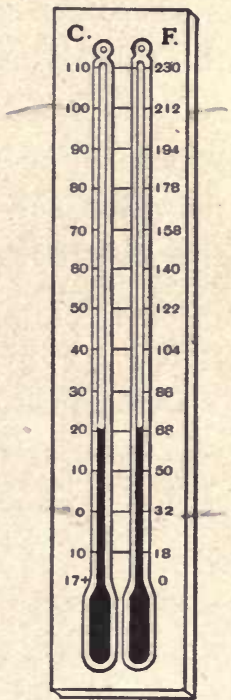

Fig. 16. A centigrade a n d Fahrenheit thermometer. 
thermometer is divided into one hundred equal divisions between the freezing and boiling points of water. The freezing point of water is marked $0^{\circ}$ and the boiling point of water $100^{\circ}$.

Construction of centigrade thermometer. From your examination of a centigrade thermometer you have discovered that it consists of a hard glass tube of varying length, with a very fine hair-like opening or bore running through the center. One end of the tube is blown out into a small bulb, filled with mercury, which

- also projects into the hair-like bore. In some thermometers colored alcohol is used instead of mercury.

The other end of the tube is closed and the stem of the tube is marked for degrees, with the $0^{\circ}$ marked freezing and the $100^{\circ}$ marked boiling. The height to which the mercury rises is called the temperature of the given substance. Thus if mercury in a centigrade thermometer is at 20 in the room in which you are sitting, then we say the temperature of the room is $20^{\circ} \mathrm{C}$.

Determination of freezing and boiling points. To construct a thermometer and determine the essential points, a glass tube of fine bore is taken and the bulb and tube are filled with mercury at a temperature slightly above the highest temperature for which the thermometer is to be used. The open end of the tube is then sealed off in a hot flame. As the mercury cools and withdraws from the tube into the bulb, it leaves a vacuum above it. 
The bulb of the thermometer is then surrounded with melting ice and left until the mercury in the tube comes to a standstill. This point on the tube is marked $0^{\circ}$, the freezing point of water. Likewise the bulb is suspended in the steam arising from boiling water in a flask and the point on the tube at which the mercury comes to rest is marked $100^{\circ}$, the boiling point of water. The intervening distance on the tube is divided into 100 equal parts called degrees. Divisions of the same length are

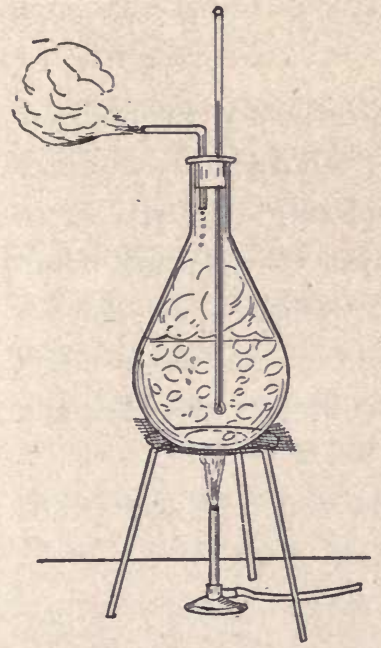

Fig. 18. Method of determining the boiling point.

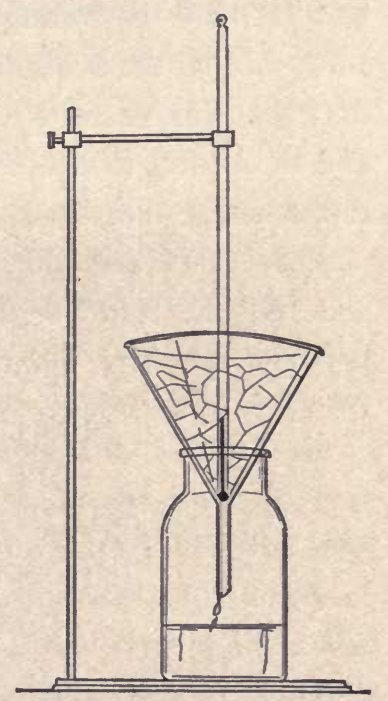

Fig. 17. Method of determining the lower fixed point on a thermometer.

extended above $100^{\circ} \mathrm{C}$. and below $0^{\circ} \mathrm{C}$.

The Fahrenheit thermometer is similarly constructed, with the freezing point of water marked $32^{\circ}$ and the boiling point of water $212^{\circ}$. The intervening space on the stem is divided into 180 equal divisions. 
Value of a centigrade degree in terms of Fahrenheit and vice-versa. Although the freezing point of water on the centigrade thermometer is $0^{\circ}$, and on the Fahrenheit $32^{\circ}$, and the boiling point of water on the centigrade $100^{\circ}$, and on the Fahrenheit $212^{\circ}$, it must be clear to all that the difference in temperature between the freezing and the boiling points of water is the same, by whatever therrameter measured.

Since there are $100^{\circ} \mathrm{C}$. between boiling and freezing and $180^{\circ} \mathrm{F}$. $\left(212^{\circ}\right.$ boiling $-32^{\circ}$ freezing $=180^{\circ} \mathrm{F}$. $)$ between the same points

$$
\begin{array}{r}
100^{\circ} \mathrm{C} \text {. equal } 180^{\circ} \mathrm{F} \text {. } \\
1^{\circ} \mathrm{C} \text {. equals } 9 / 5^{\circ} \mathrm{F} \text {. }
\end{array}
$$

Likewise

$$
\begin{array}{r}
180^{\circ} \mathrm{F} \text {. equal } 100^{\circ} \mathrm{C} \text {. } \\
1^{\circ} \mathrm{F} \text {. equals } 5 / 9^{\circ} \mathrm{C} \text {. }
\end{array}
$$

Hence to reduce from the centigrade to the Fahrenheit thermometer, multiply the number of centigrade degrees by $9 / 5$. Then, remembering that the centigrade degrees were measured from the freezing point, start at the same point on the Fahrenheit thermometer. If the temperature is above freezing, add the product to $32^{\circ}$. If below freezing, subtract the product from $32^{\circ}$.

To reduce from the Fahrenheit to the centigrade scale, find how many Fahrenheit degrees the given temperature is above or below freezing, and multiply the number of degrees by $5 / 9$. 
Remember always to make all computations from the same starting point on both thermometers.

Range of mercury thermometer. For all ordinary temperature measurements the mercury thermometer is most satisfactory. However, mercury freezes at $-39^{\circ} \mathrm{C}$. and boils at $360^{\circ} \mathrm{C}$. Alcohol thermometers are serviceable for temperatures lower than the freezing point of mercury, since the freezing point of alcohol is $-130^{\circ} \mathrm{C}$. For both very high and very low temperatures the gas thermometer is the standard.

Unit of heat measure. To measure anything we must have some measuring unit. For example, to measure length, we have the foot or the yard as a unit. So to measure the amount of heat a substance contains it is necessary to have a unit of heat measure. The unit here accepted is the heat required to raise the temperature of one gram of water through one degree centigrade. This unit is called the (gram) calorie. Thus, if 100 grams of water has its temperature raised $5^{\circ} \mathrm{C}$. we say 500 calories of heat have passed into the water; or on the other hand, if 100 grams of water drops $5^{\circ} \mathrm{C}$. in temperature, we say 500 calories of heat have passed out of the water. To determine the number of ealories of heat that have passed into a given amount of water, multiply the number of grams of water by the increase in degrees centigrade. The result will be in calories. 


\section{Questions}

1. Who was Galileo? Tell something of his work.

2. What is temperature and how is it measured?

3. State the principle upon which the thermometer is based.

4. Give several reasons why mercury is the most satisfactory of all known substances for use in ordinary thermometers.

5. Would the range of a mercurial thermometer of given length be increased or decreased by reducing the size of the bulb? By making the bore of the tube smaller? Would the distance representing a degree be increased or decreased?

6. How would the readings of a thermometer be affected if the bulb should contract after the graduations had been made?

7. How would you proceed to test experimentally the points on a mercurial thermometer?

8 . The following temperature measurements were taken with a Fahrenheit thermometer: $77^{\circ}, 41^{\circ}, 14^{\circ}$, $-4^{\circ},-40^{\circ}$. What would a centigrade thermometer have indicated?

9. The difference in temperature between two vessels of water is $35^{\circ} \mathrm{C}$. What is the difference in $\mathrm{F}$. reading?

10. A $100 \mathrm{~g}$. mass of copper rises in temperature from $15^{\circ} \mathrm{C}$. to $100^{\circ} \mathrm{C}$. How much heat does it absorb?

11. Who was Fahrenheit?

12. Do you know why he established $32^{\circ}$ on his thermometer as the freezing point and $212^{\circ}$ as the boiling point of water?

13. Who was Celsius?

14. What is the meaning of centigrade? 
15. Which of the two thermometers should be adopted for general use? Why?

16. How is a thermometer made?

17. How are the essential points of freezing and boiling determined?

18. What is the freezing point of mercury? Of alcohol?

19. Why is a heat unit necessary?

20. What is the name of the heat unit used?

21. How much heat does this unit represent?

22. One gram of water has its temperature raised $20^{\circ} \mathrm{C}$. How many calories of heat were used?

23. The temperature of fifty grams of water was raised $1^{\circ} \mathrm{C}$. How many calories of heat were used?

24. How many calories of heat are required to raise the temperature of 15 grams of water from $10^{\circ} \mathrm{C}$. to $18^{\circ}$ C.? From $32^{\circ} \mathrm{F}$. to $50^{\circ} \mathrm{F}$.? 
CHAPTER VI

\section{CHANGES IN STATE OF MATTER}

Three states of matter. It is a familiar fact that water may exist in three different forms. It may be a solid, a liquid, or a gas. When a solid it is called ice; when a liquid, water; and when a gas, steam.

It is not so well known that many other substances also exist in three forms. The chief reason for this lack of knowledge is the fact that few substances are as useful as water, in all three forms in which they exist. Few substances, therefore, have been studied as carefully as water.

Most of us know many substances which exist both as solids and as liquids. Iron and lead we know can be melted; paraffin can easily be melted and thus changed from the solid to the liquid state. Many substances require extremely high or extremely low temperature to change from one of these states to another. Most metals, for instance, assume the gaseous state only at very high temperature, and many common gases become liquid and solid only at very low temperature. Air has been known in the liquid and the solid states only within the last twenty-five years.

So far as is known, all substances become solids when 
sufficiently cooled. Some change directly from gases into solids, or solids into gases, without assuming the intermediate liquid state. For instance, when crystals. of iodine are heated they pass directly into the gaseous state. On a cold winter day, snow or ice on a cement walk will disappear and yet the walk has not been wet at all. The snow or ice passed from the solid to the gaseous state without becoming water. This water vapor may then pass directly back to the solid from the gaseous state; as, for instance, when snow and frost are formed. It is impossible to convert some solids into liquids, because if heated beyond a certain temperature they burn. Wood and paper, for example, do not become liquid when heated.

Change from solid to liquid, and liquid to gas. Changes in the state of matter are most readily brought about by changes in temperature. In raising a body from a lower to a higher temperature, heat is consumed. For instance, heat is consumed in raising 100 c.c. of water from $25^{\circ} \mathrm{C}$. to $35^{\circ} \mathrm{C}$, or in raising ice from $-10^{\circ} \mathrm{C}$. to $-2^{\circ} \mathrm{C}$.

Heat, however, is also consumed in changing a solid to a liquid or a liquid to a gas. If ice at $-10^{\circ} \mathrm{C}$. is slowly heated, a thermometer, imbedded in the ice, will show a gradual rise in temperature until $0^{\circ} \mathrm{C}$. is reached. Then for some time the thermometer will show no rise in temperature. During this time the ice is melting.

As soon as the ice has melted, the rise in temperature 
begins again. This rise continues until a temperature of $100^{\circ} \mathrm{C}$. is reached. Then the mercury in the thermometer again becomes stationary. This time the

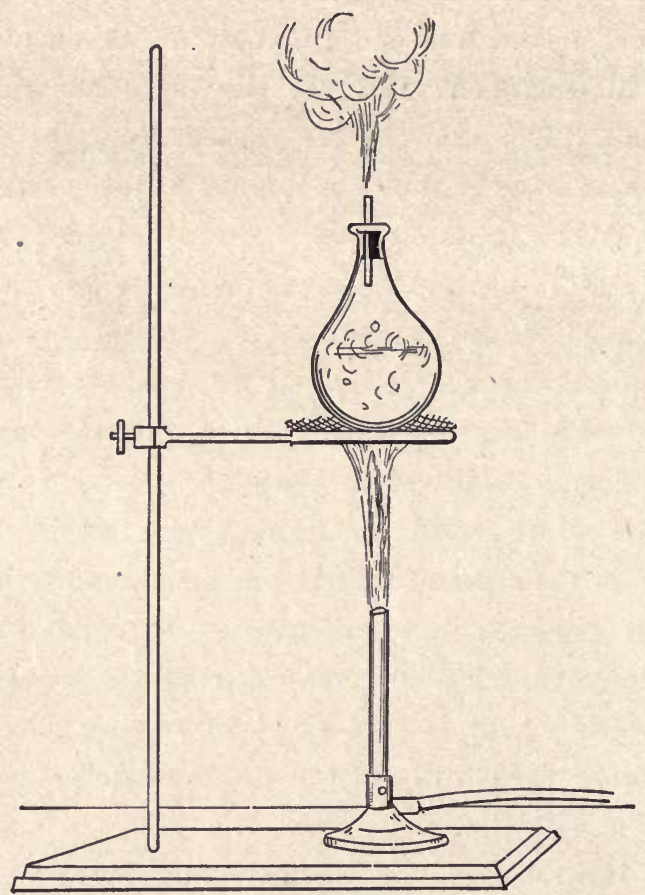

Fig. 19. When water is heated it changes to a gas, which as it escapes, forms bubbles in the water. This water vapor is transparent when it is in the flask, and also where it issues from the end of the tube. As soon as it cools, it again condenses in the form of steam.

water is being changed into steam. When the water has all been converted into steam, the mercury again rises, provided the steam is in a vessel from which it can not escape. 
Since the temperature of the ice when it begins melting is $0^{\circ} \mathrm{C}$, and since the temperature of water immediately after melting is $0^{\circ} \mathrm{C}$, it is evident that the heat has not caused an increase in the temperature of the water. It is thus clear that all the heat must have been used in effecting the ehange of state from solid ice to water.

Since the temperature of the water just before it changes into steam is the same as it is after it has all become steam, the heat must be consumed in the change from water to steam.

Quantity of heat necessary to change ice to water. Heat is necessary to change ice to water. In order to determine the amount of heat necessary for this purpose, the experiment must be conducted so that all the heat used will be consumed solely for melting the ice.

From a number of experiments it has been learned that it requires about 80 calories of heat to change 1 gram of ice to water. (See Laboratory Manual, Exercise 15.) Heat must then be applied to ice to melt it.

We have learned that it takes heat to melt ice, or to change it to water. In the laboratory the source of this heat is the Bunsen burner, or some other artificial means. However, when ice melts on exposure to the air, or without any special attempt being made to apply heat to the ice, the fact that a considerable quantity of heat is required to melt it is often overlooked. The source of heat in this case is from the air itself and from the surrounding objects. 
The fact that ice in melting withdraws heat from the surrounding objects is of value in many ways. The ice in an ice chest, in melting, takes heat from the food placed in the chest. When snow melts in the spring it cools the air, and thus prevents the very rapid melting of snow which might otherwise cause floods.

Heat necessary to dissolve a substance. If a handful of salt is placed in a glass full of water and very slowly stirred with a thermometer, the temperature gradually decreases as the salt dissolves. The salt is changing from a solid to what may be considered a liquid. In order to do this heat is necessary. In this experiment, the heat comes from the water.

In ice cream freezers the chopped ice is mixed with coarse salt. Heat is taken from the cream not only to melt the ice but also to dissolve the salt. As a result the cream freezes. The mixture of salt and water does not freeze because its freezing point is below that of pure water.

Heat given off when liquids become solids. A flask in which 50 grams of sodium hyposulphite and 10 c.e. of water have been placed is heated slowly until all the sodium hyposulphite is dissolved. The flask is then removed from the flame, closed with a plug of cotton, and very carefully set aside to cool. Care should be taken that the flask and its contents are not disturbed for about forty minutes. If the cotton plug is then removed, and a thermometer is placed in the liquid, the solution at once begins to crystallize. The hypo changes from 
the liquid state to the solid. As this change is taking place the temperature gradually rises, as is indicated on the thermometer.

When a liquid changes to a solid, heat is given off or liberated. The amount of heat given off is equal to the amount consumed in changing the substance from a solid to a liquid. For example, the amount of heat lost by freezing water is exactly equal to the amount of heat absorbed by melting ice.

The temperature of the atmosphere near a lake or river in which the water is freezing, is higher than that of the surrounding atmosphere because of the heat given off by the freezing water. When the water at the surface of a lake or river freezes, it gives out its heat to the air immediately above. Ice and water are both poor conductors of heat, and the layer of ice once formed over the surface prevents the underlying water from giving off any more heat. This causes the freezing to be very slow. It also accounts for the comparatively slight depth to which the water freezes.

Farmers sometimes make use of this fact by placing in their cellars tubs of water, which, as it freezes, gives out heat and thus prevents vegetables from freezing. Fortunately, most winter vegetables do not suffer from cold until a temperature of several degrees below the freezing point is reached.

Melting points. At ordinary pressure of the air, ire melts at $0^{\circ} \mathrm{C}$. This temperature is known as the meliting point of ice. Other substances do not melt at 
this temperature, but each has its own melting point. For instance, alcohol melts at $-130^{\circ} \mathrm{C}$, mercury at $-39.5^{\circ} \mathrm{C}$, zine at $419^{\circ} \mathrm{C}$, copper at $1065^{\circ} \mathrm{C}$, and cast iron at $1200^{\circ} \mathrm{C}$.

The melting temperatures of some substances, especially gases, are so low that they have never been seen in the solid state outside of the laboratory, or in the liquid state except in laboratories where very low temperatures can be artificially produced.

The fact that the melting points of substances differ greatly makes it possible to melt sugar in a glass vessel, or glass in an iron vessel. Why?

Some substances gradually soften and become pliable before they melt. This fact is utilized in the molding of glass or iron into different forms.

Boiling points. The temperature at which a liquid becomes a gas is known as its boiling point. The boiling point of a substance is also the temperature at which, in a gaseous state, it condenses and again becomes a liquid. For instance, water boils at $100^{\circ} \mathrm{C}$. Steam also condenses at this temperature.

Liquids have their characteristic boiling points just as solids have their characteristic melting points. The boiling point of ether is $35^{\circ} \mathrm{C}$, of alcohol $78^{\circ} \mathrm{C}$, of water $100^{\circ} \mathrm{C}$, of mercury $350^{\circ} \mathrm{C}$, of sulphur $448^{\circ} \mathrm{C}$., of zine $1040^{\circ} \mathrm{C}$, and of copper $2100^{\circ} \mathrm{C}$.

Some substances boil at very low temperatures. Most of those substances are never seen in the liquid state, except in laboratories. They are known only in 
the form of gases. Such gases are hydrogen, oxygen, and carbon dioxide.

Distillation. The fact that different liquids boil at different temperatures is utilized in the separation of various substances by means of a process known as distillation. If a mixture of alcohol and water is heated between $78^{\circ} \mathrm{C}$. and $100^{\circ} \mathrm{C}$. the alcohol will boil and pass off as a vapor, while the water will remain. If the alcohol vapor is then cooled, it will again become a liquid. If the boiling points of the two liquids lie close together, as they do in this case, repeated dịstillation is necessary. Even then a complete separation can not be obtained by distillation alone.

Commercially, distillation is a very important process. When liquids contain dissolved solids, the liquids

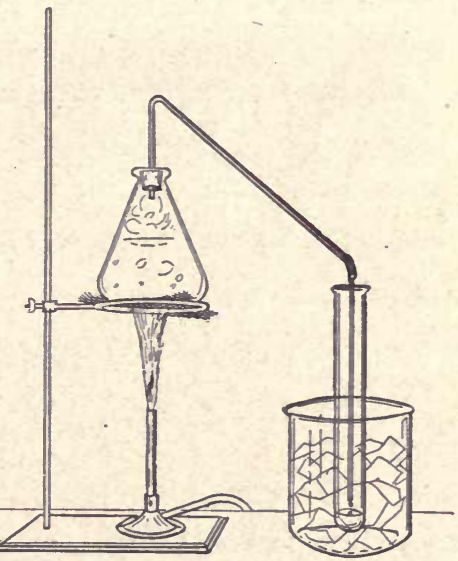

Fig. 20. Distillation. The solution to be distilled is placed in the flask. The steam passes through the tube, is cooled, and condenses in the test tube. Any impurities present in the original liquid are left in the flask.

can usually be distilled. Water can be freed from impurities by it. If muddy water is boiled, the water evaporates, or passes off in the form of steam, but the impurities remain in the vessel in which the water is being boiled. The steam can then be condensed and pure water obtained. Water freed from impurities in this way 
is called distilled water, and the process is called distillation. By this method, the salt water of the ocean may be separated into pure drinking water and salt. Distilled water is used by chemists in their work; it is used in the manufacture of artificial ice and also for drinking water.

Turpentine is made by distilling the sap of pine trees. The sap is collected and heated. Turpentine passes off as a steam, and rosin is the mass left in the boiler.

Effect of change of pressure on boiling point. Water is placed in a flask and heated to about $70^{\circ} \mathrm{C}$. A thermometer is then put in the flask; the whole apparatus is placed under the receiver of an air pump, and the

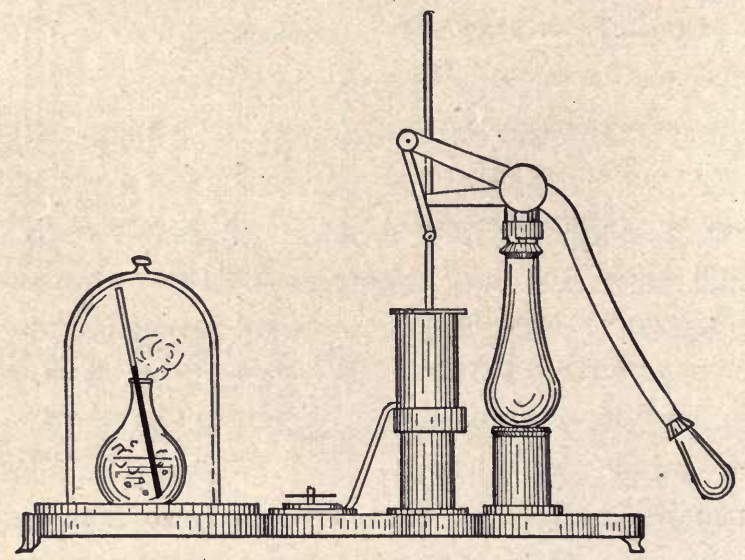

Fig. 21. If part of the air is withdrawn by means of an air pump from around the flask, water in the flask will boil at a temperature far below $100^{\circ} \mathrm{C}$.

air is exhausted. When the pressure is sufficiently diminished the water boils violently at a temperature far below the usual boiling point. 
Water is boiled in a flask until the air has been expelled by the steam. It is then quickly closed with a tight cork and inverted. If cold water is then poured over the flask, the water within it boils violently. The cold water condenses some of the steam in the flask, thereby diminishing the pressure in the flask, and as a result the water boils.

From these experiments we learn that the boiling point of water is lowered if the pressure is diminished.

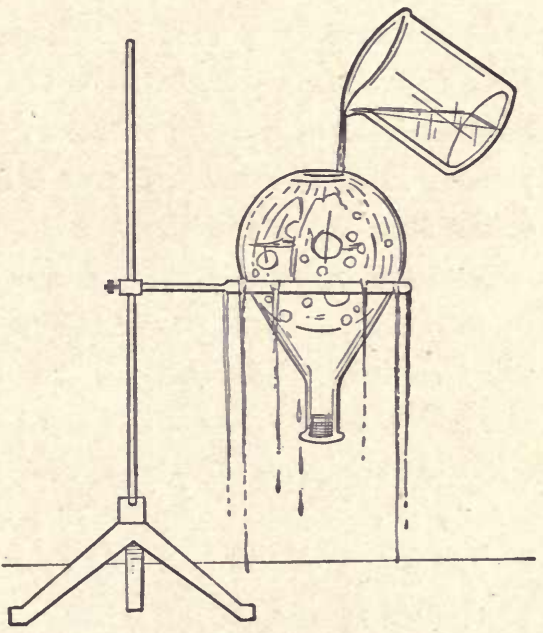

Because of the di- Fig. 22. Water is boiling in the minished atmospheric flask while cold water is being poured pressure at high altitudes, the boiling point of a liquid is considerably lower upon a mountain than it is near sea level. On Pike's Peak water boils at about $86^{\circ} \mathrm{C}$.

On the other hand, experiments have shown that water will not boil even at a temperature of $100^{\circ} \mathrm{C}$., if the pressure is increased above normal at sea level. A change in pressure also affects the melting points of substances. A decrease in pressure will usually 
raise the melting point, and an increase in pressure will usually lower the melting point.

Quantity of heat used in changing water to steam. The quantity of heat necessary to change 1 e.c. of water into water vapor, or steam, can be determined. (See Laboratory Manual, Exercise 18.) Experiments have proved that it takes about 536 calories of heat to convert 1 c.c. of water into vapor. This is about $5 \frac{1}{3}$ times as much heat as is necessary to raise the same amount of water from $0^{\circ}$ to $100^{\circ} \mathrm{C}$.

Heat withdrawn in evaporation of liquids. If chloroform or ether is left exposed to the air it evaporates very rapidly. Likewise, if water is left exposed to the air it evaporates. The liquids, which have apparently disappeared, have passed into the surrounding air in the form of vapor. When water is converted into vapor by ordinary evaporation, heat is consumed in the same manner as when water is converted into steam by boiling, but the process is very much slower. The heat, which is used in evaporation, is withdrawn from the surrounding objects.

Evaporation is a slow process, oceurring at all temperatures. It is hastened in the summer because of the large amount of heat in the atmosphere.

After a shower of rain, the water evaporates and cools the air. When streets are sprinkled, the water not only lays the dust, but in evaporating cools the atmosphere. When perspiration evaporates from the skin it cools the surface of the body. In tropical 
countries water is cooled by being placed in porous jars. A small quantity of water passes through the pores of the jar, and, on evaporating, withdraws enough heat from the water remaining in the jar to cool it.

\section{Artificial ice. This} same principle is utilized in the manufacture of artificial ice. In countries where it is never cold enough to freeze the water in ponds, all the ice formerly used had to be shipped from colder countries. Of late years, however, men have devised methods by which ice may be made very

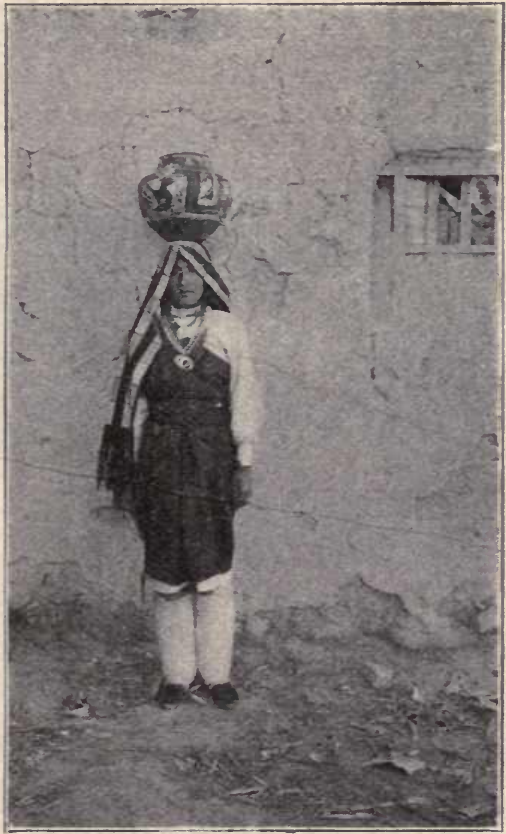

Copyright by Henry G. Peabody. Fig. 23. An Indian woman carrying an olla, a porous water jug, in which the water is cooled by the evaporation of water from the outside of the olla. cheaply even in the warmest places. In fact, these methods offer so many advantages, that even in our northern cities great quantities of artificial ice are used.

The method most commonly used in the artificial production of ice is known as the ammonia method. This depends upon the fact that pure ammonia, which 
is a gas, may be condensed into a liquid form by great pressure, and as soon as the pressure is removed the

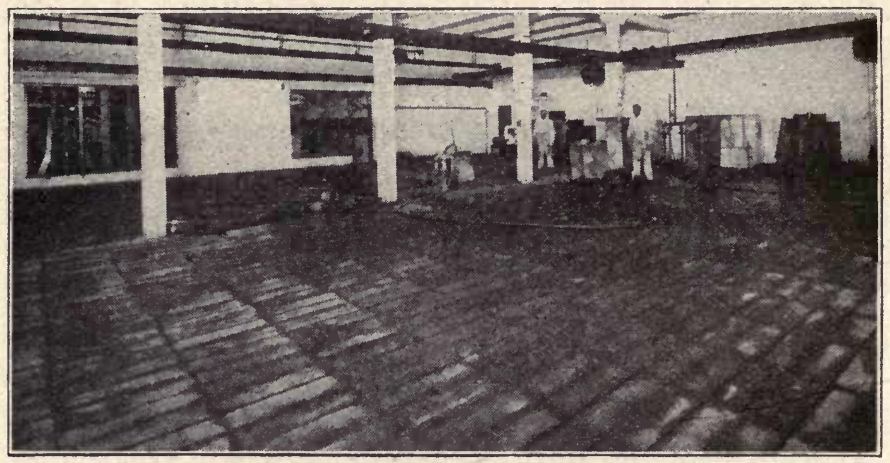

Fig. 24. Interior of tank room in ice factory. The brine tank and the ammonia coils are under the floor. Two cans ready to be flled with distilled water are shown at the right.

liquid quickly changes into a gas again, the rapid change requiring much heat.

Ammonia gas is liquefied by strong pressure and low temperature. It is then allowed to flow into pipes which run through tanks containing salt water. As soon as the pressure is reduced, the liquid ammonia evaporates and becomes a gas. In doing this it withdraws heat from the salt water, reducing its temperature far below the freezing temperature of pure water. Immersed in the salt water are molds containing pure water. The water in the molds freezes and is withdrawn as solid cakes of ice.

Heat given off in condensation. If a glass plate is held over boiling water, drops of water collect on it. The steam is cooled on coming in contact with the glass 
plate and condenses into water. In winter, steam collects on the window panes, if the room is warm and the air is moist. A pitcher of ice water when standing in a warm room becomes covered with drops of water. When the moisture in the air comes in contact with the cold surface, it immediately condenses.

When steam condenses into water, heat is released. The amount of heat thus liberated is equal to the amount of heat used in transforming the water into steam. In other words, it requires 536 calories of heat to convert 1 gram of water into steam, and 1 gram of steam gives off 536 calories of heat during its condensation into water.

The liberation of heat by condensation is made use of in the system of steam heating. Water is boiled in a boiler, and a large amount of heat is used to convert the water into steam. The steam passes through pipes which run to the radiators in various parts of the building. There the steam condenses and in so doing liberates large quantities of heat, thereby giving up to the air of the room much of the heat which it had absorbed from the fire.

Change in volume resulting from change in state. A change in the form of a substance, from a solid to a liquid, for example, is invariably accompanied by a change of volume.

With the exception of ice, most solids expand on becoming liquids, and liquids expand when they become gases. The volume of water is greatly 
increased when it becomes steam. All of us know of the force exerted by steam. This enormous force is utilized in all the numerous kinds of steam engines.

The return from the gaseous to the liquid state, or from the liquid to the solid state, is always accompanied by a considerable decrease in volume.

Molecular changes resulting from change in state. We already know that if the temperature of a solid is increased, its volume is also increased. We also know that this is because the molecules of the solid have been driven farther apart. By continuous heating, the molecules of a solid may be driven, or forced, far enough apart actually to change the form of the substance from that of a solid to that of a liquid. Similarly, when the molecules of a liquid are forced far enough apart, the liquid becomes a gas.

Anything which interferes with the free movement of the molecules will increase the amount of heat necessary to change, for example, a liquid to a gas. Consequently, if the air pressure on a liquid is increased, its boiling point is raised. The reverse is also true, that if the pressure upon a liquid is reduced, the molecules can move apart more readily, and consequently, less heat is necessary to convert the liquid into a gas.

We thus see that by decreasing the pressure upon solids or liquids, less heat is necessary to change them into gases.

It is also true that to change a gas to a liquid, or a liquid to a solid, the molecules must be brought closer 
together. This can be brought about in two ways: first, by reducing the temperature of the substances, and second, by increasing the pressure upon them.

It is only by the combination of a great increase in pressure and a great decrease in temperature, that it has been possible to convert some gases into liquids, and the resulting liquids into the solid state.

\section{Questions}

1. In what three forms may a substance exist?

2. Name two solids which cannot be changed to liquids. Why is it impossible to convert them into liquids?

3. At what temperature does water boil? Freeze?

4. How many calories of heat are required to change one gram of ice to water?

5. What are the sources of heat for melting ice in a refrigerator?

6. Is it warmer or cooler near a body of melting ice than it is at some distance away? Why?

7. Why is salt mixed with chopped ice for use in ice cream freezers?

8. What effect does water which is melting have upon the surrounding temperature?

9. How many calories of heat are given off when 10 grams of water are changed to ice?

10. What is the melting point of ice? Alcohol? Mercury?

11. Why is it impossible to melt iron in a glass dish?

12. What is the boiling point of water? Alcohol? Ether? Mercury? Copper? 
13. What is meant by distillation?

14. State several ways in which the process of distillation is of commercial value.

15. Why is it impossible to cook potatoes, by boiling, on top of Pike's Peak?

16. How many calories of heat are required to change one cubic centimeter of water into steam?

17. Why is it cooler after the streets have been sprinkled?

18. How does perspiration cool the body?

19. What is the method used in the production of artificial ice?

20. Why can you see your breath on a cold winter day?

21. Explain how heat is transferred by means of steam from the coal burning in the furnace to the rooms of a house.

22. What change takes place in the volume of a substance when it changes from a solid to a liquid? A liquid to gas? A gas to a liquid, or a liquid to a solid? 


\section{PHYSICAL AND CHEMICAL CHANGES}

Physical change. Matter may undergo many changes. One class of these changes is not accompanied by any alteration in the composition of matter. When a piece of glass is broken the small pieces do not differ from the original piece except in size. A piece of iron may be broken, it may be magnetized, it may be heated, it may be melted, and it may be converted into a vapor. In none of these changes, however, has the composition of the iron been affected. The pieces of iron, the magnetized iron, the heated iron, the melted iron, or the iron vapor are just as truly iron as was the original piece. Sugar may be dissolved in water, but neither the sugar nor the water is changed in composition. The resulting liquid has the sweet taste of sugar, but the water can be evaporated by heating and the sugar recovered unchanged. Such changes are called physical changes. Physical changes are those which do not involve a change in the composition of substances. In other words, a physical change is a change in the form but not in the nature of a substance. 
Chemical change. Matter may undergo other changes in which its composition is altered. When a piece of coal is burned, ashes and invisible gases are formed. These are entirely different in composition and properties from the original coal. Iron when exposed to moist air is gradually changed into rust. This rust is not the same as the iron. If sugar is covered with sulphuric acid and slowly heated, a black substance is formed which is neither sweet nor soluble in water. Such changes are evidently quite different from the physical changes just described, for in them new substances are formed in place of the ones undergoing change. Changes of this kind are called chemical changes. Chemical changes are those which involve a change in the composition of substances and result in the formation of new substances.

\section{Questions}

1. What is a physical change?

2. Name three physical changes.

3. How does a chemical change differ from a physical change?

4. Name three chemical changes.

5. Classify the following as examples of physical or chemical changes:

a. Ice to water.

b. Hydrochloric acid on marble.

c. Burning of wood.

d. Carbon dioxide in lime water.

e. Electric current passing over a wire. 


\section{CHEMICAL PHENOMENA}

Physical and chemical properties. Many so-called properties of a substance can be noted without causing the substance to undergo chemical change, and are therefore called its physical properties. Among these are its physical state, color, odor, taste, size, shape, and weight.

Other properties are discovered only when a substance undergoes chemical change. These are called its chemical properties. We know, for example, that wood burns in air; that carbon dioxide turns lime water milky ; and that iron rusts when exposed to the air.

Classification of matter. At first sight there appears to be no limit to the varieties of matter of which the world is made. For convenience in study we may classify all these varieties under three heads; namely: mechanical mixtures, chemical compounds, and elements.

Mechanical mixtures. If equal amounts of salt and iron filings are thoroughly mixed together, the resulting product has the appearance of a new substance. If it is examined more closely, however, it will be seen to be merely a mixture of salt and iron, each of which 
substances retains its own peculiar properties. The particles of salt and the particles of iron can be easily detected. $\Lambda$ magnet held over the mixture draws out the iron just as if the salt were not there. On the other hand, the salt can be separated from the iron. If the mixture is covered with water and then poured through a filter, the particles of iron will remain on the

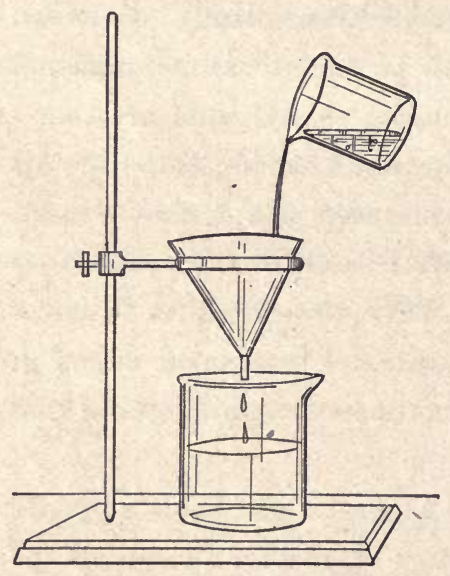

Fig. 25. A flter paper is folded and placed in the funnel. The liquid is poured from the beaker. The flitrate runs through the filter. paper in the filter. The liquid which passes through the filter is known as the filtrate. By boiling this filtrate, the water will evaporate, and the salt will remain in its original form. Both substances have been recovered in their original form and no new substance has been formed. If two or more substances are placed together, and each retains its original properties, the resulting substance is called a mechanical mixture.

Chemical compounds. If iron filings and powdered sulphur are thoroughly ground together in a mortar, a yellowish green substance results. As in the case of the salt and the iron this is again a mechanical mixture, from which the sulphur and the iron can easily be separated. 
If this mixture is placed in a test tube and heated in the flame of a Bunsen burner, a very striking change takes place. The mixture begins to glow at the bottom of the tube, and then the glow rapidly extends through the entire mass. If the test tube is now broken and its content examined, it will be found to be a brittle substance, which in no way resembles the sulphur or the iron with which we started. The magnet will no longer attract the iron, neither can the sulphur be separated by any physical process. A new substance has been formed, resulting from the action of the heat upon the mixture of iron and sulphur. This new substance is iron sulphide. Such a substance is called a chemical compound. When two or more substances unite in such a way as to lose their characteristic properties, and to form a new substance with new properties, such a substance is called a chemical compound.

Elements. It has been seen that iron sulphide is composed of two entirely different substances, iron and sulphur. The question now naturally arises: do these substances each contain different substances, that is, are they also chemical compounds?

Chemists have tried in a great many ways to decompose them, but all their efforts have failed. Substances which can not be decomposed into other substances are ealled elements. It is not always possible to prove that a given substance is an element. It is always possible that by some yet untried method the supposed element 
may be decomposed into other simpler forms of matter and thus be proved to be a compound. Water and other familiar compounds were at one time thought to be elements.

An element may be defined as a substance which can not be separated into simpler substanees by any known means.

Number of elements. The number of substances now supposed to be elements is not large. There are eightyfour elements. Probably there are some undiscovered, but it is generally believed that the present number will not be greatly increased. These elements are analogous to the letters of the alphabet, and by their various combinations make up the matter of the universe, somewhat as letters form words.

About ten of these elements are gases at ordinary temperatures, two are liquids, and all the others are solids.

Each element is designated by a symbol, which is an abbreviation of the name, or in some cases an abbreviation of the Latin name. A list of the more common elements with their symbols follows:

$\begin{array}{lrlrlr}\text { Aluminum } & \mathrm{Al} & \text { Chlorine } & \mathrm{Cl} & \text { Krypton } & \mathrm{Kr} \\ \text { Antimony } & \mathrm{Sb} & \text { Copper } & \mathrm{Cu} & \text { Lead } & \mathrm{Pb} \\ \text { Argon } & \mathrm{A} & \text { Fluorine } & \mathrm{F} & \text { Magnesium } & \mathrm{Mg} \\ \text { Arsenic } & \mathrm{As} & \text { Gold } & \mathrm{Au} & \text { Manganese } & \mathrm{Mn} \\ \text { Bismuth } & \mathrm{Bi} & \text { Helium } & \mathrm{He} & \text { Mercury } & \mathrm{Hg} \\ \text { Bromine } & \mathrm{Br} & \text { Hydrogen } & \mathrm{H} & \text { Neon } & \mathrm{Ne} \\ \text { Calcium } & \mathrm{Ca} & \text { Iodine } & \mathrm{I} & \text { Nickel } & \mathrm{Ni} \\ \text { Carbon } & \mathrm{C} & \text { Iron } & \mathrm{Fe} & \text { Nitrogen } & \mathrm{N}\end{array}$




$\begin{array}{lrlrlr}\text { Oxygen } & \text { O } & \text { Silicon } & \text { Si } & \text { Tungsten } & \text { W } \\ \text { Phosphorus } & \text { P } & \text { Silver } & \text { Ag } & \text { Uranium } & \text { U } \\ \text { Platinum } & \text { Pt } & \text { Sodium } & \text { Na } & \text { Xenon } & \text { Xe } \\ \text { Potassium } & \text { K } & \text { Sulphur } & \text { S } & \text { Zine } & \text { Zn } \\ \text { Radium } & \text { Ra } & \text { Tin } & \text { Sn } & & \end{array}$

Chemical synthesis. We have already learned that if iron filings and sulphur are thoroughly mixed and then heated, a chemical compound, iron sulphide, is formed. When two or more substances combine chemically and form a compound, the process is known as chemical synthesis.

Chemical Analysis. Just as it is possible for substances to combine and form more complex substances, so also, it is possible to decompose these complex substances into the elements of which they are composed.

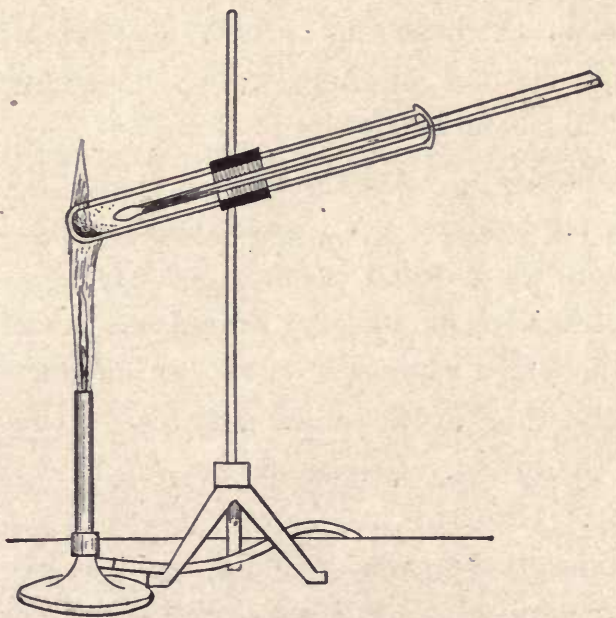

Fig. 26. If a glowing pine splinter is inserted into a test tube containing highly heated mercuric oxide, the splinter burns more brightly. 
A small amount of mercuric oxide, a light red powder, is placed in a test tube. The tube is then thoroughly heated. If, while the tube is in the flame, a glowing pine splinter is inserted into it, the splinter at once breaks into a flame. Evidently there is something being given off from the highly heated mercuric oxide which causes this change in the splinter. This substance is the gas, oxygen, an element which forms about one-fifth of the air.

If the tube is allowed to cool, the inside of it will be found to be covered with a thin coating of mercury. Thus mercuric oxide has been separated by means of heat into its elements, oxygen and mercury. This process of separating or decomposing a compound into its elements is known as chemical analysis.

Chemical affinity. It is evident that in the formation of the chemical compound, iron sulphide, the two elements, iron and sulphur, were in some way combined. This combination was brought about by the action of heat. The force which caused these two elements to combine and which held them together when combined is called chemical affinity.

The attraction, or affinity, which one substance has for another is always the cause of chemical union. Frequently this union does not take place except through the action of some agency, as heat, light, or electricity.

Sometimes these same agencies may overcome this attraction and as a result cause the decomposition of a compound. Mercuric oxide we have learned is com- 
posed of mercury and oxygen. It was found possible, however, by heat to overcome the attraction which the mercury and oxygen had for each other and thus to decompose the compound which they had formed by their union.

\section{Questions}

1. Name two physical properties of iron.

2. Name one chemical property of iron.

3. Give an example of a mechanical mixture. Explain why the example given is a mechanical mixture.

4. Is iron sulphide a mechanical mixture or a chemical compound? Why?

5. Define the term chemical element.

6. How many elements are there?

7. Name ten elements. What is the symbol for each?

8. What are the differences between chemical synthesis and chemical analysis?

9. Give two examples of chemical synthesis. Two of chemical analysis.

10. What is the name given to the force which holds elements together when they form compounds?

11. Through what agencies may this force be overcome?

12. State several conditions under which elements will unite. 


\section{CHAPTER IX}

\section{CARBON}

\section{$($ Carbon $=\mathrm{C})$}

Introduction. Carbon, though perhaps not known by that name, in some form is known to all of us. We are all familiar with the black soot which collects on the side of a lamp-chimney from the burning of an unevenly trimmed lamp wick. To this substance the name lampblack is given.

All have seen the charred remains of bones that have been roasted out of reach of air. This substance we know as bone black. Charcoal, too, is somewhat familiar from its use in filtering water or as a deodorizer, while coke and coal are known as our chief sources of fuel for heating purposes. The so-called lead of the lead pencil is graphite, a form of carbon, while the diamond is another form.

As widely as these substances vary in physical properties, yet each is chiefly carbon. Carbon is the most widely distributed of all the known elements. It is found in all living matter, whether plant or animal, and it also forms a considerable part of the earth's crust. In the uncombined or free state it is found as diamond, coal, and graphite. 
Charcoal. If a piece of eharcoal is examined carefully it will be seen to look very much like a small block of wood. And sueh, in fact, it is. It is usually made by heaping up the small blocks of wood into mounds and covering the whole with soil and turf to exelude the air. Then a fire is started underneath the wood and although some of the wood burns, yet the greater portion only smolders. The result is that all other substances are driven off, leaving practically pure carbon. A more modern method of producing charcoal is to heat wood in closed iron ovens. The principle involved in either case is the same; namely. to break down the compounds which comprise wood into simpler substances, and drive off all but carbon. Animal carbon is prepared by burning bones away from air.

Uses of charcoal. Because of its porous nature, charcoal is a great absorber of gases. This quality renders it of great value in contributing to our comfort and welfare. The unpleasant odors which arise from sewers can be prevented by suspending bags of charcoal in the man-holes. Cistern water is kept sweet and clean by filtering through charcoal. In many homes in our cities all water used for drinking and cooking purposes is passed through charcoal filters. In passing through the porous charcoal the impurities are removed. However, unless the filter is cleaned frequently it may become a menace to health rather than a benefit. The pores in the filter become clogged 
with impurities and furnish a hotbed for whatever germs may find their way there. So, instead of removing the things that are injurious, it may be the means of supplying them. The necessity of keeping the filter thoroughly cleaned must be clear to all.

Charcoal is also used as a decolorizer. For this purpose, however, animal charcoal is chiefly used. If you have ever visited a sugar beet factory, no doubt you were impressed by the difference of color in the dark sap from which the sugar is made and the beattiful white crystals of commercial sugar. This transformation in color is brought about in the large filters, called charfilters, which contain this finely divided charcoal through which the syrup passes. Large quantities of charcoal are used in sugar refining.

Lampblack. Lampblack or soot is practically pure carbon. It is obtained by incomplete burning; that is, by burning with a limited supply of air. This can be shown by cutting off the air to your Bunsen flame and holding a white porcelain plate over the flame. The soot will collect on the plate. This finely divided black powder furnishes the pigment for the manufacture of printer's ink and paint.

Coal. Generally speaking, coal is divided into soft, or bituminous, and hard, or anthracite coal. The difference is greater than the mere physical difference of degrees of hardness and is explained by the greater percentage of carbon found in the hard coal. Anthra- 
cite coal generally consists of about $95 \%$ carbon while bituminous coal contains $80 \%$ or less of carbon.

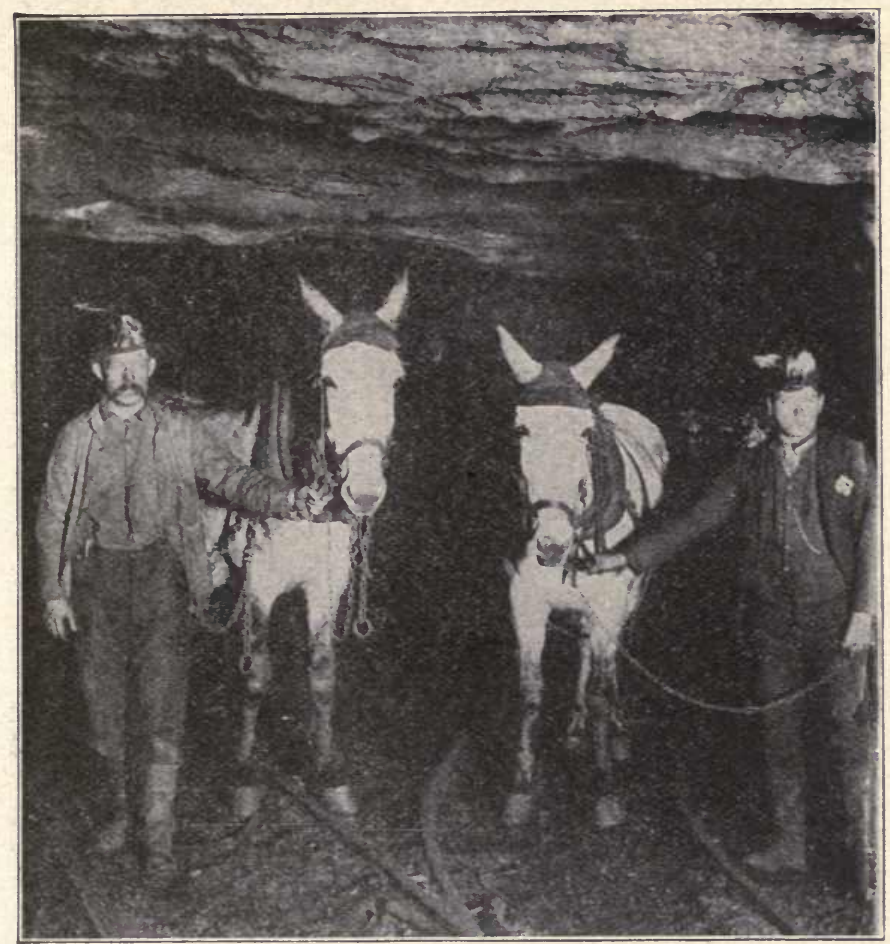

Copyright by Undervood \& Undervood, N. Y. Fig. 27. Mining anthracite coal three miles underground.

Coal is wood that has undergone great changes during past centuries. The harder the coal the longer this change has been taking place. During a period of the earth's history known as the Carboniferous Age, the earth was covered with a luxurious growth 
of vegetation under swamp and marsh conditions. As this fell and accumulated year after year, and century after century, and became submerged, many of the more volatile gases were driven off, with some of the carbon, no doubt, but much of the carbon was preserved. As the pressure of the accumulating weight increased, further changes took place until eventually coal, our chief source of heating fuel, was produced.

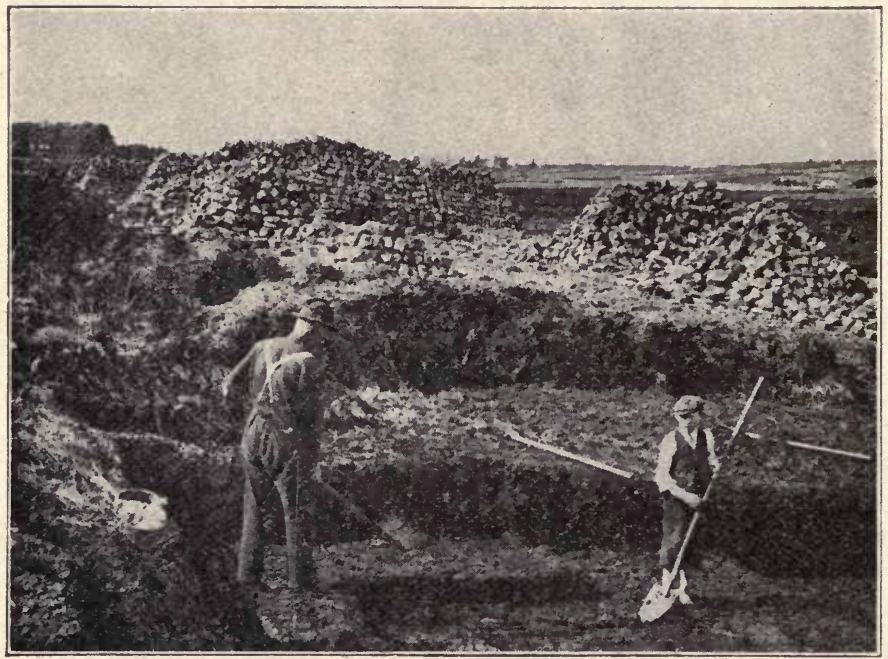

Copyright by Underwood \& Underwood, N. Y. Fig. 28. Cutting peat in Ireland, where it is used as a substitute for coal.

Successive stages in coal formation are wood, peat, lignite or brown coal, soft or bituminous coal, and hard or anthracite coal.

Coke is produced from coal in very much the same manner that charcoal is produced from wood. When 
coal is heated away from air, coke is the solid substance that remains.

The chief use of coke is for fuel for coke ovens, blast furnaces, and steam engines. It is superior to soft coal, because it gives off more heat; but inferior to hard coal, because it burns more rapidly and requires more attention. Because it is a good conductor of electricity it is used also in the electrical industry.

Graphite. Graphite is another form of carbon taken from mines in the earth. The best of these are found in Siberia and Ceylon, though much is mined in England, California, and New York. Graphite differs from other forms of carbon in that it is very soft. Its uses are many: as a lubricant for machines, as polish for stoves, as a covering to conduct the electric current in electrotyping, and mixed with clay, to supply the "lead" of the lead pencil.

In the manufacture of lead pencils, graphite is mixed with clay, and worked up into a pasty mass. From this pasty mass the thin rods of the pencil are produced which are finally encased in the wood. The hardness of the pencil depends upon the relative proportions of graphite and clay; the more clay the harder the pencil.

Diamond. The diamond is pure carbon. It differs from other forms of carbon in its hardness, being the hardest substance known in nature. Because of its rarity it is a very eostly gem, its value being deter- 
mined by the clearness of its crystals which refract the light in passing through it into brilliant colors. The refractive power of the diamond is increased by cutting its surface into numerous facets. Being the hardest substance known, it takes diamond to cut diamond, so this process is accomplished by grinding the stone to be cut with black and imperfect pieces of diamond which are valueless as gems.

Diamonds which are valueless as jewels are of much value in pointing glass cutters and in making drills to drill rocks.

The most valuable diamond mines are the Kimberly mines of South Africa, though the stone is found in smaller deposits in South America and Australia.

Carbon dioxide $=\mathbf{C O}_{2}$. Burning is a phenomenon familiar to all and yet in the process many chemical changes may be taking place. The visible results are that the object burned is separated into smoke, flame, and ash, together with the heat given off. Another product of most burning is an invisible gas called carbon dioxide. This gas is formed by the union of the oxygen of the air with the carbon in the substance. It may be expressed as $\mathrm{C}+2 \times \mathrm{O}=\mathrm{CO}_{2}$ in which two parts of oxygen combine with one part of carbon to form carbon dioxide. It is constantly emitted wherever there are living organisms, for all living forms "burn" carbon in the body, and the carbon dioxide is given off in breathing. Even in decay, plant and animal forms give off this gas. 
Preparation and test for carbon dioxide. Carbon dioxide may be supplied in many ways, but the simplest method for class use is to place a few pieces of

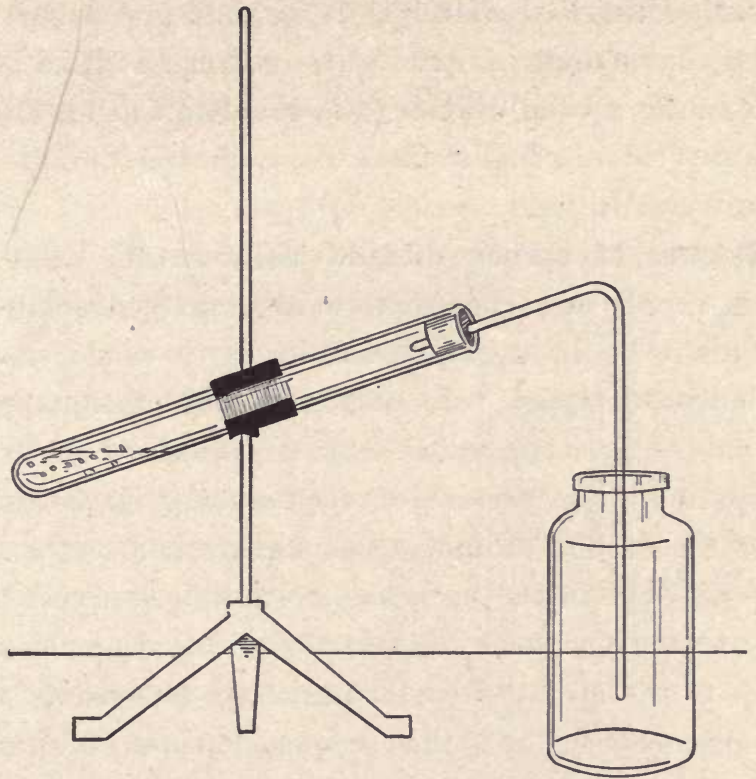

Fig. 29. The action of the hydrochloric acid on the pieces of marble in the test tube decomposes them, releasing carbon dioxide. The gas escapes through the bent tube into the bottle.

marble in a test tube, and pour hydrochloric acid on it. In the chemical action which takes place between the marble and the hydrochloric acid, carbon dioxide is given off and a salt (calcium chloride) and water are left in the tube.

If a bottle of this gas is collected it will be found to be colorless, with little taste or odor. It is about $11 / 2$ times as heavy as air and thus can be collected 
with the bottle upright; for, as the heavier gas enters, the air is forced out. If a burning pine splinter is inserted into a bottle of earbon dioxide it will be extinguished immediately. It neither burns nor supports combustion. If lime water is poured into a bottle. containing earbon dioxide, and shaken, it at once turns a milky color. This is the test for carbon dioxide and is universally used.

Balance of carbon dioxide maintained. From the great supply of earbon dioxide constantly pouring into the air it would seem that life on earth would soon be endangered. However, earbon dioxide has its place in nature as it provides some of the food for green plants. In the process of food-making, green plants take the carbon dioxide from the air and water from the soil, and in the presence of sunlight eonvert them into starch (or food for the plant). Oxygen is given back to the air by the plant as a waste product from this process. Thus the proper balance of carbon dioxide in the air is maintained.

Commercial uses of carbon dioxide. Carbon dioxide is soluble in water, which at ordinary temperature absorbs an amount about equal to its own volume. Under pressure, however, it may be charged with many times its own volume. This may be observed at any ordinary soda fountain. Soda water is made by simply charging water with carbon dioxide under pressure. It is then kept in sealed jars away from the air. When soda is drawn at the fountain, the effervescence is 
due to the rushing forth of the confined carbon dioxide.

If carbon dioxide is poured over a burning candle, the flame is extinguished at once. Carbon dioxide, being heavier than the air, forms a blanket or covering about the candle thereby excluding the air or oxygen, and without oxygen fire is impossible.

This fact gave rise to carbon dioxide fire extinguishers. These are made of certain chemicals, which when placed together produce carbon dioxide. The chemicals commonly used are bicarbonate of soda and sulphuric acid. The extinguisher consists of a metallic case containing a small vessel of strong sulphuric acid embedded in the bicarbonate of soda. When the extinguisher is inverted the acid mixes with the soda, producing earbon dioxide which escapes through a tube. As this gas is poured upon a burning object, it forms a layer of the heavier gas about the object, excluding the oxygen and thus extinguishing the fire.

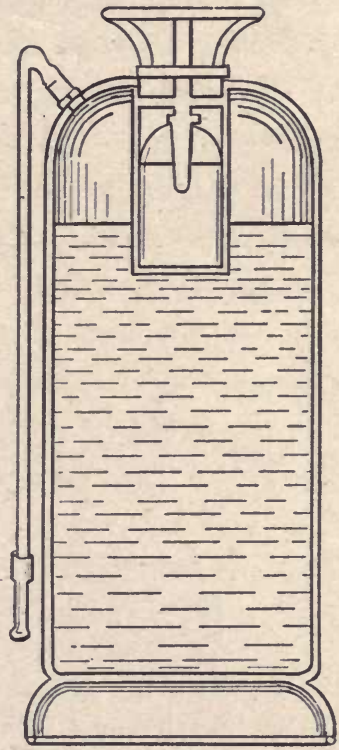

Fig. 30. Inside view of a fire extinguisher.

Carbon dioxide also plays an important part in a process which is familiar to all of us, the rising of 
dough in bread making. As a result of the action of yeast, the sugar in bread is broken down into carbon dioxide and small quantities of alcohol. The firm dough then swells because the gas imprisoned within it forms air spaces. In baking the dough, the spaces are enlarged as the gas escapes, and at the same time the alcohol is evaporated.

Yeast is not always used to produce this earbon dioxide. Sometimes, as in soda biseuits, baking soda (bicarbonate of soda) is used and to it is added cream of tartar or sour milk. In either ease, by the action of the cream of tartar or the sour milk upon the soda, carbon dioxide is given off. If baking powder is used, as in baking powder biseuits, cakes, and many other foods, the action of the substances within the baking powder is such as to liberate carbon dioxide. This escapes through the dough and makes it light and porous.

\section{Questions}

1. Chemically speaking, what is charcoal?

2. How is charcoal made?

3. To what various uses is it put?

4. How is lampblack produced?

5. Has lampblack a commercial value? What is it?

6. What is coal?

7. What are the suceessive stages in its formation?

8. Look up all the material you can on coal formation and write an essay on it.

9. How is coke made from coal? 
10. For what purposes is coke used?

11. Where are the best graphite mines?

12. What are the uses of graphite?

13. How are lead pencils made?

14. Diamond and coal are both carbon. What causes the great difference in the market values of these two substances? Three reasons.

15. Where are the best diamond mines located?

16. Do you know how diamonds are mined? Look it up and bring this information to class with you.

17. How is carbon dioxide produced?

18. Is it necessary to life?

19. Is it poisonous?

20. Would too much of it prove fatal to life? Why?

21. Explain fully why people and other animals are sometimes killed in going down into old wells and mines.

22. What is the test for the presence of carbon dioxide?

23. Is there any soda in "soda water"?

24. Whence then does it receive its name?

25. What causes the effervescence of "soda water"? 


\section{PHOSPHORUS}

\section{(Phosphorus $=\mathrm{P})$}

Introduction. Phosphorus is not found in the free state in nature, but in compounds, in small quantities rather widely distributed. It is a part of all living matter and is found in all fertile soils, as plants can not grow without phosphorus. Large deposits of minerals are found containing phosphates, which are extensively mined for use as fertilizers. Bone consists of $80 \%$ of calcium phosphate, which, together with the phosphates found in large mineral deposits, form the chief sources of commercial phosphorus.

Preparation. In obtaining phosphorus from bones the combustible matter is burned out, leaving bone-ash behind.

Bone-ash or a pure mineral phosphate is then heated with sand and carbon in an electric furnace. In the heating, phosphorus vapor escapes through tubes and is led under water where it condenses in molds.

Properties. Yellow phosphorus in the pure state is a translucent, waxy solid which when exposed to light takes on a coating of darker color. If a piece of yellow phosphorus is exposed to the air, it will begin to give 
off white fumes almost immediately and if left thus exposed for a minute or two, will ignite. Because it ignites at such a low temperature, phosphorus must

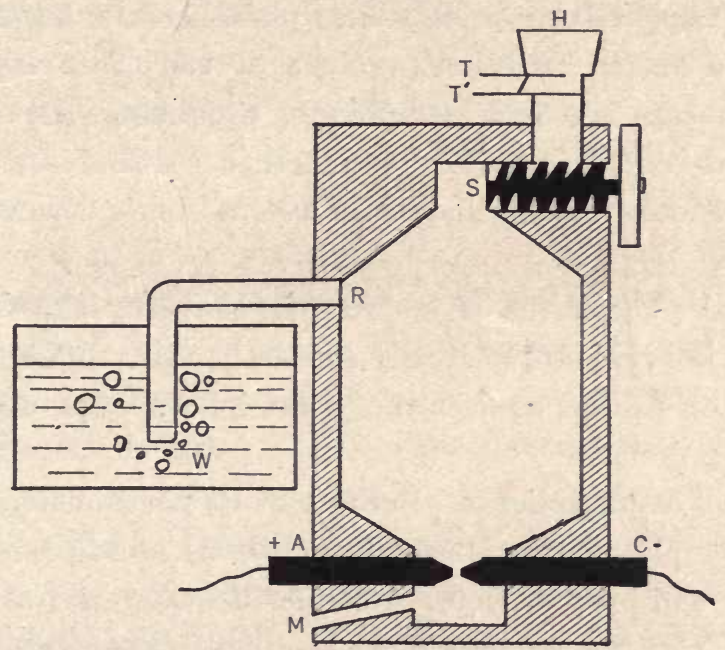

Fig. 31. Phosphorus furnace. A mixture of calcium phosphate, sand, and carbon is admitted at $H$ through $T$. $T$ is then closed and ' $T^{\prime}$ opened. The mixture is slowly admitted over the screw $\mathrm{S}$ and drops between electrodes $A$ and $C$. The slag which forms flows out at M. Phosphorus vapor and carbon dioxide pass. out through $R$. The phosphorus condenses in the water W, and the carbon dioxide bubbles up and passes off through the water.

always be kept under water. It must always be cut under water, for the friction of the knife caused in the cutting will raise its temperature to the point of burning. Great care must be exercised in dealing with phosphorus and forceps should be used to handle it. If touched by the hands the heat of the body may ignite it and cause a burn. A phosphorus burn is very serious, the wound requiring months to heal. Phosphorus is very poisonous, and great eare must be taken 
not to breathe the fumes. Because of the rapidity. with which oxygen and phosphorus unite, phosphorus emits a light when exposed to air. This property is known as phosphorescence. If yellow phosphorus is heated in closed vessels to a temperature of $250^{\circ} \mathrm{C}$. to $300^{\circ} \mathrm{C}$., its nature changes completely, producing the form called red phosphorus. On further heating it undergoes another change and becomes yellow phosphorus once more.

Red phosphorus is a dull red, powdery substance, very inactive and perfectly safe to handle. It does not give off a light as does the yellow phosphorus, neither is it poisonous.

Uses of phosphorus. Because of its poisonous nature yellow phosphorus is used in preparing poison for rats, mice, and other vermin. Its chief use, however, as well as that of the red phosphorus, is in the manufacture of matches.

Friction match. In preparing the common friction match, the end of the stick is soaked in a mixture usually containing paraffin, sulphur, phosphorus, glue, and some compound containing a great deal of oxygen. On striking the match the heat produced from the friction kindles the phosphorus, which unites with the oxygen in the compound on the head of the match, and also with the oxygen in the air. The sulphur and paraffin are then ignited, and their burning sets fire to the wood.

Safety match. The safety match differs from the 
friction match in that the phosphorus, instead of being placed on the head of the match, is placed on the side of the box. For this purpose red phosphorus is used. To ignite the match it is necessary to strike its head on the side of the box or some similar surface. The heat thus produced is sufficient to convert a small portion of the red phosphorus on the box to yellow phosphorus, which kindles and ignites the substances on the head of the match.

Dangers of friction match. When we consider the ease with, which ordinary friction matches ignite, the langer resulting from leaving them about becomes apparent. Disastrous fires with thousands of dollars loss, have resulted from mice or rats clawing matches; from children striking them, or from their being stepped on. Because of the fact that the safety match will not easily ignite unless rubbed on the specially prepared surface, it is far safer. The chance of accidentally igniting them is much less, and in some countries, notably Switzerland, manufacture of the common friction match with yellow phosphorus is forbidden. Property destruction is not the only loss resulting from the manufacture of the friction match. The continued breathing of the vapor from the phosphorus by men in the factories produces an incurable disease called necrosis. This is characterized by falling out of the teeth, and the ulceration and decay of the jaw bones. The only way to prevent the spread of the disease is to remove the affected part. Because of the 
dangers of poisoning resulting from the common friction match, its manufacture should be forbidden.

\section{Questions}

1. What is the chief source of phosphorus?

2. How is it prepared?

3. What are the two different kinds of phosphorus?

4. What are some of the more prominent characteristics of each?

5. Why should yellow phosphorus be kept under water? Why should it never be touched, with the hands?

6. What are the chief uses of phosphorus?

7. Write an essay on the match industry.

8. Why do some countries forbid the manufacture of friction matches? 
CHAPTER XI

\section{SULPHUR}

$($ Sulphur $=\mathrm{S})$

The sulphur ordinarily used in the laboratory is of two kinds, roll sulphur and flowers of sulphur. The difference is merely a physical one and is due to the method by which each is prepared from the element as it is found in nature.

Occurrence. Sulphur is found both in the free state and in combination with other elements, though commercial sulphur is prepared chiefly from sulphur in the free state. It is found very widely distributed, being usually associated with volcanic regions. The largest deposits occur in Sicily, Texas, and Louisiana, with Japan, Mexico, and California adding to the world's supply. In Yellowstone Park it is found in sulphur springs. It is also found in many vegetables and in the yolk of eggs, and it forms no inconsiderable part of the human body, more than four ounces of it being present in the body of a man of ordinary size. Sicily formerly held first rank in the amount of sulphur annually given to the markets of our country. This was due to the great abundance of the element throughout that region and to the cheapness 


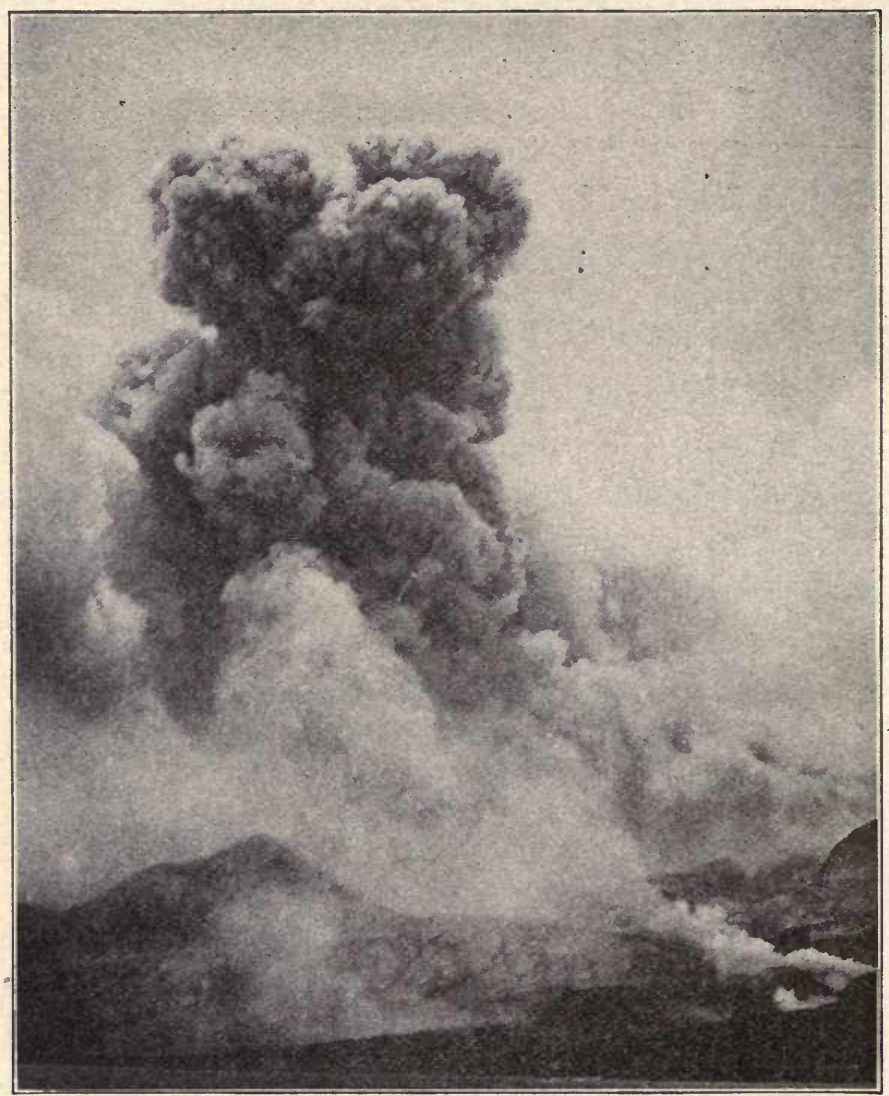

Copyright by Underwood \& Underwood, N. Y. Fig. 32. A volcano sending forth steam and sulphurous fumes.

of labor there. Today Louisiana has outstripped Sicily because of the discovery of new methods of working. Preparation. Although found deposited in immense beds in the free state, sulphur is practically always mixed with various kinds of earthy substances. Before 
the element can be of commercial value, it is necessary to free it of all impurities. In Sicily where the largest deposits occur, this is done by digging out the sulphur and heaping it into large piles. The mounds are then covered with sod and dirt and a fire is started underneath.

The heat produced causes the sulphur to melt, and it is then run out into troughs. Naturally much of the sulphur is burned and passes off as sulphur dioxide. Thus a large percentage of waste results. This loss has now been overcome by heating the substances out of contact with the air.

The method is first to place the ore in heaps in closed vessels and to heat it until the sulphur melts and thus separates from the earthy substances. The low melting point of sulphur makes this possible. It is then further purified by heating it in closed iron vessels having ducts leading into a cooling chamber made of bricks. The sulphur vaporizes; when the vapor comes into the cooling chamber it is suddenly cooled, and some of it collects as fine powder on the walls of the chamber. This form is known as flowers of sulphur. Most of the sulphur vapor condenses to the liquid form and falls to the bottom of the cooling chamber. It is then run into molds where it hardens into the cylindrical shaped rods known as roll sulphur. The method used in the United States consists in sinking into the sulphur beds four concentric iron tubes. The inner tube is one inch in diameter; the 
next, three; the third, six; and the outer tube, ten. Water heated under pressure much above the boiling point is forced through the three inch tube into the

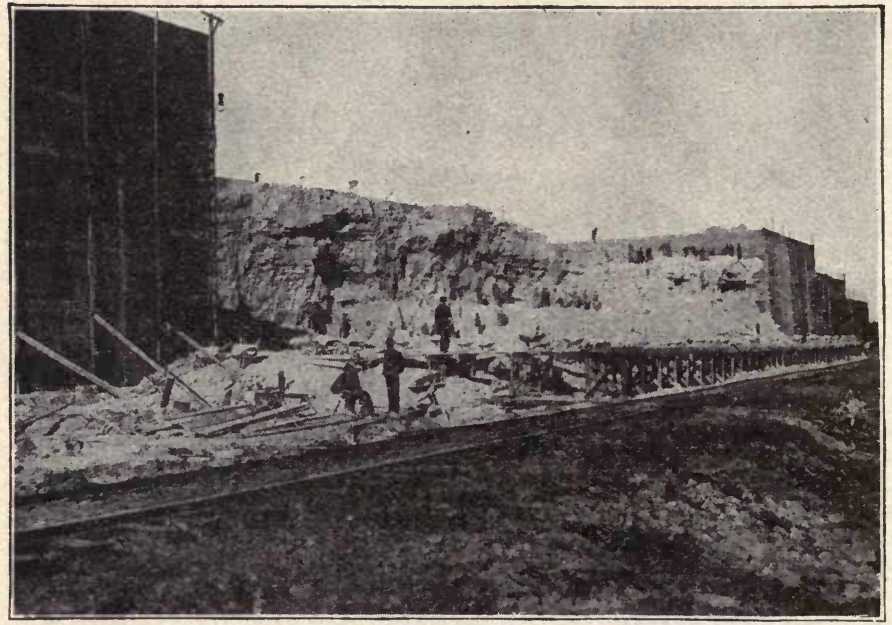

Permission United States Geological Survey.

Fig. 33. Sulphur which has been brought to the surface and consolidated, ready for shipment, at Sulphur, Jouisiana.

beds to melt the sulphur. Air under pressure is forced through the one inch tube. The melted sulphur mixed with air then bubbles up through the outer tubes. The sulphur is collected in large bins built of wood, where it solidifies to form large blocks of practically pure sulphur. These blocks, often containing as much as 100,000 tons, are broken up by blasting and prepared for market.

Physical properties. Sulphur is pale yellow in color, and without taste or odor. It is insoluble in water. 
When heated to $114.5^{\circ} \mathrm{C}$, , sulphur melts to a clear, amber colored liquid which flows almost as readily as water. As the temperature is increased, the color of the liquid gradually thickens and passes through the various shades of amber to a dark red wine color, until at $200^{\circ} \mathrm{C}$. the color is almost black and the mass so thick and viscous that the vessel in which it is heated

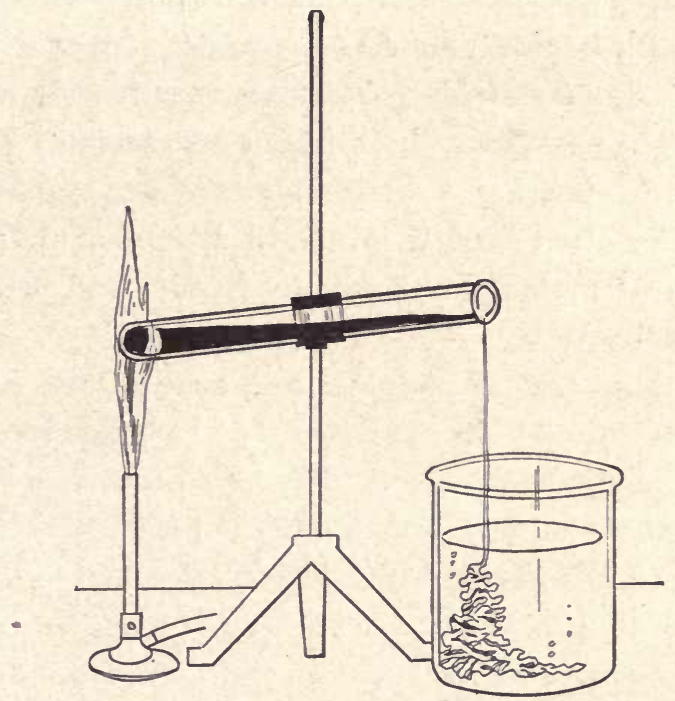

Fig. 34. Melted sulphur forms an elastic mass when suddenly
cooled in water. may be inverted without the mass running out. Further heating converts it into a black liquid again, which if suddenly cooled by pouring into water, will be found to be elastic in nature. If the temperature is increased to $448^{\circ} \mathrm{C}$., the liquid boils, giving off a 
pale yellowish gas, which if collected on a cool surface will be found to be the yellow sulphur with which we started. On cooling, the same changes take place in reverse order.

This entire cycle of changes through which sulphur has passed is purely physical and due to the different degrees of temperature to which it was subjected.

Chemical properties. Sulphur burns in the air or in oxygen with a pale blue flame, forming an oxide of sulphur (sulphur dioxide). It unites very readily with most metals, when heated, to form a compound. This is shown by heating a little sulphur on a piece of silver. The black deposit formed is a compound from the union of the sulphur and silver and is called sulphide of silver.

Uses. The uses of sulphur are many. We have already mentioned its use in the manufacture of matches. Sulphur is one of the ingredients found in the head of the match. Its kindling point is above that of phosphorus, which produces the spark when lighted, and below that of wood. So the sulphur ignites from the phosphorus and its burning ignites the wood.

Sulphur dioxide, the gas produced when sulphur burns, has a very suffocating odor. It is impossible for germ life to exist long in its presence; therefore it is a valuable disinfecting agent. It is very commonly used in fumigating rooms that have been occupied by persons having contagious diseases. This is done by making the room as nearly air tight as possible, then 
the gas is formed by burning sulphur in the room. A safer method, however, is to purchase a small can of sulphur dioxide in liquid form. On opening the can the gas escapes into the room.

Sulphur dioxide is also used for bleaching purposes, especially for straw, feathers, and fabrics.

The elastic nature of the suddenly cooled sulphur gives a hint of another commercial use of sulphur. Much of it is used in vulcanizing rubber.

It is also used in making fireworks, gunpowder, and as a spray to free trees, shrubs, and vineyards from attacking fungi.

\section{Questions}

1. Name the different kinds of sulphur in the laboratory.

2. How do they differ?

3. Is this a chemical or a physical difference?

4. Where is sulphur found?

5. How is it mined in Sicily?

6. How in Louisiana?

7. What are the chief physical characteristics of sulphur?

8. What are some of its chemical characteristics?

9. Name a number of commercial uses of sulphur.

10. What part does sulphur play in the manufacture of the friction match?

11. How is sulphur dioxide produced? What are some of its uses? 


\section{IRON}

$$
(\operatorname{Tron}=\mathrm{Fe})
$$

Introduction. Of all the metals, iron is by far the most useful to the human race.

Railroads cover the surface of the earth with a network of iron rails over which iron engines draw iron cars. The automobile, the bicycle, the buggy, the ocean

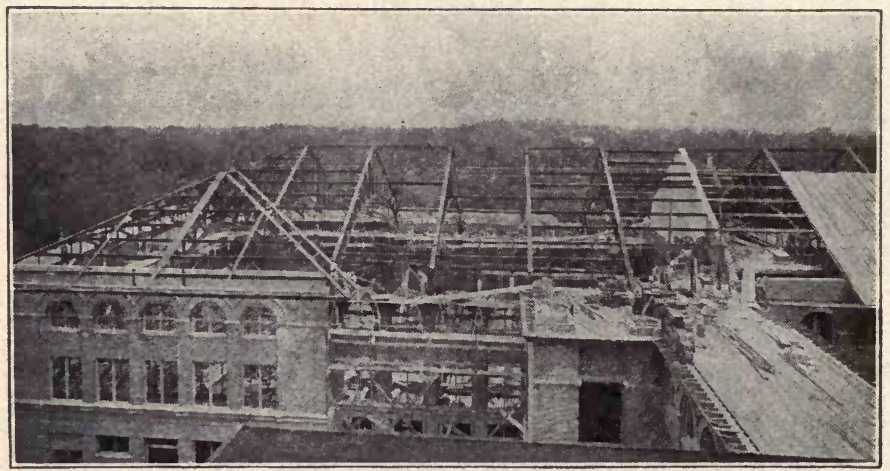

Fig. 35. Steel is used extensively in modern building.

liner, and the aeroplane, all contain more or less iron in their construction. Even in riding horseback one is unable to escape the accompaniment of iron, for the horse is shod with iron shoes and the bridle and saddle 
contain a liberal amount. Practically all construction is fundamentally of iron which has been built with iron tools.

Thus iron has become an absolute necessity to the physical wants of the race. Its great utility is due to the fact that it can be made into so many different things.

Occurrence. Iron is not found in nature in the state in which we know it commercially, though occasionally free iron which has dropped to the earth from meteors is found. It is widely distributed over the whole earth combined with other substances, in which form it is known as iron ore. It exists chiefly in combination with oxygen, carbon, or sulphur in the form of oxides, carbonates, or sulphides. The United States is the greatest iron producing country in the world. The iron mines of the Lake Superior region are the richest and best known, and supply a large part of the world's annual output.

The south also contains rich mines, Birmingham, Alabama, being the center of the industry in the south. This is due to the fact that coal and limestone, two other substances necessary in iron making, are found deposited there. The mineral kingdom is not the only place where iron is found. The element is necessary for the life of all green plants and is found in the hemoglobin of the blood, where it plays a very important function in carrying oxygen to the various parts of the body.

Preparation from ore. To produce the metal iron 
from the various substances with which it is combined in the ore, it is necessary to separate the element from them.

This is accomplished by heating a mixture of the ore, coal or coke, and limestone in a blast furnace. The blast furnace is from 50 to 100 feet high with a diameter varying from fifteen to twenty feet. It is lined on the inside with firebricks. A furnace with a body

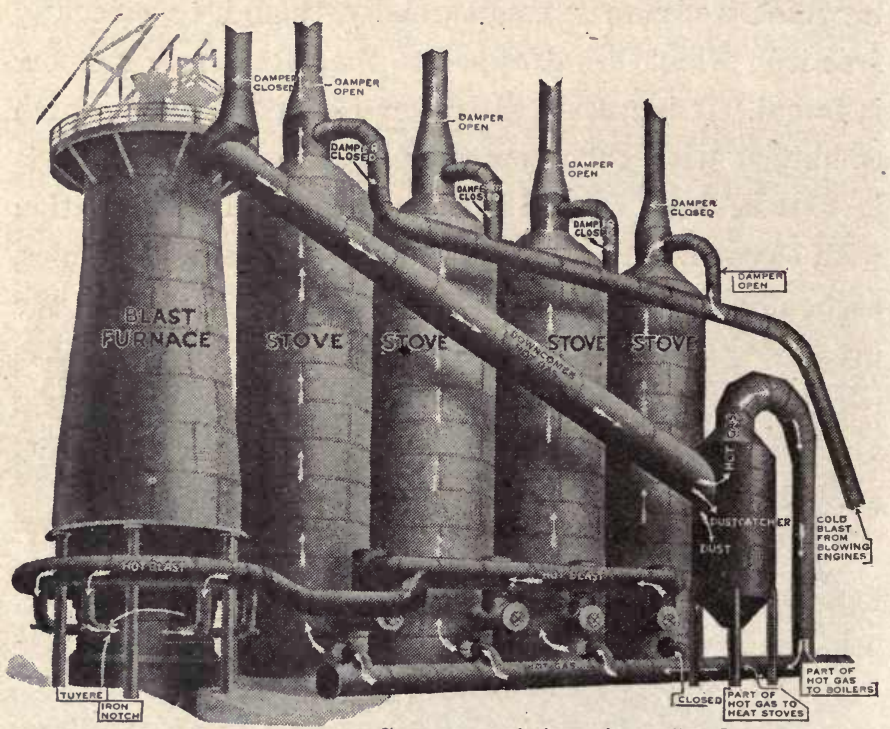

Courtesy of American Steel \& Wire Co. Fig. 36. A blast furnace produces pig iron. One furnace is shown with the four stoves which heat the blast.

of these dimensions will use a great deal of fuel and for its combustion much air is necessary. This air is supplied through pipes from the bottom under very great pressure. Thus the gases in the ore are burned 
out, the lime combines with the clay-like impurities of the ore to form a slag, and the molten iron sinks to the bottom of the furnace where it is drawn off through holes into molds. These molds are called "pigs," from which the iron gets its name of pig iron.

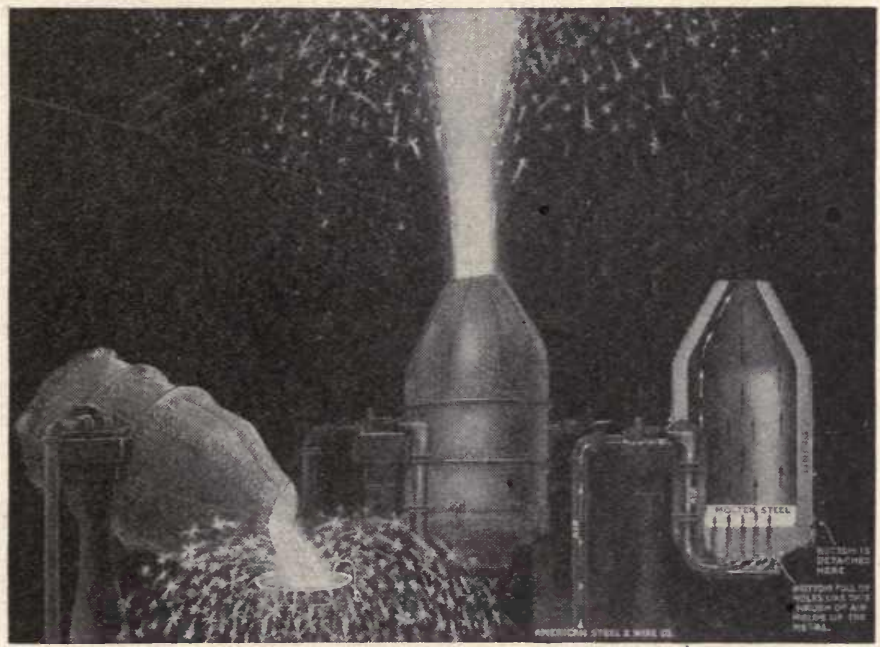

Courtesy of American Steel \& Wire Co.

Fig. 37. Bessemer converters in which pig iron is made into steel. The view on the right shows the inside of a converter; the middle one shows a converter in action throwing sparks of burning steel particles into the air. The converter on the left is discharging the finished steel.

Three forms of iron. The three forms of iron known to commerce are cast iron, wrought iron, and steel. Each kind is truly iron, though having very widely differing physical properties. Pure iron is practically unknown. The different kinds contain carbon and small amounts of other substances in composition. 
Cast iron contains the largest amount of carbon, varying from 2 to $5 \%$. It is a brittle substance and can be used only where it is not to be subjected to great shocks. It is used in casting articles such as stoves, radiators, machines, etc.

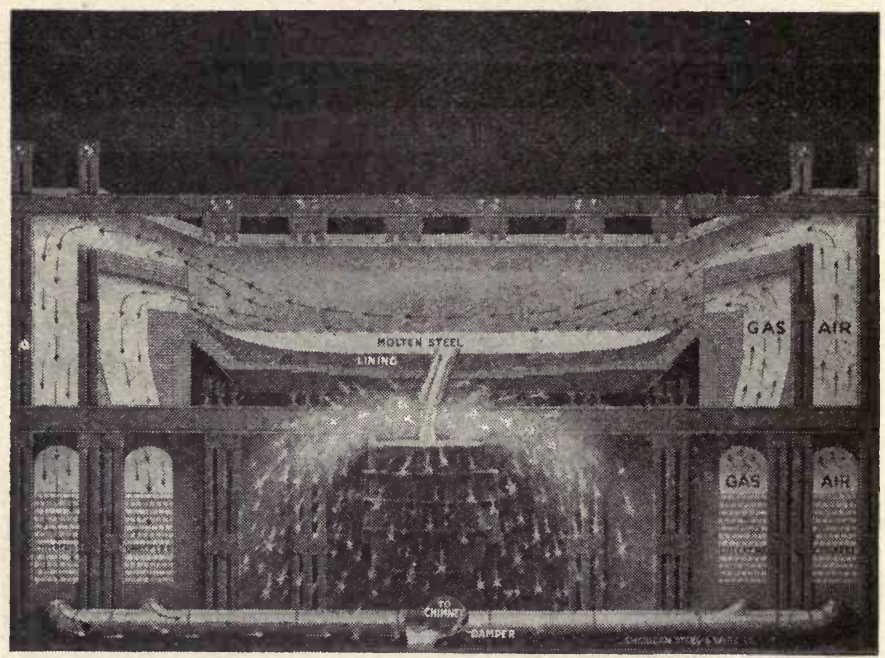

Courtesy of American Steel \& Wire Co. Fig. 38. Ore of less purity than that used in the Bessemer process is made into fine steel by the open hearth process.

Wrought iron is the purest form of iron, containing less than $1 \%$ of impurities and usually less than $0.2 \%$ of carbon. It is made from cast iron by burning out the carbon. It is a tough iron which can be bent, stretched, hammered, or rolled into various forms. It is easily forged and welded and thus becomes the iron of greatest use to the blacksmith.

Steel is also produced from cast iron by burning out 
the carbon. It contains less carbon than cast iron and slightly more than wrought iron. Its carbon content varies from practically nothing in some forms to $a_{\text {, }}$ little less than $2 \%$ in others. Steel serves many uses for mankind, from the steel rail to the main spring of a watch.

\section{Questions}

1. Following are some of the properties of iron. Classify them under the head of physical or chemical properties: (a) it rusts easily, (b) melts at 1,200 degrees C., (c) has a specific heat of 0.114 , (d) burns in oxygen, (e) is magnetic, (f) has a density of 7.8, (g) "dissolves" in hydrochloric acid. How would you prove your answer for $(\mathrm{g})$ ?

2. Name a number of commercial uses of iron.

3. How is it found in nature?

4. Look up material on how commercial iron is made from the ore and write an essay on it for class.

5. Name the three different kinds of iron enumerated in the text.

6. How do they differ from each other?

7. To what uses is each different kind put? 
CHAPTER . XIII

OXYGEN

$($ Oxygen $=0)$

Introduction. Oxygen is by far the most abundant of all the elements. It is found practically everywhere, either in the free state or in combination with other elements. It is found in the air in the free state and forms one-fifth of its volume. In combination with another element, hydrogen, it forms eight-ninths of the weight of water.

Nearly one-half of the earth's crust is oxygen in combination with other elements. Even living matter is made up largely of oxygen in combination with other substances. The human body contains $66 \%$ oxygen.

Oxygen is also one of the most important of the elements. If a lighted candle is placed in a glass jar and the jar tightly closed, the flame will soon be extinguished. Then if the gas in the jar is examined no oxygen will be found. Likewise, if a living being is enclosed with a limited supply of oxygen, as sometimes occurs in the caving in of the wall of mines, the life soon goes out.

In fact, without this important element there could 
be no fire; there could be no water; there could be no life, and the earth would be a barren waste.

Preparation. One of the simplest ways to obtain oxygen is to separate it from some compound in which it is found, and collect the gas by downward displacement of water. This is done by inverting large mouth bottles filled with water over the bridge in a pneumatic

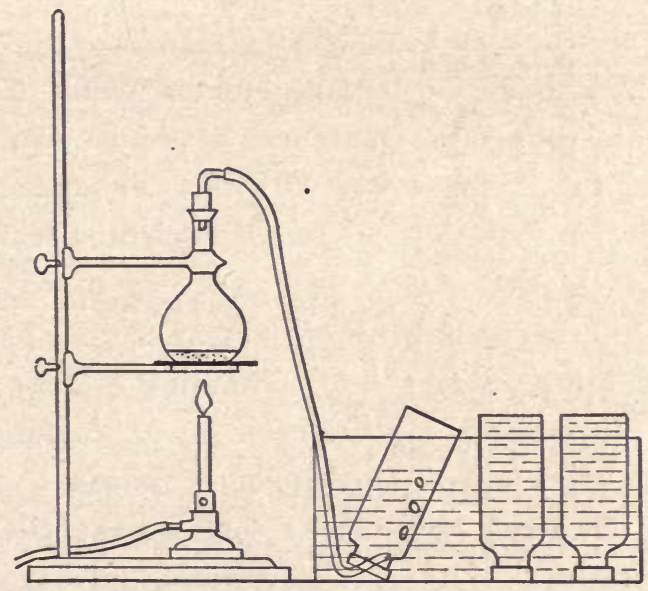

Fig. 39. Preparation of oxygen. A mixture of potassium chlorate and manganese dioxide is being heated in the flask. The gas passes out through the delivery tube and collects in the bottles.

trough which is filled with water to a depth just covering the bridge. A tube leads from the flask containing the compound, to the mouth of the bottle under the -water. As the compound is broken up and the oxygen separated from it, usually by the application of heat, the gas being much lighter than water rises into the 
bottle and forces the water out. After the bottle is filled with oxygen, it should be removed with a cover over the mouth and kept right side up, because oxygen is 1.1 times as heavy as air and if left inverted would soon run out.

Mercuric oxide is a compound sometimes used to obtain oxygen. It is a red powdery substance which, when thoroughly heated, separates into its component parts, mercury and oxygen:

Mercuric oxide= mercury and oxygen.

In this connection mercuric oxide is also of historical interest, for it was with this compound that in 1774 Joseph Priestley, an English scientist, carried on experiments that led to the discovery of oxygen.

When larger quantities of oxygen are desired potassium chlorate, a compound containing a large amount of oxygen, is used. It has been found that potassium chlorate gives up its oxygen more quickly if a black, finely powdered substance, manganese dioxide, is mixed with it. Although manganese dioxide contains oxygen, it gives up none of it in this process. The sole function of the black powder is to hasten the breaking up of the potassium chlorate. The change which takes place may be expressed as follows:

Potassium chlorate $=$ potassium chloride + oxygen.

Properties. On examining a bottle of pure oxygen, it will be found colorless, odorless, and tasteless. It is a very active element and combines readily with many substances. With some it combines so actively 
that both heat and light are produced, and we eall the process burning. If a glowing ember be thrust into a bottle of pure oxygen, the ember at once ignites and burns vigorously. Charcoal, which barely glows in the air, will glow intensely with an almost invisible flame in the oxygen. Sulphur, which burns with a pale blue flame in the air, burns with a brilliant blue flame in oxygen. Even a steel watch spring, or a ball of steel wool, if dipped in sulphur and ignited and then thrust into a jar of oxygen, will burn vigorously and throw off brilliant sparks.

Oxidation. The gas left in the bottle after the burning of the charcoal was carbon dioxide, a colorless gas. The burning sulphur left behind a colorless gas, called sulphur dioxide; and the burning steel threw off the brilliant sparks which formed molten globules of oxide of iron. From these statements it is apparent that oxygen combined with the various elements, earbon, sulphur, and iron, to form oxides of these substances. In fact, oxygen combines with all but a very few of the known elements. The process of the union of oxygen with some other element or compound is called oxidation.

The product resulting from oxidation is a compound called an oxide.

The above chemical phenomena may be expressed as follows :

Carbon + oxygen $=$ carbon dioxide

$$
\mathrm{C}+2 \times \mathrm{O}=\mathrm{CO}_{2}
$$


Sulphur + oxygen $=$ sulphur dioxide

$$
\mathrm{S}+2 \times \mathrm{O}=\mathrm{SO}_{2}
$$

Iron + oxygen $=$ oxide of iron .

$$
3 \mathrm{Fe}+4 \times \mathrm{O}=\mathrm{Fe}_{3} \mathrm{O}_{4} \text {. }
$$

Rapid oxidation is always aceompanied by heat and light. To fully appreciate this statement you need but recall the methods employed in heating our homes. Wood, coal, coke, ete., are burned in a furnace. Burning is rapid oxidation. In other words, the oxygen of the air eombines with the carbon of the wood, coal, or coke, and the home is made eomfortable with the heat evolved in the process. If more heat is desired, we inerease the burning or oxidation by admitting more oxygen to the fuel through the draughts. If less heat is desired, the draughts are elosed, admitting a smaller amount of oxygen, thus reducing oxidation.

If, however, oxidation is very slow, as in the rusting of iron or the decay of wood, it is not accompanied by any noticeable amount of heat or light, though the sum total of the heat evolved during the process of decay is as much as would be given off were the same pieee of wood completely burned in a few minutes.

Uses. Oxygen is absolutely necessary to life. Only a few very minute forms of plant life can exist without it. Oxidation goes on in the bodies of living organisms in very much the same manner as it does in the furnace. Of course, it is not accompanied by. light, but the results are the same. In the process of respiration, oxygen is taken into the lungs, where some of 
it is absorbed into the blood. It is then carried to all parts of the body where the tissues are oxidized and the oxides, chiefly carbon dioxide, are taken by the blood to the lungs or to other organs, where they are eliminated. By heat evolved in the process of oxidation, the bodily temperature is maintained and the energy developed for thought and action.

Oxygen is slightly soluble in water, about three parts in a hundred. This small amount supports all the varied forms of aquatic life. As stated above, all burning, all decay, are dependent upon oxygen. Thus, in this way, oxygen serves as a purifying agent, for all dead animal and vegetable products are slowly oxidized and thus changed into harmless substances.

Oxygen is also used by the physician in instances where the patient is unable to inhale a sufficient amount from the air.

Source. From the fact that oxygen combines so readily with so many different substances, it would seem that the supply would eventually be exhausted. However great the oxidation, the proportion of oxygen in the air is not much affected, for all green plants are continually giving back to the air oxygen, which is thrown off in the process of food making in the plant.

\section{Questions}

1. Who was Joseph Priestley? What is his claim to fame?

2. Name the chief properties of oxygen. 
3. Can you suggest any reason why practically all the oxygen of the earth is locked up in water and in the compounds which make up the rocks?

4. What keeps up the amount of oxygen in the air when it is constantly being used up by burning?

5. A flame is a burning gas. Why do not pure charcoal and iron wire burn with a flame in pure oxygen?

6. Name three different ways to obtain free oxygen in the laboratory.

7. What is burning? Oxidation? An oxide?

8. What is the significance of opening the draught in the furnace?

9. What oxidations are valuable? What oxidations does man cause to occur for his comfort? Mention others which man wishes to prevent.

10. Describe as well as you can the condition of things if the atmosphere were pure oxygen. Judge from your knowledge of the activity of oxygen.

11. How is the balance of oxygen in the air maintained? 
CHAPTER XIV

\section{HYDROGEN}

\section{$($ Hydrogen $=\mathrm{H})$}

Occurrence. Although hydrogen is found widely distributed in combination with other elements, it is found but rarely in the free state. It is sometimes found free among the gases expelled from volcanoes, in meteorites, and a trace of it is found in the air.

Hydrogen makes up $11 \%$ of water, which covers nearly three-fourths of the earth. It is found as a constituent part of natural gas and the oils obtained from the earth as fuel, and forms a part of all vegetable and animal matter.

Preparation. Hydrogen may be obtained either from water or from any acid, of which substances it forms an essential part. Water is a compound of hydrogen and oxygen. If an electric current is passed through water to which a small amount of acid has been added, it may be separated into its component parts, oxygen and hydrogen. The method commonly used in the laboratory is to separate the hydrogen from some acid. Some metal, as zinc or iron, is used for this purpose.

Place a few small pieces of zinc in a flask and close 
the flask with a rubber stopper, fitted with a thistle tube through which acid may be poured into the flask; and a short glass delivery tube through which the

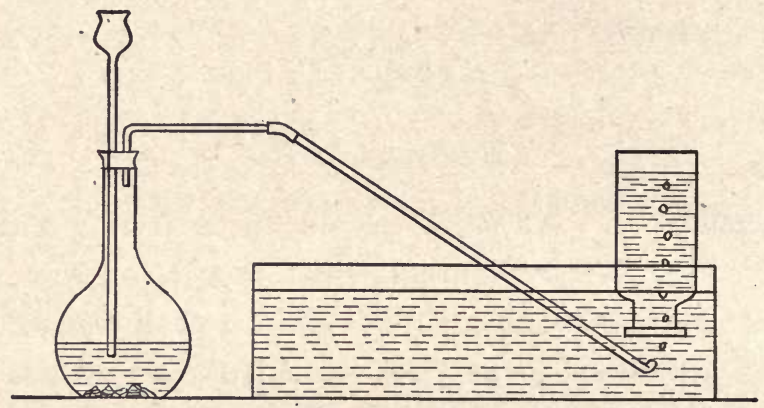

Fig. 40. Preparation of hydrogen from hydrochloric acid and

gas may escape. When the zine eomes in eontact with the acid, a chemical action takes place by which hydrogen is set free. Any acid will do, though hydrochloric acid is the one most generally used. Hydroehloric acid is a compound of the elements chlorine and hydrogen. When the acid and the metal come in contact, the metal displaces the hydrogen and combines with the ehlorine to form zine ehloride. Zinc + hydrochloric acid $=$ zine chloride + - hydrogen

$$
\mathrm{Zn}+2 \mathrm{HCl}=\mathrm{ZnCl}_{2}+2 \mathrm{H} \text {. }
$$

The freed gas escapes through the delivery tube and may be collected by downward displacement of water, as was oxygen.

The gas from the generator should be allowed to escape until you feel sure that all the air that was in the flask and tubes has escaped. Great care must be 
exercised not to bring a flame near a mixture of oxygen and hydrogen, for if the mixture is lighted an explosion will surely follow. So every care must be taken to free the hydrogen from air before it is lighted.

Properties. Hydrogen is a colorless, odorless, tasteless gas. It is the lightest known gas and because of this fact it is used as the standard of weight by which all gases are measured. In speaking of the weight of any other gas it is spoken of as being so many times as heavy as hydrogen. Thus air is 14.4 times as heavy, and oxygen 16 times as heavy as hydrogen. It combines readily with oxygen, burning with a pale blue flame. If a burning splinter be brought to the mouth of an inverted bottle of hydrogen, a slight explosion will occur and a pale blue, almost invisible flame will burn upward into the bottle. This is the test of hydrogen. If the burning splinter is thrust quickly into the hydrogen an explosion occurs at the mouth of the bottle, but the flame on the splinter will be extinguished. This shows that hydrogen will burn, but will not support combustion.

Although it is not poisonous to breathe hydrogen, one could not live long with only hydrogen, as oxygen is necessary to life.

Uses. Because of its lightness, hydrogen is used sometimes in filling balloons, though hot air and coal gas are more frequently used because they are cheaper. In recent years hydrogen has been used in 
air ships because of its lifting power. Hydrogen is also important as a fuel. A number of mixtures of combustible gases, consisting largely of carbon compounds and hydrogen, are used extensively for the production of light and heat. Those chiefly used are coal gas, water gas, natural gas, and acetylene.

\section{Questions}

1. Is hydrogen found in the free state in nature?

2. How may pure hydrogen be obtained?

3. When generating hydrogen, why should the first gas always be allowed to escape from the end of the tube?

4. What are the chief properties of hydrogen?

5. What use is made of the fact: (1) that hydrogen is a very light gas, (2) that it unites energetically with oxygen, giving out much heat, (3) that it is a constituent of oil and natural gas, (4) that it is very hard to liquefy it? 


\section{NITROGEN}

\section{$($ Nitrogen $=\mathrm{N})$}

Occurrence. Nitrogen is another element that plays an important part in plant and animal life. In combination with carbon, hydrogen, and oxygen, it forms protein, one of the main classes of foodstuffs. It is an essential constituent of all living organisms. It is also found in nature in the form of potassium nitrate, a compound commonly called niter, from which fact it derives its name. As an element it forms about fourfifths of the air.

Preparation. For class use nitrogen is usually obtained from the air. Since oxygen and nitrogen make up more than $99 \%$ of the atmosphere, when oxygen is removed, nitrogen is left sufficiently pure for the study of its physical properties. Oxygen is removed by combinbining it with any element whose oxide is readily

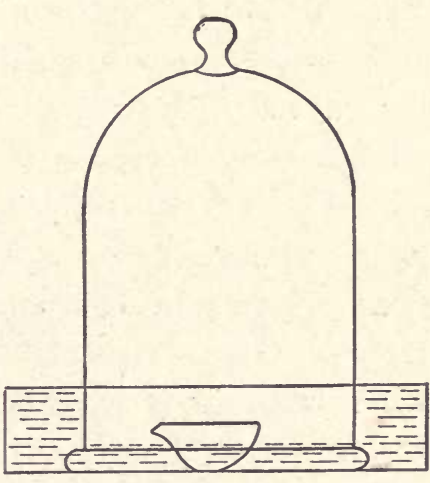

Fig. 41. Experiment to determine the composition of air. 
absorbed by water. For this purpose phosphorus is most generally used. After filling the pneumatic trough with water to the depth of two inches, float a small piece of cork on it. Place on the cork with forceps a piece of yellow phosphorus about the size of a small pea. After igniting the phosphorus, quickly invert a belljar over it so as to confine a portion of the air. The phosphorus will burn as long as there is any oxygen in the jar, forming a white cloud of solid particles, oxide of phosphorus. During the next twenty or thirty minutes this cloudy oxide will be absorbed by the water, and the gas remaining in the jar is nitrogen.

Nitrogen may also be prepared by taking a mixture of 8 grams of sodium nitrite and 3 grams of ammonium chloride, to which is added about 15 c.c. of water heated gently below the boiling point of water. In the ehemical action resulting between these compounds, nitrogen is liberated, which may be collected as were oxygen and hydrogen.

Properties. Nitrogen is a colorless, odorless, tasteless gas. That it is very inactive may be seen by inserting a burning splinter into a bottle of the gas. The flame is extinguished at once. Nitrogen neither burns nor supports combustion. Because of its inactivity it is only with the greatest difficulty that it can be made to unite directly with any substance.

Uses. The very great inactivity of nitrogen might lead one to think it of little use in nature. It is in 
that very characteristic, however, that much of its value lies. We have seen how very rapid oxidation is in pure oxygen. An atmosphere of pure oxygen would be almost as disastrous as one with no oxygen. A mixture of oxygen with a harmless, inactive gas which will hold the oxygen in check is necessary. This seems to be the chief use of nitrogen. Forming as it does about four-fifths of the air, it dilutes the other one-fifth, which is oxygen, and thereby guards against too rapid oxidation, and consequently widespread destruction.

Nitrogen is necessary to plant life, and although it forms a large part of the air, plants are unable to use it in the free state. They obtain the element from the soil from some soluble compound of nitrogen, usually a nitrate. If for some reason these compounds become insufficient in the soil for the proper growth of plants, they must be restored in some way. This is done by nitrogenous fertilizers, such as nitrate of soda (Chili saltpetre) and sulphate of ammonia.

Nitrogen is used commercially in compound form in the manufacture of ice. Nitrates are also of great commercial value in the making of explosives, gunpowder, dynamite, and nitro-glycerin.

\section{Questions}

1. Name the properties of nitrogen.

2. What are the chief sources of nitrogen?

3. State two ways of preparing it for class use. 
4. What are the chief uses of nitrogen? nitrogen?

5. What proportion by volume of the air is

6. Which is more important in the air, oxygen or nitrogen?

7. What would probably result if the balance in either direction were very much disturbed?

8. Oxygen is 16 times as heavy as hydrogen, nitrogen is 14 times as heavy as hydrogen. Air is $\frac{1}{5}$ oxygen and $\frac{4}{5}$ nitrogen by volume. How many times as heavy is a quart of air than a quart of hydrogen? 9. From what source do most plants obtain nitrogen?

10. What is a nitrogenous fertilizer? 


\section{ACIDS, BASES, AND NEUTRAL SUBSTANCES}

Introduction. In every kitchen may be found three things: vinegar, ammonia, and common salt. They are three examples of three great classes of compounds. Vinegar belongs with the acids. Ammonia belongs with the bases. Common salt belongs with the general group of salts.

Acids. There are many acids with which you are already familiar. There is not a boy, at least, who does not know of the sour, puckery juice of a green apple. The grape, the peach, the plum, and practically all other fruits are characterized in their early stages by their distinctly acid taste. The lime, the lemon, and some other fruits retain this acid even in the ripened form. Sweet cider when exposed to the air becomes sour and acid. Most of the acids which we know in the home come from the plant world. There are other acids, however, which are prepared and used in almost countless processes in shops and factories. The three most important of these are hydrochloric acid, sulphuric acid, and nitric acid. 
Characteristics of acids. Much as the acids may vary in their individual qualities, they all possess certain qualities in common.

They all contain hydrogen. Hydrochloric acid, for example, is composed of hydrogen and chlorine, $\mathrm{H}+\mathrm{Cl}=\mathrm{HCl}$. Nitric acid is composed of hydrogen, nitrogen, and oxygen, $\mathrm{HNO}_{3}$; and sulphuric acid, of hydrogen, sulphur, and oxygen, $\mathrm{H}_{2} \mathrm{SO}_{4}$.

They all have a sour taste.

The most valuable test by which acids may be recognized comes from their action upon a certain vegetable substance known as litmus. Paper colored by this substance is known as litmus paper, and it is used as the common test for an acid. Acids turn blue litmus to a red color.

Bases. Bases are substances with which we do not so frequently come in contact. Mention has already been made of ammonia. In the laboratory the bases most commonly used are sodium hydroxide and potassium hydroxide. These are white solids, soluble in water.

Characteristics of bases. Bases, like acids, have certain distinguishing characteristics. All bases contain hydrogen and oxygen. For example, sodium hydroxide contains sodium, hydrogen, and oxygen, NaOH. Potassium hydroxide contains potassium, hydrogen, and oxygen, KOH.

A solution of a base has a soapy feel and taste. 
It reverses the color change produced by acids. Bases turn red litmus paper blue.

Neutralization. If the right amount of hydrochloric acid is mixed with the right amount of sodium hydroxide, a base, all properties of both the acid and the base disappear. The resulting substance does not have a sour taste, or a soapy feeling, and it does not have any action at all on litmus paper. The acid has neutralized the base, and the base has neutralized the acid. All the distinguishing acid and basic properties have gone. If the solution of the acid and the base is evaporated a white powder remains. If this is tasted, it will be found to be common table salt. The liquid evaporated was water. When an acid is added to a base, the product formed is a salt and water. This may be written in the form of the equation:

$$
\text { acid }+ \text { base }=\text { salt }+ \text { water. }
$$

This action of an acid on a base is called neutralization.

Salts. The products of neutralization are a salt and water. Salts as a class have no particular taste. They have no action at all on red or blue litmus paper and hence are known as neutral substances. Not all neutral substances are salts, however. For example: water, alcohol, and milk are neutral substances, but they are not salts.

$$
\begin{aligned}
& \mathrm{Acid}+\mathrm{Base}=\mathrm{Salt}+\text { Water. } \\
& \mathrm{HCl}+\mathrm{NaOH}=\mathrm{NaCl}+\mathrm{H}_{2} \mathrm{O} . \\
& \mathrm{H} \mathrm{NO}_{3}+\mathrm{NaOH}=\mathrm{Na} \mathrm{NO}_{3}+\mathrm{H}_{2} \mathrm{O} . \\
& \mathrm{H}_{2} \mathrm{SO}_{4}+2 \mathrm{NaOH}=\mathrm{Na}_{2} \mathrm{SO}_{4}+2 \mathrm{H}_{2} \mathrm{O} .
\end{aligned}
$$


These equations indicate the reactions which take place in the process of neutralization. In each case the name of the salt is derived from the names of the acid and the base used in its production. Hydrochloric acid and sodium hydroxide produce common table salt, sodium chloride; nitric acid and sodium hydroxide produce Chili saltpetre, sodium nitrate; sul-

- phuric acid and sodium hydroxide produce Glauber's salt, sodium sulphate.

\section{Questions}

1. Name three foods which contain acids.

2. How do you know these foods contain acids?

3. How does the amount of acid in green fruit compare with that in ripe?

4. Name three acids frequently used in commercial processes.

5. State three characteristics common to all acids.

6. What is the source of litmus?

7. What is the test for an acid?

8. What is the symbol for hydrochloric acid? Nitric acid? Sulphuric acid?

9. Name three bases.

10. What is the appearance of sodium hydroxide? Potassium hydroxide?

11. Write the symbols for two bases.

12. What are the principal characteristies of bases?

13. What is the test for a base?

14. How does a neutral substance differ from an acid and from a base? 
15. How can a neutral substance be made from an acid and a base?

16. How can you obtain common salt from hydroehloric acid and sodium hydroxide?

17. What are the products of neutralization?

18. Name three salts.

19. Complete the following equations:

$\mathrm{HCl}+\mathrm{NaOH}=$ ?

$\mathrm{HNO}_{3}+\mathrm{NaOH}=$ ?

$\mathrm{H}_{2} \mathrm{SO}_{4}+2 \mathrm{NaOH}=$ ?

20. Are all neutral substances salts?

21. Name three neutral substances which are not salts.

22. How is the name of a salt derived? 
CHAPTER XVII

\section{WATER}

\section{$\left(\right.$ Water $\left.=\mathrm{H}_{2} \mathrm{O}\right)$}

Introduction. Of all substances on the surface of the earth, water is by far the most abundant.

In the liquid form it makes up the oceans, lakes, seas, rivers, springs, and brooks, while the air holds vast quantities of it in the gaseous form. Add to this the vast stretches of ice and snow of the polar regions, and one soon realizes the truth of the statement, "threefourths of the earth's surface is covered with water."

Composition. For a long time water was regarded as an element. However, toward the close of the eighteenth century it was proved to be a compound of the two elements, hydrogen and oxygen.

This can be shown in two ways. First, by breaking up the compound into its elements with the electric current; and, second, by combining the two elements by ignition.

Take an electrolysis apparatus, such as is shown in Figure 42 , and fill the burettes with water containing a small amount of sulphuric acid. Each arm of the apparatus holding the burette is closed at the bottom with a rubber stopper, through which passes a glass tube 
holding a wire with a piece of platinum extending into the arm, and a free end projecting outward. To the projecting wires attach the wires leading from the source of the electricity and turn on the current. As soon as the current passes, bubbles of gas rise from the pieces of platinum to the upper parts of the tubes. The gas in one tube collects just twice as rapidly as in the other. If the gas in each tube is tested, the tube with the smaller quantity will be found to contain oxygen, while the other tube with twice as much volume will be found to contain hydrogen.

Thus the formula, water $=\mathrm{H}_{2} \mathrm{O}$.

Again, if oxygen and hydrogen gases àre mixed in a dry vessel and then ignited, vapor collects on the sides. This vapor, resulting from the explosion or union of oxygen and hydrogen, is the oxide of hydrogen, or water.

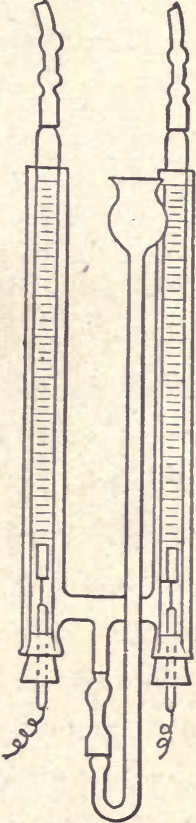

Fig. 42. D ec o m position of water. An electric current passed through the water in the tubes decomposes it into hydrogen and oxygen.

Properties and uses. Pure water is an odorless and tasteless liquid. In thin layers it appears colorless, though in larger bulk it has a bluish tinge. At ordinary pressure it boils at $100^{\circ} \mathrm{C} .\left(212^{\circ} \mathrm{F}\right.$.) and freezes at $0^{\circ} \mathrm{C}$. $\left(32^{\circ} \mathrm{F}\right.$.) Most substances contract upon cooling. 
Water, as you have learned, contracts upon cooling until $4^{\circ} \mathrm{C}$. $\left(39^{\circ} \mathrm{F}\right.$.) is reached, then it begins to expand. One hundred cubic feet of water, as ice, will require one hundred and nine cubic feet of space. Thus as water freezes a layer of ice spreads over the surface of the water, while the life underneath continues unmolested.

The expansive force of freezing water will be understood if you will recall what happens to the pipes when the water in them freezes. The freezing water expands, and as the pipe does not expand and the ice must have more room, the pipe bursts.

Perhaps you have noticed the "fluffed up" appearance of the garden soil in the spring just before the frost has gone out of it. During the fall and winter, the water from rains and snow trickled down into the earth and later froze. Ice requires about one-eleventh more space than liquid water, and as the water in the crevices and cracks in the soil froze it required more room. The pressure thus exerted pushed up the surface soil, giving it the fluffy appearance. This is a great boon to the farmer, as it helps to pulverize the soil. On rocky hills and mountain sides, this form of weathering is making new soil by splitting off particles of rock, which are carried to the base of the mountain with each rain.

Another great use of water is its power of solution. If a spoonful of sugar is placed in a glass of water, the sugar disappears. It has been dissolved by the water. 


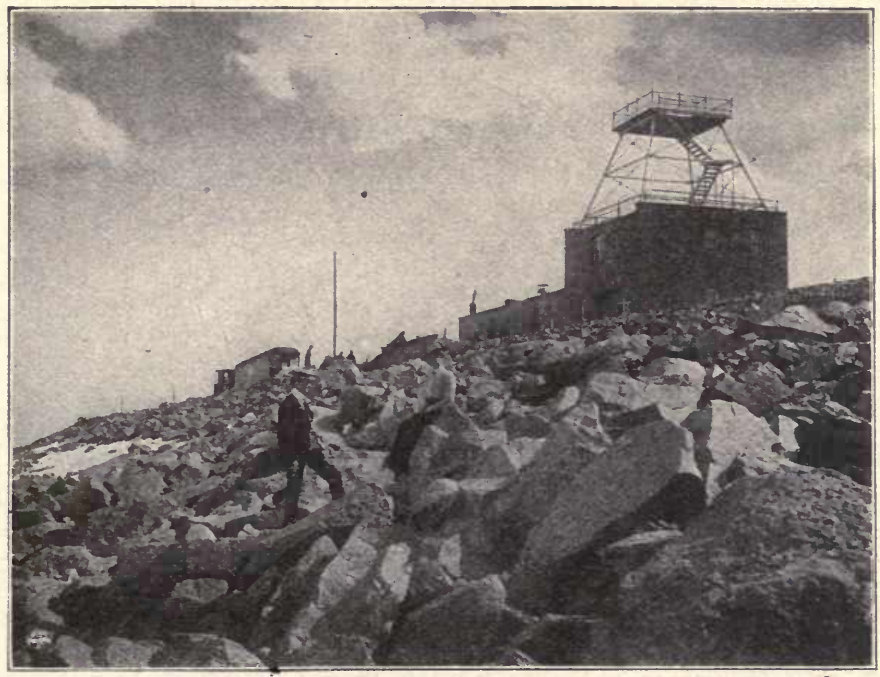

Photograph by Detroit Publishing Co. Fig. 43. Summit of Pike's Peak, showing rock fragments split off principally by alternating heat and cold.

That it is present in the water is recognized by its sweetened taste, and may also be shown by evaporating the water, when the sugar again appears in the solid form at the bottom of the vessel. Some substances that are not dissolved in water may be held in suspension, giving to the water the color of the substances thus held.

When starch and water are shaken together in a tube, the starch does not dissolve, but its particles are held in suspension, giving to the water a milky white appearance.

After every rain the water of the small streams is of muddy color. This is due to the particles of soil the 
water is carrying along. Floods are dreaded and leave much destruction in their wake, and yet the productive river bottoms owe their fertility to the mineral substances brought in solution and the new layers of soil left by the flood.

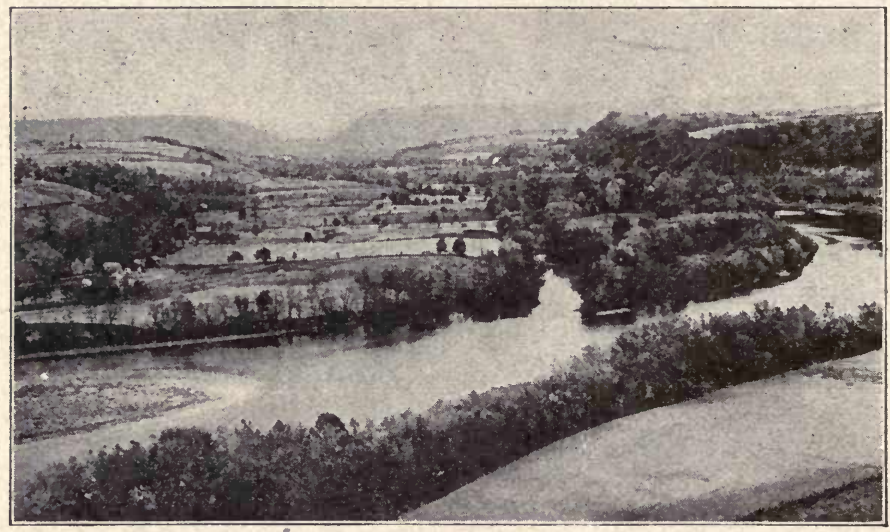

Permission United States Geological Survey. FIG. 44. View of Delaware water gap, a productive river valley.

Hard and soft water. The terms hard and soft water are in common use in the home. You know, too, that hard water lathers soap only with difficulty, while soft water lathers it freely. On this basis we can classify rain water as soft water, while water from the spring or well is hard. Since all spring and well water were once rain water, it is evident that they have become hard in passing through the earth. The hardness is due to the mineral substances held in solution by the water. Sometimes hard water becomes soft after boiling. The minerals held in solution are deposited on the bottom of the vessel, 
as in the tea kettle, and if this deposit is tested with hydrochloric acid, it will be found to be a carbonate of lime. On the other hand, some water is not changed by boiling, in which case either calcium sulphate or magnesium sulphate is present, or both may be present. Water of this kind is rendered soft only by chemical means.

Hard water is more expensive for cleansing than soft water, because the soap used to soften it is wasted as far as cleansing is concerned.

Plant and animal life dependent upon water. The service of water to plant and animal life cannot be overestimated. Most of the food used by plants comes from minerals in the soil. For these they are absolutely dependent upon water, as the plant can obtain its food from the soil only in solution. As water sinks within the earth it dissolves from the soil much of the food materials, which are absorbed by the fine root hairs into the plant.

Water is also vitally necessary to all animal life. Before food can be absorbed into the blood it must be dissolved and reduced to a thin liquid. Also the broken down wastes of the body must be dissolved to be absorbed into the blood, and carried to the eliminating organs. The system must be kept constantly flushed to eliminate the waste and poisonous matters from the body if one is to remain vigorous and active.

Water applied freely within and on the exterior of the body will prevent the accumulation of the waste 
matters which nature must elininate. Through the lungs and kidneys, the average person excretes about four pints of water per day.

Thus the demand for fresh water is constant. This is not entirely supplied by the water we drink, for the greater part, by weight, of many of our solid foods is water. Thus potatoes contain $78 \%$ water, milk $85 \%$, beef over $50 \%$, tomatoes and asparagus $94 \%$, while some fruits, such as strawberries and watermelons, are over nine-tenths water. Bread probably contains as little water as any of our common foods, and it is about $35 \%$ water.

Dangers in water. Pure water is practically unknown. Owing to its solvent action, all water that passes through the soil carries more or less mineral substances or gases in solution. The peculiar taste or odor of the water from a mineral spring is due to the substance the water holds in solution. Even rain water, which is water that has been evaporated from the surface of the earth into the higher atmosphere and then sent back again, is not pure. In its passage through the air it carries along with it the small dust particles it encounters and it probably absorbs some gases from the air. The substances thus far mentioned are not necessarily harmful. Indeed, the dissolved minerals are necessary to plant and animal life. But bacteria are found practically everywhere, on the surface of the earth and in the air. It is when the harmful bacteria get into drinking water that it becomes a 
menace to health. Epidemics of typhoid fever, scarlet fever, and cholera have been traced to drinking water that had become contaminated with the forms that produce these diseases. Our city goveruments keep a close watch on the water supply to protect the inhabitants from the dangers of polluted water.

Filtering water is a wise precaution, if one is careful to cleanse the filter frequently, as it reduces the dangers from pollution to a minimum.

When water is under suspicion it is wise to boil it before using. Fifteen minutes' boiling destroys all living forms in the water and renders it safe for drinking. True, boiled water has a flat taste, because the air which was held in solution was driven off in the boiling, but this can be overcome partly, at least, by filling sterilized bottles half full with boiled water, and mixing the air and water by shaking. The bottles should then be closed and set in a cool place until ready for use.

The following method of purifying any drinking water so that it will be safe to drink is given by Dr. W. A. Evans, former Health Commissioner of Chicago:

"Take a level teaspoonful of chloride of lime and rub it up, until there are no lumps, in a teacup of water. Dilute this with three cupfuls of water, and keep this stock solution in a stoppered bottle for use. A teaspoonful of this stock solution, added to a two-gallon pail of water, and well stirred up, will destroy all typhoid or other dysentery producing germs in ten 
minutes, and will make the water safe to drink. If this quantity makes the water taste, use a little less, otherwise not. Get the chloride of lime in metallic cases."

\section{Questions}

1. Is water an element or a compound?

2. In what two ways can this be shown?

3. How long has this fact been known?

4. Give the chemical formula for water.

5. Name the most essential physical properties of water.

6. How does water differ from most substances when cooled below $4^{\circ} \mathrm{C}$. ?

7. Of what advantages is this peculiarity in nature's plan?

8. How do you account for the "fluffed up" appearance of the garden soil early in the spring?

9. How does water help to enrich the soil?

10. What is meant by hard water?

11. How may hard water be rendered soft?

12. Explain fully the role of water in the life of most plants and animals.

13. What danger is there in drinking surface water?

14. Of what advantage is filtered water?

15. Why is it necessary to clean the filter frequently?

16. How may water that is under suspicion, be rendered safe for drinking purposes?

17. Why should the citizens of a community heed carefully the warnings of the Board of Health or the 
City Bacteriologist concerning the condition of the city's water?

18. When camping or traveling in the country, it is unwise to drink from a spring or well. To make sure that the water is safe to drink, follow the method of purifying the drinking water given by Dr. W. A. Evans (See page 117).

19. Name two substances which will dissolve in water.

20. Why does water in streams look muddy after rains or heavy winds?

21. Why are river bottoms usually very fertile?

22. Do we obtain water from our solid foods? Give examples. 


\section{CHAPTER XVIII}

\section{ATMOSPHERE}

Introduction. Fish live in an ocean of water, but just as truly do we live in an ocean of gas, which we call the atmosphere. This atmosphere which envelops us at all times extends more than two hundred miles above us.

No part of our environment is of more immediate importance to us than the air we breathe. If it is pure we are strong. If we are deprived of air for but a single hour we die.

Perhaps no other part of our environment has had so great an influence in our development. How we dress, what we grow, and what we eat are chiefly determined by the conditions of the atmosphere, with reference to its temperature, moisture, and winds.

We are not always conscious of the air around us. We know roughly that on certain days the air seems heavy, while at other times we feel its bracing effect. Generally it is quiet and we are utterly unconscious of it; at other times we are very much aware of it, because of its heavy winds.

Our atmosphere is thus at one time heavy; at another time hot and oppressive, or cold and invigorating. At one time it is almost quiet, and at another traveling at 
the rate of over fifty miles an hour, forming a furious gale.

Such variations constantly oceur on the same level. Change the level and other variations occur. Ascend a lofty mountain and the air becomes rarer and rarer, until men on such heights gasp for breath to gain sufficient oxygen to feed the body fires.

Composition. The composition of the atmosphere is nearly the same at all times and at all places where it has been analyzed. It is made up chiefly of two gases, nitrogen and oxygen. Besides these two gases, several lesser constituents are present. Of these, the most important are carbon dioxide and argon. Water vapor and dust are also present in amounts which are extremely variable.

Air is essentially a mechanical mixture. The gases in it are not united or combined in any way, but are almost independent of one another, and each of them retains its own qualities in the mixture. The composition of air, according to Kahlenberg, follows:

Compositiox of Air

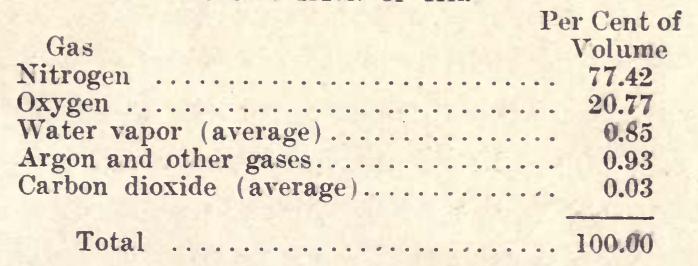

Properties and uses. Nitrogen, we have already learned, is extremely inactive and does not combine 
readily with other elements. Because it is so inactive its chief function in relation to life is often said to be "to dilute the oxygen." Since nitrogen constitutes more than three-fourths of the weight of the air, the pressure of the air, the force of the wind, the flight of birds are largely possible because of it.

Another important use of nitrogen is as a plant food. Most plants use the nitrogen compounds which are in the soil. These in solution are taken into the plant through its roots. When plants are grown in the same place year after year, they. take out so much of the nitrogenous matter as to decrease the fertility of the soil. If the soil is lacking in nitrogen, no plant will thrive. One large family of plants, of which peas, beans, alfalfa, lentils, and a number of others are menbers, have on their roots little nodules in which certain kinds of bacteria live. These bacteria possess the power of absorbing the nitrogen from the air and combining it with the oxygen and some of the salts of the earth to form nitrates. These nitrates are very valuable as plant foods. These plants are now extensively grown not only for their value as crops, but also because they enrich the soil by adding nitrogen to it.

Oxygen from the air is consumed all the time by animals and plants in breathing. Without it they could not live. Oxygen, we have already learned, combines readily with most other elements. By its chemical union with other elements we-know that heat and sometimes light are produced. This heat, developed by 
the process of oxidation, is used to warm houses, to produce steam, to run trains, to drive machinery, and in many other ways.

The readiness with which oxygen unites with most other elements, makes it an important agent in the disintegration of rocks and minerals, and the decomposition of dead animal and plant matter.

In spite of the fact that oxygen is being consumed all the time, its amount does not appear to grow less. Evidently to keep this equilibrium, it must be supplied as fast as it is consumed. This is true, and the principal source of this supply, as we shall see later, is green plants.

Carbon dioxide, though present only in small amounts in the air, is extremely important. It is produced constantly by the burning of fuel, by the decay of organic matter, and by animal and plant respiration. From these various sources it is supplied constantly to the atmosphere. It has been estimated that carbon dioxide is being supplied to the atmosphere at the rate of about 75 tons per second.

- Because carbon dioxide is formed as a result of combustion and respiration, the amount of it in the air in cities is greater than in the open country.

Carbon dioxide is supplied very rapidly to the air, yet the amount of it remains about the same. We infer, therefore, that in some way this gas is being removed, or taken out of the air, about as rapidly as it is formed. Again we must look to the plant for the explanation. 
Green plants.use the carbon dioxide for food, and in so doing they remove it from the air.

The little solid particles in the air we eall dust. The amount of dust in the atmosphere is always great. It is constantly settling everywhere, indoors and out, whenever the air is dry. Much of the dust about us is harmless, but some of it is very dangerous because it consists of minute organisms which produce diseases.

Heat is received by the air from several sources, but the heat from the sun is much greater than that from all other sources. That the atmosphere depends chiefiy upon the sun for its heat is shown by the variations in temperature from day to night, from cloudy days to sunny ones, and from season to season.

Moisture in atmosphere. Water vapor is supplied by evaporation. It is eonstantly entering the atmosphere from all damp surfaces and from all bodies of water. Its presence in the air may be proved in various ways. If a pitcher of ice water stands in a warm room, drops of water appear on the outside of it. Window panes in the winter are eovered with moisture.

The amount of water vapor in the atmosphere is extremely variable. It varies from place to place, and from time to time in the same place. Some water vapor, however, is always present, even in the desert where the air seems driest. Since we can not see nor smell this vapor we are usually not conscious of its presence.

The term humidity is used in referring to the amount of moisture in the air. If there is much moisture, we say 
that the humidity is high. If there is very little, we say it is low. When there is as much water vapor in the air at a given time as it can hold, the air is said to be saturated.

Dew point. If saturated air at any temperature is cooled, a part of the water vapor immediately condenses into water. When water vapor is condensed in the air it becomes visible. In this manner dew, frost, fog, clouds, rain, and snow are formed. The temperature at which the water vapor in the air begins to condense is called the dew point.

Dew and frost. Due to radiation, the temperature of the surface of the ground, and especially of the vegetation, becomes lower than that of the surrounding air. This occurs frequently in the clear still nights of summer and autumn. This causes the invisible water vapor to condense as dew. We thus see that the old saying that "dew falls" is incorrect.

Frost is formed in much the same way as dew, although in this ease the formation takes place below the freezing point of water. The water vapor then passes directly from the gaseous state to the solid state.

Anything which will check the cooling of the ground and the lower atmosphere tends to prevent the formation of dew and frost. A cloudy sky prevents excessive radiation. Winds constantly change the air and thus hinder cooling. As a result, it is rare to have frost on cloudy or windy nights. 
Fog and clouds. Fog and clouds are very much the same. Fog is at or near the surface of the earth, while the clouds are usually half a mile or more above it. In either case, a warm mass of air carrying large quantities of water vapor is cooled.

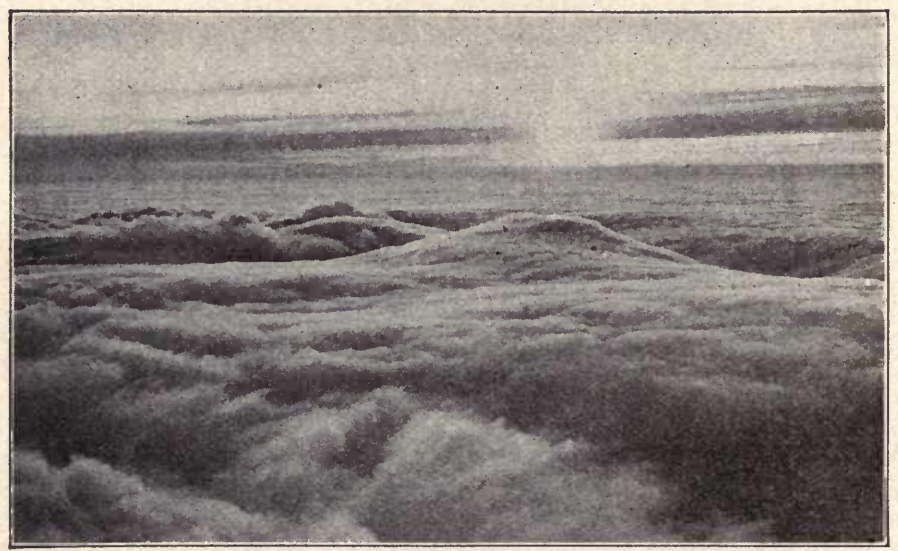

Copyright by Henry G. Peabody. FIG. 45. Sunrise above the clouds, Mt. Washington, New Hampshire.

Rain. If the temperature of air saturated with water vapor is greatly lowered, there will be so much water condensed that it will collect in drops which are too large to float. Rain then takes place, and continues if the condensation continues.

Snow and hail. Snow is formed in the same way that frost is formed. It forms when the water vapor passes directly into the solid state. Snow crystals are very beautiful and are of many varieties.

Hail is frozen rain. The rain falls through a layer 
of cold air and is frozen. Frequently the small hail stone thus formed is carried about by currents of air and more layers of frozen water are added to it. This process may continue for some time, and as a result the large hail stones with which we are all familiar are occasionally formed. Much damage to windows and crops may be caused by the larger hail stones.

\section{Questions}

1. What is the height to which the atmosphere extends?

2. What is meant by "our environment"?

3. Of what importance is atmosphere to us?

4. What changes may take place in the atmosphere?

5. Is air a mechanical mixture or a chemical compound? What are the reasons for your answer?

6 . What gases are found in the air?

7. What per cent of each of these gases is present?

8. Are there any advantages in having fourfifths of the air composed of an inactive gas like nitrogen?

9. Explain in what way alfalfa or clover makes soil more fertile.

10. Of what use is the oxygen in the air?

11. Why does not the supply of oxygen become exhausted?

12. What are the sources of carbon dioxide in the air?

13. How is an equilibrium of carbon dioxide maintained? 
14. Under what conditions may dust be harmful?

15. How is the atmosphere heated?

16. What are the sources of water vapor in the atmosphere?

17. What is meant by the expression "air is saturated"?

18. Define humidity. Dew point.

19. Under what conditions is dew formed? Frost?

20. Why does covering plants with a piece of paper or cloth help to keep them from freezing?

21. What are clouds? What is their distance from the surface of the earth?

22. Under what conditions is rain formed? Hail? Snow?

23. How can you account for the fact that a large hailstone is made of concentric layers of ice? 


\section{ATMOSPHERIC PRESSURE}

Introduction. It is a well known fact that water has weight and exerts pressure. It is more difficult for us to believe that the air around us is constantly exerting pressure, first, because we do not feel conscious of it; second, because air is invisible.

Imagine for a moment that extending for over two hundred miles above us there were water. We can easily appreciate that it would have weight. Similarly, the air above us has weight, and hence exerts pressure. Suppose we consider a column of air one inch wide and one inch thick and over two hundred miles high. If this column of air could be placed upon one pan of a balance, it would be found to weigh about 15 pounds. This weight would vary from time to time, and from place to place. If we weighed the column of air extending above one square inch on top of a mountain, its weight would be less than 15 pounds, because the column would not be so high.

We are practically never conscious of this really enormous pressure of the atmosphere, which is exerted over every inch of our bodies. We are not conscious of it because the pressure is exerted equally over the 
inside and the outside. We are so constructed as to be most healthy when under this pressure. Without it we feel uncomfortable. If this pressure is suddenly changed outside of our bodies, we are at once conscious of it. On tops of high mountains breathing becomes more difficult, headaches and other results follow.

Aeronauts have never ascended much higher than seven miles. At that height the pressure, outside of the body is reduced to about one-fifth of what it is at sea level. As a result of the high internal pressure the blood is forced to the surface, the walls of the blood vessels frequently rupture, and other physical difficulties result.

Fish living at the bottom of the sea are subjected to enormous pressure. Nevertheless they are adapted to those great depths. Were the pressure to which they are accustomed diminished to any great extent, they would suffer great pain, and possibly death. Alexander Agassiz says: "In fish brought up from the deep water, the swimming bladder often protrudes from the mouth, the eyes are forced out of their sockets, the scales fall off, and they present a most disreputable appearance."

Just as they are adapted to the pressure at the bottom of a sea of water, so we are best adapted to the pressure near the bottom of a sea of air.

Air presses in all directions. Place a piece of pasteboard, or blotting paper, over the mouth of a tumbler filled with water. Shake the tumbler until the paper 
is thoroughly moistened. Then invert the tumbler. The water does not run out because the pressure of the

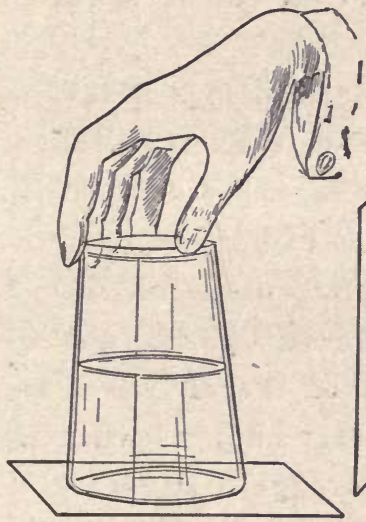

Fig. 46. ${ }^{\mathrm{A}}$ The pasteboard does not fall off from because the pressure of the air on the outside of it is greater than that of the water in the tumbler. In $A$, the air presses from below; in $B$, from the side.

air outside of the pasteboard is at least equal to the downward pressure of the water in the tumbler.

If the tumbler is held so that the mouth faces sidewise, the water does not run out, because the air also presses upon the pasteboard from the sides.

Tie a piece of sheet rubber over the large end of a belljar. Now exhaust the air from the belljar by means of an air pump. As

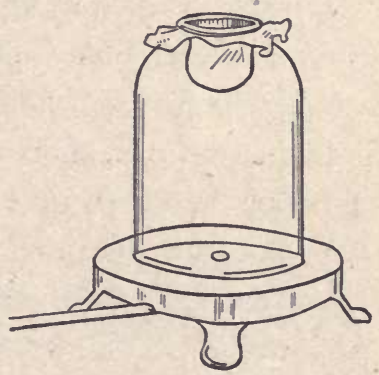

Fig. 47. When air is pumped from the glass jar, the sheet of rubber fastened over the top of it is forced downward by the weight of the air above it. 
soon as a part of the air is pumped out of the glass, the pressure of the air beneath the rubber is less than the pressure of the air above it, and the rubber is forced down into the glass.

If a piece of glass tubing is placed in a beaker of water, the water will not rise in the tube. If the air is then drawn out of the tube by the mouth, the water will rise in the tube. When the air is withdrawn from the tube by the mouth, the pressure within the tube is reduced. The liquid is then forced up the tube because of the pressure of the air on the surface of the water in the beaker. This is what happens when we take soda water or lemonade through a straw.

A test tube filled with water is closed by the thumb and then inverted mouth downward into a jar of water. After the thumb is removed the water does not run out of the test tube, because the pressure of the air on the surface of the water is suffieient to prevent this.

If there is a limit to the amount of pressure which the air exerts, there must be a limit to the column of water which it will hold up.

If, instead of a short test tube, a tube 35 feet or more in length had been used, would the result have been the same as that obtained with the test tube? This has been tried. Careful experiments have shown that the pressure of the air at sea level is sufficient to hold up about 34 feet of water.

If the area of the opening at the base of the tube is one square inch and the height of the column of 
water is 34 feet, it has been determined that the weight of the water in that tube is $\mathbf{1 4 . 7}$ pounds. The water is therefore pressing downward with a pressure of 14.7 pounds to the square inch. The air is pressing downward on the surface of the water with the same force.

Column of mercury held by air pressure. If the water were twice as heary as it is, the column of water which the air would hold up would be only about 17 feet. Mercury is $\mathbf{1 3 . 6}$ times as heavy as water, consequently the highest column of mercury which can be held up by atmospheric pressure is $1 / 13.6$ of 34 feet. or about 2.5 feet, or 30 inches.

This can easily be demonstrated. Fill a glass tube, a Torricellian tube, about 36 inches long, with mercury. Close the open end of the tube with the finger and then quickly insert the end of the inverted tube into a dish of mercury. When the finger is removed, the mercury falls somewhat. If the height of the mercury is measured, it will be found to be about 30 inches, exactly what we should expect. If tubes of very different diameters are taken, it will be found that mercury can be held up to the same vertical height in all of

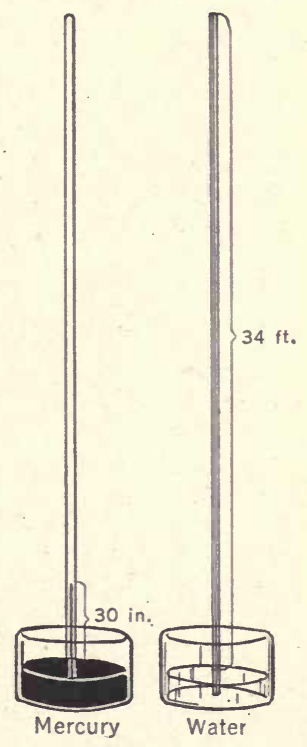

Fig. 48. Air supports a column of mercury 30 inches, a column of water 34 feet. 
the tubes. The shortness of the mereury tube compared with that of water makes the use of mereury more convenient for both experimental and practical purposes.

Variations in pressure due to elevation. The pressure of the atmosphere upon any square inch of surface depends upon the total quantity of air directly overlying that surface. The quantity will be greater at the level of the sea than on the summit of a high mountain, in the bottom of a valley than on top of a hill, at the base of a building than in one of its upper stories.

Other factors determine the pressure as well as elevation. Condition of the weather, temperature, winds, amount of water vapor, all tend to modify the atmospheric pressure not only from day to day, but even from hour to hour. It is possible to record these

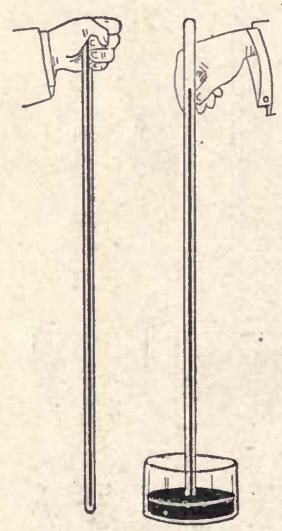

FIG. 49. A simple barometer. changes in pressure. The instrument used for this is called a barometer.

Barometer. A glass tube with thick walls, closed at one end, is filled with mercury. This is then inverted into a small dish of mercury. The whole is attached to a board which is marked in inches or centimeters. As the pressure of air upon the surface of the mercury in the dish varies, the level of the liquid in the tube rises or falls. 
Use of the barometer. The barometer may be used to determine elevations. At sea level the barometer will read 30 inches. If the barometer be carried to elevations above sea level, the mercury gradually falls. It falls at the rate of one inch for a rise in elevation of about 910 feet.

Changes in air pressure are also very closely connected with changes in the weather. In general it may be said that a rapid rise of the mercury in the barometer indicates fair weather, and a rapid fall indicates stormy weather. The barometer is thus of great assistance in predicting the general trend of the weather.

\section{Questions}

1. How can you prove that air has weight?

2. What is the weight of a column of air over one square inch at sea level?

3. Why is not the atmospheric pressure on the top of a mountain the same as it is at the bottom?

4. Why are we not always con-

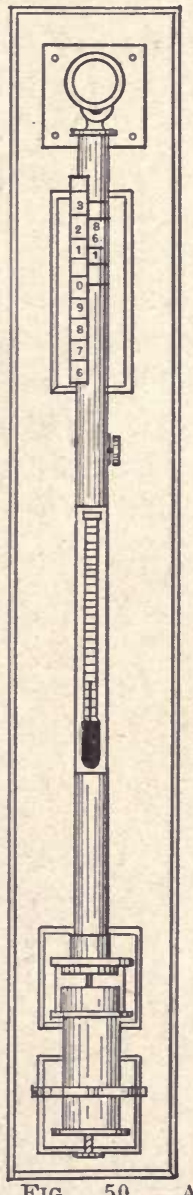

FIG. 50 . A standard $\mathrm{m}$ e rc u ri a l barometer. scious of the great pressure of the air around us?

5 . What are some of the effects of high altitudes on the human body? 
6. How high will the atmosphere hold a column of water? Of mercury? How do you account for the difference in these heights?

7. Does the height of the column of mercury held by the atmosphere vary with the diameter of the tube?

8. How can you prove that air presses in all directions?

9. Does the pressure of the atmosphere vary? If so, under what conditions?

10. What is the structure of a barometer?

11. Why do we use mercury in a barometer instead of some other liquids?

12. What are the uses of a barometer?

13. What kind of weather does a high barometer indicate? A low one? 


\section{WINDS AND STORMS}

Winds. We are all familiar with the sometimes regular, but more often fitful and irregular movements of the air, which we call winds.

Winds are important in many ways. They transfer great masses of air from one part of the earth to another; they carry away the impurities of city air; they furnish power for windmills and sailing vessels; they cool hot regions and warm cold ones. Most changes of weather are due to changes in the direction of the wind. Some winds are agreeable and favorable to life. Some bring suffering, destruction, and death. Even light breezes effect a continual change of air which is beneficial for both plants and animals. To man, winds are as a rule stimulating and invigorating, while calm air is often enervating.

Cause of winds. A piece of wire gauze is placed over
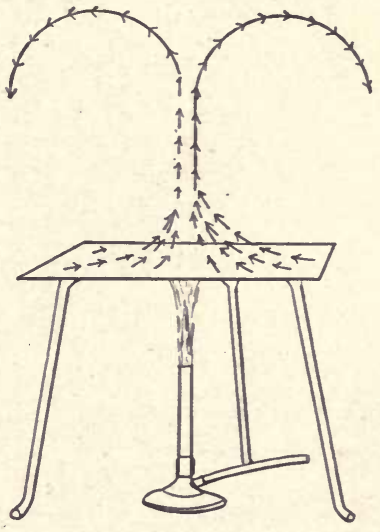

Fig. 51. When air is heated it expands, becomes lighter, and is pushed up by the colder air which is the flame of a Bunsen burner. drawn down beneath it. If very small pieces of cotton are dropped upon the 
gauze they soon rise, being carried upward by the currents of heated air.

We already know that when air is heated it expands and becomes lighter. The surrounding colder air, because it is heavier, is then forced into the place occupied by the heated lighter air. The heated air is then pushed up and produces an air current. This, on a small scale, is a wind. If for any reason the air above one place becomes heavier than that above another, there will be a transfer of air from the place where the pressure is greater to that where it is less. This movement of the air we eall wind. Winds are eaused by unequal pressure. The inequality of pressure is usually the result of unequal heating.

It is a well known fact that all parts of the earth are not equally heated. It is also known that the amount of heat received by the earth at any given place varies from hour to hour, day to night, and month to month. These variations in temperature are largely the result of the shape of the earth, its movements, and its position with reference to the sun.

Just as the earth is unequally heated, so likewise is the air immediately above it unequally heated. As a result the pressure of the air varies in different places, being lightest where the air is hottest, and heaviest where its temperature is lowest. In those portions where the earth is greatly heated, the warm air will be pushed up by the cold air from the surrounding regions which will come in to fill its place. 
General effect of unequal heating. The effect of heating the earth is to cause the air to rise from the surface. Since all parts of the earth are not evenly heated, the air does not rise evenly. It rises most over the equator and in the tropics where the earth receives the greatest amount of heat. This warm upper air moves from equatorial regions toward the poles. As it does so, it gradually becomes cooler and consequently heavier, until in the regions of 30 degrees north and south of the equator, it settles down upon the earth. This movement of the air establishes a region of high pressure in each hemisphere. From each of these regions currents of air move outward; one toward the nearest pole, and one toward the equator. The elements of the general circula-

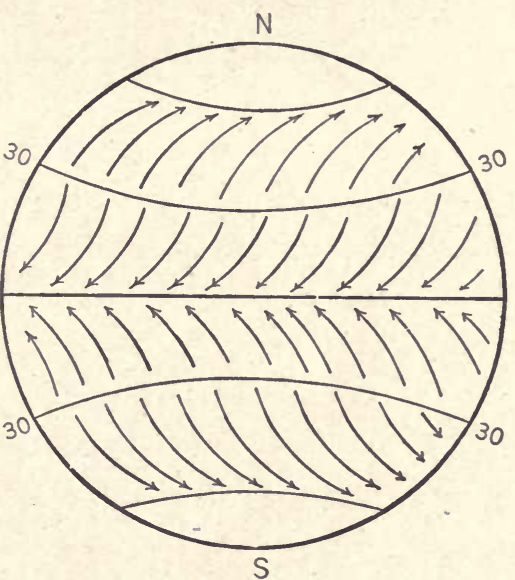

Frg. 52. Diagram of the general circulation of the air. The trade winds blow toward the equator, the prevailing westerlies blow toward the poles. tion, then, are: 1 . the rising of warm air in the tropies, 2. the moving poleward of this air, 3 . its settling, 4 . the moving poleward of part of this air and the moving equatorward of the remainder.

If the earth did not rotate, the poleward moving 
air would more north in the northern hemisphere and south in the southern hemisphere. The air moving toward the equator would move directly south in the northern hemisphere and north in the southern. The rotation of the earth, however, turns the currents of air to the right in the northern hemisphere and to the left in the southern. (See Figure 52.) Thus in the temperate regions of both hemispheres, the winds usually come from the west. These winds are known as the prevailing westerlies. The winds blowing from the regions of high pressure toward the equator are known as the trade winds. They blow obliquely toward the equator from the northeast and from the southeast. These winds have been given their name on account of the steadiness with which they blow. Navigators have known of these winds and have taken advantage of them for ages.

The prevailing westerlies are of the most importance and of the most interest to us because the United States lies in their region. Because of the regularity of these winds most of our storms move eastward. We are all familiar with the fact that our storms are generally first seen in the west.

Land and sea breezes. If you have lived near a large body of water, you are familiar with the cool breezes which blow from the water over the land during the day, and in the opposite direction at night. Land heats and also cools more rapidly than water. As a result, during a hot day the land becomes warmer 
than an adjacent body of water. The air above the land also beeomes warmer and expands more than that over the water. This expansion reduces the pressure and causes the air to move toward the land from the water. This movement of the air is of great value along densely populated sea coasts or lakes. This sea breeze, as it is called, lowers the temperature and also brings in pure air.

At night the land cools more rapidly than the water. Consequently breezes blow from the land to the water.

Cyclones. The regularity of the general system of prevailing winds is frequently disturbed by local and temporary disturbances which are called storms. These are brought about by the fact that the atmospheric pressure $\mathrm{N}$ is not the same in all places at the same time. For example, if we should receive reports of barometric readings from a number of places in the United States taken at the same time, we should find
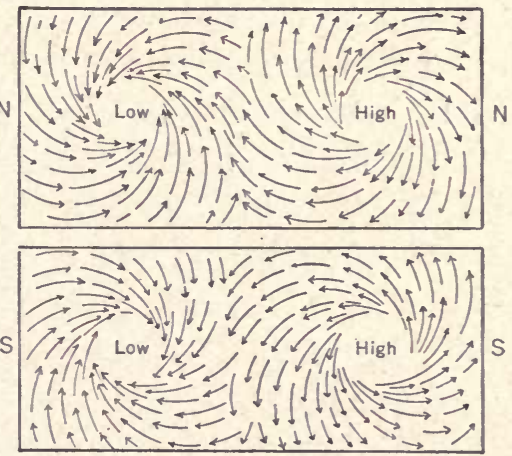

Fig. 53. Diagram to show the circulation of air about a low and about a high. The rotation of the earth turns the currents of air to the right in the northern hemisphere and to the left in the southern hemisphere.

that they were not all alike. In some parts of the country the readings would be high, in other parts low. As a result of the differences in pressure, there is always 
a movement of air from the region of high pressure toward the one of low. Such a movement is called a cyclone. We must not think that a cyclone is always a violent, destructive wind storm. Such storms are correctly known as tornadoes.

At the same time that there is a movement in toward a region of low pressure, there is also an outward movement from the area of high pressure. Such a movement is known as an anticyclone.

Because of the rotation of the earth, cyclonic winds do not blow straight toward the center of the region of low pressure. In the northern hemisphere they are deflected toward the right. (See Figure 53.)

A region of low pressure is generally characterized by rain, relatively high temperature, and shifting winds. These conditions constitute a cyclonic storm. A cyclone is not stationary, but moves generally in an eastward or north eastward direction. As it moves it is followed by an area of high pressure in which the winds are moving spirally out from the center. This anticyclone is associated with low temperature and clear skies. Frequently during a cyclone so much warm air from the south is brought into northern regions that unseasonable warm weather follows. Similarly, sometimes cold air spreads over a great area extending south. When accompanied by a driving snow this constitutes a blizzard.

Thunderstorms. We are all familiar with the characteristic conditions of the atmosphere and sky pre- 
ceding and during thunderstorms. This type of storm is frequent in the United States. It occurs in cyclones, but usually some distance from the center and toward the south.

A thunderstorm generally occurs in the warm season and often follows a period of intense heat. The first indication of a thunderstorm in temperate latitudes is a large dark eloud in the west. It moves eastward, preceded by a sharp breeze. The sky becomes overspread and rain pours down. The rainfall is often heavy and the drops are large. It lasts, however, but a short time, usually less than an hour. The sky then becomes clear, and the air is noticeably-cooler and fresher.

Frequently in a thunderstorm the sun appears when some rain is still falling. A rainbow may then be seen opposite the sun. As the sun's rays pass through the drops of water, the white light of which the ray is composed is broken up into a number of different colored rays.

The lightning which accompanies a thunderstorm is due to the fact that electricity is produced when water condenses rapidly in the air. Each drop of water becomes charged with electricity, which is then discharged between clouds, between parts of elouds, or between the earth and the clouds.

The flashes of lightning cause vibrations in the air

- which produce a noise, which we eall thunder. Sound travels much more slowly than light; consequently we 
hear the thunder some time after we have seen the lightning.

Tornadoes. Like thunderstorms, tornadoes occur in hot weather and generally in a cyclone. They differ from a cyclone because the atmospheric pressure at the center is very low, and the area of low pressure is very small. In some tornadoes the atmospheric pressure has been reduced as much as one-half. As a result, the winds are violent and very destructive. It is probable that in some instances the velocity of the wind is as great as 500 miles an hour. Fortunately tornadoes do not occur frequently, and the path over which they travel is very narrow. In tornadoes of recent years in the United States many lives have been lost and much property destroyed. In St. Louis in 1896 the property loss was estimated at $\$ 13,000,000$, and in Louisville in 1890 at $\$ 2,500,000$. Tornadoes at sea are called water spouts.

Effect of winds on rainfall. We can scarcely overestimate the importance of rainfall to all living things. We know that much of our own western country has remained uninhabited because the annual rainfall is not sufficient to enable plants to grow, or because it does not fall during the growing period of plants. We do not have any extensive deserts in the United States, yet about one-third of the land is too arid to grow crops successfully. By means of irrigation we are succeeding in watering artificially millions of acres of land. Because of the fertility of the soil and 
the abundant sunshine, luxuriant crops can then be grown in these otherwise arid regions.

Winds are important factors in the distribution of the rainfall. Air becomes filled with moisture over surfaces where water is evaporating. This moisture laden air is carried along until it comes to a region of lower temperature or higher pressure, where the vapor condenses and falls as rain.

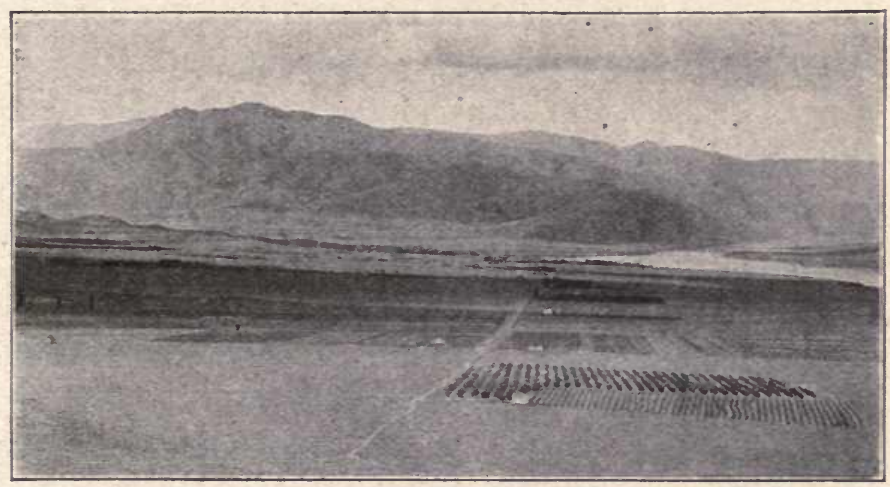

Photograph by Henry G. Peabody.

Frg. 54. Columbia River Valley in Washington.

The ranches on this plain are irrigated by streams which come down from the mountains in the distance. The land in the foreground has not been reclaimed and is covered with sagebrush.

Since the prevailing windsein the United States are for the.most part from the southwest, those which blow toward the land along the western coast are filled with moisture from the Pacific Ocean. In the summer the land is warmer than the ocean, and the winds blowing over the lowlands along the coast do not deposit their moisture until they reach the moun- 
tains. This causes the dry summer season characteristic of much of California. Along the coast of Washington the mountains are very close to the coast line, and moisture is deposited where the winds strike the high mountains. Washington, as a result, does not have the dry summer season characteristic of the southern part of the western coast.

In the winter the land is cooler than the ocean; consequently the winds begin to give up-their moisture as they blow over the lowlands, and continue to do so until they reach the Cascades in the north and Sierras in the south. Beyond the mountains the air is then dry. The winds descend and blow over the lowlands and form the arid lands of the Great Basin, eastern Oregon, and Washington. As the winds continue eastward they strike the Rocky Mountains where they are again cooled and their moisture is deposited. East of the Rocky Mountains as far as the Atlantic these winds are dry, for they do not cross any more high mountains and the temperature is not low enough to cause precipitation. East of central Kansas and Nebraska the lands are well supplied with rain. This rainfall is not due to the prevailing westerlies, however, but to cyclonic storms.

The amount of rainfall in the United States varies from over 60 inches per year along the coast of Washington and Oregon and part of Florida, to less than 5 inches in parts of Nevada, southern California, Arizona, and Utah. 


\section{Questions}

1. State three ways in which winds are of importance.

2. What is the principal cause of winds?

3. What is the direction of the movement of air over the equator and in the tropics?

4. In what latitude does this air begin to settle down on the surface of the earth?

5. In what directions does the air move from the regions of high pressure formed at $30^{\circ}$ north and south -latitudes?

6. Why do not prevailing winds blow directly north and south?

7. Toward what direction are winds deflected in the northern hemisphere? In the southern?

8. What are the prevailing westerlies?

9. What are the trade winds?

10. What are land and sea breezes? What causes them?

11. What are the characteristics of a cyclone? An anticyclone?

12. Under what conditions do thunderstorms arise?

13. What is the cause of a rainbow?

14. How do you account for lightning? Thunder?

15. Why do we hear thunder some time after we have seen the lightning?

16. How could we estimate the distance from the earth to the clouds during a thunderstorm?

17. What is a blizzard?

18. Why are tornadoes so destructive?

19. In what parts of the United States have we had tornadoes?

20. What is a water spout? 
21. Of what importance is rainfall to man?

22. What is meant by irrigation?

23. What proportion of the land in the United States is too arid to grow crops successfully?

24. How can you account for the wet and dry seasons of Southern California?

25. Why is there a scanty rainfall just east of the Rocky Mountains?

26. What is the average rainfall in the region in which you live?

27. What is the cause of most of the rain in the Middle West?

28. In what parts of the United States is the amount of rainfall greatest?

29. What parts have the least rain? 


\section{CHAPTER XXI}

\section{WEATHER AND CLIMATE}

Weather. The condition of the atmosphere at any given time constitutes the weather. The amount of rain, the atmospheric pressure, the direction and the velocity of the wind, the humidity, the state of the sky, and the temperature are factors which determine the kind of weather. We are well aware of the fact that one of the most prominent characteristies of the weather is its changeableness. The variations in the weather are brought about by the rotation of the earth on its own axis, its inclination on its axis, its revolution around the sun, and such changes as result from the passage of storms.

Climate. When we speak of the climate of any region we say it is cold, hot, temperate, dry, or wet. We are then referring to the average weather conditions of that region for a long period of time. In general the weather of any region follows the same course from year to year. Occasionally, however, a winter may be very mild, or there may be an unusually heavy snow. It is thus necessary to have the average of the weather conditions for a long period 
of years in order to determine the climate of that region.

There is a popular notion, especially among old people, that the climate of the region in which they are living is changing. Records of the climate extending over long periods of time indicate that there is little basis for this current impression. A few exceptional seasons, an intensely cold winter or a very wet summer, make a greater impression and are consequently the ones which are best remembered.

The principal elements of climate are moisture, wind, and temperature. In previous chapters we have discussed the general distribution of wind and rainfall.

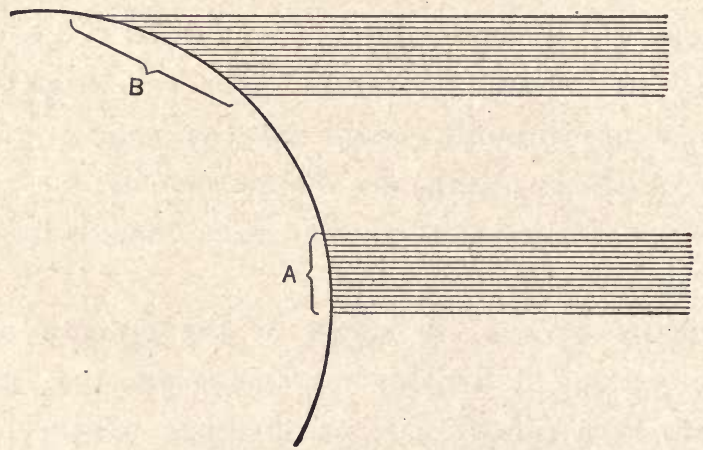

Fig. 55. The amount of heat received depends upon the angle at which the sun's rays strike the surface of the earth. The same number of rays fall on a smaller area at $A$ than at $B$.

Effect of temperature on climate. Practically all the heat which warms our atmosphere comes from the sun. This is shown by the difference in temperature between day and night, and between that on a 
cloudy and a sunny day. The sun's rays falling all day on the land and water warm them. This heat then radiates outward and heats the air, which receives very little heat directly.

The surface of the earth receives most heat where the sun's rays fall most nearly vertically. The rays are then most eoncentrated and pass through less air. We are all familiar with the fact that the air is

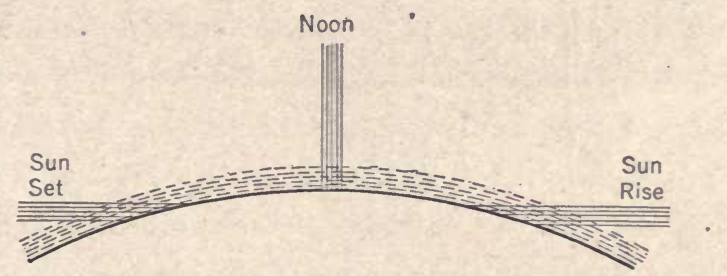

FIG. 56. Diagram showing the difference in the angles at which the sun's rays strike the earth at sunrise, noon, and sunset.

warmer at noon when the sun's rays are nearly vertical than it is in the evening or in the morning when they are oblique.

Day and night. In your study of geography you learned that the earth rotates on its own axis once in twenty-four hours, and also that it revolves about the sun in a little more than three hundred and sixtyfive days. As a result of the rotation. of the earth on its own axis, any given point on the earth is turned during part of each twenty-four hours toward the sun, producing day, and during the remainder of the time away from the sun, producing night. The uniform succession of days and nights is due to the regularity of the rotation of the earth. 
Seasons: Seasonal changes in temperature are the result of the revolution of the earth about the sun. The path of the earth about the sun is known as its orbit. This orbit is an ellipse; eonsequently the distance from the sun to the earth varies from time to time. As the earth moves, its axis (a line drawn through the center of the earth from pole to pole) is not perpendicular to the plane of its orbit. It is inelined toward this plane at an angle of about $231 / 2$ degrees. This position of the axis, together with the motion of the earth, eauses the changes in the length of day and night and also the succession of seasons.

One half of the earth is being illuminated by the sun's rays all of the time. If the earth's axis were perpendicular to the plane of its orbit, day and night would always be of equal length. Sinee the rays of light would then always fall at the same angle and for the same length of time at a given place on the earth, there would be no change of season.

We all know, however, that in June the sun shines more directly on the earth in the temperate latitude, and also for several hours more than it does in January. As a result, the temperature of several months which we call summer, is higher than that of winter. In autumn and spring the angle of the rays and the length of daytime are intermediate.

By referring to Figure 57 you will notice that the hemispheres are at one time inclined toward the sun and at another away from it. For example, from 
March 21 to September 22 the northern hemisphere is inclined toward the sun. During that time the region around the north pole receives light contin-

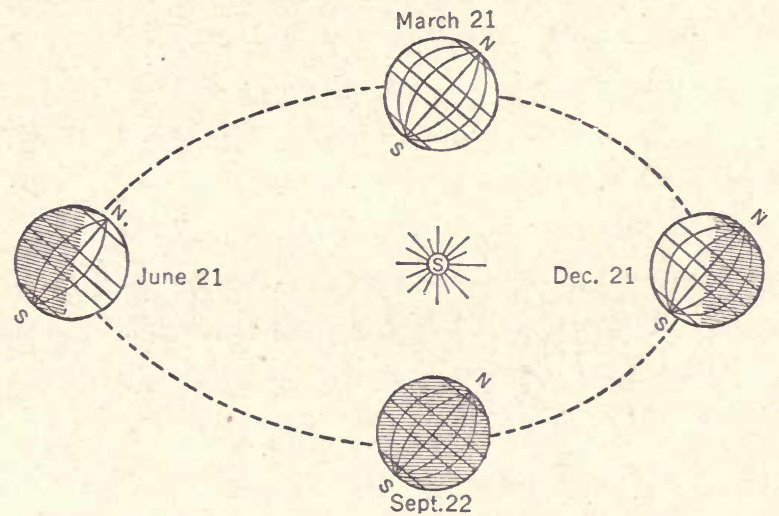

Fig. 57. Diagram of the path of the earth around the sun showing the position of the earth with reference to the sun on four dates. The dotted line represents an ellipse, and the earth and sun are in the same plane.

uously for some time. Throughout all the northern hemisphere, during this period, the days are longer than the nights.

The rays are most nearly vertical in our latitude on June 21, and our day is then the longest and our night the shortest. From then on, the inclination of the earth's axis toward the sun becomes less until September 22, when it is at right angles to the sun and the day and night are equal in length.

Gradually the north pole becomes inclined away from the sun, the rays from the sun become more and more oblique in the northern hemisphere, the temperature becomes lower, and the nights become longer. 
On December 21 we have our shortest day. The days then gradually become longer until on March 21 the nights and days are again equal.

The hottest days in our latitude do not come in June at the time when the sun's rays are most nearly vertical. During the long days at that time more heat is received by the earth than is given off during the short nights. There is thus a gradual accumulation of heat, and our hottest days come later in the summer. During the fall the earth slowly loses more heat than it receives, but it is some time after our shortest day, December 21, that we have our coldest weather.

The change of seasons and the difference in the length of day and night vary greatly with the latitude. In the temperate regions there are four seasons, summer, fall, winter, and spring. In the polar regions the difference is chiefly a matter of daylight and of darkness. Seasons differ but little in the tropics because the days and the nights are always nearly equal, and the sun's rays are nearly vertical all the time.

All the variations which are due to day and night, seasons, rainfall, winds, etc., are of great importance to the life of man and to human industries. The distribution of life is largely the result of climate.

Weather maps. Weather maps are prepared every day by the United States Weather Bureau, which is a part of the Department of Agriculture. Telegrams are received daily at the Weather Bureau from stations in different parts of the country. Each telegram 
tells the temperature, direction and velocity of the wind, pressure, rainfall or snowfall, cloudiness, etc., at the station from which the report is sent.

These reports are then combined and placed upon a map. From these maps it is then possible for an expert to tell not only what the weather is, but also to predict what it is likely to be. These predictions are sometimes wrong, due to the fact that reports from some stations may be missing or to a change in the rate at which a storm is advancing. The few mistakes made, however, are almost negligible as compared with the many correct forecasts.

Through the services of the Weather Bureau warnings of coming frosts, storms, and floods are made which save annually not only many lives, but millions of dollars' worth of property. Millions of dollars' worth of fruit may be saved by these warnings of cold waves sent to fruit growers. Shipping interests are also served by warnings of approaching storms.

Explanation of a weather map. If we examine a weather map (see Figure 58), we notice that there are many things represented on it. Let us give our attention first to the heavy black lines. These lines are isobars (iso, equal; barus, heavy). All the weather stations on the map which have the same barometric pressure are joined by a solid line. At the end of each of these lines is marked the figure which represents the pressure at all points on the line. These lines make it possible to see very easily where the high 


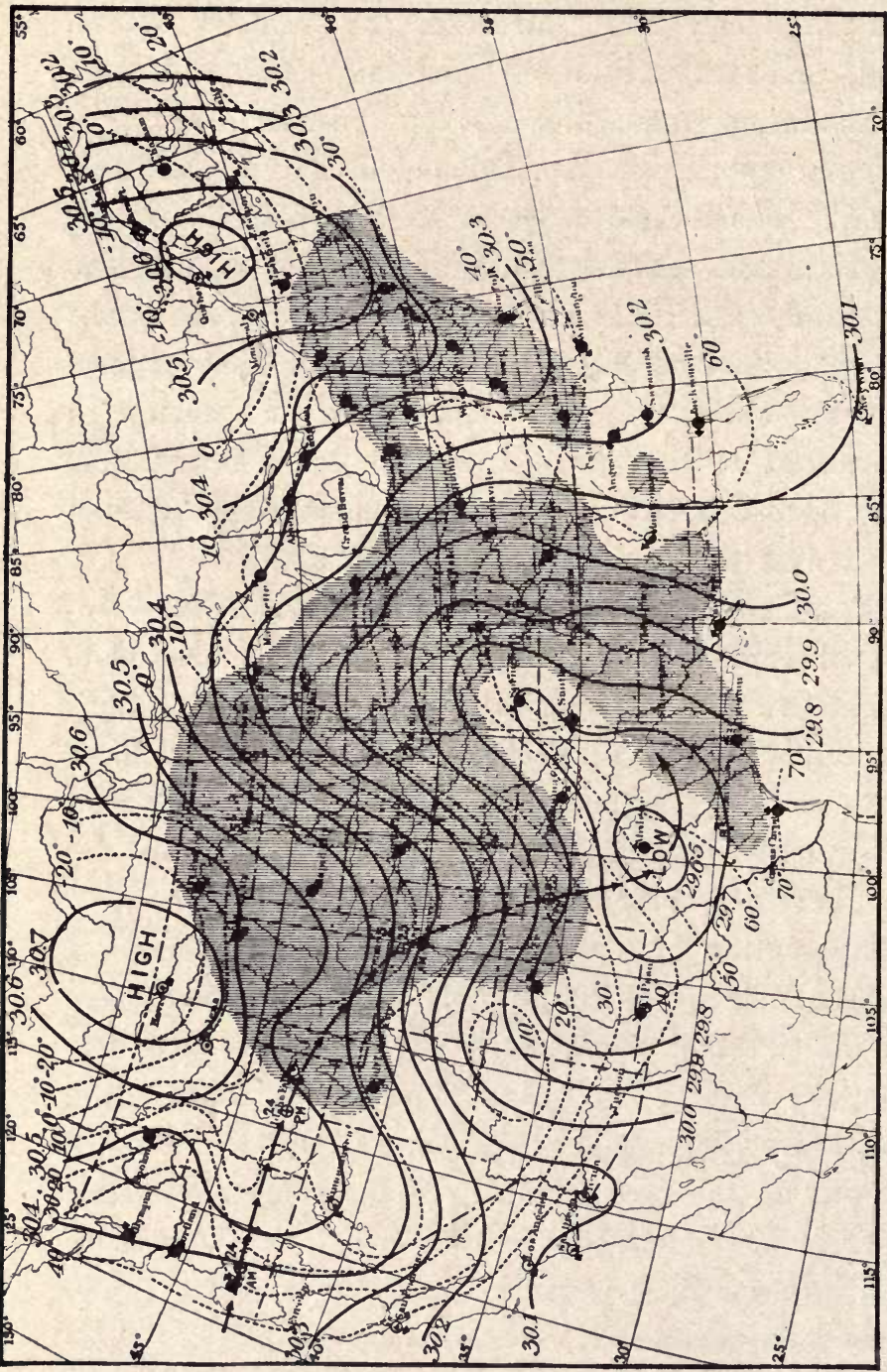

(3)

उ

ॠ

$\therefore \quad \frac{1}{3}$

$\stackrel{0}{\approx}$.

(3) $\ldots \pi$

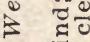

- BO

3.

¿

ㄴㄷㄷㄴ

$3+i$

$\approx \sigma^{5}$

$\therefore-12$

क $6 \circ$

$\stackrel{N}{*}$

(5)

入 0 造

है

U...

(1) ह

A क्ष

ย를

4. 0

․․․

क्ष

तै

का 02

웡

एँ

उ० ह

$\pm$

$-0$

$\infty$ 다요

in

너

II 응

次

0

듀유

D

02

¿ี兀

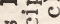

ขอ

요.

¿ 02

투을

잉응 


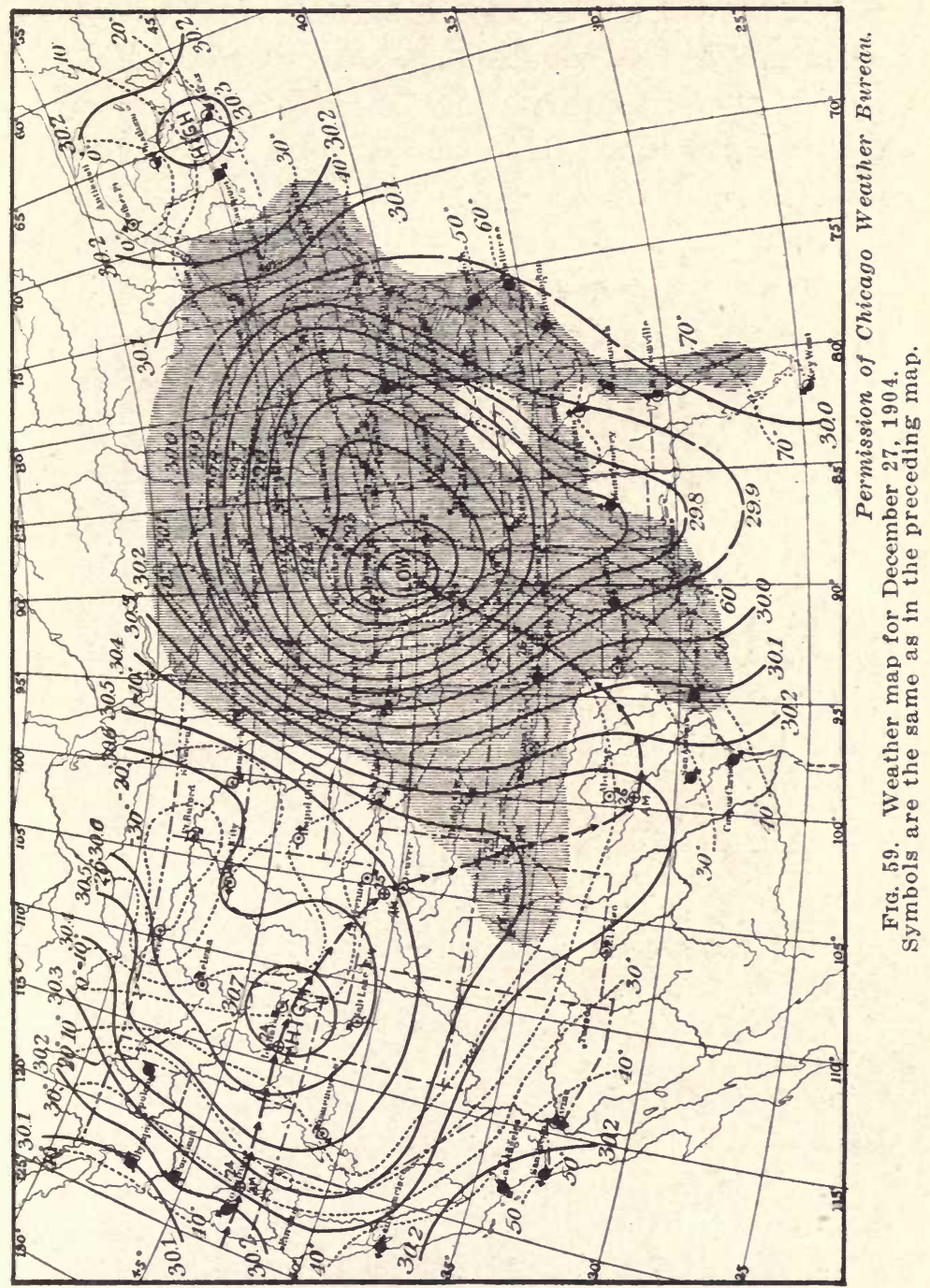


and low pressure centers are located. The isobars curve in irregular circular lines about these areas of high and low pressures. We have already learned that low centers are those toward which air tends to move from all sides. This movement toward a low pressure area constitutes a cyclone. Consequently a low pressure represents a storm center. A high .pressure on the other hand, represents an anticyclone, or a region of fair clear weather. By examining weather maps of several successive days it is possible to trace the path of a low area as it moves along and across the country. (See Figures 58 and 59.) The path of the high pressure area which follows it can also be traced. Arrows on the map indicate the direction of the winds. Places of equal temperature are also indicated on a weather map. They are connected by dotted lines which are called isotherms.

\section{Questions}

1. What are the principal causes of variations in the weather?

2. Explain the differences between the terms weather and climate.

3. Explain the causes of the differences in the seasons.

4. How do you account for the fact that cloudy days are cooler than days on which the sun is shining?

5. Why is it warmer at noon than it is in the morning or evening? 
6. What causes day and night?

7. Why do day and night vary in length?

8. How many degrees is the inclination of the earth's axis to the plane of its orbit?

9. What is the position of the earth with reference to the sun on June 21? September 22? December 21 and March 21 ?

10. Has climate in any way affected the distribution of man?

11. How are weather maps made?

12. Of what value are weather maps?

13. What are isobars? Isotherms?

14. Are weather forecasts generally correct?

15. Why is it sometimes difficult to make accurate weather predictions?

16. Of what value are weather forecasts?

17. Is the government justified in maintaining weather bureaus?

18. Where is the weather station located which is nearest to the place in which you are living? 
CHAPTER XXII

\section{THE SURFACE OF THE EARTH}

Everybody has observed that the surface of the earth is not smooth, but more or less irregular. Some of these irregularities, as mountains and large valleys, are very conspicuous, while others, as hills, ravines, ridges, cliffs, and flats, are less conspicuous but more widely distributed. These irregularities, which make up the relief features of the earth, may be classified as follows: continents and oceans; mountains, plateaus, and plains; and minor land forms.

Continents and oceans. The relief features of the first group, the continents and ocean basins, have practically always occupied the positions they now have. It is not positively known how they came to originate or to occupy these positions. When the earth cooled from its original heated condition, there was a down folding where the ocean beds now are, and a corresponding elevation over the continental areas. When the surface of the carth was cool enough to allow the atmospheric waters to remain, they accumulated in the depressions, and thus made the seas.

Although in name there are five great oceans, in reality there is but one. As all the ocean water of the 
earth is one continuous body, it is only for convenience that different parts have received different names. In area the ocean covers about three-fourths of the earth's surface. Its average depth is about two and one-half miles. If all irregularities of the earth's crust were smoothed off, the water would cover the entire earth's surface to a depth of nearly 9,000 feet.

The ocean is continually at war with the land. Its main work, with the aid of rain and streams, is to carry the land into the sea. Charlotte P. Stetson has expressed it thus:

I am the Sea! I hold the land As one holds an apple in his hand;

Hold it fast with sleepless eyes, Watching the continents sink and rise. Out of my bosom the mountains grow, Back to its depths they crumble slow. The iron cliffs that edge the land

I grind to pebbles and sift to sand;

I comfort the earth with rains and snows Till waves the harvest and laughs the rose. Flower and forest and child of breath With me have life-without me death. The earth is a helpless child to me.

$$
\text { I am the sea! }
$$

The ocean may never entirely complete its task. Water is held on the surface of the earth by the interior heat which allows it to penetrate only to a certain 
depth. As the heat recedes towards the center of the earth by cooling, the waters follow. In the very remote future the earth will have cooled to a depth permitting the absorption of all the water and atmosphere now on its surface. Such is considered to be the condition of the moon now.

Continents are great bodies of land surrounded by water. The average height of the land above sea is less than one-half mile. While continents have undergone many changes in the past, they have practically always occupied their present position.

Mountains, plateaus, and plains. Mountains, the glory of the earth, the culminating places of scenic grandeur and beauty, are the most conspicuous land forms. Most mountain systems are located on the sides of continents adjacent to the ocean; furthermore, the highest mountains border the largest oceans. The birthplaces of mountains are marginal sea bottoms. As the interior of the earth loses heat it contracts. But, as the crust of the earth is already cool, it is more or less rigid; hence, to accommodate itself to the shrinking interior, it must fold. This folding naturally takes place along lines of weakness in the earth's crust. Marginal sea bottoms are lines of weakness. Here for ages have accumulated enormous deposits of sediment. As the sediment accumulates, the interior heat rises toward the surface, and in the presence of water included in the sediment, produces, a semi-fused condition. This condition, of course, pro- 
duces lines of weakness where folding will occur. This process goes on very slowly. To produce mountains like the Rockies has taken untold ages of time. In every mountain there is a period of birth, growth, maturity, decay, and death. The Appalachian mountains are now in the period of decay; at one time they were almost as high as the Rockies.

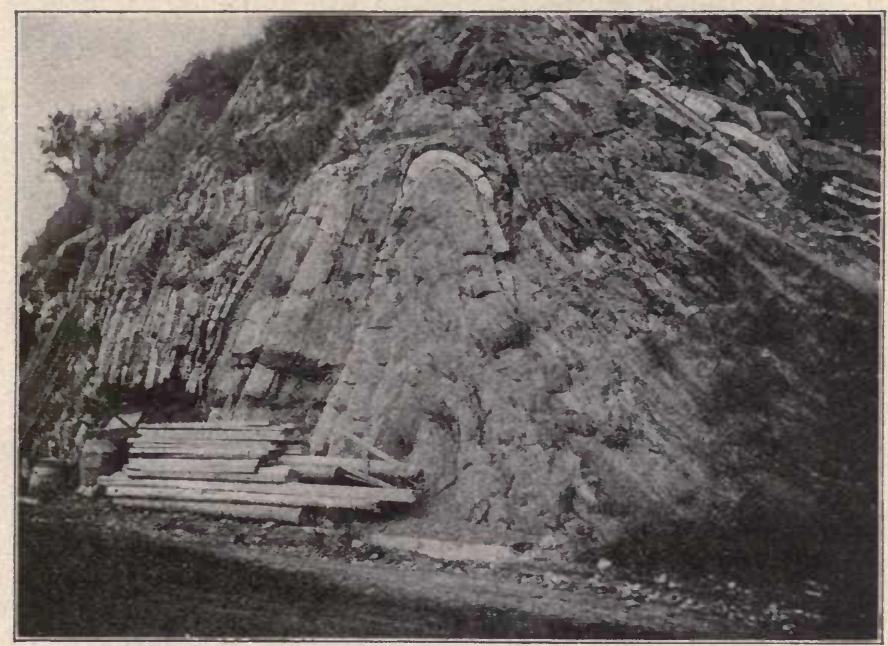

Permission of U. S. Geological Survey. Fig. 60. An anticlinal fold in the rock at Levis Terrane, Quebec.

Plateaus are highlands of considerable area. Not all plateaus are the same height; the Piedmont Plateau between the Appalachian Mountains and the Atlantic Ocean is rather low; while the Plateau of Tibet is about 15,000 feet high.

Plains are the lowlands of the earth. They have great economic importance, for here is located a 
large part of the agricultural lands. They differ greatly in height, origin, fertility, position, and shape of surface. Plateaus and plains, like mountains, frequently have their origin in the folding of the earth's crust.

Minor land forms. Hills, cliffs, mesas, buttes, ridges, flats, and other minor land forms constitute the third group of relief features. They, unlike the other groups, are caused by erosion and weathering brought about by the atmosphere and water.

Effect of the atmosphere on the earth's surface. The atmosphere has both a mechanical and a chemical effect upon the earth's surface.

Mechanical. Small particles can be blown about from place to place by the wind. This is a mechanical change. Dust is the easiest material for the wind to move. The sources of dust are highways, fields, streets, voleanoes, meteoric smoke, pollen, and spores of plants. During some volcanic eruptions much dust is thrown into the air and carried long distances by the wind. Meteors or "shooting stars" when they come into the atmosphere from outer space are probably traveling eighteen or twenty miles per second. The friction of the atmosphere is sufficient to heat them to such a temperature that they are consumed. The dust resulting settles to the earth. It is said that the bottom of the deep sea is covered to a considerable depth with this meteoric dust free from other accumulations. Loess beds are deposits of dust which oceur 
at different places. In the Province of Shansi, China, are deposits several hundred feet thick. - Near Kansas City, Missouri, there is a deposit at least thirty feet thick.

Sand is also earried by the wind, but since it is heavier than dust, a much stronger wind is necessary for carrying it. Sand never rises to any great height, but is earried near the earth. There are many obstacles on the earth to stop it. Sand blown by a strong wind has considerable cutting force. For this rea-

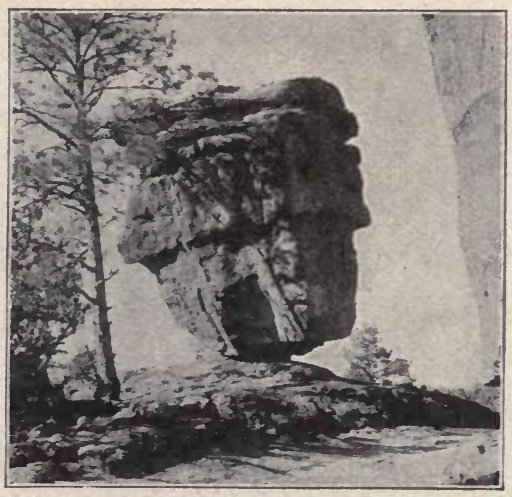

Photograph by Detroit Publishing Co. Fig. 61. Balanced Rock, Colorado Springs, Colorado. This rock has been cut by wind-blown sand.

son sand blasts are sometimes used for etching glass. In the semi-arid regions of western United States, projecting rock eliffs are often carved into strange and fantastic forms. The softer parts of the rock are eut more rapidly so that the harder parts are left projecting. Even the hard rocks are not able to withstand the long continued action of blown sand.

Sand dunes. Mounds and ridges of wind-blown sand are called dunes. In the dry parts of western United States there are thousands of square miles where dunes are abundant. On the east and south shores of 


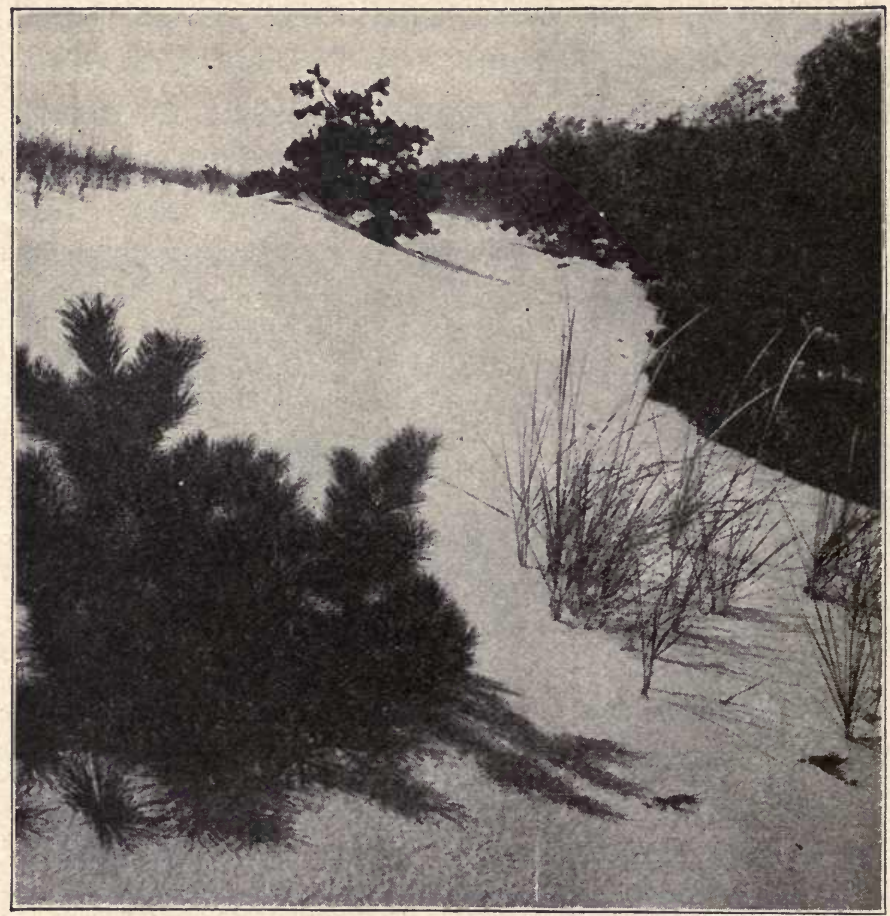

Copyright by Underwood \& Underwood, N. Y. FiG. 62. A forest on Cape Cod planted as a windbreak is being

Lake Michigan are other sand dune regions. Dunes vary much in size. Very large ones occur in central Wyoming. The largest ones are found in the Sahara Desert where they reach a height of several hundred feet.

The growth of a dune begins when the sand is stopped by some object on the earth's surface. Once started, the dune increases by the addition of more 
sand. They are not stationary, but migrate in the direction toward which the prevailing wind blows. The migration of the dunes may do great damage by covering up farm land, forests, railroads, and some-

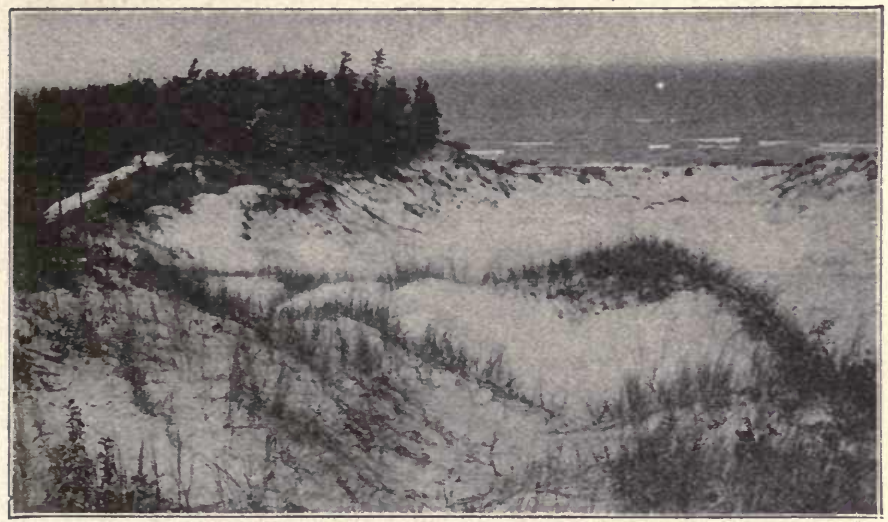

Fig. 63. The pines and grasses shown at the left hold the sand and prevent the migration of the sand dune.

times buildings. Trees, shrubs, and grasses that will grow in sand are sometimes planted on dunes to prevent their migration. The roots of the plants hold the sand.

Effect of change of temperature on rocks. Changes in the temperature of the atmosphere also have a mechanical effect on the earth's surface. You have already learned that heat expands and cold contracts objects. Exposed rock surfaces are heated in the day and cooled at night. On mountain tops this daily change of temperature is very great. This continual 
change of temperature causes rocks to scale off. In mountainous regions great piles of this broken off debris collect at the base of mountains and cliffs. Such deposits are called tailus. The total effect of this shell-

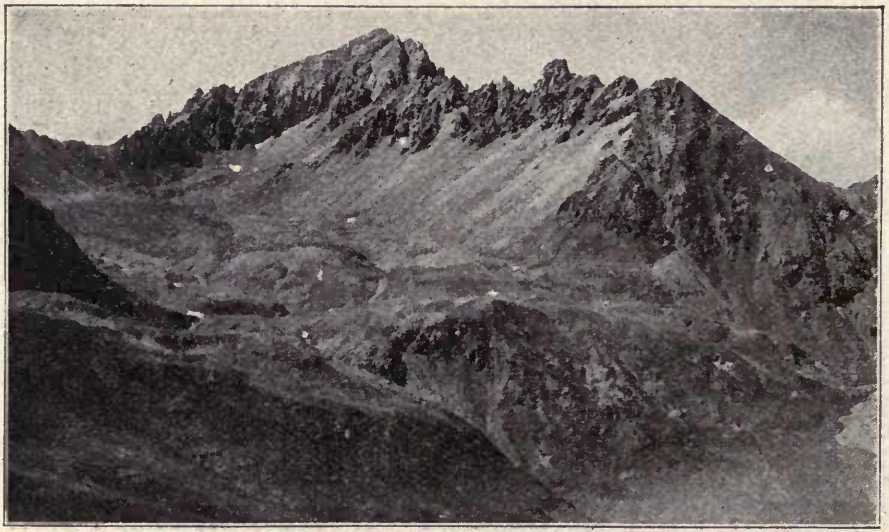

Permission of U. S. Geological Survey. FIG. 64. Great piles of debris, called talus, have collected at the base of these mountain peaks in Colorado.

ing off of exposed rock surfaces through the ages has been very great. If you examine the surface of a boulder or rock, you can notice this shelling off effect.

Chemical. The oxygen of the air is its most active chemical element. If a piece of iron is exposed to the air in the presence of moisture, it rusts. The oxygen of the air unites with the iron and forms a red rust; in time the whole of the iron is converted into the oxide. Oxygen attacks many rocks in a similar manner. As the oxidizing process is continually going on, the total effect is very considerable. Other 
constituents of the air may also attack rocks chemically, but oxygen is the most powerful.

Work of rain in causing relief. All have observed that streams are muddy after a heavy rainfall. This

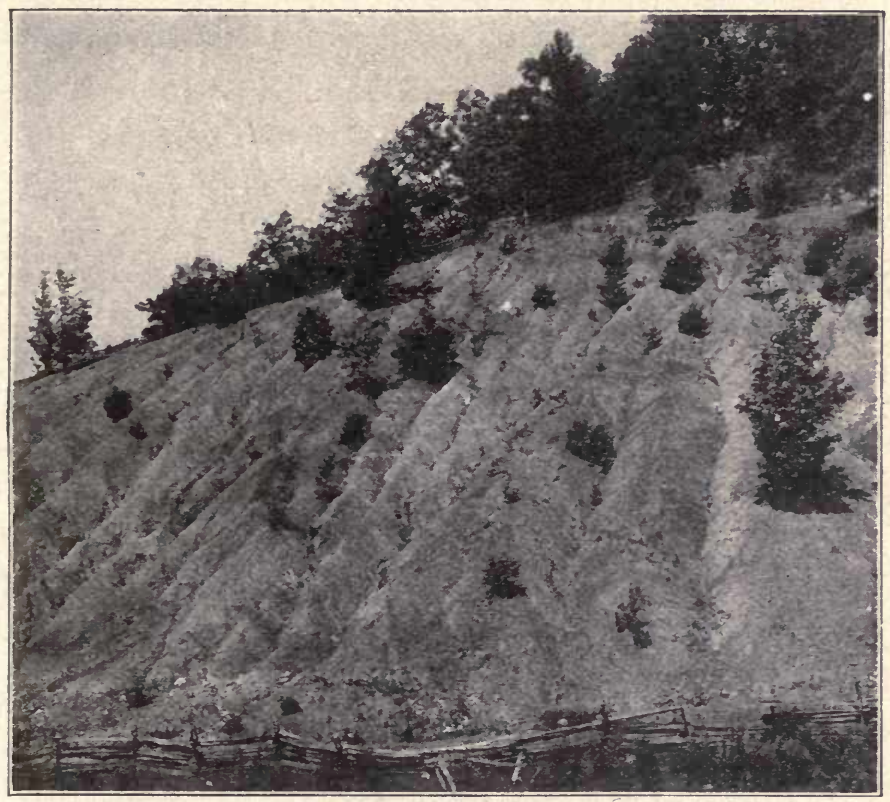

Permission of United States Forest Service.

PIG. 65. Gullies in a hillside formed by running water.

muddiness is caused by the rain carrying soil into the streams. With every rain more or less earth is discharged into streams; the total effect of rain erosion is enormous. Perhaps rain has had more to do with producing relief features than any other one agent. Its effect as an erosive agent is more notice- 
able in hilly and mountainous regions. The gullies and ravines cut in hillsides attest this fact. The fanlike deposits of soil often seen at the end of these gullies and ravines also give evidence of the power of rain in moving soil and earth. It has been estimated that the Mississippi Valley is lowered one foot every 5,000 years by this erosion. As the Mississippi Valley is considered to be an average one, this may be considered to be the average rate of erosion of the earth's surface. Add to this the solvent effect of rain water on the soil, and the total lowering is about one foot in 4,000 years. This impresses us with the fact that the continents are indeed on their way to the sea. Tennyson in his "In Memoriam" has written:

The hills are shadows and they flow

From form to form, and nothing stands:

They melt like mist, the solid lands,

Like elouds, they shape themselves and go.

\section{Questions}

1. Name and loeate on a map of the world the five great oceans.

2. What proportion of the area of the earth's surface do these oceans cover? What is their average depth?

3. Name and locate the continents.

4. Do mountain systems border oceans? Give examples to illustrate your answer. 
5. Name and locate the principal mountain systems in the United States.

6. What change takes place in the earth's crust to form mountains?

7. Which are older, the Rocky or Appalachian Mountains? How do they differ?

8. Name the principal industries in mountain regions.

9. What is a plateau?

10. Of what economic importance are the plains of the United States?

11. What are the principal sources of dust?

12. If sand is blown by a strong wind, what are some of the effects which it has on the earth's surface?

13. How are sand dunes formed? Why are they destructive to plant life? How can their migration be prevented?

14. Explain how rocks are broken off by changes in the temperature of the atmosphere.

15. Where is this effect most evident?

16. How is the earth's surface changed as a result of the chemical action of the atmosphere?

17. What is meant by erosion?

18. Explain fully why erosion is of great importance. 


\section{CHAPTER XXIII}

\section{STREAMS AND THEIR WORK}

Introduction. Rain that falls on the earth is disposed of in three different ways: part may evaporate; part may immediately run off into streams; part may sink into the ground. Of that which sinks into the ground a portion may gradually rise to the surface by capillary action and then evaporate; another portion may come to the surface as springs; still another portion may never appear again on the surface, but may find its way to the sea by underground passage.

Streams and stream erosion. Streams receive their water from several sources : rainfall, lakes, ponds, and melting snow and ice from mountain tops, as well as ground water.

We are all aware of the fact that streams carry sediment; in fact, it frequently appears that the principal work of a stream is to earry land into the sea. All streams are incessantly at this task of lowering their valleys to the lowest possible level. We can thus understand why streams are important factors in modifying the topography of the land.

The erosive power of a stream depends upon four 
conditions: first, the swiftness of the current; second, the volume of the water; third, the amount of sediment it carries; fourth, the character of the surface over which it flows. At flood time the erosive

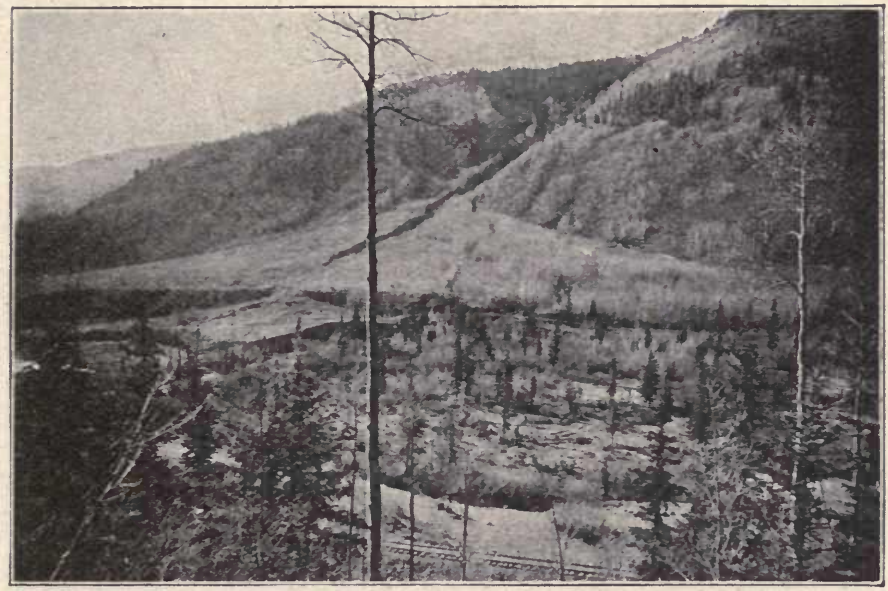

Permission of U. S. Geological Survey.

Fig. 66. Alluvial fan at the mouth of Aztec Gulch, southwestern Colorado. The deposit at the base of this slope is left by the running water when its velocity is suddenly checked.

power of a stream is greatest, for then it flows with greater velocity, as it has a larger volume of water. As a result, we find it carries much more sediment then than at any other time. This sediment in turn makes it possible for the stream to have a great erosive effect. By being rolled along the bed and against the banks, the sediment scours the bed deeper and broader. The carrying power of a stream varies as the sixth power of the velocity. If the velocity is doubled at flood 
time, it can carry stones sixty-four times as heavy as at the normal stage, for $2 \times 2 \times 2 \times 2 \times 2 \times 2=64$. Thus as the velocity of some mountain streams is increased many times during floods, we may easily account for

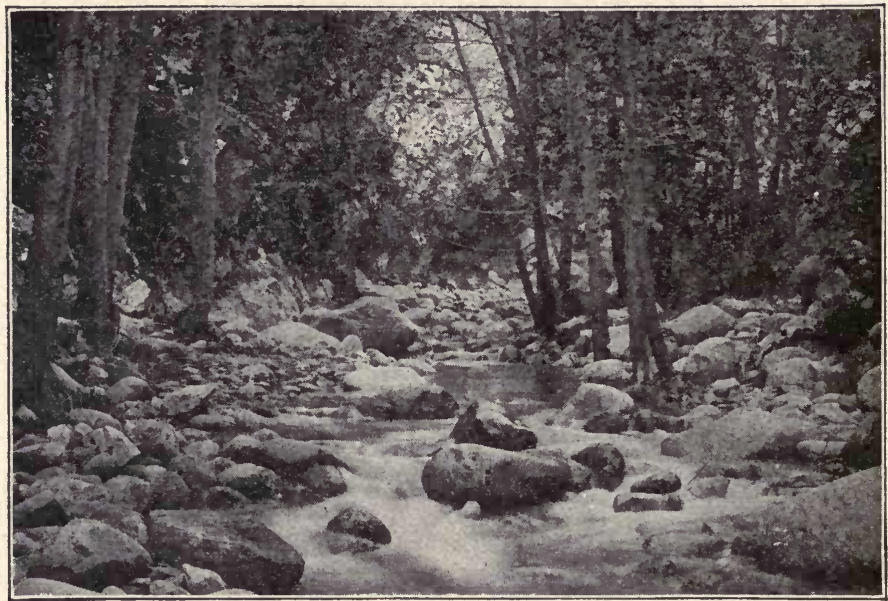

Copyright 7020 by Perry Pictures Co.

FIG. 67. Arroyo Seco River, Sierra Madre Mountains, Southern Stones serve as tools for cutting river beds deeper and broader. - In this process the stones become smooth and rounded.

the marvelous power that these streams exhibit in transporting enormous boulders great distances.

The amount of sediment carried by streams is enormous. It is calculated that the Mississippi River carries more than 1,000,000 tons of rich soil into the Gulf of Mexico every day. The yearly loss to the country of this soil is said to be about $\$ 500,000,000$. As this is a very serious loss, and in some parts of the country soil 
erosion is more rapid than soil formation, the problem of lessening soil erosion is one of the important tasks of conservation. It takes about 10,000 years to form one foot of residual soil; that is, soil that remains in the place where it is formed. The methods generally employed to prevent soil erosion are: first, deep cultivation of the soil allows the water to penetrate the soil and not to run off and earry the soil with it. Second, in hilly countries, plowing at right angles to the slope instead of up and down the slope saves the soil. The furrows check and hold most of the sediment. Third, covering the soil with regetation, as growing crops, prevents erosion. Fourth, growing grasses on the slopes tends to hold the soil. Fifth, planting forests on the steep slopes checks soil movement. Sixth, the building of terraces makes a series of level plains. This problem of soil conservation is an important one and should receive consideration by every land owner.

Stream development. A stream goes through three stages of development: youth, maturity, and old age. These terms, as related to streams, do not refer to years but rather to stages of development. Each stage has features that are characteristically its own. A river in youth has some or all of the following eharacteristics :

First, a young river bed has a steep slope. Enough time has not elapsed so that the stream has eroded its bed to a gentle slope. 
Second, it has a rapid current. The velocity of flow is largely determined by the steepness of the slope.

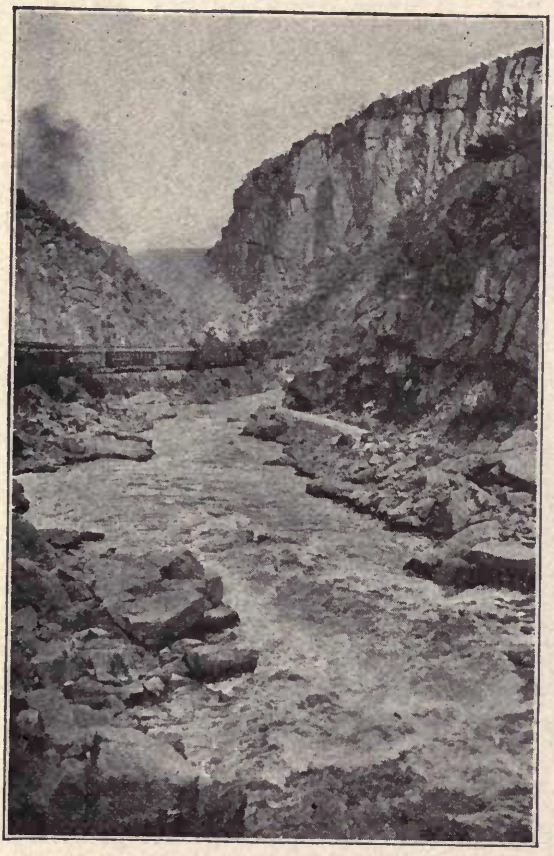

FIG. 68. A gorge cut by the Colorado River. A young river valley is narrow, its sides are steep, and the stream forming it is swift.

Third, its course is comparatively straight. When a stream originates, the drainage runs along the lowest level of the ground, which is usually a straight course. Streams have a tendeney to become more and more crooked as they grow older.

Fourth, young streams have narrow and $\mathrm{V}$-shaped valleys. The first work a stream has to do is to erode its bed to a low level; after the most of the downward erosion has been accomplished it begins eroding the sides. A V-shaped valley indicates very little lateral erosion; hence, it may be concluded that the stream is young.

Fifth, there is practically no flood-plain. By this 
- term is meant the low land along a stream that is flooded in time of high water. A flood-plain is formed by the stream widening its valley by erosion on the sides. If the stream has not lowered its bed to the level where lateral erosion can take place, it is in a stage of youth.

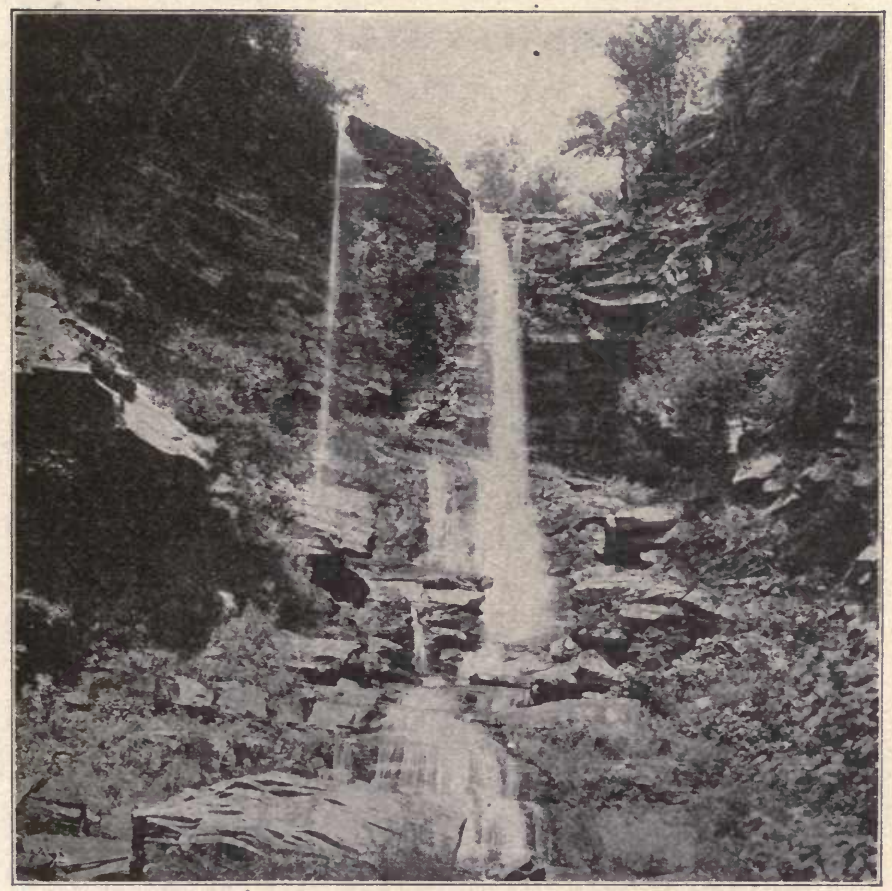

FIG. 69. Waterfall in Catskill Mountains, New York.

Sixth, waterfalls are frequent along the courses of young streams. To produce a waterfall there nust be a hard stratum of rock over which the stream is 
flowing; under this is a softer stratum. At Niagara Falls there is a solid compact layer of limestone at the top with softer shale underneath. The water falling over the falls wears away the soft shale. As this continues the limestone is left projecting; finally, this limestone breaks off and falls into the stream below. Thus the falls slowly recede up stream. At Niagara the rate of recession is about five feet per year. Falls may disappear from stream eourses: first, by the recession of the falls to the source of the stream; second, by bed erosion, entirely removing the hard strata. Then the falls may become rapids and finally disappear. Long periods of time are required to accomplish either of these results.

Seventh, lakes in the course of a stream indicate a period of youth. Streams are the enemies of lakes, and in two ways are working for their destruction. First, the outlet is being lowered by erosion. The level of the lake falls as erosion of the outlet proceeds. Second, the stream flowing into the lake brings sediment which is deposited in the lake, and thus fills it. Both of these forces at work finally eause the disappearance of the lake.

The Yellowstone, Upper Colorado, Snake, Green, and Grand Rivers are the best examples of young streams in this country.

Maturity. A mature stream has the following characteristics: first, the slope is rather gentle, as erosion has accomplished this; second, the current is not very 
swift; third, its flood plain has been formed by latera] erosion; fourth, its course is rather crooked, and winds back and forth across the flood plain; fifth, its valley is wide and its sides are not steep, the V-shaped val-

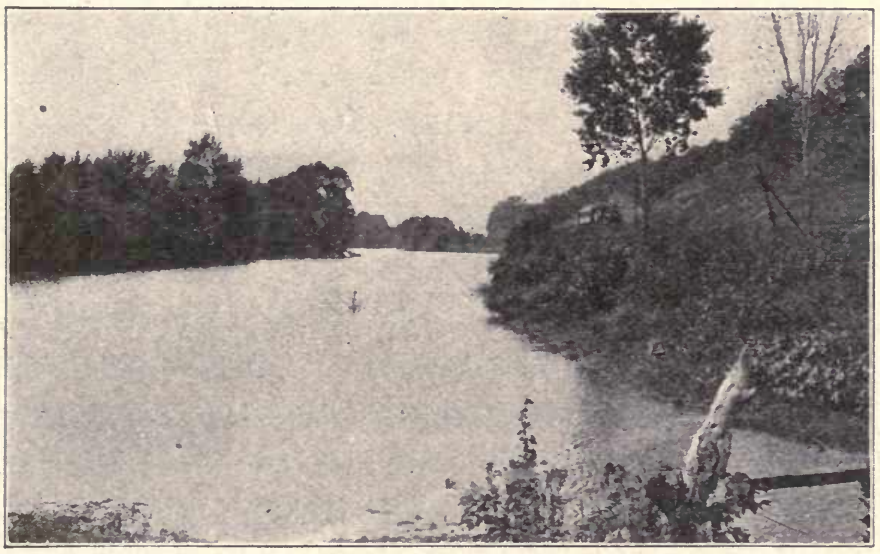

Photograph by Detroit Publishing Company. Fig. 70. A river in maturity.

ley of the young stream having disappeared by erosion; sixth, waterfalls are few, for most of them have been destroyed by erosion; seventh, unless the lakes were very large, erosion and sedimentation have caused them to disappear; eighth, a mature stream carries a moderate amount of sediment. The Middle Mississippi, the Ohio, and the Wabash Rivers show the result of these conditions.

Old age. In an old stream we find the influence of erosion still more marked: 
First, its bed has a very gentle slope. It has been eroded to base level, the lowest level to which a stream can erode its bed and still leave slope enough for the flow of water. Very few if any streams have reached this condition throughout their entire course.

Second, it has wide flood-plains. As this erosion in the bed is nearly finished, most of the erosion is on the sides. As a result of this action in some places the flood-plain of the lower Mississippi River is eighty miles wide. The most fertile land is found on flood-plains of rivers. Perhaps the most famous flood-plain of any river is that of the Nile, which for almost 7,000 years has supported a dense population. The flood plains of the Euphrates and Tigris are almost equally as famous, as it is thought the birth of civilization. occurred on the flood-plains of these rivers. The most extensive flood-plains in the world are those of the Ganges in India and the Hoang-Ho in China.

Third, an old river is very crooked. It meanders to and fro across the flood-plain, because the soft places have eroded more rapidly than the harder, and as a result there are hollows in the bank. The current is deflected by the hollow across to the opposite side where it cuts into the side. This deflection of the current back and forth across the stream finally. produces a very winding course.

Fourth, the valley of an old stream is wide, with very gentle slopes. 
Fifth, waterfalls, rapids, and lakes have been eliminated from the course of old streams by crosion.

Study the streams of your vicinity to determine to what stage of development they belong. As you travel from one part of the country to another study the streams in a similar manner.

Accidents to stream development. Streams meet with many accidents during their life history. Few streams, if any, go through their' entire development uninterrupted. Among the important accidents that may happen to stream development are:

First, the rising of the land. If the land rises just as rapidly as the downward erosion of the stream, it will remain at a constant stage of development. If the land rises faster than the downward cutting, the slope will become steeper and the current will be accelerated. Such a stream is said to be rejuvenated, as it is taking on the characteristics of youth.

Second, the subsidence of the land. If the land is subsiding, the slope becomes less steep and the current slower. Erosion in the bed is lessened but erosion of the banks is increased. If the subsidence is below base level, the stream will deposit sediment in its bed in an attempt to build the bed up to base level. When the subsidence of the land is below base level, water from the ocean or lake will flow up the stream and eover the valley, and in this way form a drowned river valley. Many rivers of the New England States, 
as well as the Hudson, the Delaware, the St. Lawrence, the Susquehanna, and the Potomac Rivers have drowned valleys. Some of the finest harbors in the world are drowned river valleys.

Third, the migration of the divide. A divide is a ridge or mountain chain dividing two river systems. If erosion on one side of the divide is more rapid than on the other, the divide will migrate in the direction of the least erosion. This may cause the streams on that side of the divide to disappear.

Fourth, glaciers. Glaciers sometimes make deposits aeross stream valleys, causing the formation of lakes or necessitating the stream's taking another course.

Streams as factors in human activities. From the beginning of history people have chosen to live near streams, probably because they found in them a means not only for producing food, but also for conveying themselves to other sections of the country. We find in the early history of the United States that all of the settlements were made on the coast and, commonly, near the mouth of a river. As the people travcled inland the navigable streams were the centers of greatest population.

The most of these navigable streams had floodplains which were, from time to time, enriched by the layers of sediment brought down in the water. The loss caused by destruction of property during these floods is usually equalled or exceeded by the benefit gained from the fertile layer of soil that is deposited. 
The people living in the flood-plain of the Nile depend upon the deposits made by the river during its annual overflow. As the flood-plain of the Mississippi is enriched in a similar way, it is important as an agricultural region.

Until the use of steam and electricity, streams were the most important means for travel. Even now the courses of rivers are followed in exploration of a new country. It is economical to transport by water many materials when time is not an important element, as transportation by water is cheaper than by railway. In hilly or mountainous regions railroads are always built along the water courses.

As the population of the country increases, so does the demand for food; this necessitates a larger area for growing crops. Rivers help in making this possible, as they are the main sources for irrigation purposes. The semi-arid lands of western United States, where not enough rain falls for agricultural purposes, are irrigated. The Government has under way thirty projects which will irrigate $3,000,000$ acres. This is about one-fifteenth of the amount of land that can be so developed.

Waterfalls and rapids furnish water power that may be used for manufacturing purposes. The available coal supply, in the United States is limited. As the age of coal formation is past, it is evident that the supply will some day be exhausted. When this time comes it will necessitate another source of power. At 
the present time, in the United States, about $26,000,000$ horse power is developed from coal and about $5,500,000$ horse power from water. The amount of water power capable of being developed by the streams of the country depends upon the condition of the rivers, whether they be at low or high water stage. It is estimated that the streams in their low water stage will furnish almost $40,000,000$ horse power. This is much more than the total amount generated now, but the demands for power will increase as the country. grows.

\section{Questions}

1. In what ways is the rain which falls upon the ground disposed of?

2. Upon what conditions does the erosive power of a stream depend?

3. How much sediment has it been estimated that the Mississippi River earries into the Gulf of Mexico every day?

4. Why is this considered a great loss to the country?

5. Suggest practical methods for preventing soil erosion.

6. Describe fully the stages through which a river passes in its development from youth to old age.

7. If possible, name and locate rivers which are examples of these different stages.

8. How do you account for the fact that Niagara Falls is receding? 
9. What is a flood plain? Give examples of flood plains.

10. Describe some of the accidents which occur to rivers during their life history.

11. What is meant by a drowned river valley? Give examples of rivers having such valleys.

12. How do you account for the fact that so many of our large cities are located on rivers?

13. Why are streams not of so much importance as a means of travel as they formerly were?

14. How can you account for the fact that railroads have so frequently been built along water courses?

15. Can you think of any objections tō having railroads along water courses?

16. About how many acres of land are now being irrigated in the United States?

17. If possible, ascertain the value of the crops grown upon this irrigated land.

18. To what extent is water power used in the United States for manufacturing purposes? 


\section{SOIL}

Introduction. Soil to most pcople simply means a layer of dirt covering the surface of the carth; something necessary perhaps, yet objectionable because of the dust that it produces in drought, and mud, in rainy weather. Yet this same dirt is one of the substances indispensable to all life. If a sample of soil be taken from almost any place on the surface of the earth and examined carefully, it will be found to be largely a layer of sand and clay mixed with more or less decayed animal and vegetable matter. This surface layer is less than one foot in depth over the greater portion of the earth's surface, yet in places it extends to a depth of several feet. Beneath the soil is a layer of more compact earth containing less of the decayed organic matter and usually lighter in color. This layer is called sub-soil and grades down gradually into the solid rock, called the bed rock, from which all soil originally came.

Origin. From $60 \%$ to $95 \%$ of the weight of ordinary soil consists of rock fragments. The fragments have come either from the layer of rock bed just below the sub-soil, in which case it is called residuary or seden- 
tary soil, or from the rock bed at a distance and brought down by running streams or other agents, and called drift or transported soil.

To produce soil many agents in nature are at work, the chief of which are water, wind, plants, and animals.

The wearing off of the rock by water and air is called weathering. The oxygen of the air combines readily with other elements in the rocks to form new compounds, which break away from the surface. This action is very similar to the rusting of iron. All are familiar with the small flakes of rust thus produced. Similar flakes are formed on the surface of the rocks. This is a slow process, to be sure, but in the course of the ages that this process has been at work, great changes have been effected. The air, as wind, sweeps up the smaller particles of sand and earth and whips them together and against the surface of projecting rock, thereby grinding the smaller particles finer and also wearing off the surface of the larger, harder rocks.

Water has great power of dissolution and dissolves the more soluble compounds out of the rocks, thereby weakening and eventually breaking them up into smaller pieces. Pure water dissolves but slowly, but all soil water usually has taken on carbon dioxide as it came down through the air, or acids from the soil or roots of plants, which make it a most powerful disin tegrating agent.

Wherever water seeps through the soil into the. 
cracks and crevices of rocks, it slowly but surely dissolves some of the more soluble compounds out of them, and carries them in solution to some other place.

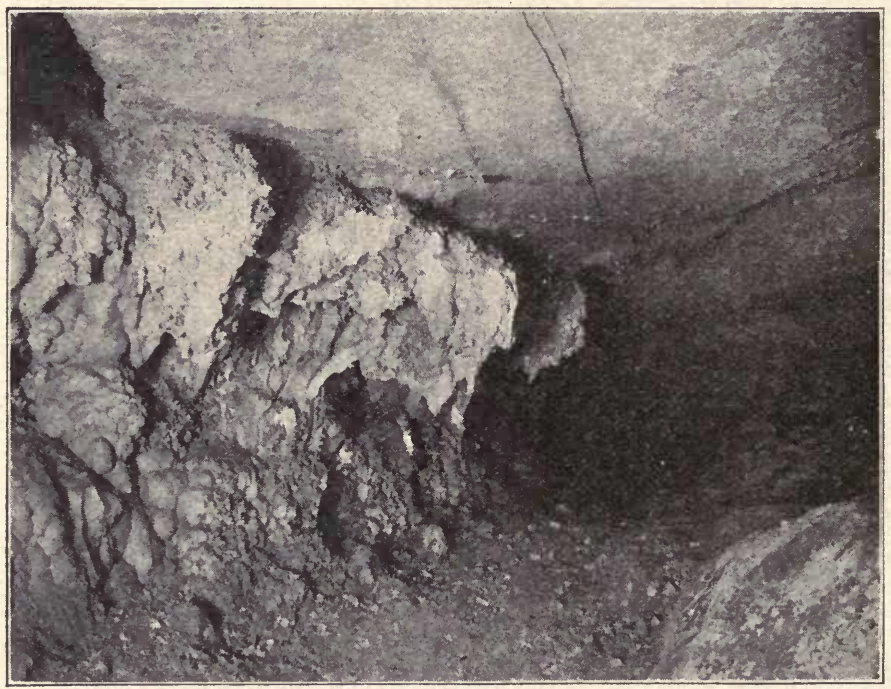

Fig. 71. Rock has been dissolved and carried away by water forming this underground channel. Water from a higher level slowly passes into this channel through cracks in its walls. As this water evaporates, deposits like those shown on the sides and top are left.

This is seen when the water comes to the surface again, as it does in a spring, which in some instances leaves a deposit of the dissolved minerals in a layer around its mouth.

The carrying power of water is an important factor in producing and transporting soils. With every rain some of the water "runs off" of the surface, carrying 
particles of soil and rock with it into the valleys and ravines. When the stream is swollen and the current swift, large rocks are carried, and as they are rolled along, they wear off the bottom and the sides of the

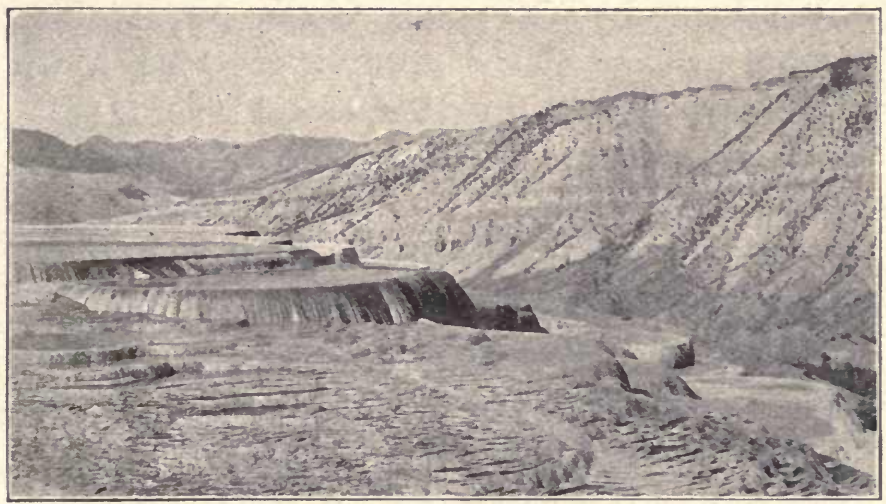

Copyright by Henry G. Peabody.

Fig. 72. Top of Jupiter Terrace, Yellowstone Park. Hot water carrying mineral matter in solution comes to the surface in the upper terraces. It then flows over the surface, and as it cools the mineral matter is deposited.

river bed, break off the edges of other rocks against which they strike, and grind the finer rock particles into the mealy powder which makes up the soil. As the current slackens it drops its load, the larger, coarser particles first, with the finer particles on top.

This may be seen on any bottom land after the floods have subsided. The frequent floods of these lands account for their unusual fertility. Rocks are further broken up by alternate freezing and thawing. The water which has been absorbed into rock freezes, and 
as the ice expands it eventually splits and crumbles the rock into many smaller pieces.

Kinds. Since the surface of the earth originally was solid rock and water, it is evident that soil is the product of decayed rock, together with the remains of decayed plant and animal life.

In the weathering of rocks we find two kinds of soil resulting. The fine, soft powder, or rock flour, is called clay; while the hard, loose, insoluble particles form sand.

Clay. Clay, when dry, is a powdery substance; when wet, it is sticky and plastic, and easily molded. It takes up water slowly and when thoroughly wet becomes compact and solid, difficult to cultivate and difficult for the roots of plants to penetrate.

It is equally slow to give up the moisture once absorbed. When thoroughly wet it is able to hold as much as $40 \%$ of its weight of water. Thus in wet weather it may hold too much water for good growth, while in drought it may bake and become too difficult for roots of plants to penetrate.

Air in the soil is necessary for plant life. Although clay is finely powdered and affords great pore space, because of the smallness of the spaces, air moves about in it with difficulty, aërating it but poorly.

Sand. Sand is made up of hard separate particles. It is loose and gritty, absorbs water readily, and gives it up just as readily. It often contains less than $5 \%$ of water. When wet the particles of sand are some- 
what loosely held together in a mass, and when dry it does not bake nor crack, but returns to its loose granular form.

The larger particles of sand afford larger spaces between their particles, thereby permitting air to circulate among them quite freely.

The roots of plants have no difficulty in penetrating sand, but because of the looseness of its particles and the ease with which they shift about, most plants are unable to get started in it. Thus sand alone is an unsuitable soil for plants. To verify this you need but recall the almost lack of vegetation on sand dunes.

The material in the soil which comes from the decay of organic matter is called humus, or leaf-mold. It is dark in color and makes up a large part of the soil of heavily shaded forests. The humus part of soil is very important. It teems with microscopic plant and animal forms so necessary in the soil to the life of green plants.

From the fact that pure clay is difficult for the roots of plants to penetrate and sand alone may shift too frequently for plants to become established, it is apparent that neither alone is an ideal soil for plants, though either may be abundantly supplied with the minerals and water necessary for plant life.

For most plants, the best soil is a combination of clay, sand, and humus.

A soil of equal parts of clay and sand with some humus is called loam. 
Based upon the proportions of sand and clay in soils, Dryer gives the following classification:

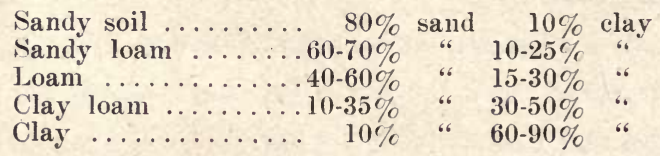

\section{Questions}

1. What is soil? Sub-soil?

2. What is the origin of all soil?

3. What is residuary soil?

4. What is drift soil?

5. What are the chief agents in the production of soil? Explain fully the work of each.

6. How do clay and sand differ?

7. Does either alone make a satisfactory soil for plants? Give reason for your answer.

8. What then is a good combination?

9. Give Dryer's classification of soils. 
CHAPTER XXV

\section{INTRODUCTION TO PLANTS}

Importance of plants. So far we have confined ourselves entirely to a eonsideration of the physieal sciences. In other words, we have studied the faets and laws dealing with things which are not living,inorganic matter. It is of equal interest and importance to know something about the living, organic things, plants and animals, including ourselves.

First, we shall study plants. To appreciate the importance of plants to man, let us consider the uses we make of them in our homes. Our houses are built, in part at least, of wood; the furniture in them is largely of wood; the fuel we burn, the food we eat, and much of the clothing which we wear are derived from plants. Thus we depend for shelter, warmth, clothing, and even for food upon the many green plants growing about us.

Neither should we forget nor underrate how much plants add to the enjoyment of life. Imagine for a moment that there were no green grass, no trees, no fruits and no flowers. What a dreary, desolate place the world would be!

A knowledge of the plant life about us is interesting 
and useful. Everything which we learn adds a new interest to our lives. Consider for a moment what you know about the plants which you see each day as you go to and from school. How do these plants live? Do they breathe? What kind of food do they require, and how does this food reach the topmost leaf on a large tree? To answer these and many other questions will afford you pleasure and satisfaction in your study of plants.

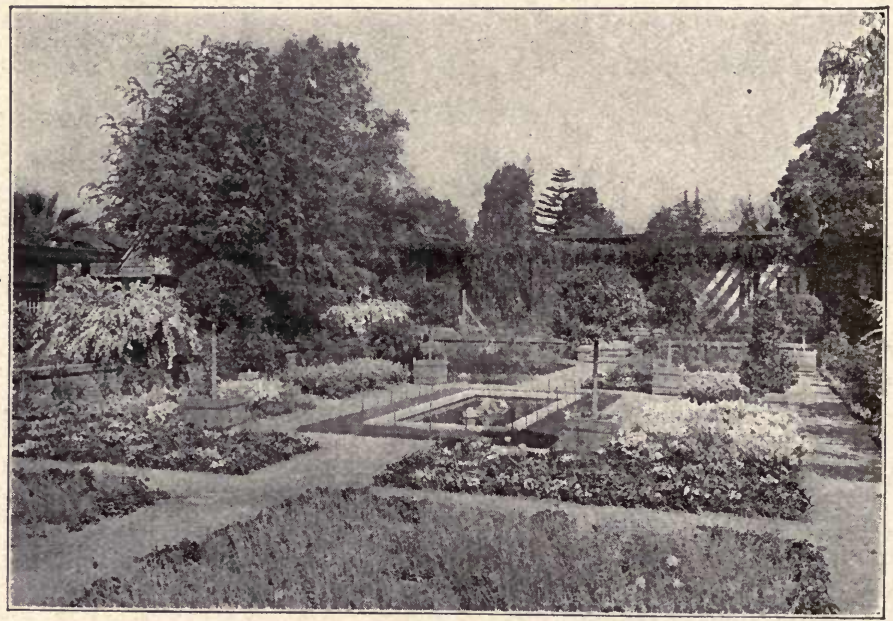

Photograph by Henry G. Peabody.

Fig. 73. A California garden.

The vegetation about us is abundant and of great variety. There are trees, shrubs, vines, herbs, mosses, ferns, mushrooms, and many other kinds of plants. They vary in size from our largest trees, over 300 fect high, to forms so small that they can not be seen without 
the aid of a microscope. But no matter what their size, form, or general structure is, they all require much the same conditions to live. Just as human life, whether in America, Africa, Japan, or Australia, depends upon food, air, and water, so plant life, too, depends upon food, air, and water.

In our study of plants we shall consider principally what they do, and how they do it. The work which any machine does is a direct result of the way in which it is constructed. It is necessary, for example, to know the structure of an automobile before it is possible to understand how it runs. Similarly we must know much about the structure of plants, before we can understand how they work.

Plants are composed of cells. Much life of which we are ordinarily quite unconscious exists about us. For instanee, if we examine under a mieroscope some scum taken from a pond, we shall find in it many small animals and plants. Among these will be found some of the simplest living things. Upon closer examination each of these small living things will be found to be round in outline and bounded on the outside by a thin membrane,

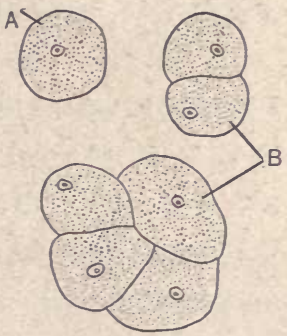

Fig. 74. Pleurococcus, a one celled plant. $A$, a single cell; $B$, clusters of cells. called the cell wall. Within this is a thin, watery substance somewhat granular in appearance, known as protoplasm. In the protoplasm is a denser spot, a more 
complicated structure, the nucleus. Protoplasm is the living part of the cell. These three parts, the cell wall, the protoplasm, and the nucleus, are the cell.

The simplest form of plant or animal life has only

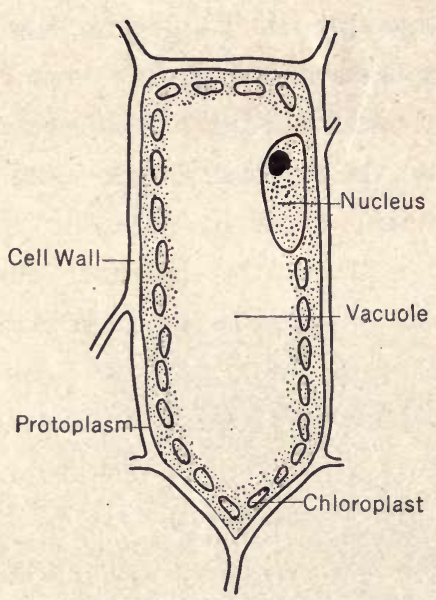

Fig. 75. Diagram of a plant one cell. Others have several cells grouped together, and still others consist of millions of cells. When a plant consists of but a few cells, these cells are very similar in strueture. However, when millions of cells are present,- as in trees, there is much variation in them. Some of them are of one kind and form the bark of the tree, others form the wood, others form tubes through which liquids travel, and still others are used to store food. Each group of similar cells is called a tissue. For example, wood is one kind of a tissue; the outer covering of a leaf is another kind of tissue; and bark is still another tissue. In all cases, while the plant is alive, the tissues are composed of cells which contain the living substance, protoplasm.

Composition of protoplasm. What is protoplasm? Exactly what is its composition? Why is it living? How does it grow? These and similar questions we can not fully answer. They still remain to us the un- 
answered riddle of life. We do know something about the chemieal composition of protoplasm. We know that it is a very complex compound; that is, it contains many elements. The chief elements are carbon, hydrogen, oxygen, and nitrogen. Sulphur, phosphorus, iron, potassium, calcium, silicon, and minute quantities of other elements are also found in its composition.

Properties of protoplasm. Although the living matter of which both plants and animals are composed is almost impossible of correct analysis, we do know that it possesses certain properties which inorganic matter does not possess. These properties are as follows:

1. Protoplasm grows. It has the wonderful power of taking in food material and then changing it from a non-living substance into living protoplasm.

2. Protoplasm breathes. It can take in oxygen with which it unites to produce the heat and energy necessary for movement and other activities.

3. Protoplasm can rid itself of waste materials. Substances, which are of no use to them, collect in organisms, and are, in turn, thrown off.

4. It is sensitive to influences, or stimulations, from without its own substances. Light, heat, electricity, and other stimuli will cause protoplasm to move.

5. Protoplasm can reproduce itself. Cells can divide and form other cells. Plants are constantly appearing to take the place of those that die:

Comparison of plants and animals. From observations, we are all familiar with many living organisms. 
Some of these we call plants and others animals. The question naturally arises: What are the differenees between these two groups of organisms? We have just learned that the difference is not one of composition, for in each the living substanee is protoplasm. The difference most evident. is in the relative powers of motion. Animals, we may say, can move from place to place, but plants ean not. This difference, however, does not hold, for some animals are attached and ean not move. The more common of such animals are corals and sponges. Motion is also present in plants. If a plant is placed in front of a window the leaves move toward the light; a root will move toward water; and the cells (spores) from which some plants are formed are eapable of swimming about as rapidly as some animals do.

The ehief difference between plants and animals is one depending upon the kind of food-materials which each requires. Plants, we already know, secure some of their raw food-materials from the soil. It is eommonly believed that they seeure most of their food supply from this souree, but this is not wholly correct. The plant takes water from the soil, and a very small part of the soil itself is used. The remainder of the materials required are supplied by the air in the form of carbon dioxide. Out of these raw materials, water, carbon dioxide, and small quantities of minerals from the soil, a plant is able to make its own food. An animal, on the other hand, can not make its food. 
From another point of view, we find that the differences between the food habits of plants and animals is not in the substances which they require, but in the way they secure them. Starch and sugar, for example, form an important part of both plant and animal food. The animal secures this starch from a plant or some other source in which it is all ready to be used. The plant, however, manufactures its own starch and sugar out of very simple substances, water $\left(\mathrm{H}_{2} \mathrm{O}\right)$ and carbon dioxide $\left(\mathrm{CO}_{2}\right)$. The parts of the plant in which the starch is made are the leaves.

\section{Questions}

1. What are the principal plants used by man for food? For clothing? For fuel?

2. Explain other uses of plants to man in addition to the uses for food, clothing, and fuel.

3. May a knowledge of plants be of any value to you apart from its value in making a living?

4. Name the trees with which you are familiar.

5. When do the leaves first appear on these trees?

6. Name the wild flowers you have noticed.

7. What is the largest plant which you have seen? The smallest?

8. What are the three things necessary to plant life? Are they also necessary to your life?

9. What is a cell? What are its parts?

10. What is a tissue? Give examples.

11. What is known about the composition of protoplasm? State five properties of protoplasm.

12. Explain fully the chief differences between plants and animals. 


\section{CHAPTER XXVI}

\section{LEAVES}

Structure of leaves. It is necessary to know something about the structure of leaves in order to understand the method by which they carry on the processes which make them such important parts of plants. You

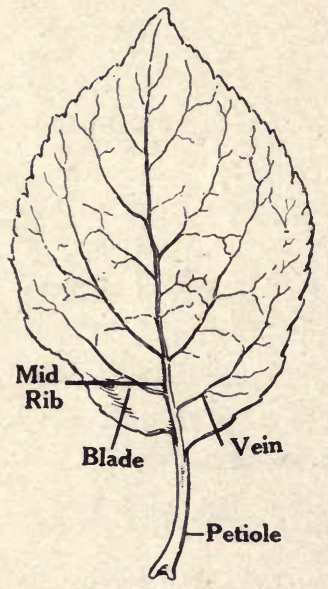

Fig. 76. Apple leaf, net-veined. already know that a leaf has a broad part of green color, the blade. Most leaves also have a stem-like part, the petiole. Sometimes two leaf-like parts, stipules, are present at the base of the petiole. The blade may take almost any conceivable shape, but it is always strengthened by a framework of $t u b e s$ called veins. These veins are continuous with tubes passing through the petiole and down through the stem of the plant into the root. Veins

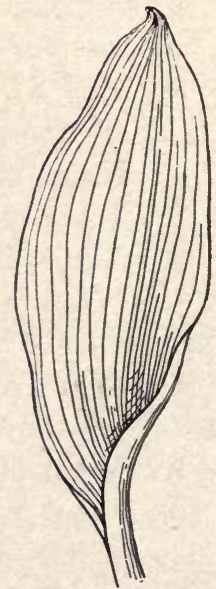

Fig. 77. Leaf of lily-of-the. valley, parallelveined. 
usually present a netted appearance, but in some leaves, such as those of lilies and grasses, they run in somewhat parallel lines.

When examined under a microscope, each leaf is found to be composed of an almost countless number of cells, which vary in structure and in use. The outer surface, or epidermis, of the leaf is composed of large irregular-shaped cells. The interior of the leaf is filled between the veins with loosely arranged cells forming what is known as the mesophyll. The epidermis,

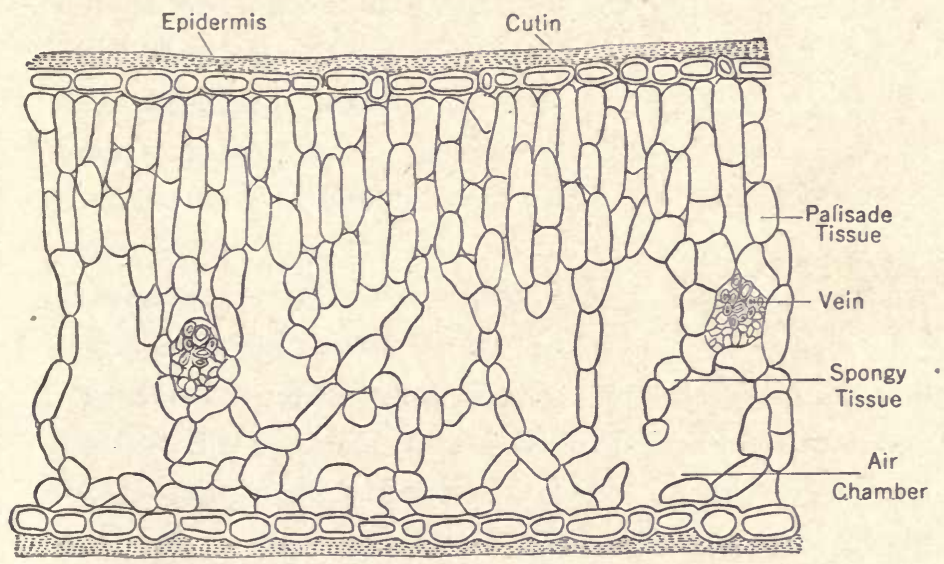

Fig. 78. Cross section of a leaf of a barberry showing the internal structure.

although frequently very thin, serves as a protection to the mesophyll, which is easily crushed and dies quickly when the epidermis is removed. In the epidermis, on the under surface of the leaf, there are a number of tiny oval openings. These are called 
stomates. (The Greek word stoma means mouth.) On each side of a stomate there is a kidney-shaped cell called a guard cell. The shape of these cells can be

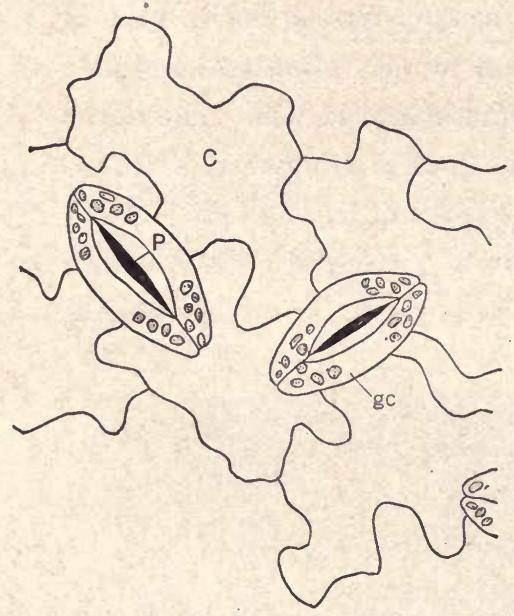

Fig. 79. Epidermis of a leaf of geranium showing stomates; $c$, cell;
$p$, opening of stomate; $g c$, guard cell.

changed and in so doing the openings into the leaf can be made smaller or larger. It is not exactly clear of just what service this is to the leaf. There are thousands of stomates on each leaf, usually only on the under surface. Gases pass in and out of the leaf through the stomates. A crossseetion of a leaf shows that, immediately below the epidermis, there is a row of green cells closely packed together. Below these are the large, green, loosely-arranged cells of the mesophyll. The stomates open directly into the spaces, air chambers, formed between these cells.

Chlorophyll. Some things in nature are so common that we do not stop to study them; we take them for granted. We know that most plants have a great many leaves and that these leaves are green. We perhaps have never considered the nature or importance of this green color. Inside of all the cells of the leaves, 
except those of the epidermis, there are a number of green colored bodies called chloroplasts. They are principally composed of protoplasm by which a green substance, chlorophyll, is manufactured. (Chloron, green; phyllon, leaf.) The chlorophyll gives the green color to the chloroplast. It is upon the presence of this substance that the most important work of the plant depends, and upon that work all life, including our own, depends. Think of the significance of this fact.

Food making. We have already stated that a plant uses as a part of the raw materials, from which to make its food, earbon dioxide and water. Out of these inorganic materials leaves can manufacture starch; this is their principal function. The water is obtained from the soil and passes up through bundles of tubes from the roots to the veins of the leaves. Carbon: dioxide from the air enters through the stomates. The carbon dioxide and water are then combined to form starch or sugar. Starch and sugar belong to a group of foods known as the carbohydrates, which are composed of carbon, hydrogen, and oxygen. They always contain twice as much hydrogen as oxygen. To form carbohydrates from the raw materials we know that chloroplasts and light are essential. By means of protoplasm and chlorophyll, chloroplasts absorb energy from the sun's rays. With this energy, the chloroplasts are able to break the compounds, water and carbon dioxide, into carbon, hydrogen, and oxygen, the elements of which they are composed. These three ele- 


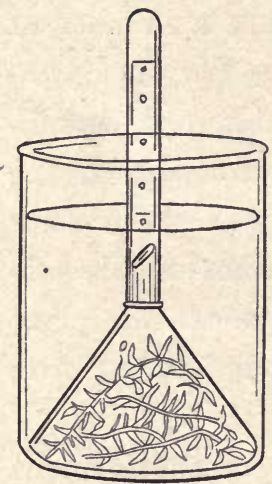

Fig. 80. Experiment to show that oxygen is given off by green plants in the sunlight.

ments then immediately unite and finally form sugar and starch. The exact chemical processes which this involves are not completely known. Carbohydrates contain twice as much hydrogen as oxygen. Carbon dioxide $\left(\mathrm{CO}_{2}\right)$ and water $\left(\mathrm{H}_{2} \mathrm{O}\right)$ contain only two parts of hydrogen for every three of oxygen. Consequently there is an excess of oxygen in this process. This oxygen is given off as a byproduct. The process of starch-making may be expressed with the following chemical equation :

$$
\mathrm{N}\left(6 \mathrm{CO}_{2}\right)+\mathrm{N}\left(5 \mathrm{H}_{2} \mathrm{O}\right)=\mathrm{N}\left(\mathrm{C}_{6} \mathrm{H}_{10} \mathrm{O}_{5}\right)+\mathrm{N}\left(6 \mathrm{O}_{2}\right)
$$

Carbon dioxide + water $=$ starch + oxygen

On bright days starch is formed very rapidly. During the night this food is transformed into soluble forms and then moves from the leaf to other parts of the plant. Much of this is stored away in the form of starch in such parts of plants as the seeds of cereals, grains, fruits, potato tubers, etc. From these all animals derive food. Upon this starch-making process of the green plants all life is dependent for the ultimate source of food. Carbohydrates make up a very large part of the food of all animals. Indirectly the meat which we eat is derived from these carbohydrates made by plants. Beef, for example, is procured directly from 
cattle, but they in turn feed upon various kinds of plants or parts of plants.

Food storage. We frequently think of potatoes, carrots, onions, radishes, sweet potatoes, beets, fruits, seeds, etc., as food for ourselves. No doubt it has never occurred to most of us that these parts are of real use to the plants on which they are formed. As food is manufactured by the plant it is disposed of in either of two ways. It may be used immediately for repair and growth, or it may be stored and some of it may subsequently be used by the plant.

Food may be stored in almost any part of the plant, but in many plants this storage takes place in parts underground, either roots or underground stems. Such parts are the beet, turnip, carrot, parsnip, radish, onion, potato, and sweet potato. This stored food is often consumed by the plant for growth during the early part of the following season. Seeds and fruits also serve as places for food storage. Small plants depend at first for their growth upon this reserve food in the seeds from which they were produced.

Because of the great amount of food present in potatoes, carrots, etc., and in all kinds of seeds, such as wheat, corn, rye, oats, and in fruits, these parts serve as the most important articles of food for men and other animals. These food storage parts are used directly or else products are manufactured from them, such as oatmeal, cornmeal, flour, corn starch, and tapioca. The economic importance of plants in trades 
and industries can scarcely be estimated. The accompanying table will be of some value in helping you to appreciate their importance:

Value of Crops in the United States in 1909 *

\begin{tabular}{|c|c|c|c|}
\hline Crop & Value & Crop & Value \\
\hline All crops. & $\$ 5,487,161,223$ & Fruits and nuts. & $\$ 222,024,216$ \\
\hline Cereals .. & $2,665,539,714$ & Strawberries. & $17,913,926$ \\
\hline Corn & $1,438,553,919$ & Blackberries & \\
\hline Oats .. & $414,697,422$ & and dewber- & \\
\hline Wheat & $657,656,801$ & ries & $3,909,831$ \\
\hline Other grains and & & Orchard fruits... & $140,867,347$ \\
\hline . seeds $\ldots$. & $97,536,085$ & Apples ....... & $83,231,492$ \\
\hline Dry beans.. & $21,771,482$ & Pears & $7,910,600$ \\
\hline Dry peas..... & $10,963,739$ & Cherries & $7,231,160$ \\
\hline Peanuts. & $18,271,929$ & Grapes & $\cdot 22,027,961$ \\
\hline Cotton and cot- & & Nuts & $4,447,674$ \\
\hline $\begin{array}{l}\text { ton se } \\
\text { egetables }\end{array}$ & $824,696,287$ & & \\
\hline $\begin{array}{l}\text { egetables } \\
\text { Potatoes }\end{array}$ & $\begin{array}{l}418,110,154 \\
166,423,910\end{array}$ & & \\
\hline
\end{tabular}

*Thirteenth Census of the United States, 1910.

Other foods manufactured by plants. Other foods, proteins, are manufactured by the plants from the carbohydrates and the various substances which come up from the soil. These mineral substances, which are dissolved in soil water, are called solutes. Proteins contain carbon, hydrogen, oxygen, nitrogen, and in addition small quantities of many other elements. These are all combined to form a very complex compound which is more like protoplasm than any other nonliving substance. We do not know how plants manufacture proteins. They appear to add nitrogen and other substances from the soil to the carbohydrates. We have before referred to the fact that it is essential 
that the soil contains soluble nitrogen compounds (see page 103). We now know the use of this nitrogen.

Uses of food. You know that to live you must have food. You know, too, that this food must be digested and taken to all parts of your body. There it must be changed from non-living into living material to be used for growth, repair, or oxidation to produce heat and energy. In order to make this possible, you need air as well as food. In connection with the changes which take place in the wearing out and the building up of parts of the body and in the formation of energy, certain waste substances are formed. These are harmful to the body and must be gotten rid of. The entire process necessary to keep you alive is known as the process of nutrition.

A plant, likewise, must carry on this process of nutrition. From carbon dioxide from the air, water, and solutes from the soil, and energy from the sun, the plants make their own food. After they have manufactured their food they are then ready to take up the processes of nutrition just where we do after food is eaten. Their food must be digested. By that we mean that it must be transformed into soluble form so that it can be transferred to all parts of the plant. A wonderful process then takes place. This digested food is made into protoplasm. The exact nature of the chemical processes which this involves we do not know, but in some way this non-living food material is made into living protoplasm. Evidently this process can be 
carried on only by living material, for man has never succeeded in producing living from non-living material.

Transpiration. Water plays an important part in the life of plants. It is the most important single factor which determines the way plants grow and where they grow. All plant activity depends upon its presence in considerable amount. Although there is great and continual need of water, and although frequently the supply is inadequate, still there is always an enormous loss by way of the surface of the leaves. This evaporation, or passing of the water from the leaves,

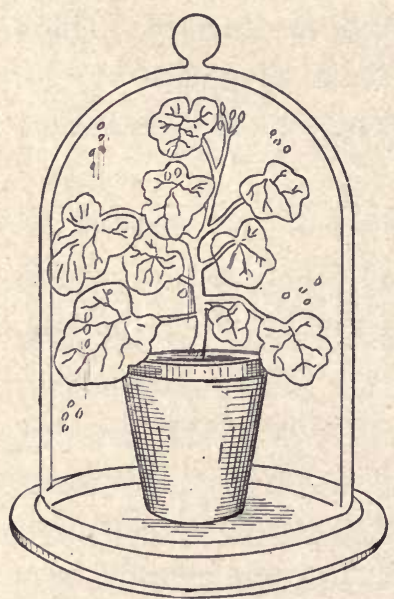

Fig. 81. Experiment to show transpiration. The wat e r w h c h evaporates from the leaves condenses on the inside of the belljar. is known as transpiration. Since this water passes off in the form of a gas, we are usually not aware that water is constantly evaporating from the leaves of plants. There are several ways, however, by which this can be demonstrated. When a potted plant, the pot of which has been carefully wrapped in sheet rubber to prevent the escape of moisture, is placed under a belljar, within a few hours drops of water collect on the inside of the belljar. The amount of water lost by a plant can be determined by weighing a potted plant, so covered that no moisture can escape 
from the pot. If the area of the leaves is then ascertained, it is possible to know how much water is evaporated per day, per square inch. It has been estimated that a sunflower plant transpires about a quart of water on a warm day. A tree transpires a great quantity of water, in some cases as much as $\mathbf{1 7 5}$ gallons a day. The grass on an average city lot will distribute to the air at least half a ton of water in twentyfour hours.

Disadvantages of transpiration. The disadvantages to the plant of this great loss of water are very evident. From personal observation, you know that many plants die because of lack of water, which evaporates from them more rapidly than they can replace it. This excessive loss of water is the greatest danger to which plants are exposed, and it renders necessary constant provision for water in the soil where plants grow.

Advantages to plant. There is a difference of opinion as to the advantages of transpiration in plants. Recent experiments indicate that this process of evaporation cools the leaves and thus prevents them from being overheated. Water passing out of the leaves makes it possible for more water to enter at the roots. As a result, there is a stream of water passing through the plant constantly, entering through the roots and going out through the leaves. This is known as the transpiration current. Entering the roots with the water are solutes, mineral substances in solution. These solutes must pass from the roots to the leaves, a 


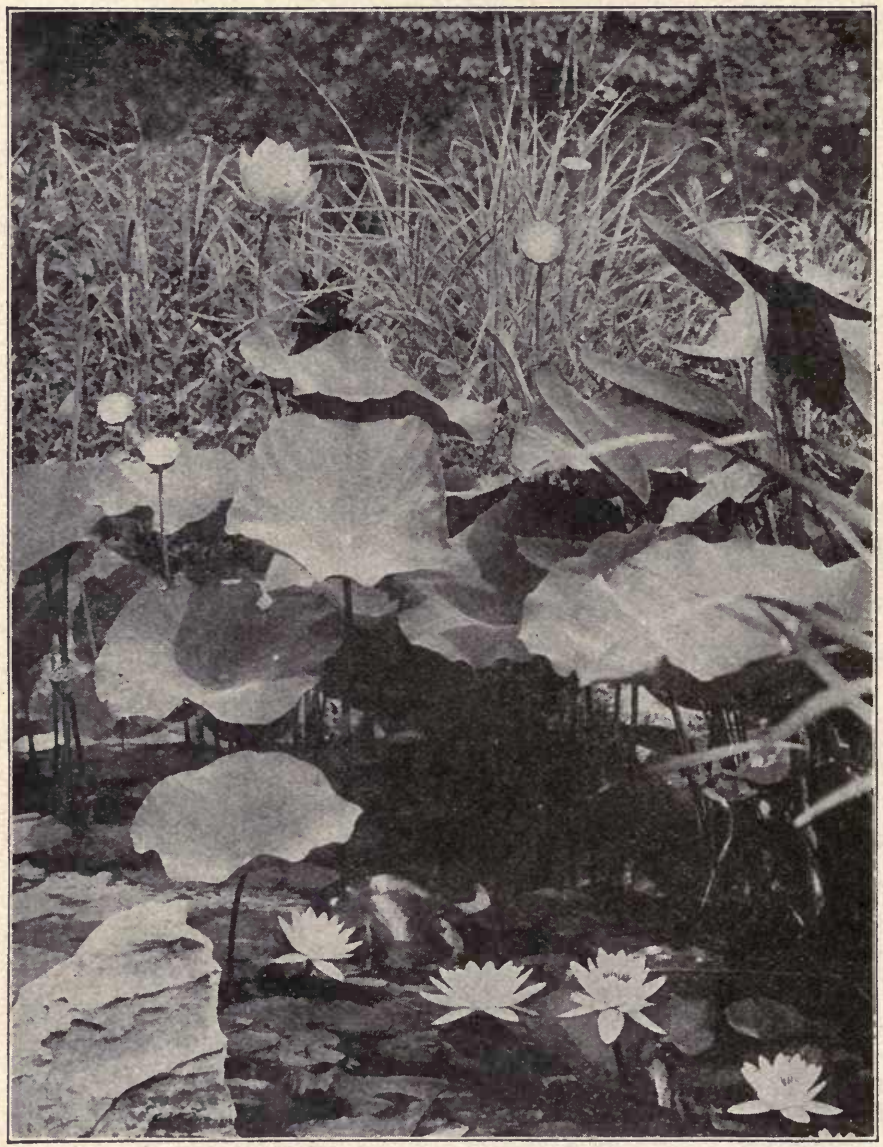

Fig. 82. An artificial water-lily pond.

distance in some cases of hundreds of feet. When passing through living parts of the plant, these solutes pass from one cell to the next by diffusion. In the larger plants the water and solutes are carried part 
of the way through tubes which are dead. In such regions the solutes are carried along in the water, the movement of which is partly due to the fact that a constant stream is kept up because of the evaporation taking place at the surface of the leaves.

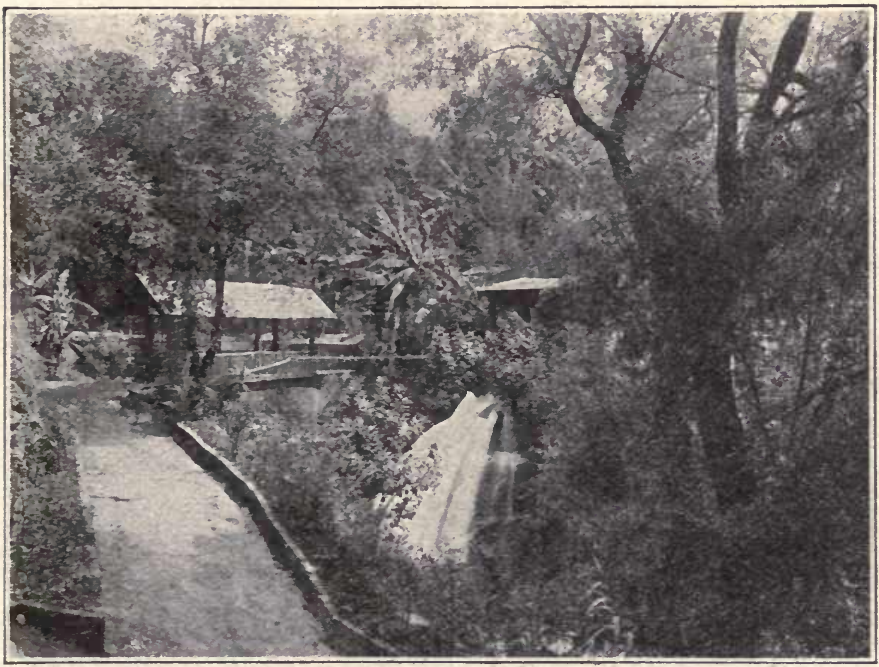

Photograph by Henry G. Peabody.

Fig. 83. Conditions in a moist, semi-tropical forest.

Habitat dependent on water supply. The conditions upon the earth's surface favorable for plant life are very diverse. Plants, as a result, become grouped according to the conditions favorable for their growth, forming so-called plant associations or plant societies. These associations are determined by combinations of conditions such as light, temperature, and water. Perhaps the most important single condition is water. 
The amount of available water varies from a very small supply in deserts to the abundant supply in swamps and lakes. The character of the soil also has a very important effect on the water supply. Some soils retain water and others do not. The structure of the plants varies according to the water supply. Plants living under water differ greatly from those living on land.

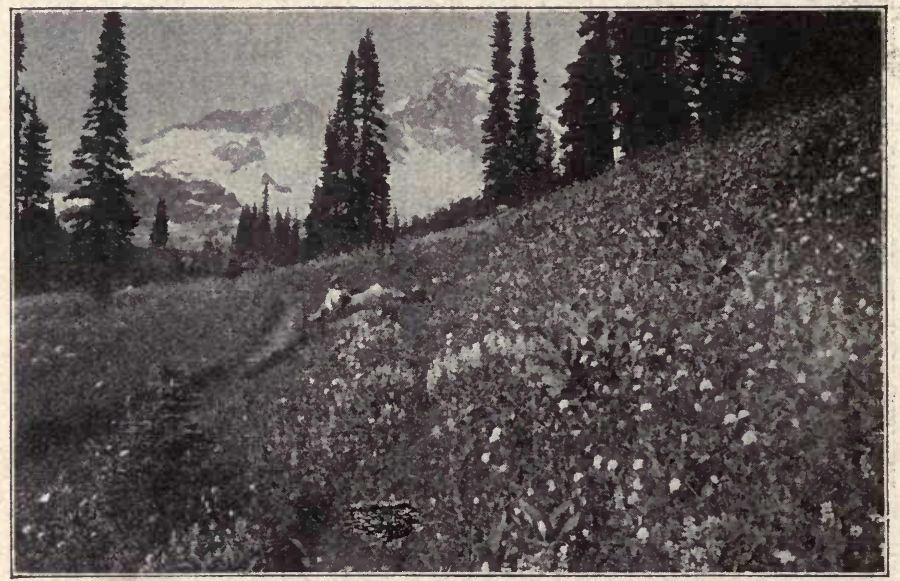

Permission of Chicago, Milwaukee and St. Paul Railroad. Fig. 84. Type of vegetation found on a mountain slope.

Those which are so constructed that they lose a great amount of water can live only under conditions where the supply of water is equal to the loss. In some regions plants must store water to tide them over long periods of drought. This is especially true of desert plants, some of which, such as cactuses, when cut open, give out enough water for men and other animals to 
drink. In many such plants the stems or roots are greatly swollen and contain large quantities of water. Leaves also serve as organs for water storage. The thick leaves of century plants are good examples of this kind of leaf.

Protection against loss of water. Plants have many methods of protection against excessive loss of water. One of the most evident methods is in the reduction of the size of the leaves. Plants such as the heaths, which live in very dry soils, have very small leaves. In some desert plants, such as cactuses, the leaves.

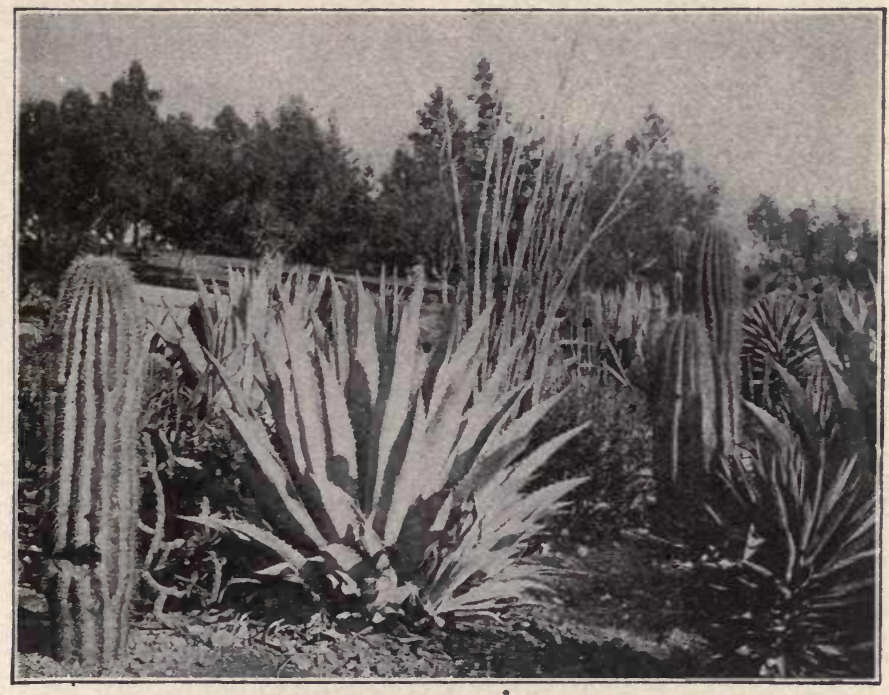

Fig. 85. A group of cactus plants.

are practically wanting. Evaporation is frequently retarded by modification of the epidermis of the leaves. 
The outer portion of the cell walls contains a cork-like substance which is waterproof. The surface of the leaves of some plants is covered by a film known as the bloom. If this is removed, evaporation takes place much more rapidly. You have probably noticed this bloom on some leaves such as the tulip, and certainly on fruits like grapes and plums. Sometimes the leaves are covered with soft hairs. In some instances, as the mullein, these hairs are very numerous. They are also numerous on very young leaves. This is especially evident on young fern leaves. These hairs are known to retard evaporation.

Stomates serve to admit air to the interior of the leaf, and they also allow moisture in the form of vapor to pass out. By changes in the guard cells, the stomates of many plants may be opened and closed. When they are open, the gas exchanges necessary for food-making are facilitated. This condition, however, also increases transpiration. The presence of stomates only on the under surface of most leaves is probably an advantage in reducing transpiration. On leaves which stand erect, as grasses, they are almost equally distributed on both sides, and on those which lie on the surface of the water, as the giant water lily, they are present only on the upper surface.

Many plants shed their leaves at the beginning of a cold or a dry period. This is, no doubt, of great advantage to the plant because it results in an enormous reduction of transpiration. Plants which have the 
habit of shedding their leaves are called deciduous. In temperate regions all plants, except the few evergreens, shed their leaves in the autumn. As soon as the temperature of the soil is at the freezing point, the plant can absorb very little water. When the time comes for shedding of leaves a special layer of tissue is formed at the base of the petiole. This tissue gradually cuts the leaf off and at the same time covers the wound which is produced. The brilliant coloration of autumn leaves is closely associated with the changes which take place in the

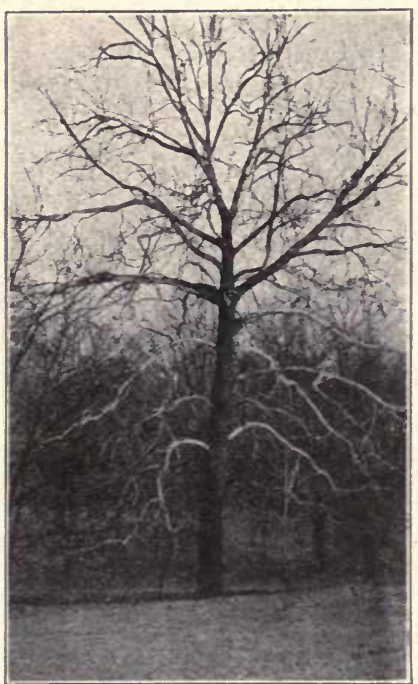

Fig. 86. A sycamore tree in winter condition.

\section{leaves previous to their}

removal. The food materials are withdrawn from the leaf before it is shed, and the gradual-reduction of the activity of the leaves and the breaking-down processes which take place in the dying leaf produce the brilliant colors. These processes may be caused by frost, but not necessarily so.

Respiration. All living things require oxygen. A plant takes in oxygen largely through the stomates of the leaves, but this function is not limited to the leaves. 
To a less extent oxygen is also taken in through the stems. The oxygen, after entering the plant, passes by diffusion to all parts of the plant, where it is used to decompose the complex protoplasm, or perhaps food materials, into simple substances. Just what ehemical processes this may involve we do not know, but oxygen is consumed, complex plant substances are broken down, and, as a result of this decomposition, energy is released. By means of this energy plants are enabled to perform their work. This process results in the formation of various simple compounds, chief of which are earbon-dioxide $\left(\mathrm{CO}_{2}\right)$ and water $\left(\mathrm{H}_{2} \mathrm{O}\right)$. These are waste products, and they are passed off through the same organs that take in oxygen.

This proeess in plants (also animals) in which oxygen combines with the living tissues and releases energy is known as respiration. It should be kept distinctly in mind that the exchange of gases in respiration in plants is exactly the same as that in animals. It was once customary to contrast plants and animals by stating that the former took in $\mathrm{CO}_{2}$ and gave off $\mathrm{O}$, while the latter took in $\mathrm{O}$ and gave off $\mathrm{CO}_{2}$. This confusion arose beeause the processes of food-making and respiration in plants were not fully understood. In bright sunlight the process of food-making takes place so rapidly that it masks the process of respiration. As a result, plants in breathing were supposed to use $\mathrm{CO}_{2}$ and to give off $\mathrm{O}$.

Air storage. In most plants there is an abundant 
supply of oxygen for respiration, and of carbon dioxide for carbohydrate synthesis. In stagnant swamps and undrained ponds, however, the oxygen supply is often very scant. In plants living under such conditions there are frequently present in the interior of the plant extensive air chambers for storing air. By means of this “inner atmosphere," respiration and carbohydrate synthesis are much aided when air is not available. In water plants those air spaces make the plant buoyant. In the water hyacinth, for example, the large air spaces in the petioles make the plant so light that it floats. Many sea weeds are buoyed up by so-called air bladders.

\section{Questions}

1. Name the parts of the outside of a leaf.

2. What is the structure of the inside of a leaf?

3. What are stomates? Where are they found? How numerous are they?

4. What is the function of stomates?

5. What is chlorophyll?

6. Is chlorophyll of any importance to us?

7. What are the raw materials used by plants for the manufacture of carbohydrates?

8. Under what conditions are these raw substances combined to form carbohydrates?

9. What is the waste product in this process?

10. Why is this process of so much importance to animals?

11. In what parts of plants is food stored? 
12. When is this food used by the plant?

13. Is this stored food of any value to us? Explain in what ways it is of value.

14. How does the composition of proteins differ from that of carbohydrates?

15. What are solutes?

16. Explain what is meant by the process of nutrition.

17. Is it necessary for plants to digest their food?

18. Define transpiration.

19. State the disadvantages of transpiration.

20. State the advantages of transpiration.

21. Describe the general relation of plants to water.

22. How do plants living in water differ from those living in a desert?

23. What are the principal ways in which plants are protected against loss of water?

24. Is the loss of leaves in the autumn of any advantage to plants?

25. What causes the brilliant colors in leaves in the autumn?

26. Why is it necessary for plants to breathe?

27. What are the waste products formed in the process of respiration? Where are they given off from the plant?

28. How does the exchange of gases in respiration in plants compare with that in animals?

29. Name plants in which air is stored. 


\section{CHAPIER XXVII}

\section{ROOTS}

Function. By roots we generally mean that part of the plant which is underground. This position at once suggests the most obvious use of roots, that of anchoring the plant. The fact that a plant will not grow unless the roots are placed in suitable soil, which must be kept moist, suggests a

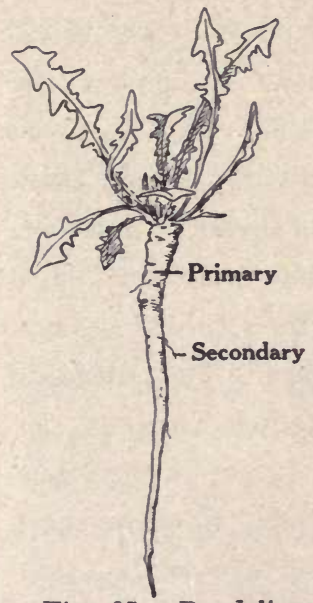

Fig. 87. Dandelion showing a tap root.

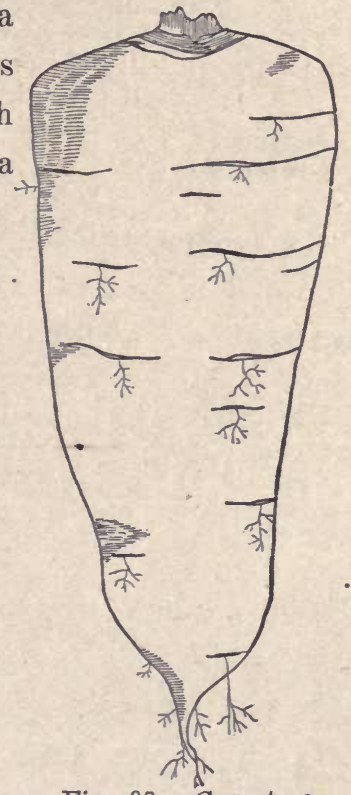

Fig. 88. Carrot, a fleshy tap root.

second important function for roots; namely, to absorb from the soil water and substances in solution. 


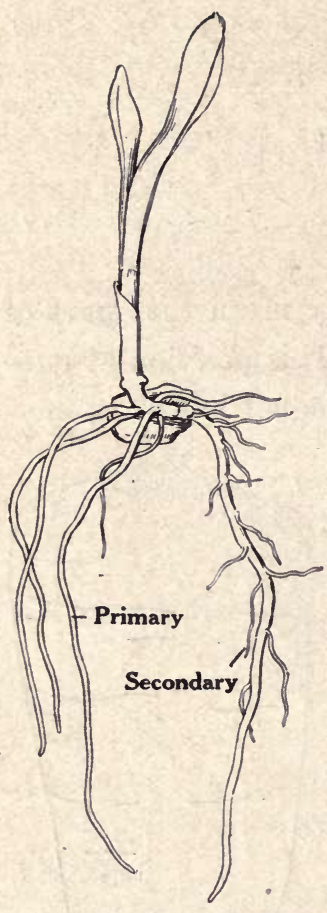

Fig. 89. Seedling of corn showing fibrous roots.

Structure. In many plants the root system contains one main root much longer than any of its branches. This is called a tap root. Frequently food accumulates in this main root forming a fleshy tap root such as the carrot, radish, dandelion, beet, or turnip. Some plants have no single main root, but many smaller roots arising from the same point. These are known as fibrous roots, examples of which are found in all the grasses. Sweet potatoes are thickened fibrous roots. The part of the root near the stem may be large and stout and covered with a thick bark. The branches, however, gradually become smaller, more slender, and with a thinner covering, or epidermis. The ultimate branches give rise to many very delicate organs, the root hairs. When a plant is pulled out of the ground, the root hairs are generally broken off. Each of these very numerous hairs is an extremely thin walled tube which opens into the cell of the epidermis from which it arises.

Absorption of water and solutes. If we recall the amount of water transpired by plants, we can form 


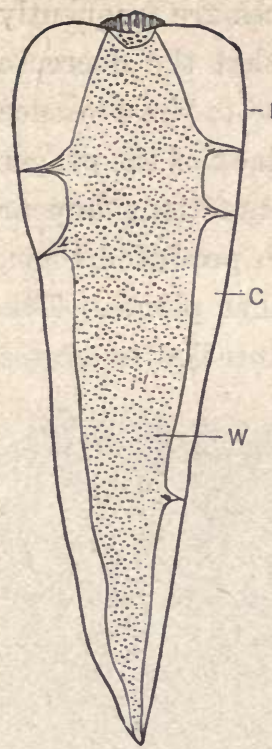

Fig. 90. A lengthwise section of a carrot showing the internal structure; $E$, epidermis ; $C$, cortex; and W' woody part.

some estimate of the amount of water which enters the roots of plants each day. This absorption of water takes place chiefly through the root hairs. The soil water contains all the substances which it can $d$ is s olve from the earth through which it passes. This water with these solutes then diffuses through the thin walls of the root hairs. We have already learned that some liquids will diffuse through an animal membrane even though there are no

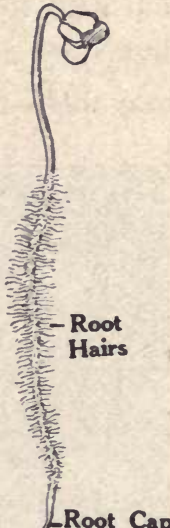

Fig. 91. Radish seedling grown in moist air to show the root hairs. visible pores in the membrane. In exactly the same manner as the molecules of molasses and water diffused through the animal membrane (See Exercise 5), the soil water and solutes pass through the walls of the root hairs. From there they are conducted through tubes up through the root into the stem. Substances also pass out of the roots into the soil. Movement takes place in both directions through the walls of the root hairs. Those substances which pass out of the root are waste products, excretions. 
It is now known that these substances are frequently injurious to plants. It is probable that the decrease in the fertility of soil is frequently due to the presence of these excretions rather than to the lack of the proper mineral materials. Most of these excretions appear harmful to the species of plants which produced them, but they are not necessarily so to other plants. This may help to explain the benefits of rotation of crops.

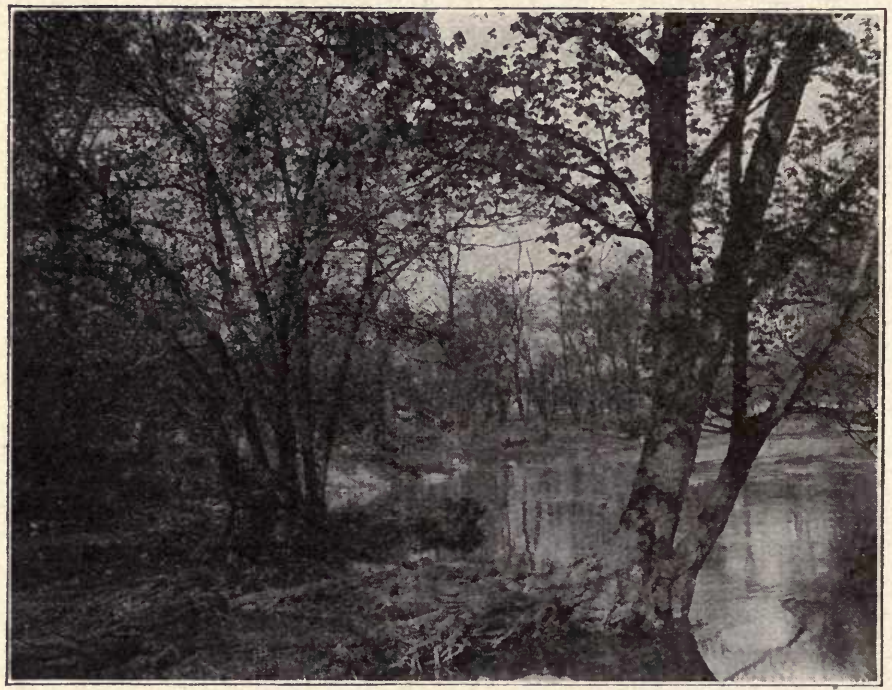

Fig. 92. Soil is washed away by the water, but large roots serve as an effective means of anchoring this tree.

Anchorage. Roots usually serve as a very effective means of holding plants in place. Many plants are so well anchored that during a heavy wind a plant will be broken off, but it will not be uprooted. The 
roots of ordinary plants are much larger than we suppose. When a plant is pulled out of the ground, the larger part of the root system is broken off and left in the ground. The roots of trees ordinarily spread much farther underground than their branches do above.

Roots seem to be modified to suit their surroundings. However, we must not fail to recognize the fact that plants can not adapt themselves to conditions. In many ways they are very well adapted or suited to the conditions under which they live, but that is because they are the only plants which have survived. On the whole, large aerial stem systems are commonly associated with extensive root systems. The roots of plants along streams and shores are especially effective for anchorage. The roots of these plants are frequently matted together, thereby clinging firmly to the earth. As a result, the water can not wear away the soil and dislodge the plant.

The size of the root varies greatly with the amount of available water. The roots of water and of swamp plants are usually short. Those of desert plants, on the other: hand, are often enormously developed.

"One of the most notable examples of an enormously. developed root system is found in the mesquite of the far Southwest and Mexico. When this plant grows as a shrub, reaching the height, even in old age, of only two or three feet, it is because the water supply in the soil is very scanty. In such cases the roots extend down to a depth of sixty feet or more, until they reach 
water, and the Mexiean farmers in digging wells follow these roots as guides. Where water is more abundant, the mesquite forms a good-sized tree, with much shorter roots."

\section{Questions}

1. State two important functions of roots.

2. Define tap root and give examples.

3. What is meant by fibrous roots? Give examples.

4. Describe root hairs.

5. What substances diffuse into the plant through the root hairs? What substances pass out of the root?

6. Do plant excretions have any effect on the fertility of soil?

7. How does the size of the root system of a tree compare with that of its branches?

8. How do you account for the fact that desert plants have such large root systems?

"Bergen and Davis, Principles of Botany. Gim and Company. 


\section{CHAPTER XXVIII}

\section{STEMS}

Functions. The main divisions of a plant are the root, stem, and leaves. The materials from which the plant makes its own food are taken in through the roots and through the leaves. Since the leaves are the factories in which the food is manufactured, the raw materials, water and solutes, which are taken in through the roots, must be transferred to them. In return, some of the food, after it has been made, must be carried to the roots. This necessitates a transfer of materials both to and from the leaves. To make starch, we already know, the leaf must have light. Clearly, it would be a decided disadvantage to plants if all of their leaves were attached directly to the roots. In most plants an intermediate part, the stem, is present. This connects the roots with the leaves and thus forms a passageway for the movement of food and raw materials. The chief function of stems, however, is to bring the leaves up into the sunlight where they can work to best advantage.

Kinds. Stems determine to a great extent the general form of plants. They often branch, and in that way increase their power for displaying the leaves to 
the light and to the air. Stems exhibit a great variety of form and habits. The upright, or erect stem, is the most common, and altogether seems to be the best device for properly bringing the leaves to light. The most conspicuous erect stems are those of trees. The branches of erect stems usually have a more or less horizontal position, and are so arranged that one does not shade another. Hard tissues are always present

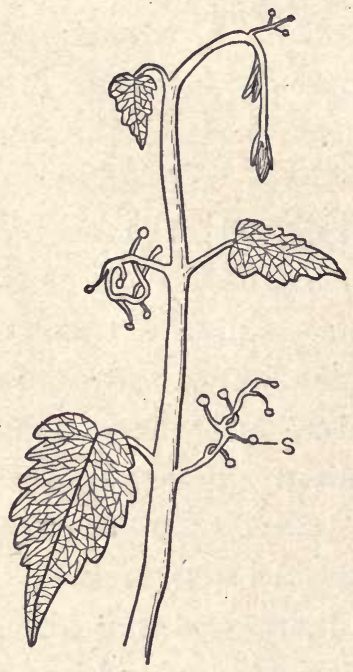

Fig. 93. The ivy climbs by means of sucking disks, $S$. in the large erect stems to give them support much as bones give support to the bodies of animals.

In many plants the stem lies prostrate on the ground, as in the strawberry. Others have developed a climbing habit. Such stems can not stand alone, but they have the ability to sustain themselves by using supports. They have various ways of attaching themselves to the supports; the ivy by means of sucking disks; the grape by tendrils ; beans, morning glories, and hops twine their stems about the support. The stems of desert plants are usually very short and thick. This is quite in contrast to the enormously developed root system of these plants. In the cactuses the leaves are reduced to spines, and the short thick 
stems are green and make the food for the plants. They also, you recall, store water.

Structure. An ordinary stem is a jointed structure. In some, such as the corn stalk and the cane (used for fishing rods), these joints, or nodes, are very evident. In others, the joints are evident only because they are the places where leaves and branches appear. If the internal structure of a stem is studied in detail, it will be found to be very complex and difficult to understand. We shall attempt to study only such parts as can be seen with the naked eye. If a twig of any growing woody plant, such as the box elder or maple, be cut across, it will be seen to be made up of four distinct parts: 1. An outer protecting layer, the epidermis. 2. A second layer of soft tissue, usually green, the cortex. 3. A layer of wood, the vascular cylinder. 4. A central portion, the pith. The cortex when green is able to manufacture carbohydrates just as the leaves do. The wood is the conducting region; and it also gives strength Fig. 94. Cross section of a three-yearand rigidity to the stem.

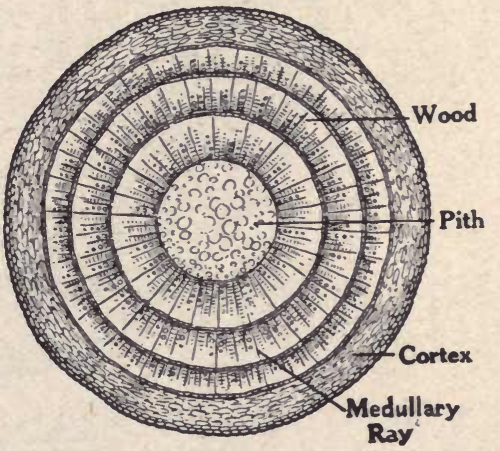
old woody stem.

If examined more closely this section of wood will be seen to be divided into a number of segments by plates of cells passing from the pith to the cortex. These 
are known as pith, or medullary rays. The wood itself is made of bundles of tubes known as vascular bundles. Some of the tubes in each bundle are used for conducting water from the root to the leaves, and others for conducting prepared food materials downward.

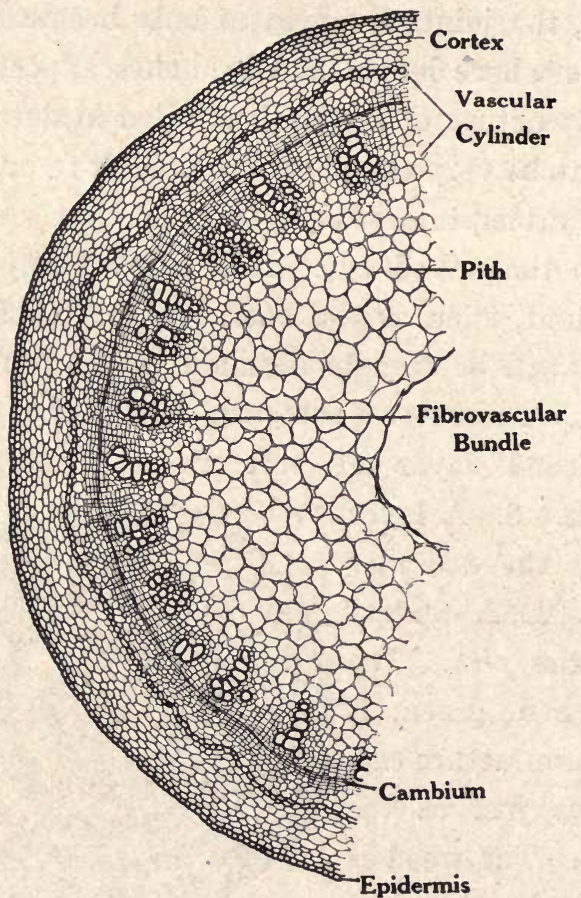

Fig. 95. Cross section of a woody stem showing details of structure.

If a cross section of a young stem were examined under a microscope, a region of thin-walled, rectangularshaped cells would be found between the wood and bark regions. This is the growing region of the stem 
and is called the cambium layer. It is in this layer that the new cells which make the new wood and bark are formed.

Stems of this type can increase in diameter. A new layer of wood is formed outside of the old wood. Usually these layers of rood are so distinct that a section of a woody stem shows a series of concentric rings, usually one ring for each year. If a three or four year old twig is examined, several changes which take place as stems grow older will be noted. A thicker covering composed of waterproof bark is present. The wood cylinder will be found to be much larger, and the pith, smaller. In the stems of some plants, such as lilies, grasses, and palms, the vascular bundles

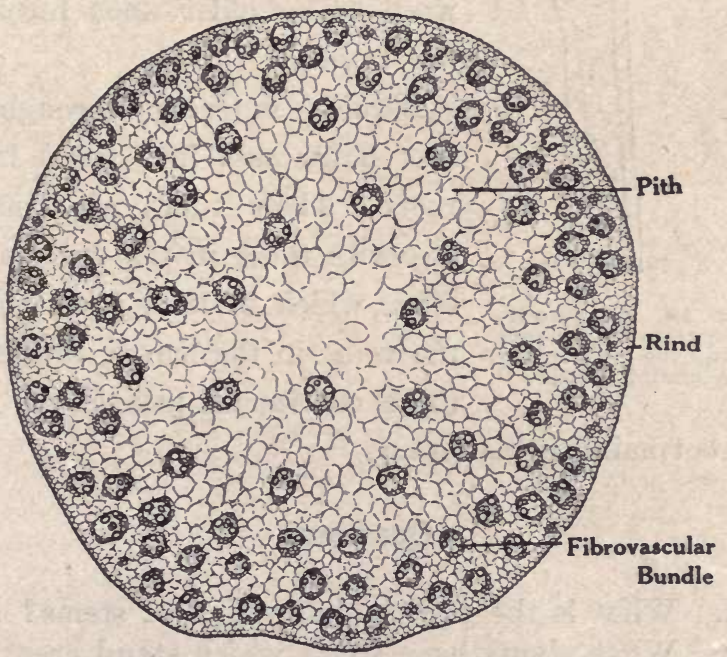

Fig. 96. Cross section of a corn stem showing the vascular bundles scattered in the pith. 
are not arranged in the form of a hollow cylinder, but are more or less irregularly scattered through the pith. In these stems each vascular bundle has its own cambium layer.

If the cut ends of any young branches are placed in red ink (a solution of eosin) and left in the sunlight for a few hours and then examined, the red ink will be found to have passed up the stem. In sections of such stems the color will, be found in the woody tubes

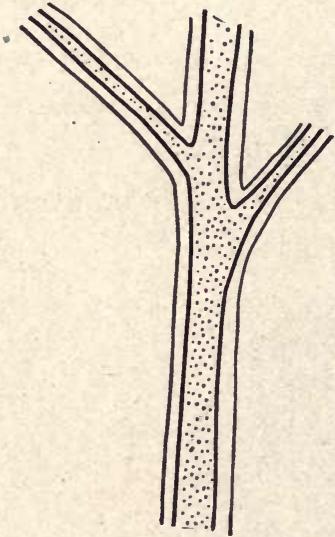

Fig. 97. Longitudinal section of a stem showing the path taken by ascending water. just beneath the bark. This color indicates the path taken by the ascending water. The liquids in trees abandon the inner older wood and move only through the newer wood. This older wood forms the heart wood.

Liquids entering through the root hairs pass into tubes in the roots. These tubes are continuous with those in the wood of the stem, which in turn join those in the veins in the leaves, thus forming a continuous passageway from the root hairs to the leaves.

\section{Questions}

1. What is the principal function of stems?

2. What plants have stems which stand erect?

3. Name plants which have the climbing habit. 
What are some of the ways by which they attach themselves to their supports?

4. Describe the internal structure of a woody stem.

5. What are vascular bundles? What are their functions?

6. How do trees increase in diameter?

7. What forms the grain in woods?

8. Describe the way in which the vascular bundles in a corn stem are arranged.

9. What is the path taken by liquids as they pass from the roots of plants to the leaves?

10. Where do liquids travel in passing from the leaves to the roots? 


\section{CHAPTER XXIX}

\section{REPRODUCTION}

Reproduction and nutrition. By means of roots, stems, and leaves, as we have just learned, plants are able to carry on certain processes by which they live. These processes of nutrition are necessary for the life of any individual plant. It is also essential, however, for new and younger plants to be produced; otherwise each particular kind (species) of plant would cease to exist on earth. This function of producing new plants is known as reproduction (to produce again). There are a number of methods by which new plants may arise from old ones. It is possible to take cuttings of willow, or geranium, or grape, plant them, and have then grow into new plants. In all the higher, so-called seed or flowering plants, seeds are used for the production of new plants. For the formation of seeds plants bear special structures, the flowers.

Flowers. Most of the plants, with which you are familiar, periodically produce highly colored structures which are called flowers. The size, shape, color, and even the structure of flowers of different plants vary greatly. In any simple flower, such as the trillium, the violet, or the geranium, four parts are always present. 


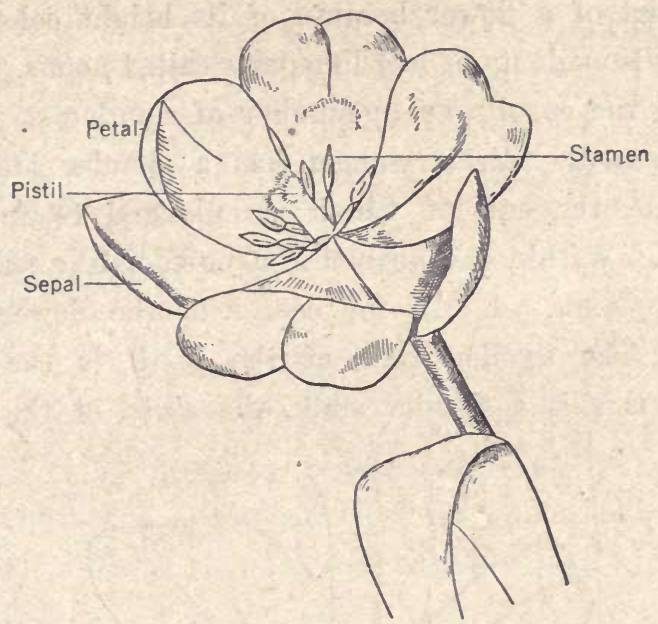

Fig. 98. Flower of a tulip.

1. The outermost part is the caly.x, which is green. It is composed of separate parts, the sepals. 2. Inside and above the calyx is the corolla, usually the most conspicu-

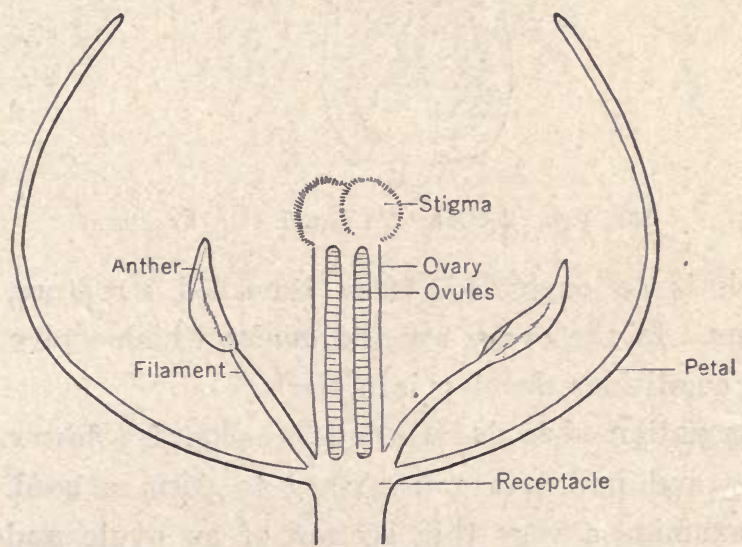

Fig. 99. Diagram of a section of a tulip flower. 
ous part of a flower because of its bright color. The corolla is made up of leaf-like parts called petals. 3. Just within the corolla are a number of slender structures, the stamens. Each stamen has a slender stalk, the filament, the end of which is enlarged to form the anther. Within the anther is a powder-like substance called pollen. 4. In the center of the flower is the pistil. The swollen base of the pistil is the ovary. Above this is a slender stalk, the style, at the top of

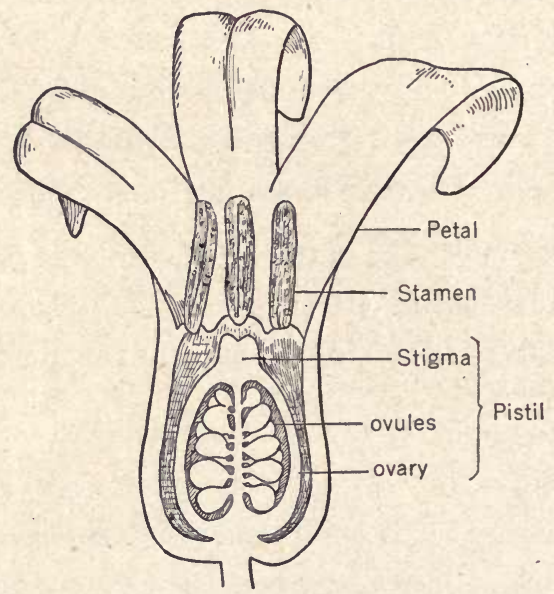

Fig. 100. Section of a flower of a hyacinth.

which is an expanded, often branched structure, the stigma. In the ovary are the ovules which under certain conditions develop into seeds.

Formation of seeds. Only two parts of a flower, the ovule and pollen, are necessary to form a seed. If we examine a very thin section of an ovule under a 
microscope, we find that. in the center of it there is an elongated sac known as the embryo sac. This contains protoplasm and several nuclei. One of these nuclei, together with the protoplasm immediately around it, forms the egg cell. The pollen grains are formed in the anther of the stamen. When the anther breaks open these small cells are scattered and some fall upon the stigma. Changes then take place in the pollen grain and as a result a tube, the pollen tube, develops. This tube continues to grow downward through the stigma and style. It enters the ovule and grows toward the egg. During this time two cells, sperm cells, have

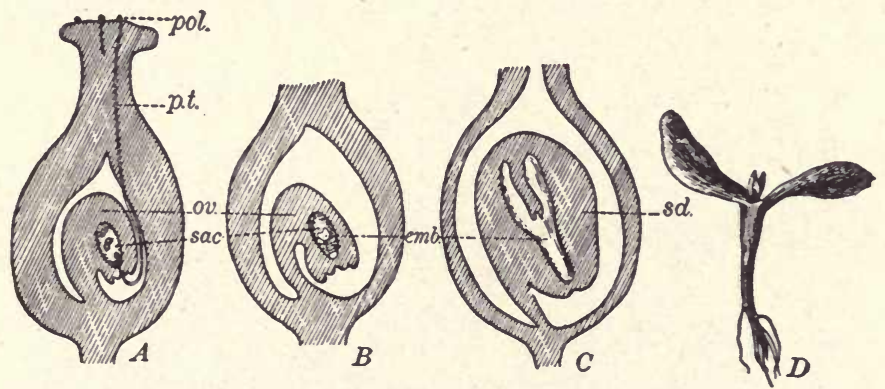

From Caldwell and Eikenberry's "Elements of General Science," by permission of Ginn and Company, Publishers.

Fig. 101. Diagram to show development of young plant from the egg. $A$, entire pistil ; $B$ and $C$, development of seed ; $D$, seedling plant; pol., pollen grain; $p$. $t$., pollen tube; ov., ovule; sac, embryo sac ; emb., embryo; sd., mature seed.

developed in the pollen tube. One of these sperm cells may unite with the egg cell and form a single cell. This process is known as fertilization. After fertilization this egg begins to divide and to form the new plant. One region develops into the root tip, 
another into a stem tip, and others into one or more leaves. After the embryo plant reaches this stage, in most cases, the wall of the ovule becomes hardened and the growth of the young plant is checked. This ovule with the thickened wall and containing a plant in a dormant condition is a seed. It may lie in this condition for a long time and then if placed under favorable conditions, the seed coat will burst and the embryo plant will continue its growth into a young plant.

Pollination. Pollen is necessary for the production of seeds. But before this pollen can fertilize an ovule, it must first be transferred from the anther in which it is formed to a stigma. This transfer of pollen from anther to stigma is called pollination. This process appears to be one of the chief activities associated with flowers. There are two kinds of pollination. Pollen may be transferred from the anther to the stigma of the same flower (self pollination), or to the stigmas of other flowers (cross pollination). Charles Darwin, the great English naturalist, found, about the middle of the nineteenth century, that certain kinds of flowers were entirely dependent for fertilization upon cross pollination. He also found that some which were self pollinated did not produce so many seeds, and that plants which grew from those seeds were smaller and weaker than plants from seeds produced by cross pollinated flowers. He also found that another advantage of cross pollination was that the plants so 
produced varied more than those which came from self pollinated seeds.

In many plants, however, self pollination occurs. Sometimes this is accidental, but in many flowers self pollination is apparently definitely provided for. The positions of the anthers and the stigmas are often such that some of the pollen must fall directly upon the stigma. Some plants, like the closed gentian, produce flowers which never open and are thus necessarily self-pollinated. Cross pollination is the more common method, and there are various devices for securing it. In some species of plants the flowers do not have both ovaries and stamens. The flowers on some plants have only ovaries, while those on other plants of the same species have only stamens. In other species the stamens and ovaries of the same flower do not mature at the same time. Cross pollination is usually secured through one of two agencies, the wind or insects. Flowers which depend upon insects for cross fertilization are made attractive. Their showy color, their odor, and the nectar which they contain, all serve as attractive features for insects. The pollen is used by many for food. Nectar is also used for food and out of it the bee makes honey. Flowers are visited by a great many kinds of insects. Those which are most useful for transferring pollen have bodies covered with hairs to which the pollen easily adheres. In the bee a certain part of the hind leg is covered with stiff hairs forming a "pollen basket." The bee collects pollen for food, but while 
getting it for itself, pollen is caught on the hairs of the body and legs of the bee and is thus carried from flower to flower. Bees, butterflies, moths, and some other insects feed on the nectar of plants: These insects have mouth parts which are very much elongated, forming a tube-like structure. This enables them to reach the nectar which is usually at the base of the flower. In so doing, however, the body of the insect must brush against the stamens and pistils. In this manner pollen is then transferred from one flower to another.

Wind pollinated flowers are usually very inconspicuous. They are structures which you probably have never considered flowers at all. The flowers of most trees, grasses, and grains are wind pollinated.

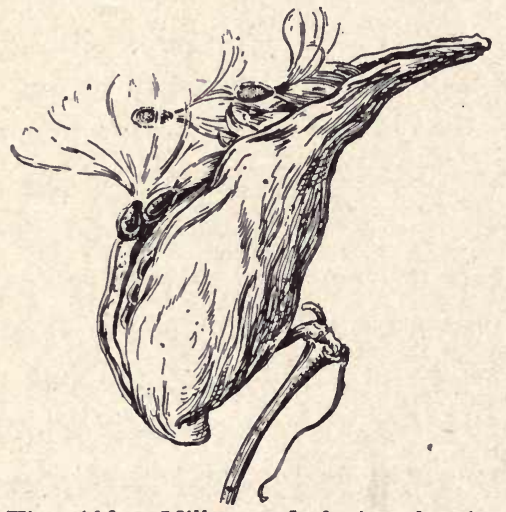

Fig. 102. Milk weed fruit, showing method of seed dispersal.

Seed dispersal. The function of the seed is to produce a new plant. In order to do this, however, certain conditions of light, air, moisture, and food are necessary. Only a small proportion of the seeds annually produced can grow. This is because a seed must not only have favorable conditions of light, moisture, etc., for growth, but it must find a place 
where there are not too many other plants wanting these same conditions. If all the seeds formed dropped about the parent plant, and developed into plants, there would soon be so many of them that they would seriously interfere with one another. It is thus of great advantage to plants to have the seeds widely scattered so that some may find all the conditions favorable to growth.

There are many methods by which seeds are widely scattered. Many seeds and fruits are so constructed
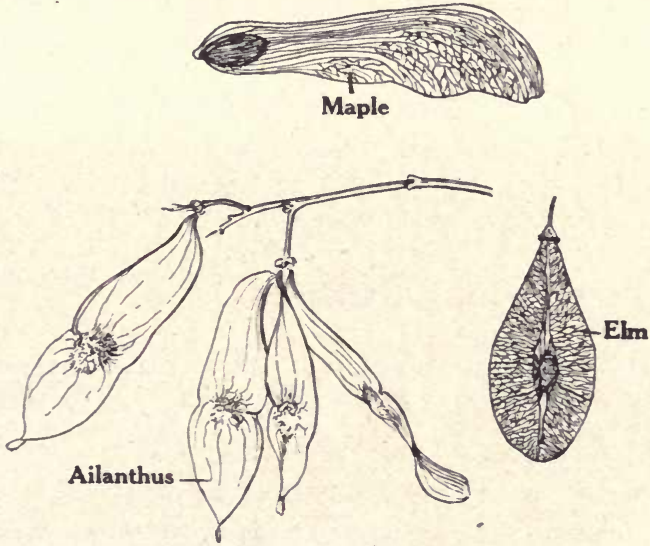

Fig. 103. Group of winged fruits.

that they are very likely to be carried about by wind, water, or animals. You can easily think of many seeds and fruits dispersed by each of these agents. Think of the winged fruits of the maples, elms, or catalpas which are so easily carried by the wind. So, too, are the tufted seed-like fruits of the thistle, dandelion, and milk weed. Various burrs, Spanish needles, and beggar 


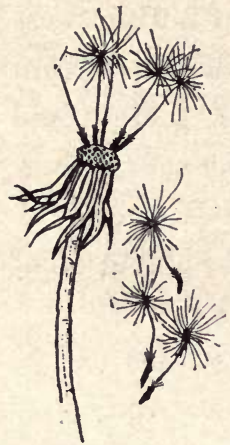

Fig. 104. Fruits of dandelion.

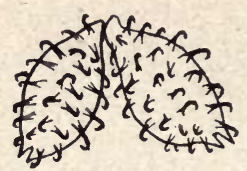

Cockleburr

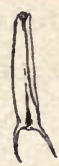

Beggar's-tick

Fig. 105. Some fruits which are carried by animals.

ticks have hooks, or spines, which enable them to cling to the hair, fur, or feathers of animals. They may be carried many miles before they are brushed off. Sometimes seeds or fruits may fall into water. Such seeds are buoyant and are frequently carried many miles before they are deposited.

\section{Questions}

1. By whàt methods may new plants arise from old ones? Give examples of plants illustrating each of these methods.

2. What is the function of a flower?

3. Describe the structure of a typical flower.

4. Which parts of a flower are necessary to form a seed?

5. What is an egg cell? A sperm cell?

6. Define fertilization.

7. How is a seed formed ?

8. Define pollination.

9. Discuss the two kinds of pollination.

10. What are the principal agencies by means of which cross pollination is aceomplished?

11. Name flowers which are wind pollinated. 
12. Name flowers which are pollinated by insects.

13. What is the function of a seed?

14. Of what advantage is seed dispersal to a plant?

15. What are the conditions necessary for the germination of seeds?

16. Give examples of seeds dispersed by wind. How does the structure of these seeds favor such dispersal?

17. Discuss the value of water as an agency for seed dispersal.

18. Give examples of seeds carried by animals. How does their structure adapt them for this method of dispersal?

19. Discuss the ways in which seeds are of importance to man.

20. What conditions are necessary for the growth of seeds?

21. Discuss the vitality of seeds. 


\section{IMPORTANCE OF PLANTS TO MAN}

Economic importance. Plants are of great economic importance to man. Some of them are important because they are beneficial; others, because they are injurious. As to benefits: they supply man "with his cereals and flour, his fruits and garden vegetables, his nuts and spices, his beverages and the sugar to sweeten them, his medicines and his dyestuffs; they supply the material out of which many of his clothes are made, the thread with which they are sewed together, the paper which covers the packages in which they are. delivered, and the string with which the package is tied. The various uses of the forest have been mentioned before; the need of trees to protect the earth, their usefulness in the holding of the water supply, their direct economic importance for lumber and firewood. Many of us forget, too, that much of the energy released on this earth to man, as heat, light, or motive power, comes from the dead and compressed bodies of plants which thousands of years ago lived on the earth and now form coal. Plants are thus seen to be of immense direct economic importance to mankind."

*Hunter, Essentials of Biology. American Book Company. 
Those plants which are the most harmful to man belong to a group of plants known as fungi. Many diseases of cultivated crops, of farm animals, and of man himself are caused by members of this group. The plants which belong to the fungi do not have chlorophyll. Consequently they are unable to make their own food and must depend upon other living organisms for securing it. Some of them obtain their food directly from living plants or animals and are called parasites. The plant or animal from which they derive their food is called the host. The parasite attaches itself to its host and sucks out its food supply. Others use non-living substances for food, but these substances were once a part of living organisms. These are called saprophytes. Yeasts, molds, mushrooms, and bacteria are fungi. Of these, bacteria have by far the greatest economic importance.

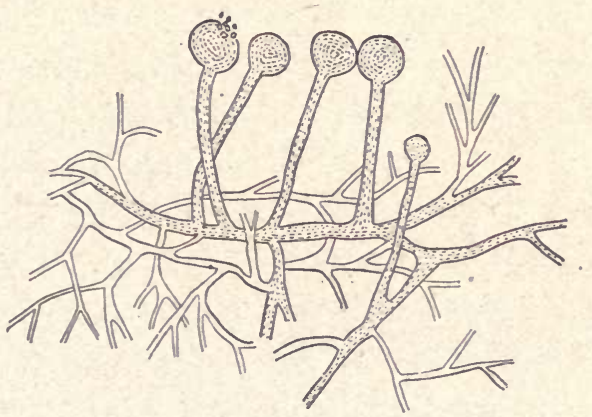

Fig. 106. A mold which forms a white furry growth on damp bread.

Bacteria. The study of bacteria is a special subject called bacteriology. This fact in itself indicates some- 
thing of the importance attached to this group of plants. Bacteria are the smallest living organisms. They can be seen only with the very highest powers of the microscope; there are reasons for believing that there are bacteria too small to be seen even with the best microscope. They are sometimes not over $1 / 50,000$ inch in diameter, and even the largest ones are not more than $1 / 10,000$ inch in diameter. In structure they are very simple, consisting of but a single cell, and little is known about them except their general external appearance. Usually three groups of bacteria are recognized. These are classed according to form: the
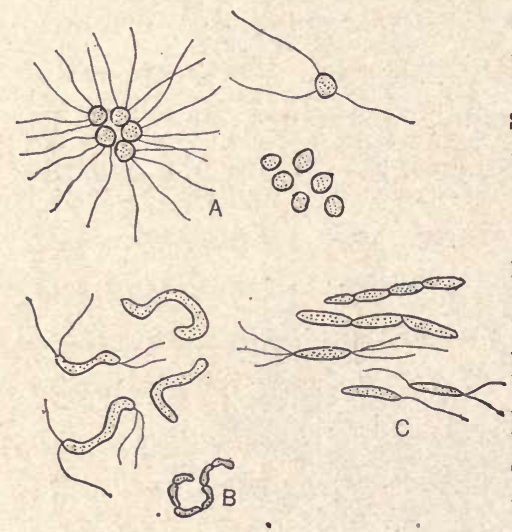

Fig. 107. A group of various kinds of bacteria ; $A$, coccus forms : $B$, spirillum forms ; and $C$, bacillus forms. spherical (coccus), rodlike (bacillus), and spiral (spirillum). Many kinds of bacteria are endowed with the power of motion. The locomotive organs consist of minute hair-like bodies which project from the bodies of the bacteria. These little hairs, called flagella, wave back and forth and by this motion drive the bacteria through the water.

Bacteria are found everywhere in the earth, in the water, and in the air. They live upon any kind of organic material and under conditions which would kill 
all other organisms. Some bacteria can live even without free oxygen. They multiply very rapidly by simple dfvision. An adult individual may divide into two, each of these into two, and so on. The rapidity with which they multiply is almost inconceivable. It has been estimated that a single individual will produce about $17,000,000$ offspring in twenty-four hour's.

Conditions for growth of bacteria. Like other living things, bacteria will not grow at freezing temperature or below. They will grow at nearly all temperatures above freezing, some species even growing at $140^{\circ} \mathrm{F}$. Most bacteria are killed by excessive heat, and usually a temperature of from $149^{\circ} \mathrm{F}$. to $160^{\circ} \mathrm{F}$., if continued for an hour, is sufficient to destroy them. When the bacteria in a substance are destroyed, the substance is said to be sterilized. A low temperature may not kill them, but it does prevent their rapid development. Most bacteria need plenty of air and plenty of water. Fortunately direct sunlight kills them, and this fact suggests a possible advantage in having plenty of sunshine in our houses.

Bacteria and disease. Many diseases of plants and animals are produced by bacteria. By far the most important of the disease-producing bacteria are those which may be parasitic in the human body and cause such diseases as tuberculosis, pneumoniá, cholera, typhoid fever, diphtheria, leprosy, lockjaw, and many others. These bacteria are frequently transferred from one person to another. A disease which can be spread 
in this way is said to be infectious. We are just beginning to realize how essential it is to use all possible precaution to prevent the spread of diseases. The modern tendency in medicine is to determine how to prevent diseases, rather than how to cure them.

Decay. If any organic substance is moist, bacteria will get into it from some source. They will grow rapidly and in a few hours marked changes will appear in the substance. The essential effect which the bacteria produce is the chemical decomposition of the material upon which they are feeding. Some of the simple substances formed by such decomposition are consumed by the bacteria; others are not, and are left behind but not in the form of the original substance. This process of decomposition brought about by bacteria is called decay. As a result of it, meats become putrid, eggs rot, milk sours, and fruits spoil. Decay is not always harmful. It is in some ways of the utmost value to man. By means of it the dead bodies of animals and plants and the waste products of living ones are decomposed and reduced to a form in which they can be removed. The materials that are broken down are thus made usable and available for the growth of other plants and animals. Decay is essential for life. Without it, all food would finally be unavailable because it would be "locked up" in the bodies of plants and animals.

To prevent the decay of food substances useful to man, it is necessary to destroy the bacteria in them, 
or to prevent their further growth. This may be done in several ways. The methods most commonly employed for killing them are boiling or using chemicals called preservatives. The former method is the better because chemicals which will destroy bacteria are likely to be poisonous to man, and therefore should not be used in his food. Preservatives frequently used are formaldehyde, borax, boracic acid, and salicylic acid. In canning fruits and other foods heat is used. The fruit is first boiled to kill all bacteria in it. The can is sterilized by putting it in boiling water, and then the fruit is sealed in it air-tight while still hot. If this process has been carefully done, there will then be no bacteria in the can and none can enter.

Other methods for preserving foods are keeping them cold (refrigeration), drying, smoking, or using salt, sugar, or vinegar.

Useful bacteria. The injury done by bacteria is so very apparent that we sometimes overlook the fact that many bacteria are of benefit to man. Mention has already been made of their value in causing decay, and in enriching the soil by adding nitrogen compounds to it (see page 122). Bacteria are also useful in the production of several foods. Vinegar, for example, is formed as a result of their action upon the fruit juice, cider. The flavor of butter is partly due to bacteria, and that of cheese is almost entirely the result of the kinds of bacteria used in "ripening" it. 


\section{Questions}

1. Name ten plants of economic value.

2. In what way is each of these plants useful to man?

3. What is the name of the group of plants which include those most harmful to man?

4. Give three examples of plants belonging to this group.

5. Define parasite, saprophyte, and host.

6. Where are bacteria found? What is their size? How do they multiply?

7. What conditions are most favorable to the growth of bacteria?

8. When is a substance said to be sterilized?

9. Is there any advantage in having plenty of sunshine in our houses?

10. Name diseases which are produced by bacteria.

11. What are infectious diseases?

12. Why is it important to know whether or not a disease is infectious?

13. Discuss the relation of bacteria to decay.

14. State the ways in which decay is of value to man.

15. What are the ehief methods used to preserve our foods?

16. What are the objections to the use of preservatives in foods?

17. Discuss the ways in which bacteria are of benefit to man. 
CHAPTER XXXI

\section{ANIMALS}

Distribution. Animals are found wherever the coliditions are suitable for their existence. The chief external conditions which influence animal life are food, oxygen, moisture, and suitable temperature. There are only a few places where these conditions are not favorable to the life of some kind of animals. In an ice covered region, like the interior of Greenland, and in exceedingly dry areas, like the Sahara and other deserts, there is almost no life of any kind. With a few exceptions like these, animals exist everywhere in great numbers and in great variety. The animal life of any region is known as its fauna.

From personal knowledge most of us are already familiar with the fact that animals differ very greatly irrespective of their living places on the surface of the earth. We know that the animals in our immediate locality are unlike. The animals which are found in the ponds and streams differ from those of the prairie; those of the field differ from those of the forest. The greatest differences exist between the animals which live in water and those which live on land. These 
differences result primarily from the methods of breathing. These two groups can again be divided into the fresh and the salt water forms, and into the land and aerial forms.

Means of distribution. Animals are distributed in many ways. The chief method for their dispersal is by means of their own powers of locomotion. They wander about to search for food, to escape drouth or a sudden change of temperature, or sometimes to escape an advancing enemy. Water forms are carried about by waves and currents. Some smaller animals are transferred on the bodies of larger ones. Many have been transferred from one place to another by man. In several instances this has proved a great disadvantage to him. The English sparrow, for example, was introduced into this country by man. It has been able to thrive here to such an extent that it has become a pest because of its great numbers and because it feeds on grains, seeds, and fruits. The gypsy moth was accidentally introduced into the United States by man. More than a million dollars are now being spent each year trying to control this pest and to protect the trees of Northeastern United States.

Factors determining distribution. Every kind of animal multiplies and spreads from a given location. It would ultimately be found all over the surface of the earth where conditions suitable for its maintenance exist except for three factors which prevent this uniform distribution: 
1. Barriers of some sort, as mountains and oceans, may prevent a given species of animal from reaching certain regions.

2. The species may reach another region, but when there, it may be unable to maintain itself.

3. It may maintain itself, but in so doing it may become so changed that it will form a new species.

Barriers to distribution. It is very evident that certain conditions will prevent the spread of animals. Land forms, for example, can not live in water; and salt water forms can not live in fresh water. Animals are prevented from reaching certain parts of the earth by mountains, by rivers, by oceans, - by deserts, and, sometimes, by falls in rivers. There is no evident reason why the lion and tiger could not live in South America or coyotes in Europe, or certain birds, as the meadow lark, in Europe, if it were not for the fact that they have been prevented from reaching those places by natural barriers.

Animals can not maintain their ground. Polar bears if introduced into the tropics could not adjust themselves to conditions so as to live. Likewise, tropical animals could not survive the cold winters of temperate regions.

Sometimes animals have been introduced into regions where the conditions were very little changed, and yet they were not able to survive. This was probably because of competition with animals already present in the new region. 
Change due to new conditions. New conditions may so alter a species of animal that it no longer exactly resembles the form from which it came. For example, animals sometimes adapt themselves to caves. As a result they become blind and lose their color.

Adaptation. There are so many animals, and consequently so much strife for a place in this crowd, that all animals must adjust themselves to conditions in order to survive. If they can not change so as to be fitted for given conditions, they die. We have already

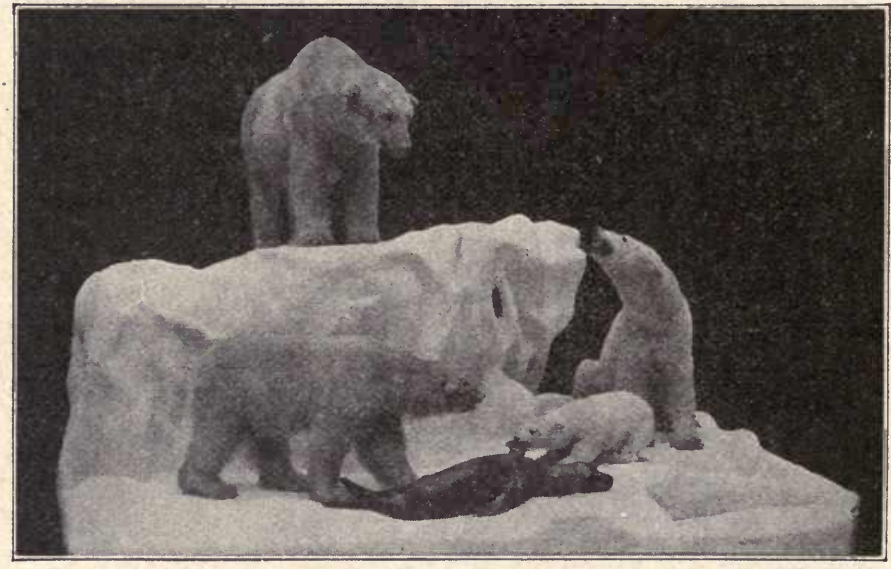

Permission of Field Museum of Natural History. Fig. 108. The polar bear is adapted for life in the Arctic regions.

noted the inability of a polar bear to live in a warm climate.

All animals are more or less fitted, or adapted, to their environment and to the kind of life which they 
must lead. Some animals, sueh as the vulture, are provided with strong claws to aid in securing food; the long neck of the giraffe enables it to feed on the foliage of the trees. Special weapons of defense are found in many animals, such as the horns of a cow, the sting of the bee, or the quills of the porcupine. Insects are frequently colored like their surroundings to escape detection. Animals like the moles, which live underground, have the legs modified for digging or burrowing. Even beginners in the study of animals can find many examples of adaptation in the forms of life about them.

\section{Questions}

1. Name the animals found in the region in which you live.

2. Are animals uniformly distributed over the surface of the earth?

3. Discuss the chief factors which determine the distribution of animals.

4. What is meant by adaptation? Give examples of adaptations found in animals. 


\section{GROUPS OF ANIMALS}

General statement. Most animals which are known to man have been classified. By this we mean that they have been placed in groups with animals which

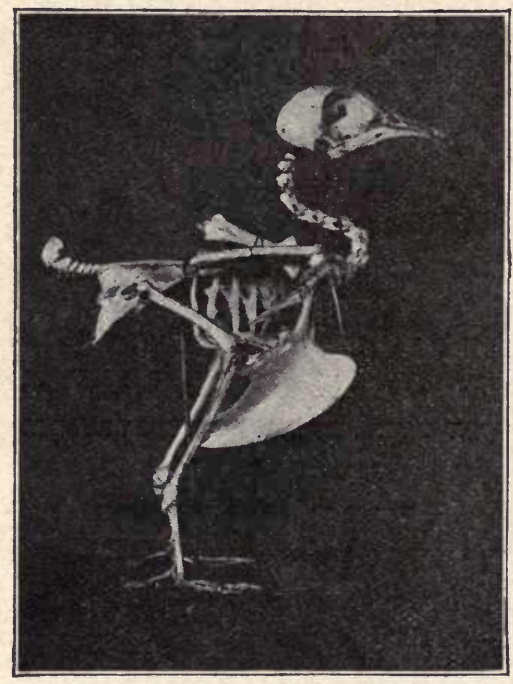

Fig. 109. Skeleton of a pigeon. resemble one another. It is interesting, even to a beginner, to know something about the groups of animals and the forms which belong to the different groups.

In some animals, such as the fish or bird, there is a supporting frame work in the body made of bone. This is the skeleton. A part of - this skeleton forms a structure known as the back bone or vertebral column. All animals having a vertebral column are placed together in one group, the vertebrates. Other animals, 
such as worms and insects, do not have a back bone and are known as the invertebrates. To the vertebrates belong most of the animals with which you are already

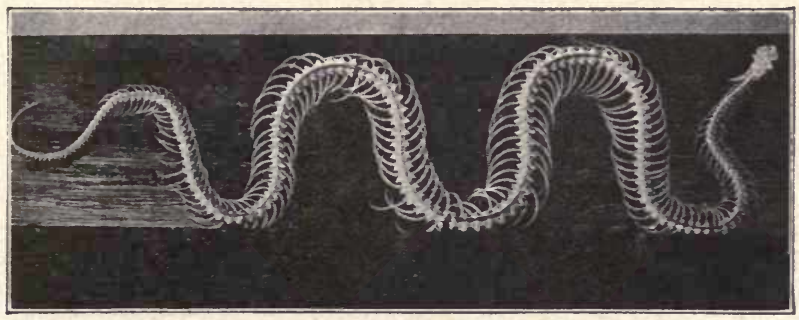

Fig. 110. The backbone of a snake is composed of many vertebrae.

familiar from personal observations. You, perhaps, have never attempted to classify them.

Mammals. Mammals are considered the highest vertebrates because of their complicated structure and because of their greater mental development. The animals in this group are so called because they produce milk, a secretion of the mammary glands, which is used as food for the young. The young of

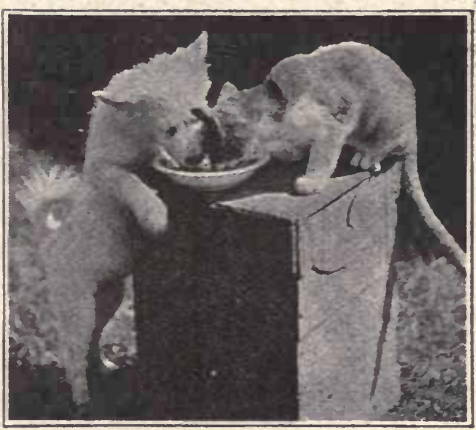

Fig. 111. Two mammals. almost all mammals are born fully formed and then for some time are eared for by the parents. The skin of mammals is partly or completely covered by hairs. 
There are about 3500 different kinds of mammals. The highest of these is man. Very similar to man are the monkeys, apes, gorillas, and chimpanzees. Differing more in general appearance, but still having the characteristies of mammals are: the rat, the squirrel, the beaver, the whale, the horse, the cow, the pig, the sheep, the dog, the eat, the lion, the tiger, and the bat. Most of these forms live on the land, but a few, such as

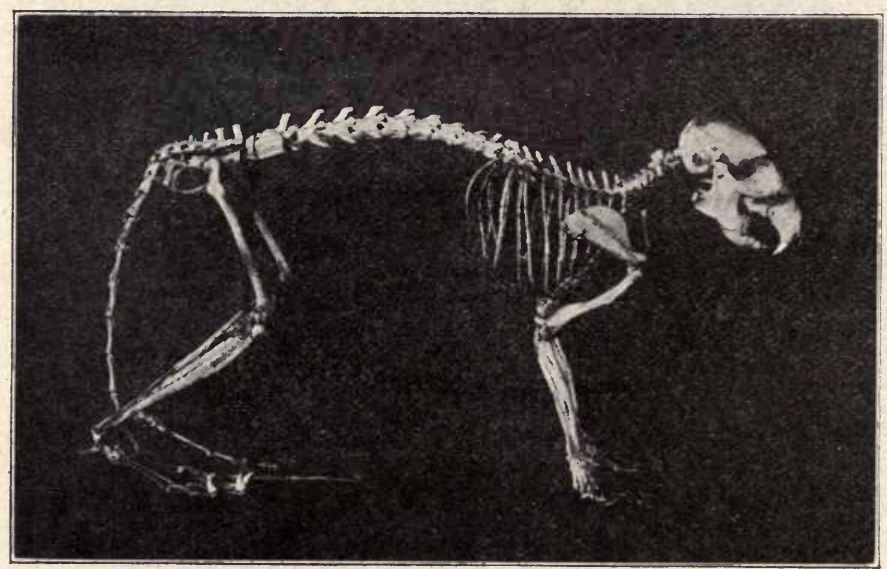

Fig. 112. Skeleton of squirrel.

In gnawing mammals the canine teeth are absent. The front, incisor, teeth grow continuously and are kept sharp by the gnawing on hard substances.

whales, porpoises, and sea-lions, inhabit the ocean. They are all air breathing. They vary greatly in size from the whale and the elephant to very small mice and moles. Many adaptations to habitat and methods of life occur in this group. Whales, sea-lions, and porpoises have the limbs modified into flippers for swim- 
ming ; mice, beavers, and squirrels have the front teeth modified for gnawing; bats have the fore limbs modified for flying.

Birds. This is one of the largest groups of animals. It has been estimated that there are about 10,000 species

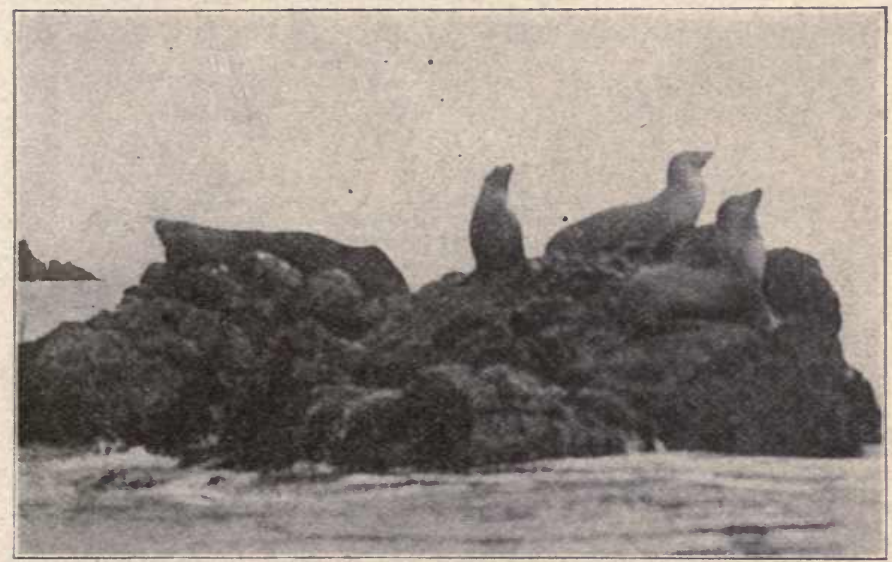

Copyright Detroit Photographic Co.

Fig. 113. Sea lions are modified for life in the water. Their feet serve as swimming organs and their bodies are fish-like in form.

belonging to it. Yet, there is scarcely another group of animals so easy to distinguish at sight as this. The characteristies common to all birds are: the body is covered with feathers; the fore limbs are modified to form wings; they all produce eggs; and the jaw is always covered with a horny substance forming a bill. Birds differ greatly in their habits of life and many interesting adaptations occur in this group. Some birds have the feet adapted for perching, others for swim- 
ming, and still others for wading. In wading birds, such as the plover, heron, and stork, the legs are very long. In perching birds there are three toes in front and one behind. This hind toe is important in holding the foot in place. The tendons and the muscles in the foot and leg are so arranged that they are self locking. Consequently even when asleep, such birds remain balanced on the perch.
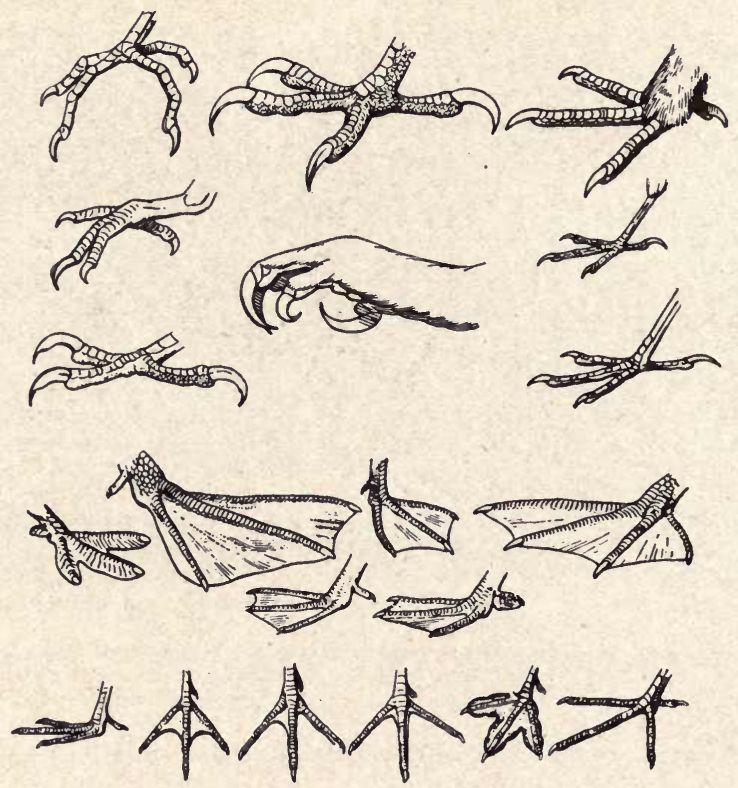

Permission of Field Museum of Natural History. Fig. 114. Adaptations in the feet of birds.

The form of the bill varies according to the habits of the bird. A duck has a flat bill for pushing through the mud; the woodpecker has a sharp bill for piercing 
the barks of trees; others, such as the vulture, have strong, curved beaks for tearing their prey.

In many ways the body of the bird is especially fitted for flying. Many of the bones of the skeleton are hollow, thus combining lightness and strength. The breast bone is greatly developed for the attachment of the
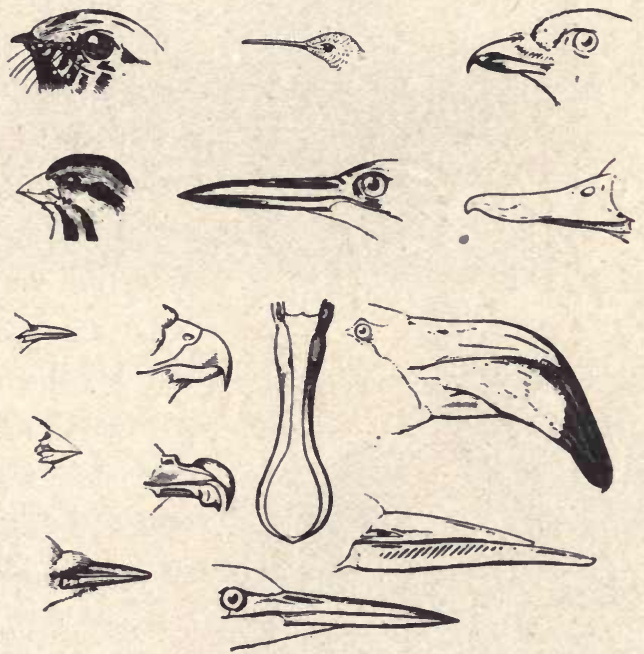

Permission of Field Museum of Natural History. Fig. 115. Adaptations in the bills of birds.

large muscles used in flying. The rounded body with its smooth covering of feathers offers little resistance in flying.

Because of the very active life of birds, the rate of respiration, the rate of the heart beat, and the temperature of the body are all higher than in any other animal. Birds breathe from 20 to 60 times a minute. 
We breathe about 15 times a minute. Our temperature is $98.5^{\circ} \mathrm{F}$., while that of birds is from $100^{\circ} \mathrm{F}$. to $110^{\circ} \mathrm{F}$.

The migrating and nesting habits of birds afford much interest to man. The song and beautiful plumage give us much pleasure; there is also no doubt that birds

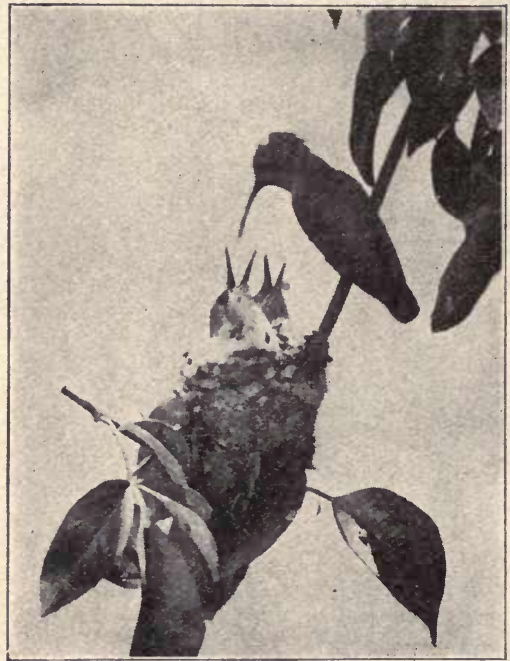

Copyright Henry G. Peabody.

Fig. 116. Humming bird feeding young. are of great value to man in the destruction of insects which destroy plants.

Reptiles. To this group belong snakes, lizards, turtles, and crocodiles. Such animals are characterized by the covering of scales or plates, they breathe by means of lungs, they lay eggs very similar to those of birds, and they are cold blooded animals. By that we mean that the blood is not always warm as it is in mammals or birds.

The members of this group differ greatly among themselves. The turtle is peculiar in having the body covered above and below by a thick shell composed of plates. This affords an excellent place for retreat in case of danger. Like the turtle, the lizard has four 
legs but resembles the snake in the scaly covering of the body. The snake is perhaps the most disliked and

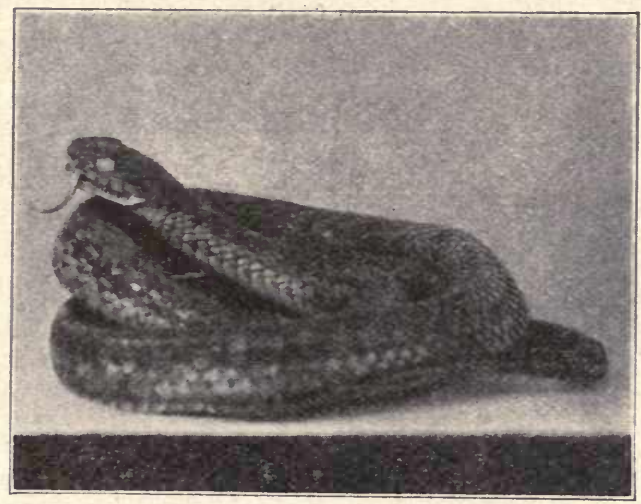

Fig. 117. Snake.

feared of all the animals. This is scarcely deserved because most snakes are harmless. The rattle-snakes, water moceasins, and copperheads are the commonest of the venomous snakes.

Amphibians. (Amphi, both; bios, life). As the name indicates, the members of this group pass a part

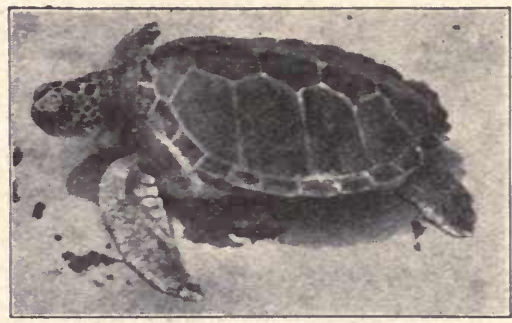

Photograph by American Museum of Natural History.

Fig. 118. Green turtle. of their lives in water and the other part on land. In the earlier stages of their development they take oxygen out of the water by means of gills, the way fish do. Later, however, they 
lose their gills and breathe by means of lungs as do the higher animals. The body is covered with a soft, slimy skin. Amphibians are also cold blooded animals. Frogs, toads, and salamanders belong to this group. Some of
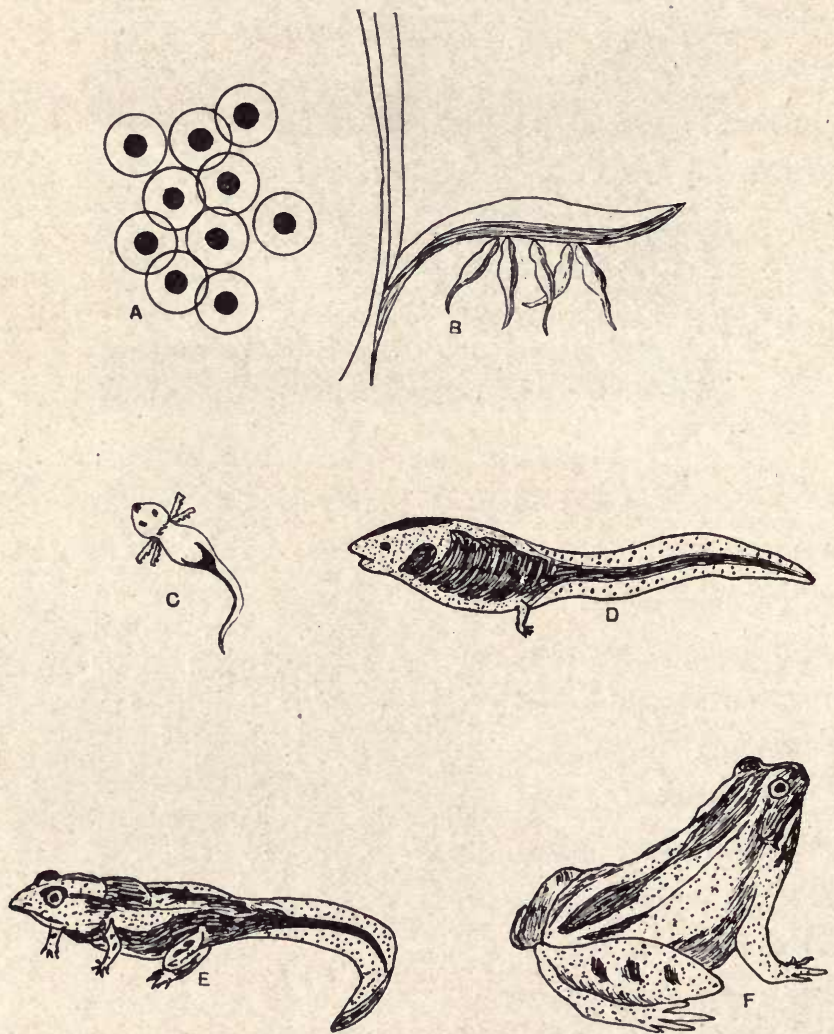

Fig. 119. Stages in the development of the frog.

these, especially the salamanders, greatly resemble lizards. From these animals they are most easily distinguished by the absence of scales. 
The development of many of the amphibians is interesting. The eggs of the frog, for example, are laid in shallow water in the early spring. After these eggs are fertilized they very soon hatch into "polywogs" or tadpoles. These are fitted for living in the water. They have gills for breathing and a tail for swimming. The tadpole grows larger and gradually the outer gills are replaced by gills which grow out under a fold of the skin. The legs soon appear, the hind ones first. By late summer lungs have developed; the legs are well grown; and the tail gradually disappears, being absorbed into the other parts of the body. About this time the young frog leaves the water. Its food is changed from a vegetable to an animal diet, chiefly insects. In some kinds of frogs it takes a longer time for the adult frog to be developed.

When marked changes, such as those in the frog, take place in the development of animals, the process is called metamorphosis (meta, beyond; morphe, form).

Fishes. Fishes, like birds, are easily recognized. To this group belong probably as many as 13,000 different species. It is the largest class of vertebrates. Fishes resemble each other in the following characteristics: gills are used in breathing, the body is often covered with scales, the appendages are fin-like, and the blood is cold.

Fishes are well fitted for their life in water. The shape of the body is such that the water is easily "cut," the fins and large tail are used in locomotion, and gills are present for breathing. The air sac is an interesting 
organ. When this is filled with air, the body of the fish has nearly the same weight as the water which it displaces, and the fish is thus buoyed up.

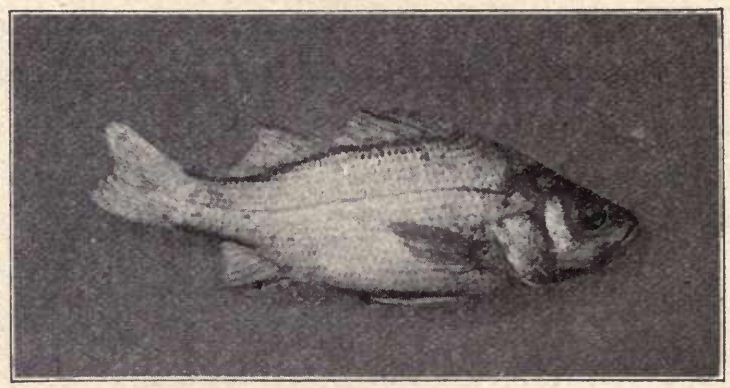

Fig. 120. White perch.

Arthropods. This group of animals, together with all those which follow, belong to the invertebrates.

The arthropods include many animals which you already know. It is an exceedingly large group, and we will consider it in three divisions: (1) Crustacea, (2) Insects, (3) Spiders. All arthropods resemble each other in a few characters: their bodies are made up of divisions or segments; attached to some of these divisions are jointed appendages; all have a hard outer covering on the body.

To the crustacea belong the crayfish, lobster, crab, barnacle, etc. These animals have a hard outer shell. The body is made up of a number of segments to which are attached many appendages, some of which are used for claws, others for walking legs, and still others for swimming. Crustacea, for the most part, live in the 
water and breathe by means of gills. Lobsters and crabs are of great value as food for man. Many of the smaller crustaceans form the principal source of food for fishes.

The insects include more species than all the rest of the animal kingdom put together. It has been estimated that there are between 200,000 and $1,000,000$ different kinds of insects. To this group belong butterflies, moths, flies, mosquitoes, ants, bees, wasps, beetles, dragon flies, grasshop pers, erickets, cockroaches, plant lice, bugs, ete. Here also belong all the

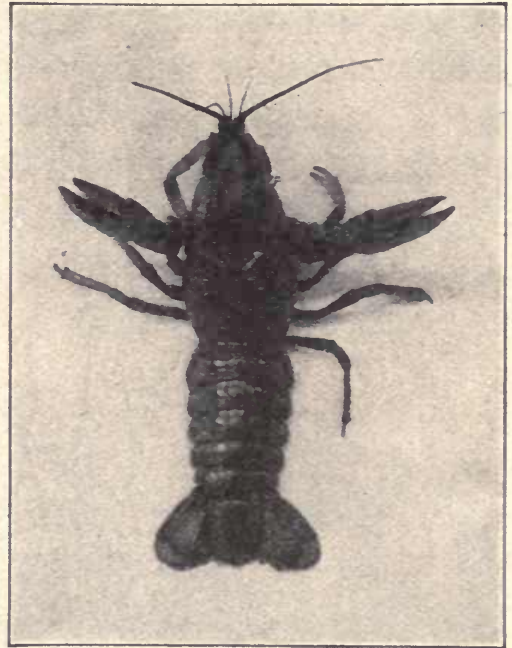

Fig. 121. Crayfish.

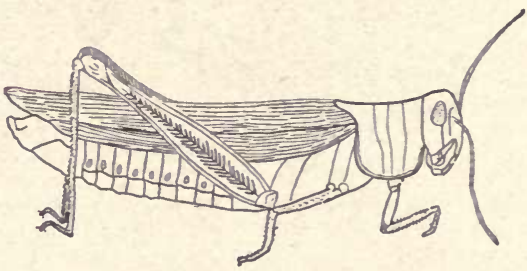

Fig. 122. Locust, a typical insect. caterpillars, maggots, and grubs, for they are one stage in the development of insects.

Insects have the body divided into three main regions: head, thorax, and abdomen. To the thorax are attached three pairs of legs, and usually two pairs of wings. 
Insects breathe by means of air tubes which are connected with the outside through openings in the sides of the body.

Many of the insects undergo complete changes, or metamorphoses, when they develop. For example, the egg of the monarch or milkweed butterfly is laid in late spring. In a few days it hatches into a worm-like larva called a caterpillar. The caterpillar grows very

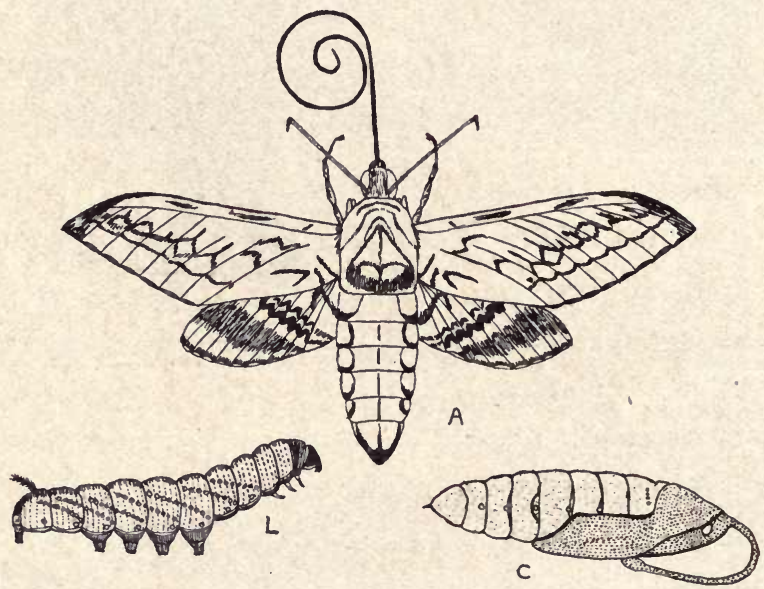

Fig. 123. Development of the sphinx moth; $L$, larva ; $C$, chrysalis ; $A$, adult.

rapidly for a few weeks. Then it stops eating and begins to spin a mat of silk upon a leaf or stem. It attaches itself to this web by the front legs and hangs there. After about twenty-four hours it has passed into a resting stage and is called a pupa, or chrysalis. After a week or more of inactivity, the shell splits and 
an adult butterfly emerges. In moths the pupal stage is passed in a cocoon made of silk or other material. Many insects pass the winter in this quiescent stage.

Insects are of great interest to man for many reasons. 1. Many adaptations occur in insects. 2. Bees and ants are a source of interest because they live in colonies. 3. Many insects are useful to man: the bee supplies honey and wax; the silk worm, silk; and the lady beetles destroy injurious insects. 4. Much destruction results from the fact that many insects feed upon plants useful to man.

The spiders differ from the insects in the absence of wings and in the fact that they have four pairs of legs. The nests of spiders are made of a silk-like material formed in the body and fashioned into the characteristic web by the legs.

Mollusks. The three most common members of this group are the clam, the oyster, and the snail. The bodies of

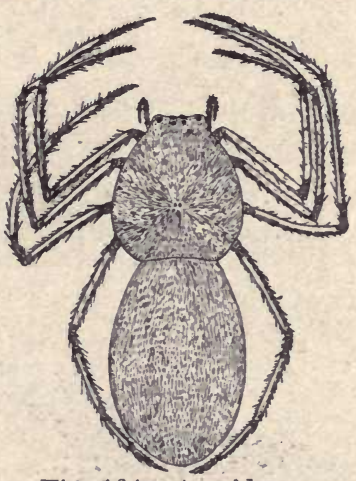

Fig. 124. A spider.

these animals are not segmented and they bear no appendages. They are soft and are protected by a shell. In the clam and the oyster this shell is composed of two parts called valves. It is formed by a fold of skin known as the mantle. Over the inside of the shell a thin, pearly substance is formed 
called "mother-of-pearl." Pearl buttons and knife handles are made from the shells of our fresh water clams. Sometimes an irritation is produced by the presence of some foreign substance, as a small worm which embeds itself in the mantle. As a result of this irritation masses of pearl are formed, frequently in concentric layers, around the irritating substances. These are pearls so much prized as ornaments. Almost all of the mollusks live in the water. They are widely used as food as well as for the commercial purposes already referred to.

Worms. You are familiar with this group from general observation. It is easy, however, to mistake the larvae of some insects for members of this group. The bodies of worms, such as the common earth worm, are composed of a great many segments. These segments are very similar in structure. Short hair-like feet, not jointed, are present on many of them.

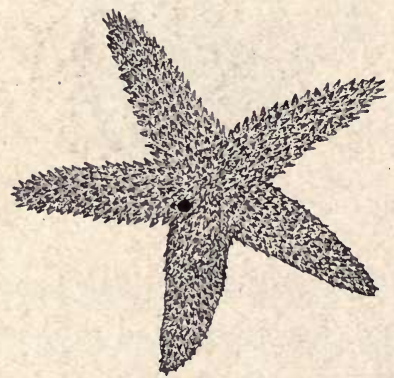

Fig. 125. A starfish.

Echinoderms. These animals are found only in salt water. Here belong the starfish and the sea urchin. The echinoderms are all made on a plan of five. This is very evident in the starfish, which has the five arms radiating from a central disc. These forms usually have the body covered with a skeleton bearing spines. 
Coelenterates. The members of this group are very simple in structure being tubular in shape with but one opening to the body. Frequently thread-like arms are present around this opening. Sometimes these animals reproduce by a process called budding. A small knoblike structure grows out at the side of the body and gradually becomes larger finally forming an adult animal. This bud may break off, or with many others like it, it may remain attached and form colonies. Here belong the jelly-fishes, sea-anemones, corals, and hydras. They are all found in water and most of them only in salt water.

The coral has long been of interest because of the islands, reefs, which are formed by the gradual accumulation of coral shells, and also because of the use of one

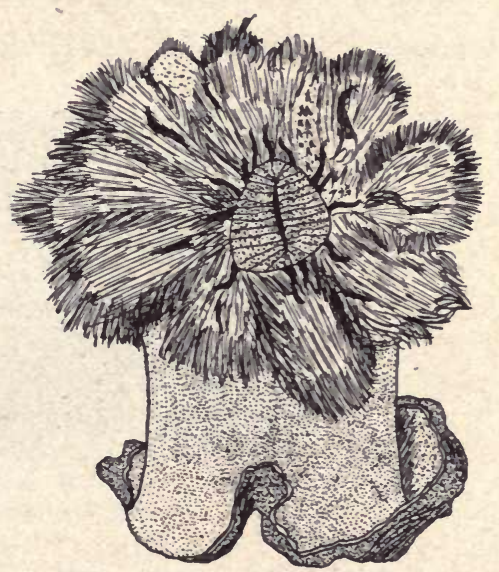

Fig. 126. A sea-anemone. kind of coral for ornaments.

Porifera. The skeletons of some of the representatives of this group form our commercial sponges. Sponges live in colonies. Each of the largest holes in a commercial sponge represents the central body cavity of a single animal. Sponges are very simple in structure; each animal consists of a cup-like structure the 


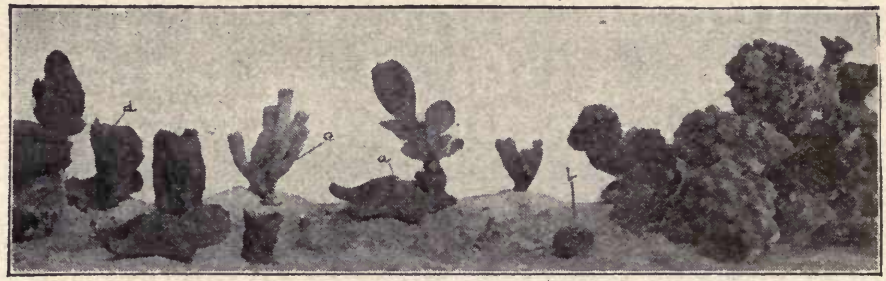

Permission of Field Museum of Natural History. Fig. 127. A group of marine animals; $A$, starfish; $B$, sea urchin; $C$, coral; $D$, sponge.

walls of which are strengthened and supported by a hard or horny substanee. All exeept a very few of the sponges live in the ocean. Most of the sponges which

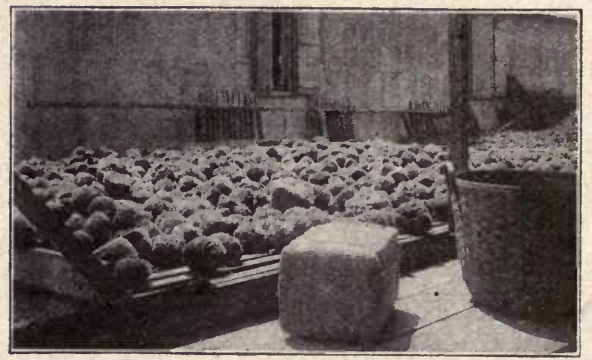

Permission of Field Museum of Natural History. Fig. 128. Drying sponges, Key West, Florida.

are used for commereial purposes come from off the coast of Florida or from the Mediterranean Sea.

Protozoa. These are the simplest animals, and like the simplest plants they consist of but a single cell. They are found in any water, but are most abundant in stagnant water. Many of them are so much like the one celled plants that it is impossible to draw a sharp line between them. All of the protozoa are very small, 
usually invisible, and they can be studied only with the aid of a microscope.

\section{Questions}

1. Name the five groups of vertebrates.

2. Give examples of animals belonging to each group of vertebrates.

3. State the principal characteristics of each of these groups.

4. To which group of animals does man belong?

5. Describe the stages through which the frog passes in its development.

6. Which class of invertebrates has the gieatest number of species?

7. Which groups of invertebrates have members which are of economic value to man?

8. Describe the development of a butterfly.

9. From what animal are pearls obtained?

10. To which group do the simplest animals belong? 


\section{LIFE PROCESSES IN ANIMALS}

Ameba. An ameba is one of the simplest animals in existence. Since it is composed of but one very small cell, its life can not be made up of many complicated

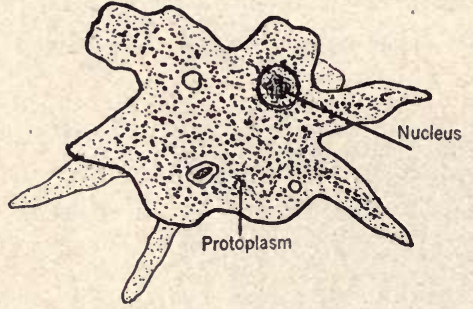

Fig. 129. An ameba. Much enlarged. processes. However, it must perform certain functions or it would not be alive. By studying the few functions which an ameba does perform, we will be able to determine what

processes are essential to the life of any animal.

In stagnant water there is often found an irregular, jelly-like mass. If this is carefully observed under a microscope, it will be found to consist of one cell containing protoplasm and a nucleus. Imbedded in the protoplasm are particles of food. Since the ameba has no mouth, food is taken into the body by a very simple method. Projections are sent out from the body which surround the food and envelop it. The protoplasm of the cell then transforms part of this food into parts of the cell. The shape of the ameba gradually changes and 
as it does so the animal moves, frequently leaving waste products in its path. These are given off at any point on the body. Amebas also breathe. Oxygen diffuses
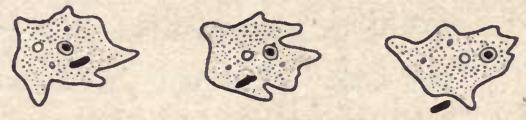

Fig. 130. An ameba giving off waste products.

into the body and carbon dioxide is given off in the same manner. When an ameba becomes a certain size it divides into two nearly equal parts, and thus two smaller individuals are formed. These simple animals are also sensitive to certain agencies, stimuli, acting upon them. They are sensitive to some extent to contact, to
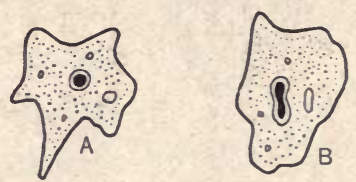
heat, to chemical conditions of the water, to food, to light, and the like.

In this simple animal we find the following processes: 1. It takes food into the body. 2. It digests this food. 3. It gives off waste products.
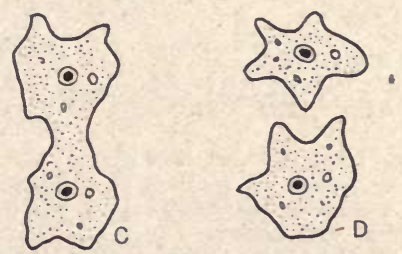

Fig. 131. Four stages in the division of an ameba.

4. It takes oxygen into the cell and earbon dioxide is given off. 5. It moves. 6 . It is sensitive. 7 . It reproduces. From the simple organization of this animal we may infer that all of these functions, at least, are necessary for the life of any animal. 
Not all one celled animals are as simple in structure as the ameba. Neither are the processes in these animals carried on in such a simple fashion. In many protozoa the body is fixed in form, and is moved by

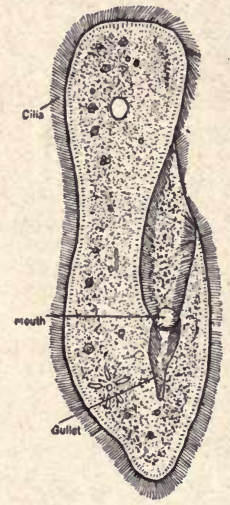

Fig. 132. Paramoecium, a one celled animal, but not so primitive in structure as the ameba. hair-like projections, cilia, which cover the body. There is often a permanent mouth through which food enters the body, and definite canals through which waste products leave it.

Complex animals. We already know that by far the greater part of the animal world is made up of forms much larger and more complex than the ameba. Most animals consist of collections of cells living together. In some animals, such as the sponge, there is very little difference in the cells which comprise it. In other forms, like the mammals, there are innumerable cells of which there are many different kinds.

As we look higher in the animal scale we find that certain parts of the animal are set apart to do certain work and only that work. In a community of people, there are some men who do manual labor; others who are skilled mechanies; some who are shopkeepers; and still others who are professional men. Just so, wherever an animal is composed of many cells, there is division of labor. Some cells are fitted to do one kind of work, others to do another kind. As a result of this division 
of labor, each kind of work in the body of an animal is performed better than it otherwise would be.

Tissues, organs, and systems. As soon as there is a difference in the work which collections of cells have to do, there is also a difference in the structure of the cells. A collection of similar cells performing the same function is known as a tissue (see page 196). Several kinds of tissues may have certain functions to perform together. Such a group of tissues forms an organ. Groups of organs working together form a system. For example, a certain part of our body is used to prepare the food so that it can be used. This is known as the digestive system. It consists of a number of organs such as the stomach, the liver, and the pancreas. Each of these organs in turn is made up of several tissues, and each tissue is made up of a number of cells.

In the higher animals certain tissues are always. present. The more common ones are muscle, connective, epithelial, bone, and nerve tissues. Each of these is composed of cells of a certain structure and having certain definite properties.

Animal functions. An ameba, we know, carries on certain processes. These same general processes are carried on in the higher animals. The difference between an ameba and a dog, for example, is not so much in what each does as in the way that it is done. In other words, there are certain general processes which must be performed by all animals if they continue to live successfully. 
These fundamental processes are:

1. Digestion

2. Respiration

3. Circulation

4. Excretion.

5. Motion

6. Sensitiveness

7. Reproduction

Digestion. Under this head we shall include all the processes connected with the use of food. It must first be taken into the body, after which it must be changed into such a form that it can pass into the body fluids.

In all of the many celled animals, food when taken into the body passes into a tube, which usually extends throughout the length of the body and has two openings. Occasionally, there is only one opening, the mouth.

The size and structure of this tube varies in different animals. Usually it is divided into several regions, such as the mouth, the throat, the esophagus, the stomach, and the intestines. Frequently this latter part is very much elongated so that the length of the digestive tract, or alimentary canal, is very much greater than the length of the body.

Obviously, so long as the food is in this tube it can not become a part of the body. Both the solid and liquid foods must be acted upon physically and chemically in such a way that they will diffuse through the walls of the alimentary canal and into the vessels carry- 
ing the body fluids. This preparation for diffusion is known as digestion. In this process the food is first broken up into small bits and parts of it are dissolved.

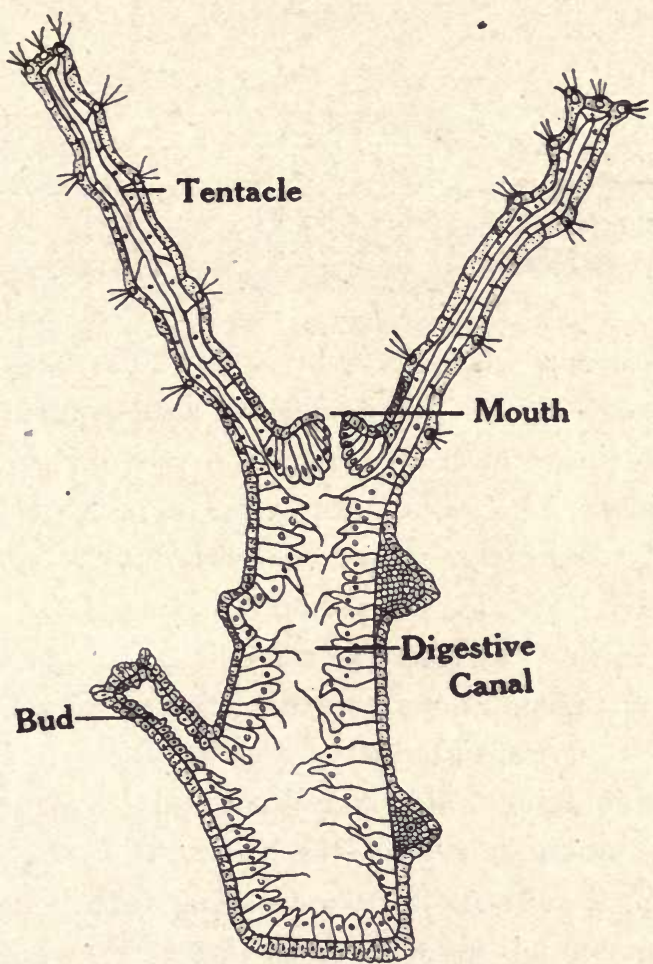

Fig. 133. Diagram of a longitudinal section of a hydra showing a simple digestive system with only one opening, the mouth. Food is digested by the cells lining this digestive cavity.

Then some chemical action takes place. This is brought about by juices which are secreted by cells lining, or opening into, the alimentary canal. Frequently masses of these cells form organs, called glands, whose duty it is 
to secrete juices for digesting the food. After digestion the food diffuses into the body fluids. This process, known as absorption, takes place principally in the intestines.

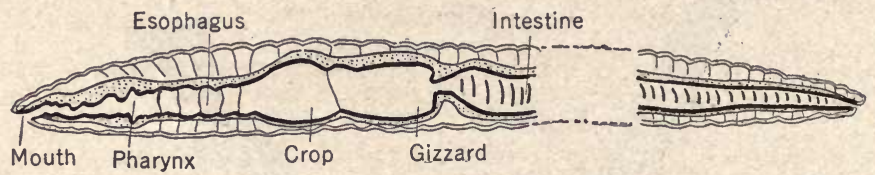

Fig. 134. Section of an earth worm showing the parts of the alimentary canal.

Respiration. The different cells in the body of an animal not only need food, but also oxygen. This is taken into the body from the medium in which the animal lives, either air or water. By means of the body fluids it is then transferred to all parts of the body. The oxygen combines with some of the tissues of the body, and as a result of this process of oxidation, heat and energy are produced. . At the same time certain waste products are formed, chief of which is carbon dioxide. This must be carried to some organ that can eliminate it from the body. This whole process, from the taking in of oxygen to the giving off of carbon dioxide, is known as respiration.

The body structure necessary for this process may be very simple. A thin, moist membrane filled with vessels containing blood or some other fluid, and in contact with air (or water) is all that is essential. Such a simple respiratory system is present in the earthworm, in which the skin is the only organ used in breathing. 
In animals living in the water, the respiratory organs consist of parts outside of the body known as gills. In other animals large sacs (lungs) or tubes (in insects) connect with the outside and serve as stations for the

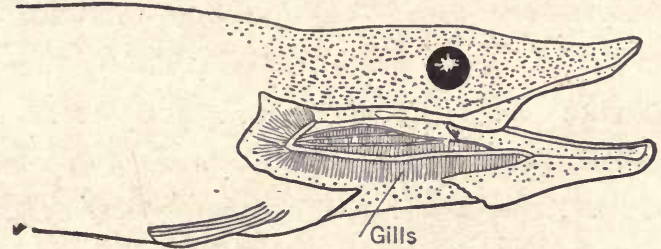

Fig. 135. The head of a fish with the operculum removed to show the breathing organs, the gills.

taking in of oxygen and the giving off of carbon dioxide.

Circulation. In a very small animal, such as an ameba, the food and the oxygen are absorbed any place on the surface of the body and pass from there into all parts of the organism. In all the larger animals, however, food and oxygen are taken into the body in special regions from which they must be carried to all parts of the body. For this purpose fluids are necessary. Generally these fluids, blood and lymph, are circulated through a series of vessels. Somewhere along the route a device is needed for forcing the . blood through these vessels. The portion set aside for this work constitutes the heart. In some animals this is merely a thickened portion of a blood vessel, which as it contracts forces the blood along in the tube. To prevent the fluid from flowing in both directions from the heart, valves are present. In the higher animals 
the heart becomes a complex organ divided into separate compartments for receiving the blood, for sending it out, and for keeping the blood filled with oxygen separated from that filled with carbon dioxide.

Excretion. By means of the blood, food and oxygen are carried to the body tissues. There the food is used for building up the broken cells, or for adding new ones; the oxygen unites with the tissues to produce energy. As a result of this process of oxidation waste products are formed, chief of which are carbon dioxide, water, and a substance called urea, containing compounds of nitrogen. These substances, if allowed to accumulate, seriously interfere with the action of the cells. It is necessary, therefore, that they be carried directly to organs which ean eliminate them from the body. This removal of waste products from the body is called excretion. In all animals the carbon dioxide is removed by the respiratory organs. For the elimination of the other waste products special organs are present. In the lower animals these are often simple tubes opening to the outside of the body, but in all of the higher animals a complex organ, the kidney, is used for this purpose.

Motion. Motion is necessary for the life of an animal. In the ameba we found that this ability to move was in the protoplasm itself. In the higher animals this power of motion is characteristic of certain cells forming muscle tissue. This tissue is present wherever there is motion. In most animals special appendages, such 
as legs or wings, are present, the movement of which makes locomotion possible. Sponges and corals, on the other hand, are always attached and can not move from place to place.

Sensitiveness. Even the simplest one celled animals respond to certain stimuli. If a point on one side of the body is touched in some way, a message is conducted to all parts of the cell and the animal moves. As animals increase in complexity they become more sensitive, and special organs are developed for special senses. An earthworm, for example, is sensitive to light and darkness. It has no eyes, but all of the skin near the head end is sensitive to light. In higher animals well developed eyes are present, which can not only distinguish between light and darkness, but also between colors. Animals also have special organs which are sensitive to touch, others to sound, and still others to odors. From these special structures the message is not transferred from cell to cell and thus to all parts of the body, but it travels along definite tracts (nerves) which carry it to a central organ, in higher animals the brain. From this central organ messages are sent out to muscles which cause them to act and produce motion.

The brain and nerves not only make it possible for animals to see, hear, and feel, but they also keep all parts of the body working together harmoniously.

Reproduction. The length of time which animals live varies greatly. Many smaller forms, such as insects, live 
only one season, while elephants are known to live two hundred years. Sooner or later, however, each animal dies. Frequently death is due to some external cause, such as disease or injury. If not, the cells of the body gradually lose the power to perform the functions of growth and repair, and finally all the life processes cease. Since animals persist on earth, evidently new ones are constantly being formed. This process of producing new individuals is known as reproduction.

In the one celled animals this process is very simple. After an ameba, for example, reaches a certain size,
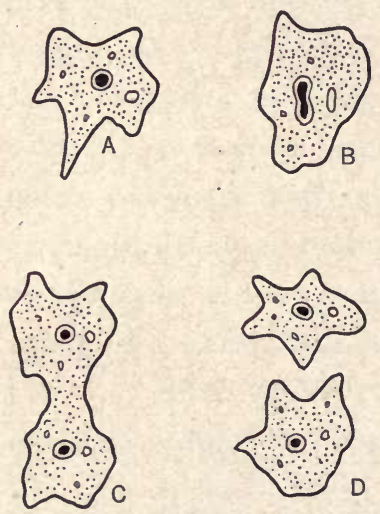

Fig. 136. Four stages in the division of an ameba.

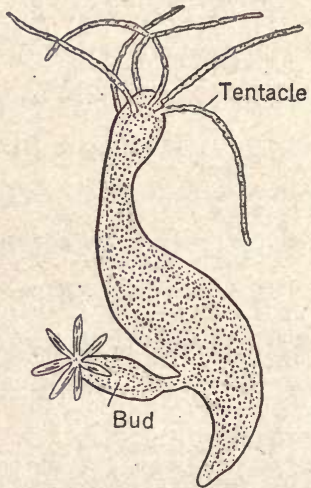

Fig. 137. Hydra showing a bud. Budding is one method by which animals may reproduce.

the whole cell divides into two nearly equal parts, each of which is a perfect but smaller individual. Sometimes, as in sponges, hydras, and corals, reproduction takes place by budding. A small knob-like outgrowth appears on the side of a sponge. This gradually 
increases in size, and finally a complete new sponge is formed.

In all higher animals certain organs of the body are used for reproduction, just as certain organs are used for digestion or for respiration. In these organs two kinds of cells, egg and sperm cells, are produced. The egg cells are formed in the ovary which is a structure present in the female, and the sperm cells are formed in the spermary of the male. One of these egg cells unites with one of the sperm cells, and a fertilized egg is formed. The single large cell then divides a great many times, and gradually a new animal is formed, which is like the parents which produced it, except smaller and younger.

All higher animals commence life as a single cell formed by the union of two cells, one from the male and one from the female. The development of the animal from this cell varies in different animals. In many animals, such as the frog, the fish, the reptile, and the bird, there is often attached to this cell a large amount of food material forming what is known as an egg. As the young animal develops in this egg it lives upon this food. In all mammals the egg develops into a young animal within the body of the mother. The new individuals are then born with the various structures of the body well formed. 


\section{Questions}

1. Where does the ameba live?

2. What is the structure of an ameba?

3. Name the processes which are carried on by the ameba.

4. How does the ameba perform each of these processes?

5. Compare the paramoecium with an ameba. Which is the more complex in structure?

6. What are the advantages of division of labor in an animal?

7. Define and give examples of tissues, organs, and systems.

8. Why is it necessary for animals to digest the food which they eat?

9. In what part of the body does digestion take place?

10. Why is it impossible for animals to live without oxygen?

11. What is the source of carbon dioxide in an animal?

12. Compare the respiratory organs of the earthworm with those of man.

13. From what source do fish obtain their oxygen supply? What kind of breathing organs do they have?

14. What are the principal functions of the circulatory system?

15. Name three waste products formed in animals.

16. Define excretion.

17. What is the name of the tissue in animals which is used to produce motion? 
18. Of what use to an animal is the nervous system? What are the principal parts of this system?

19. How long do animals live?

20. If possible, ascertain the average number of years which man lives.

21. How can you account for this low figure?

22. How do one celled animals reproduce?

23. What is an egg cell? A sperm cell?

24. What is a fertilized egg?

25. What is the function of the white and the yolk of a chicken's egg? 


\section{RELATION OF ANIMALS TO MAN}

General statement. Man is dependent upon other forms of life for subsistence. So varied and numerous are the relations of animals to human life and welfare that members of all the various groups of animals affect human interests in one way or another. To

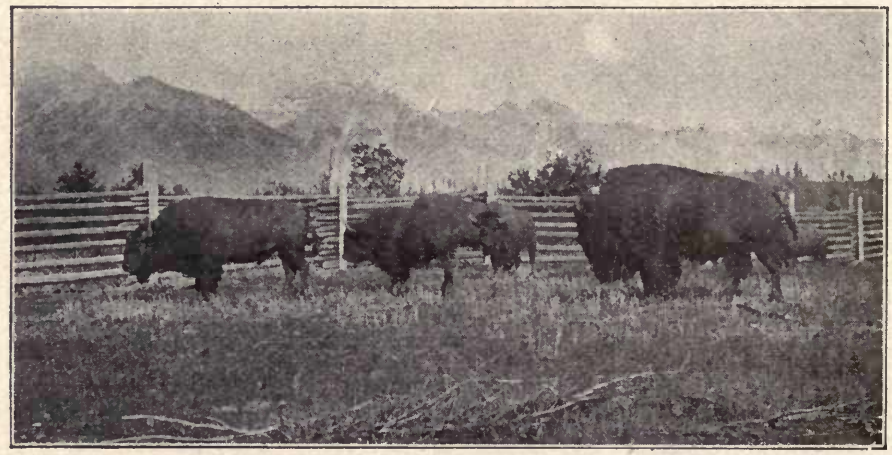

Photograph by Henry G. Peabody.

Fig. 138. Bison in Rocky Mountain Park, Canada.

This fine animal has been hunted for its skin and flesh until it is now practically exterminated.

realize this, we need only to refer to some of the facts which concern us most directly regarding animals which we use for food, such as cattle, sheep, swine, fish, frogs, turtles, oysters; those which furnish clothing 
materials-wool, furs, and silk; those which attack our crops; those which attack us and produce diseases or those which carry them; those which invade our dwellings and feed upon our clothing or stored foods; or still others which are annoying or dangerous because of their stings or bites.

Many of our greatest industries and most important articles of commerce are dependent upon animals which furnish food supplies or clothing material, such as beef, milk, butter, wool, furs, eggs, buttons, ivory, bone, oysters, fish, ostrich plumes, feathers, honey, wax, silk, lac, cochineal dyes, hair, etc.

Animals useful to man. Under this head we shall consider (1) domesticated animals; (2) animals used for food; (3) animals producing materials for clothing.

Domesticated animals. In the early stages of civilization man began to domesticate animals. At first these animals were probably used to aid in the hunting and capture of other animals for food. Gradually they were used for riding, for cultivating the soil, and for carrying loads. We scarcely appreciate the money value at the present time of horses, cows, poultry, and other domesticated animals.

Food-supplying animals. Among the invertebrates we find some very important food-supplying animals, the most valuable of which are the lobster, crab, oyster, and clam. To some extent the mussel and the snail are used as food. The lobster is highly esteemed in this respect, and is rapidly disappearing from our 
coast as a result of over fishing. The annual value of the lobsters taken on the North Atlantic eoast is about $\$ 15,000,000$. The oyster industry is even more profitable, aggregating over $\$ 50,000,000$ a year. Every class of vertebrates furnishes species used as food. The total annual value of the fisheries of the United States is over $\$ 50,000,000$. Frogs and turtles are edible, but are of minor importance for food. Many kinds of birds are eaten, furnishing annually hundreds of millions of dollars'worth of food to man. To the mammals belong the cow, the swine, and the sheep, the animals which supply most of our meat. Besides meat, chickens furnish eggs, and cows furnish milk, butter, and cheese.

Animals supplying clothing. We derive most of the materials from which our clothing is made from plants. But the use of feathers, furs, skins, and wool of animals for clothing materials is of considerable importance. From the invertebrates only one product is obtained, but that is of great value. When the caterpillar of the silk worm moth goes into the resting stage, it forms a cocoon made of silk secreted by glands in its body. The worms are killed by putting the eocoons into hot water, and then the silk is unwound. From these silk threads one of our most expensive fabrics is made. The silk industry is of much importanee in China and Japan. It has not proved profitable in the United States because of the high cost of labor. Our prineipal source of clothing is the vertebrate animals, more especially the mammals. From these we obtain a great variety 
of furs, the choicest of which come from the ermine, the seal, the sable, the beaver, the mink, the fox, the squirrel, and the skunk. Cheaper furs are obtained from the eat, the $\operatorname{dog}$, the raceoon, and the rabbit. From the skin of the coarser haired animals, such as the cow, the sheep, and the horse, leathers are made.

Animals injurious to man. Animals are injurious to man directly or indirectly in many ways. We will consider only those forms (1) which produce or carry human diseases, and (2) which are injurious to crops.

Diseases produced and carried by animals. Within recent years we have learned that yellow fever, malaria, smallpox, sleeping sickness, and some other diseases are caused by the presence and growth of one celled animals (protozoa) in the human body. Long ago it was discovered that various parasitic worms, such as the tapeworm and the trichina, lived in our bodies and were the causes of pain and injury to the body. More recently the hook-worm has been found to be responsible for much of the laziness and shiftlessness of "the poor whites" of the South. The entire South undoubtedly has been retarded in its development by this parasite. Not only are some diseases produced by animals, but some diseases are spread by them. The mosquito and fly carry malarial fever and typhoid fever, the tse-tse fly carries sleeping sickness, and the flea carries bubonic plague from rats to man.

Animals injurious to crops. Insects do the greatest damage to erops. Experts estimate that insects rob 


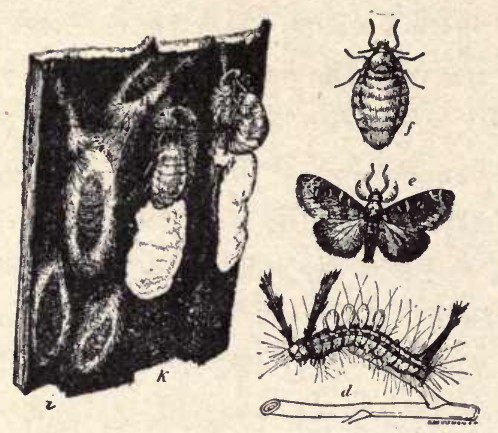

Permission of U. S. Dept. of Agriculture.

Fig. 139. The tussock moth is a common insect injurious to shade trees. $F$, adult female; $E$, adult male; $D$, larva; $K$, females laying eggs on bark of tree; $I$, pupae in cocoons.

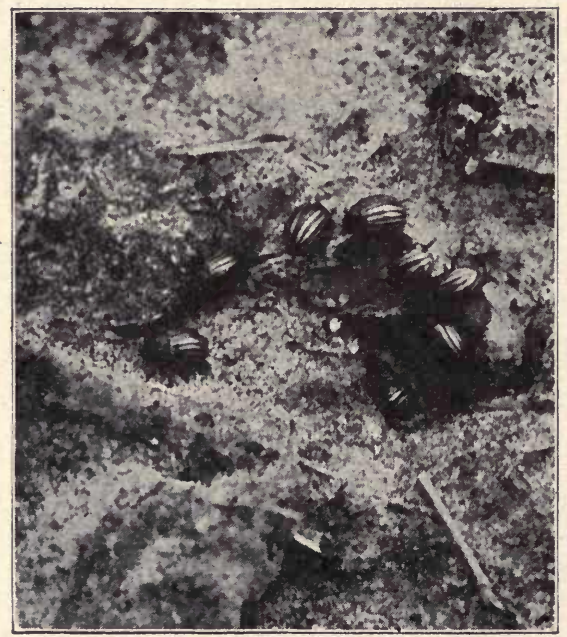

Permission of U. S. Dept. of Agriculture. Fig. 140. The potato beetle is one of the best known of the garden pests. us each year of about $\$ 500,000,000$ worth of crops, forest trees, and lumber. There are thousands of different kinds of these pests. Some devour foliage, others attack fruits and seeds, and still others bore into the wood of the tree on which they live. In combating with insects the farmer is assisted and directed by the Bureau of Entomology of the United States Department of Agriculture and by various state experimental stations. The most effective means of control thus far found is by poisonous sprays. By this method both the adult and the 
Permission of $U$. S. Dept. of Agriculture.

Fig. 141. Bollweevil, one of the most important enemies of cotton plants.

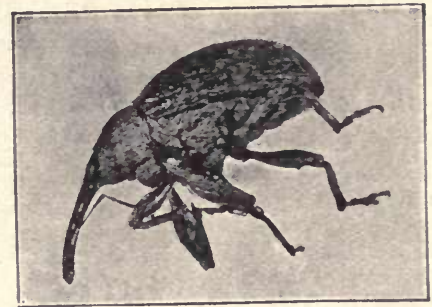

Permission of $U$. S. Dept. of Agriculture.

Fig. 142. Codling moth ; $A$, adult ; $B$, larva in apple ; $C$, pupa or chrysalis.
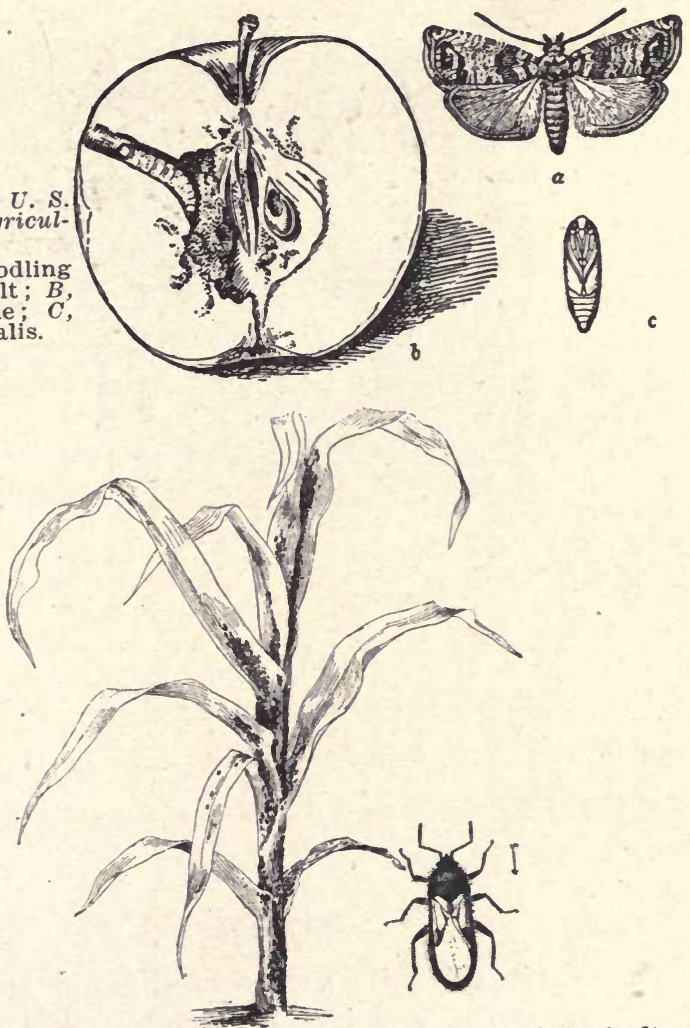

After U. S. Dept. of Agriculture. Fig. 143. Corn plant two feet tall infested with chinch bugs. Adult enlarged. 
young insects are killed. A newer method of fighting insects is the introduction of one speeies of inseet to attack and to keep in check another speeies of insect. This method has proved quite successful in the California orange orchards. It was found that a little black - and red beetle of Australia fed upon one of the seale insects which was very injurious to orange trees. These

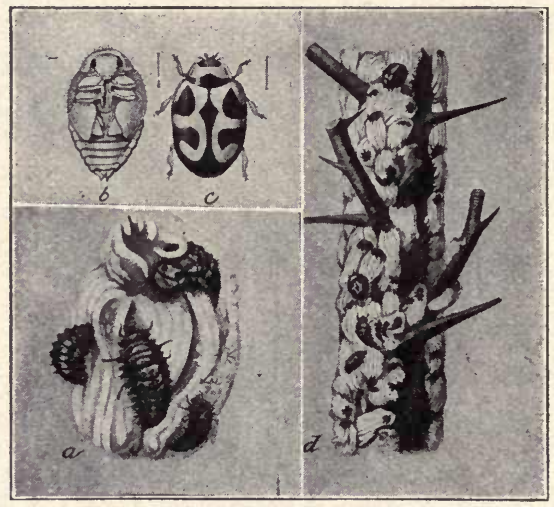

Permission of U. S. Dept. of Agriculture.

Fig. 144. Australian ladybird beetle and fluted scale; $A$, larvae of beetle feeding on scale; $B$, pupa of beetle; $C$, adult beetle; $D$. orange twig showing scales and beetles.

beetles were introduced into scale-infested orange orchards. They increased in numbers, fed upon the scale insects, and in a few years practically relieved the California growers of all anxiety concerning the scale insects.

\section{Questions}

1. Name the principal domesticated animals.

2. Learn, if possible, from what wild form each of these has come. 
3. Name five animals used by man as food.

4. Is the federal government justified in maintaining a Bureau of Fisheries? Give reasons for your answer.

5. From what animals do we derive materials for clothing?

6. How is artificial silk manufactured?

7. Name three diseases caused by one celled animals.

8. Name two parasitic worms.

9. From government pamphlets, or elsewhere, learn what you can of the history of the hookworm.

10. What is one of the functions of the Bureau of Entomology?

11. Is it important for us to know how to combat insect pests?

12. What are some of the common insects injurious to crops in the locality where you live?

13. Name the pests of shade and fruit trees in your region. 


\section{CHAPTER XXXV \\ MAN'S PLACE IN NATURE}

Classification. In our study of the classification of animals we learned that man is a member of the mammals, the highest group of vertebrates. The particular class of mammals which includes monkeys, apes, and man is known as the primates. In body structure all the members of this class are very similar, the gorilla being most like man.

The greatest difference between man and the manlike apes is not in structure but in intelligence. There is a great mental gap between man and the most intelligent of the apes, the chimpanzee. However, there undoubtedly once lived on the earth races of men who were of a much lower scale of mental development than the present inhabitants.

Differences between man and other primates. Structurally there are some very apparent differences between man and the other primates. Man is more erect in position. The back of the head, the cranium, is relatively larger in man, thereby balancing the head on the vertebral column. The arms are much shorter; the thumb is well developed and can be opposed to the fingers; the great toe is smaller and can not be opposed. 
The legs in man are better developed and the hip bones are large enough to support the body in an upright position. The brain is much more developed and much

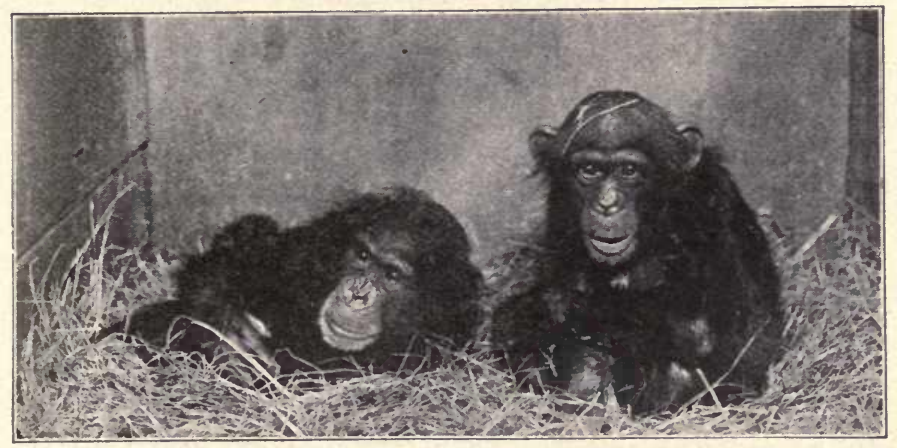

Fig. 145. Chimpanzees.

larger, weighing in the average man two or three times that of the gorilla. Because of the greater development of the brain, the modes of life and the other activities resulting from a high grade of intelligence clearly separate man from the lower primates.

Age and races of man. The first men, undoubtedly, lived much as the lower animals now live. They wandered about from place to place living upon whatever they could kill. Gradually thè began to use implements, the first of which were made of stone. These implements were at first used as weapons to aid in the capture of prey for food. As civilization advanced, implements were made of bone, and then later, copper, bronze, and iron. Finally man began to domesticate animals, to cultivate the fields, and to have a fixed 
place of abode. Man lived in this way for thousands of years. Remnants of the implements which he used have been found, but we have no other records of the history of primitive man. The earliest monuments and inscriptions which we have date back more than six thousand years.

There exist upon the earth at present at least three varieties of man. Each of these differs from the others in external appearance, in instincts, and in social customs. These three varieties are: (1) The white or Caucasian; (2) the yellow or Mongolian; (3) the black or Ethiopian. To these are often added the brown or Malay race of the islands of the Pacific, and the red or American Indian.

The human body. In our present study we are especially interested in man as he exists to-day. It is important for each of us to know how the human body is constructed (anatomy); what work, or function, each part of the body must perform and how this is accomplished (physiology); and finally, how to care for the body in such a way that all its parts are working normally, and consequently are in good health (hygiene).

We can not properly care for the body unless we know its structure and its functions. We often underestimate the value of such knowledge concerning the parts of the body used in digesting the food, the structures used for admitting air, or getting rid of waste materials. Such knowledge may be of great aid to us. Health is wealth. It not only leads to material wealth, 
such as money, but it is necessary for the greatest happiness. We all know how expensive sickness is, and we also know how much human misery it brings. In order to better understand the body, which is so like a complicated machine, it is necessary to study the structure of its parts and their different functions. Only in this way is it possible to understand the human body as a whole.

\section{Questions}

1. Name three animals belonging to the primates.

2. Discuss the differences between man and the other primates.

3. What do you know about the history of man?

4. What sources do we have for estimating the age of man?

5. Name the chief races of men. Where is each found?

6. Why is it of value to you to know something about your body? 


\section{FOODS}

Introduction. In construction work the building materials which we use depend upon the kind of building which we expect to erect. Sometimes we use bricks and cement, other times we use wood and nails. From time to time the building, after its completion, needs repair. Parts decay or become worn and have to be replaced by new material; or, sometimes, additions are made to the original building.

Much the same principle holds true for the living world, plants and animals. Each plant and each animal is constantly being worn out and being added to. The building materials which are supplied to the plant or to the animal we call food.

Elements in food. This food, obviously, must contain the elements of which the plant or animal is composed. Since all living material is much the same in chemical composition, both plants and animals need about the same elements. In the human body those elements which are most common are carbon, hydrogen, oxygen, nitrogen, calcium, phosphorus, sulphur, sodium, chlorine, fluorine, potassium, and iron.

Use of food. We need food for exactly the same 
reasons that the plant does: first, for growth; second, for the repair of tissues worn out in doing work; and third, for producing heat. For growth we need foods which contain the elements which are found in protoplasm. Heat is produced in the body by slow oxidation. Foods used for this purpose must contain large quantities of carbon, since most of the energy in the body is produced by the oxidation of carbon.

Foodstuffs. We already know that we can not live on water, carbon dioxide, and mineral matter from the soil. These simple substances constitute the raw foodmaterials for plants, but they can not serve as food for us. For our food we use complex chemical compounds in the form of meats and vegetables. Chemists have analyzed our foods, and have found that all of them are composed of one or more of five classes of compounds. These are known as the foodstuffs. The most important foodstuffs are proteins, carbohydrates, fats and oils, minerals, and water.

Proteins. Different varieties and forms of protein are found in nearly all kinds of animal and vegetable foods. The most common protein foods which we obtain from animals are meat (except fat), milk, eggs, cheese, and gelatin. Of the plants, peas, beans, and all cereals except rice give us protein.

The proteins are often called the nitrogenous foods because they always contain large quantities of nitrogen. In addition to nitrogen they contain carbon, hydrogen, oxygen, sulphur, and sometimes phosphorus 
and iron. These elements form complex compounds, the exact composition of which is not known.

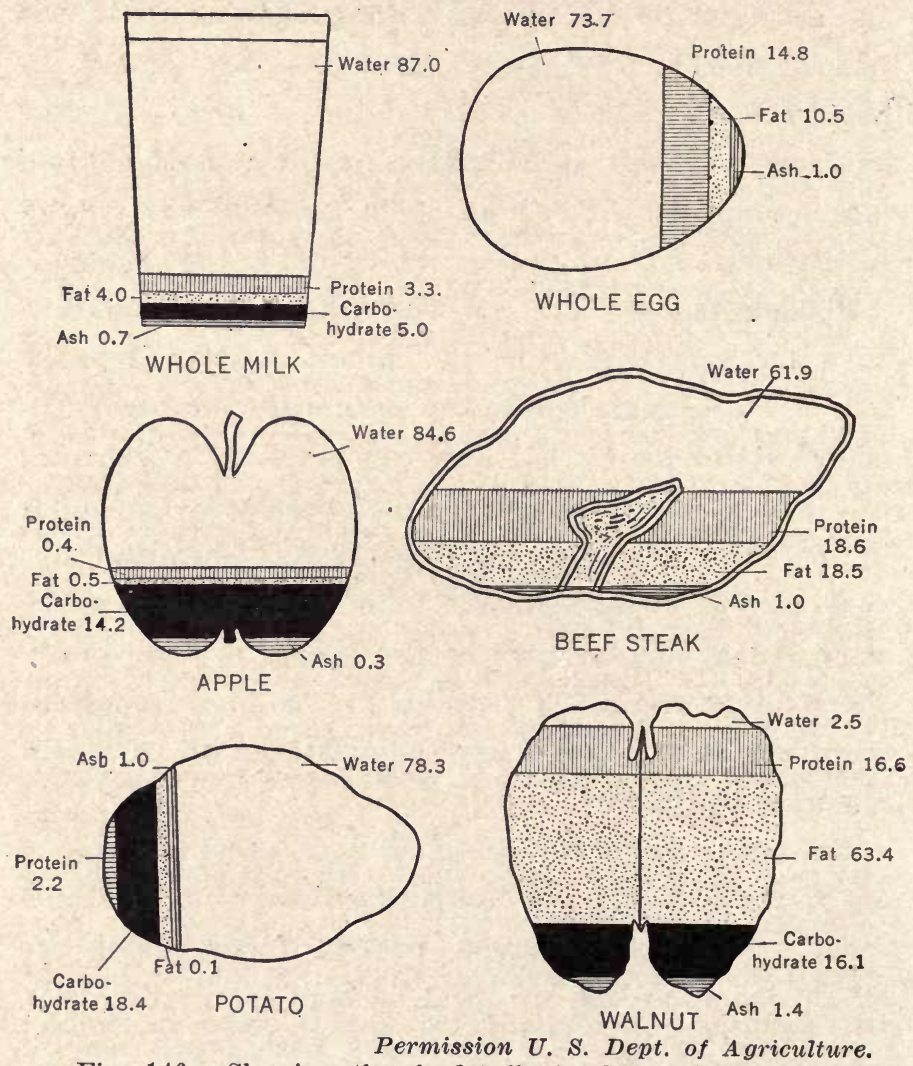

Fig. 146. Showing the foodstuffs in different foods.

Test of protein. There are a number of ways in which the presence of protein in food may be detected. One of the best methods is the use of nitric acid and ammonia. Some of the food to be tested is placed in a 
test tube, and strong nitric acid is added. The mixture is heated, and if protein is present the food changes to. a yellow color. If then the acid is poured off, and strong ammonia added, the yellow color changes to a deep orange, and we may be sure protein is present.

Carbohydrates. In this class are included starches and sugars. The carbohydrates are composed of three elements : carbon, hydrogen, and oxygen. These are so combined that there is always twice as much hydrogen as oxygen. For example, the formula for common sugar is $\mathrm{C}_{12} \mathrm{H}_{22} \mathrm{O}_{11}$, for grape sugar $\mathrm{C}_{6} \mathrm{H}_{12} \mathrm{O}_{6}$, and for starch $\mathrm{C}_{6} \mathrm{H}_{10} \mathrm{O}_{5}$.

Starch. Starch is formed in all green plants. Frequently it is stored in the cells of grain, in seeds, and especially in stems and roots. We obtain much of our starch from potatoes and bread.

Test for starch. Starch when treated with a solution of iodine turns dark blue. This is the test usually employed to detect the presence of starch.

Sugar. Sugar is likewise derived from plants. There are many different kinds of sugar; for example, cane sugar, grape sugar, and milk sugar. These substances differ more or less in chemical composition. However, both cane and milk sugar may be changed into grape sugar by boiling them with hydrochloric acid.

Test for sugar. In the test most commonly used to detect the presence of sugar, a mixture called Fehling's solution is used. If a few drops of this solution are 
added to a solution containing grape sugar and then boiled, the color becomes brick red.

Fats and oils. Under this class are included not only what we ordinarily understand as fat, but also all vegetable and animal oils. Like the carbohydrates, the fats and oils contain only the three elements, carbon, hydrogen, and oxygen, but in different proportions. They have a much lower percentage of oxygen. They are all lighter than water and insoluble in it.

Test for fats and oils. The presence of fats may be detected in one of two ways:

(a) Put a small quantity of the substance to be tested on a piece of paper and slowly heat it. If fat is present, it will make a translucent grease spot on the paper.

(b) Fats are soluble in benzine and ether. The substance to be tested is soaked in benzine or ether. Then it is filtered. If the solution is allowed to stand, the ether will evaporate. Fat, if present, will then remain, because it does not evaporate.

Mineral salts or inorganic foods. Dissolved in ordinary drinking water, in lean meat, and in vegetables are many forms of salts. Only one, common salt, do we add to our diet. All salts are unburnable. When foods are burned, if ashes are left behind, we may conclude that mineral matters are present.

Water. Nearly $59 \%$ of the weight of our bodies is water. Some water is taken into the body directly, but much of it indirectly. A large proportion of most 
of our foods is water. As we know, water evaporates. This enables us to determine the quantity of water present in a food by heating it until dry. The loss in weight represents the amount of water present.

\section{Questions}

1. Name the principal elements found in the body,

2. What is a food?

3. State two reasons why we need food.

4. What are the five foodstuffs?

5. Name the elements found in each foodstuff.

6 . What is the test for each foodstuff?

7. How do fats differ from carbohydrates? 


\section{CHAPTER XXXVII}

\section{COMPOSITION OF FOODS}

Content of foods. The extent to which the food stuffs occur in some of our foods is indicated in the following table, which is taken on the authority of the United States Department of Agriculture. The

\begin{tabular}{|c|c|c|c|c|c|c|}
\hline FOOD & $\begin{array}{l}\text { Pro- } \\
\text { tein }\end{array}$ & $\begin{array}{l}\text { Carbo- } \\
\text { hydrate }\end{array}$ & Fat & Water & Ash & $\begin{array}{c}\text { Calories } \\
\text { per } \\
\text { Pound }\end{array}$ \\
\hline Beef steak ...... & 18.6 & 0. & 18.5 & 61.9 & 1.0 & 1090 \\
\hline Veal, leg cut.... & 20 & 0 & 7 & 68 & 1.0 & 695 \\
\hline Mutton, loin ..... & 13 & 0 & 28 & 42 & 0.7 & 1415 \\
\hline Pork chop ..... & 16.9 & 0 & 30.1 & 52 & 1.0 & 1535 \\
\hline Fowl $\ldots \ldots \ldots \ldots$ & 14 & 0 & 12 & 47 & 0.7 & 765 \\
\hline Fish, mackerel .. & 18.3 & 0 & 7.1 & 73.4 & 1.2 & 620 \\
\hline Oysters ........ & 6.2 & 3.7 & 1.2 & 86.9 & 2 & 230 \\
\hline Eggs ........... & 14.8 & 0 & 10.5 & 72.7 & 1.0 & 695 \\
\hline Butter ........ & 1.0 & 0 & 83.0 & 13.0 & 3.0 & 3405 \\
\hline Milk, whole ..... & 3.3 & 5.0 & 4.0 & 87.0 & 0.7 & 315 \\
\hline Cheese, cream.... & 25.9 & 2.4 & 33.7 & 34.2 & 3.8 & 1885 \\
\hline Bread, white .... & 9.2 & 53.1 & 1.3 & 35.3 & 1.1 & 1180 \\
\hline Bread, whole wheat & 9.7 & 49.7 & 0.9 & 38.4 & 1.3 & 1110 \\
\hline Oat breakfast food & 2.8 & 11.5 & 0.5 & 84.5 & 0.7 & 280 \\
\hline Corn meal ....... & 9 & 75 & 2 & 12 & 1.0 & 1635 \\
\hline Rice $\ldots \ldots \ldots \ldots$ & 8 & 79 & 0.3 & 12 & 0.4 & 1620 \\
\hline Potato ......... & 2.2 & 18.4 & 0.1 & 78.3 & 1.0 & 375 \\
\hline Beans, green string & 2.3 & 7.4 & 0.3 & 89.2 & 0.8 & 190 \\
\hline Beans, shelled ... & 9.4 & 9.1 & 0.6 & 58.9 & 2.0 & 720 \\
\hline Corn, green ..... & 3.1 & 9.7 & 1.1 & 75.4 & 0.7 & 460 \\
\hline Apple $\ldots \ldots \ldots$ & 0.4 & 14.2 & 0.5 & 84.6 & 0.3 & 285 \\
\hline Banana ........... & 1.3 & 22.0 & 0.6 & 75.3 & 0.8 & 445 \\
\hline Strawberry ...... & 1.0 & 7.4 & 0.6 & 90.4 & 0.6 & 175 \\
\hline Walnut ........ & 16.6 & 16.1 & 63.4 & 2.5 & 1.4 & 3180 \\
\hline Peanut ........ & 25.8 & 24.4 & 38.6 & 9.2 & 2.0 & 2485 \\
\hline
\end{tabular}


carbohydrate column is mostly starch, except in milk, where it is all sugar.

The amount of energy yielded when a pound of food is oxidized is expressed in calories. For example, one pound of butter will yield 3405 ealories of heat and one pound of strawberries only 175 calories. The ash content reprèsents the mineral salts present.

According to this table, which foods will yield the most protein? Carbohydrate? Fat? Energy?

Use of foodstuffs. As we have stated before, food is used for the repair and growth of the body and to supply energy in the form of heat or action. Energy is the ability to do work. Both action and heat are thus forms of energy. Foods must supply the body with building material and with fuel.

Building material. Some foods, the nitrogenous ones, supply all that is essential for the growth and repair of the body. We would expect this when we recall that the body is composed of cells, that cells contain protoplasm, and that protoplasm and protein are nearly identical in composition. Mineral salts are known, too, to share in this repair. Proteins may be oxidized, but this is not their principal use.

Fuel. It may be that carbohydrates and fats are used as building materials, but their principal use is to serve as fuel. When they are oxidized they supply heat and power. Fat is especially suited to this purpose; that is the reason why inhabitants of cold countries eat such large quantities of fatty foods. Some 
of the fat and also some of the carbohydrates which we eat are stored away in the body to be kept for future use.

Quantity and kind of food. It perhaps has never occurred to you that there is a reason, other than taste, why we have certain combinations of foods. For example, why do we use meat, potatoes, other vegetables, and a dessert as the essential parts of a dinner? It is because meat supplies protein and fats; vegetables, protein but principally carbohydrates; and dessert, carbohydrates. All contain mineral salts and water. Together they give us a better balanced ratio of the different foodstuffs than any one food alone would give. Variety in our foods also appeals to the taste. Enjoyment of our foods usually adds to the ease with which they are digested.

It is difficult to determine how much food we need. The amount varies so much with each individual that we can not make even a general statement of much value.

Selection of food. Daily in each home a selection of food must be made. What shall determine this selection? Shall we buy the foods which we like the best? Shall we buy the foods which cost the least, or the ones which, according to market prices, are highest priced? It must be apparent to you that not any one of these factors is alone sufficient to determine this selection. It is not so easily solved that we can merely consult our tastes, or our purses, or the prices which 
conditions render necessary, or the producer pleases, to place on his goods.

It is true, these factors must be considered. But first we must determine the kind of food which will supply the materials which our bodies need. The amount of protein needed will vary with the amount of manual labor we do, the amount of fat and carbohydrate with the energy used, and also with the temperature. The highest priced foods are not always the most nutritious. Neither is it always economy to buy the cheapest foods. The problem is how to buy the largest amount of nutritious food for the least money.

Adulteration. The purchaser must also consider the relative purity of foods. This is especially necessary in different brands of canned goods. Many of them contain adulterants or preservatives which are dangerous to the health. Legislative measures are now being taken to protect the public against adulterated foods. A national law, commonly known as "The Pure Food Law," was passed in 1906 for the prevention of adulteration and misbranding of foods or drugs. This stimulated further state legislation. Now nearly every state has a general food law and is making an attempt to enforee it.

Cooking. Some foods, like. fruits, milk, and nuts, are eaten without being cooked. The great majority, however, are cooked. As a result of cooking, meats and vegetables are more easily digested and are made more palatable. 
Sometimes in foods, bacteria and other parasites are living. Most of these are fortunately destroyed at the temperature of boiling water. Trichina and tapeworm are two parasitic worms sometimes present in meats in a so-called resting stage. Trichina is found in pork. When diseased pork, poorly cooked, is eaten, these small worms again become active. They bore their way through the walls of the alimentary canal and finally settle in the muscles. This produces a painful and sometimes fatal disease. The tapeworm is found in pork and beef. It attaches itself by means of hooks to the walls of the alimentary canal, remains there and grows. It can readily be removed and no serious results follow.

Decay in meat is brought about by bacteria. If the process has continued far enough poisons, called ptomaines, are produced. The bacteria, but not the poisons, can be rendered harmless by heat. As a result ptomaine poisoning frequently follows the eating of tainted meats, especially fish, and spoiled ice cream.

Milk can be rendered harmless by heating it for half an hour in water at a temperature of $140^{\circ} \mathrm{F}$. to $160^{\circ} \mathrm{F}$. It should then be cooled and kept cool. This process, known as pasteurization, kills the bacteria and at the same time obviates some of the disadvantages of boiling milk. 


\section{Questions}

1. Name five foods rich in protein. In starch. In fats.

2. Which foodstuffs are used principally for building materials? For fuel?

3. Explain the advantages in the following combinations of foods: bread and butter, ham and eggs, macaroni and cheese, potatoes and meat, pork and beans.

4. Suggest a menu for a breakfast. For a lunch. For a dinner. Explain in each instance why you made this selection and combination of foods.

5. Upon what basis should one make his selection of food?

6. Would it be wise for a laboring man to live on potatoes only, just because they were cheap?

7. Why should the food which we eat in the summer differ from that which we eat in the winter?

8. From your grocer learn the price of foods. Using this information and the table on page 304, suggest foods which it would be advisable for a poor man to purchase.

9. What is meant by adulteration of foods?

10. What are pure food laws?

11. Why should we always read the labels on canned goods and drugs before purchasing them?

12. Why do we cook our foods?

13. What are ptomaines?

14. What is pasteurized milk? Certified milk? 


\section{DIGESTIVE SYSTEM}

Introduction. We have just discussed the composition of foods and the uses of foods to the body. It is evident to everyone, however, that many changes must take place before the food which we eat can become a part of the body. These changes take place in a set of organs which we call the digestive system. This system consists of two parts, the alimentary canal and the digestive glands.

Alimentary canal. The alimentary canal is a long tube extending through the body and having two openings, the mouth at one end and the anus at the other. In some animals this tube is almost straight and of about the same diameter throughout the body. In man, however, it is over thirty feet long and with a diameter which varies greatly.

It begins at the mouth opening, enlarges and forms the mouth cavity, which in turn communicates with the smaller throat cavity. Posterior to the throat is a tube which is called the gullet, or esophagus, opening into an enlarged pouch, the stomach. From the stomach the food is conducted into the long coiled intestine, which fills most of the lower part of the trunk of the body. 


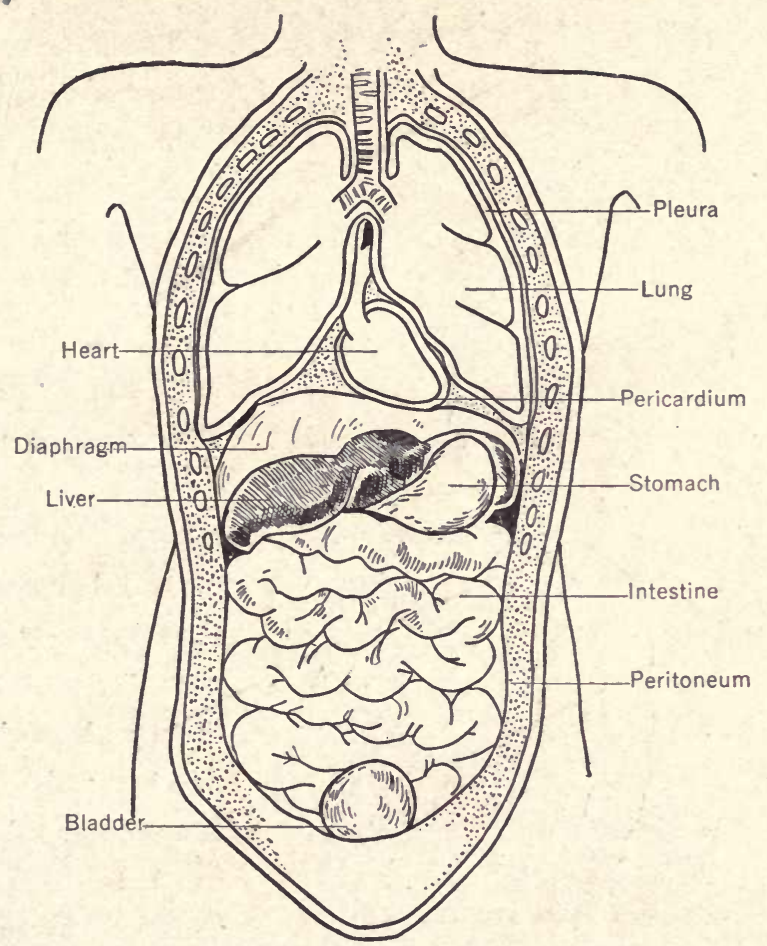

Fig. 147. Diagram showing the position of the organs in the body cavity which is divided by the diaphragm into thorax and abdomen.

Digestive glands. Connected with the alimentary. canal are a number of glands. The digestive juices which act chemically upon the food are produced by these glands. The salivary glands pour their secretion into the mouth. The gastric glands open into the stomach. The secretions from three other glands, the intestinal, the liver, and the pancreas, flow into the intestine. 


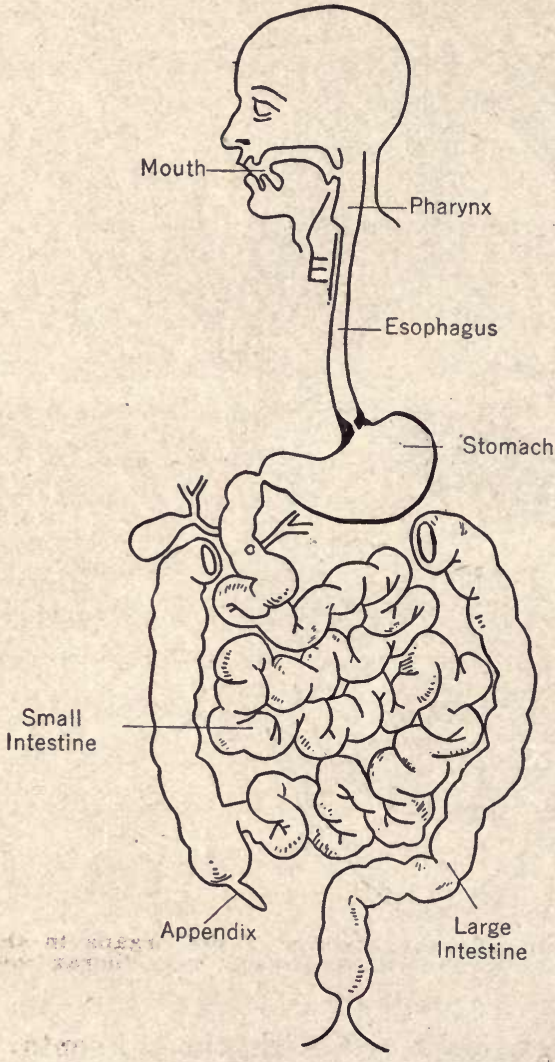

Fig. 148. The alimentary canal.

The mouth. The cavity of the mouth is bounded in front and at the sides by the lips, the cheeks, and the teeth, and below by the tongue. The roof of the mouth is formed by a horizontal plate of bone called the hard palate. Near the middle of the mouth the hard palate ends and is continued backward by the soft palate. Hanging down from the roof of the mouth, and separating it from the throat, is the uvula. The entire cavity is lined with a soft moist covering called the mucous membrane. This membrane is continuous and forms the inner lining of the whole alimentary canal. It secretes a watery fluid known as mucus.

Teeth. Within the mouth are the teeth which are 
set in sockets formed in the bone of the upper and lower jaws. In a complete set of an adult there are thirty two teeth. They are not all alike. In front in each jaw there a re four teeth with chisel shaped edges, the incisors, which are used for cutting the food. On each side of these there is one pointed tooth. Because of their resemblance to the teeth of a dog, these two teeth are called the canine teeth. Their shape fits them for tearing the food. Just behind each canine tooth there are two

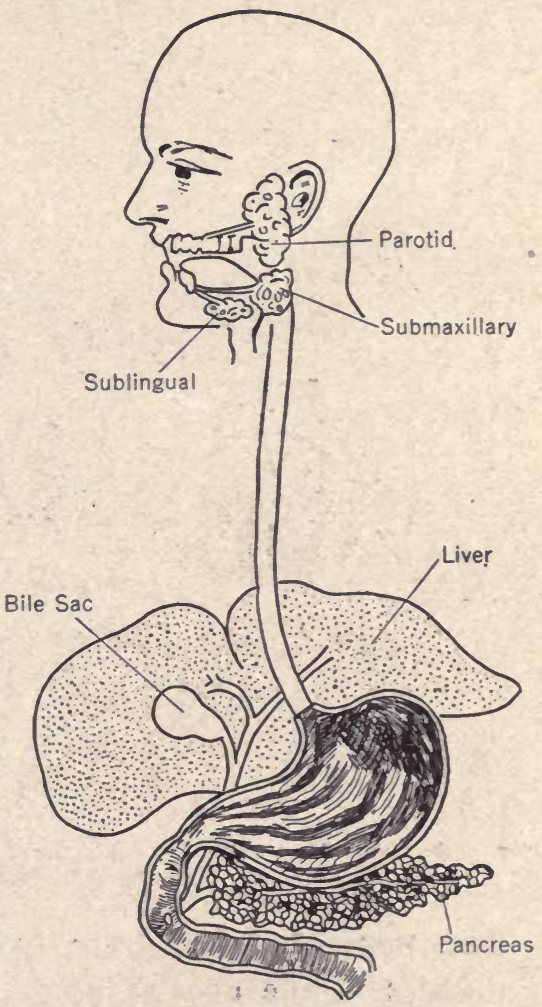

Fig. 149. The digestive glands. teeth which have the biting surface divided into two parts. These are the bicuspids, (Latin, bis meaning twice, and cuspis, a point). The three teeth on each side back of the bicuspids are the molars. These have broad flat surfaces for grinding the food into small 
pieces. The last molar on each side often appears as late as the twentieth year, sometimes later, and is ealled a wisdom tooth.

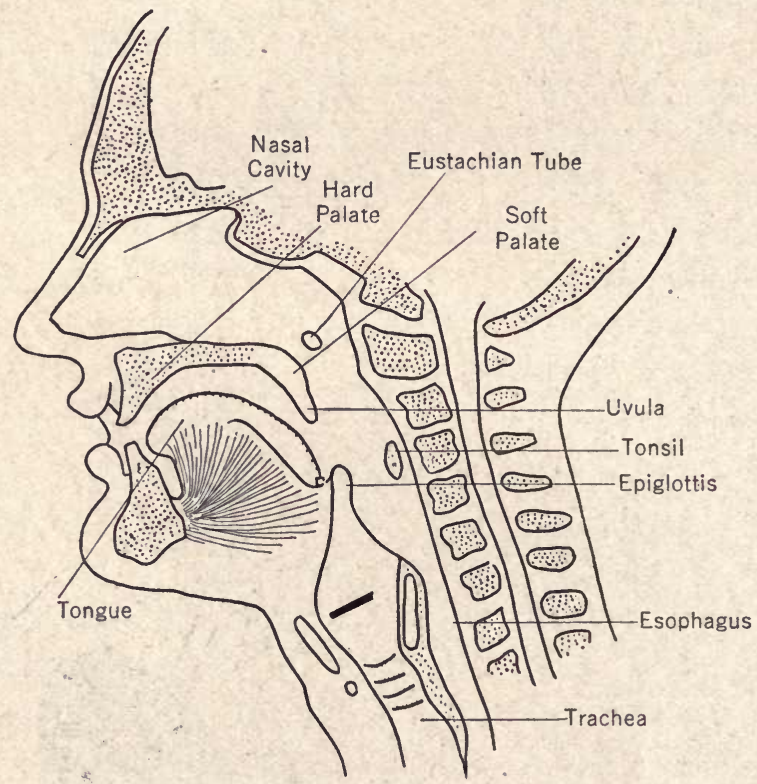

Fig. 150. Median section through the head showing the relation of the mouth and nasal cavities to the esophagus.

Structure of tooth. The portion of the tooth embedded in the bone is the root of the tooth; the exposed portion is the crown. Covering the crown is a layer of enamel, which is the hardest tissue in the body. The root has no enamel, but is covered with a layer of cement. The largest part of the tooth is composed of a bone-like substance called dentine. This surrounds a small cavity, the pulp cavity. Through a 


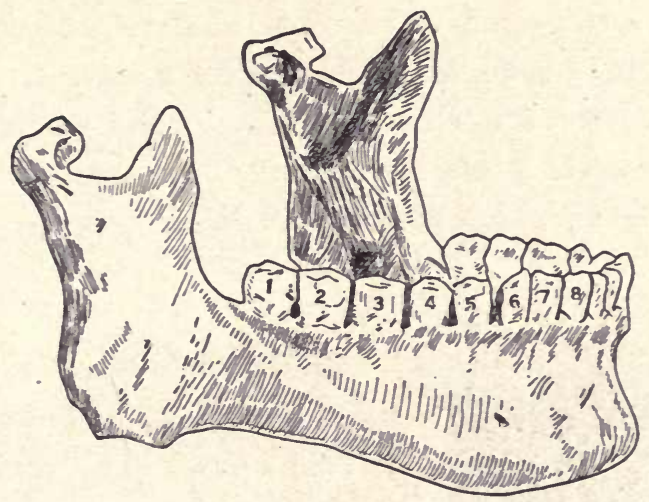

Fig. 151. Lower jaw bone with the teeth in place; 1, 2, 3, molars: 4,5 , bicuspids; 6 , canine; 7,8 , incisors.

small aperture at the end of the root, nerves and blood vessels enter this cavity.

Care of the teeth. Enamel is not a living substance and can not be repaired when injured. Frequently the enamel is cracked or worn through. This may be caused by picking the teeth with a hard instrument such as a pin. A sudden change in temperature is likely to crack enamel. Particles of food sometimes remain between the teeth. These decay and form an acid which destroys the enamel. After this, decay takes place rapidly in the soft dentine.

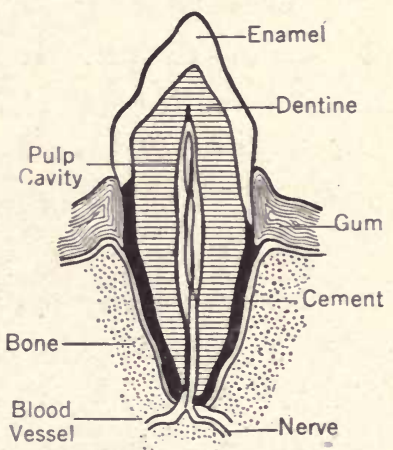

A person is always well Fig. 152. Section of a tooth. 
repaid for any care he may give his teeth. They should be carefully brushed at least twice a day. It is well occasionally to use a soft powder. A mild antiseptic mouth wash is also beneficial. The teeth should be inspected by a dentist once or twice a year.

The tongue. The tongue is a muscular organ attached at the back to the floor of the mouth. On its

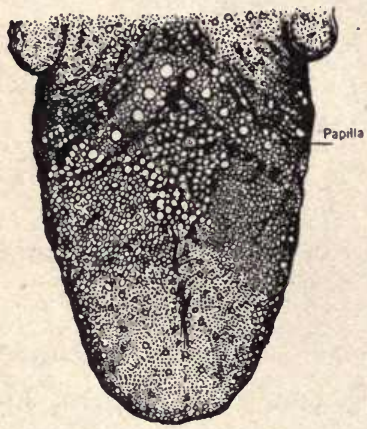

Fig. 153. The tongue. upper surface are numerous elevations of different sizes. These are called papillae; in them are located the nerves of taste. In what form must a substance be in order to taste it?

Salivary glands. In the mouth there are two secretions, mucus from the mucous membrane, and saliva from the salivary glands. There are three pairs of salivary glands. Two of these glands, the parotid (Greek meaning, "beside the ear") are loeated in front of and below the ear. These are the glands which swell in the disease known as the mumps. From the parotid gland on each side a tube, the duct, opens on the inside of the cheek opposite the upper second molar tooth.

The other two pairs of glands lie in the floor of the mouth. These are the sub-maxillary (Latin, sub means beneath, and maxilla means jawbone) and the sublingual (Latin, sub means beneath, and lingua means 
tongue). The ducts from these glands open in the floor of the mouth just below and back of the lower incisor teeth.

Throat or pharynx. This is a small cone-shaped cavity just back of the mouth cavity. On each side of the throat there is an almond-shaped gland, the tonsil. There are seven openings in the throat: two at the top open into the nasal cavity, one into the mouth, one into the esophagus, one into the wind pipe, and one into each ear. The tubes leading to the ears are known as the Eustachian tubes. The wind pipe lies in front of (or ventral to) the gullet. At the top of the wind pipe is the voice box. This can be closed by a small trap door called the epiglottis.

Esophagus. The esophagus is a narrow tube about nine inches long leading from the throat to the stomach. Just before it reaches the stomach it passes through a sheet of muscle and connective tissue known as the diaphragm. This muscular partition divides the body into an upper portion, the thorax, and a lower portion, the abdomen.

Stomach. The stomach lies in the middle of the body just below the diaphragm. It is a muscular organ, more or less pear-shaped with the larger end lying toward the left side. When moderately filled, it holds about three pints. The small end of the stomach is continuous with the intestine. The opening into the small intestine is controlled by a ring of muscle. The contraction of this muscle closes the opening and prevents 
the food from passing out of the stomach as soon as it enters.

The stomach is lined with a mucous membrane. This is larger than the stomach and is thrown into folds running lengthwise of the organ. When examined with a lens, this membrane is seen to be covered with numerous small pits, which are the openings of many little tubes formed by the folding of the mucous membrane. This further increases the internal surface of the stomach. Each tube is the outlet of a gastric gland. These glands secrete another digestive fluid, the gastric juice.

Intestines. The intestines are divided into two regions. The first, a tube about twenty feet long and with a diameter varying from two inches near the stomach to one inch at the other end, is called the small intestine. The second, the large intestine, is about five feet long with a diameter varying from two and one-half to one and one-half inches. The general arrangement of the two intestines is shown in the figure. Notice how the small intestine enters the large one. Projecting from the sack-like pouch at the beginning of the large intestine is a worm-like extension, the vermiform appendix. Inflammation of the appendix causes the disease known as appendicitis.

The small intestine, like the stomach, is lined by a mucous membrane which is thrown into folds across the tube. The surface of the mucous membrane is 
further increased by numerous minute projections called villi.

As before stated, the secretions from three kinds of glands are poured into the small intestine. The intestinal glands are embedded in the walls of the intestine. The other two glands are the liver and the pancreas.

Liver. The liver is the largest gland in the body. It is a dark red mass and lies just under the diaphragm. On the inner side of it is located a small sac, the gall bladder. In this the bile, secreted by the liver, is stored until it is needed. The duct from the liver enters the small intestine just below the stomach.

Pancreas. The pancreas, often called sweet breads, lies just below the stomach. It secretes a digestive fluid called the pancreatic juice. This enters the intestine through the same duct as the bile.

Peritoneum and mesentery. Lining the abdominal cavity there is a thin moist membrane, the peritoneum. From the back it folds over the organs of the abdomen and forms their outer covering. The stomach and the twenty-five or thirty feet of intestines are suspended by a double fold of peritoneum. This is known as the mesentery and is attached to the body wall in the upper part of the abdominal cavity. The organs hang loosely suspended in this cavity. The manner of their suspension and their smooth outer covering give the loops of the intestines perfect freedom of motion on each other. 


\section{Questions}

1. Name the contents of the thoracic cavity.

2. What organs are located in the abdominal cavity?

3. Name and locate the parts of the alimentary canal.

4. Give eight facts concerning an adult's teeth.

5. What is the appearance of the upper surface of the tongue?

6. Name the seven openings in the pharynx.

7. What is the diaphragm?

8. Locate the stomach. What is its size?

9. Compare the small and large intestines in size.

10. Locate the appendix. What is the cause of appendicitis?

11. Name and locate the salivary glands, gastric glands, liver, pancreas, and intestinal glands.

12. Which of the digestive glands is the largest? 


\section{CHAPTER XXXIX}

\section{DIGESTION}

Introduction. The alimentary canal is a series of small chemical laboratories, in each of which are special digestive fluids. These are chemicals which act, each in a special way, upon the foods with which they come in contact. This whole process we call digestion.

Necessity of digestion. We have learned in our laboratory exercises that if molasses and water are separated by an animal membrane, diffusion takes place in both directions. We did not learn, however, that all liquids would not behave in this manner. If we used olive oil or the white of egg, the results would be very different. Neither the egg nor the oil would diffuse.

In order that the food

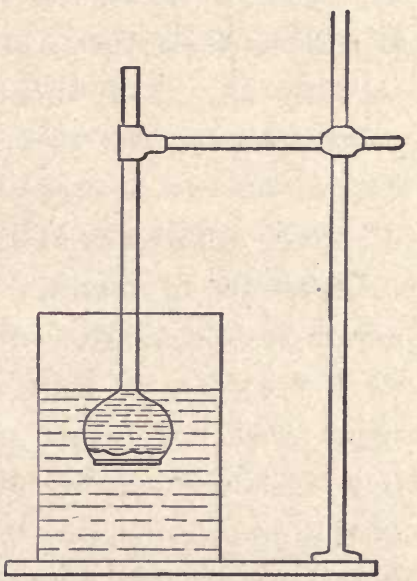

Fig. 154. Experiment showing diffusion. The liquid in the thistle tube is separated from that in the jar by an animal membrane. which we eat may be utilized, it must leave the alimentary canal and be taken to all parts of the body 
by the blood. The walls of the alimentary canal have no openings, neither have the walls of the blood vessels. Consequently the food must pass through these walls by diffusion. Obviously, then, the purpose of the process of digestion is to act upon the food in such a way that it can diffuse through these membranes. This means that it must be not only in the form of a liquid but in the form of particular kinds of liquids, for all liquids do not diffuse.

Action upon food. In its passage through the canal, food is acted upon both physically and chemically. The food is chewed or rubbed into small fragments. If soluble, these then dissolve. If they ean not be dissolved, they then undergo chemical changes which make them soluble and simpler in their composition. This action is brought about by substances in the digestive juices called enzymes.

Digestion in mouth. When the food enters the mouth it is first chewed or masticated. This enables us to swallow it more easily. But, of far greater importance is the fact that by breaking the food up into small particles we expose more of it to the action of the digestive juices. It is very important that we chew our food thoroughly. "In chewing, the food is moved about largely by the action of the tongue. At the same time, it is mixed with the liquid in the mouth, which is a mixture of mucus and saliva.

Saliva is a slightly alkaline liquid, mainly water. By it the food is moistened and softened; at the same time 
sugar, salt, and a few other substances are dissolved. Chemically, saliva acts upon starch, changing it into a form of sugar. Only a small part of the starch which we eat has time to be changed during the short time the food is in the mouth. The food is pushed back from the mouth by the tongue. It passes down the esophagus and enters the stomach.

Digestion in stomach. The walls of the stomach are composed of several layers of muscles. By the action of these muscles the food is churned about and thus thoroughly mixed with the gastric juice. The stomach may be closed by means of the ring of muscles at the lower end. At intervals it is opened to allow the food which is suitably prepared to pass on.

Gastric juice is a thin colorless liquid consisting mainly of water $(99.4 \%)$. In it are also small amounts of hydrochloric acid and two enzymes, pepsin and rennin. The pepsin and hydrochloric acid act upon proteins. As a result of this action, protein is ready for diffusion. Rennin acts only upon the protein of milk. This it curdles, after which the protein is acted upon by the pepsin. Rennin is frequently used in the manufacture of cheese. In the stomach fats are melted and oils are emulsified; that is, they are broken up into very small drops and then scattered through the fluid.

The food remains in the stomach about three hours. The gastric juice starts to flow when food enters the stomach. The flow may be further stimulated by the flavor of food. It has been estimated that about three 
quarts of gastric juice are formed in twenty-four hours.

Digestion in intestine. The food as it enters the small intestine is composed of very fine particles mixed with much fluid. These particles are partly digested. Aside from the mechanieal action on the food, part of the starch has been changed to sugar in the mouth, and protein has been partly digested in the stomach. The remainder of the starch and protein and all of the fats need now to be acted upon by the three digestive juices in the small intestine. These juices are all alkaline.

The intestinal juice acts upon starch, changing it to sugar. It also acts upon all the complex sugars, reducing them to sugars of very simple composition.

Bile assists in the digestion of fats. The pancreatic juice, the most important of the digestive juices, acts upon all kinds of foods. It contains one enzyme which acts on starches and sugars, another which acts on proteins, and still another which converts some of the fat into soap, fatty acids, and glycerine.

By the action of the muscles in the walls of the intestine the food is slowly moved along in the small intestine. At the same time that the undigested food is being acted upon, the digested food is being diffused into the blood. It probably requires seven or eight hours for food to pass the length of the small intestine.

Large intestine. The food passes very slowly through the large intestine. There are no new digestive 
juices added to the foods, but those already mixed with the food continue their action, diffusion goes on, and finally there are left in the large intestine only such substances as can not be digested. These substances, known as the feces, consist chiefly of woody parts of cell walls of regetables, hard tough parts of meats, and brown colored waste from the bile.

It is very necessary that these waste products be regularly expelled from the body. In them the conditions are excellent for the growth of bacteria, which result in the formation of poisons. These poisons, if allowed to accumulate, may become absorbed and cause headaches followed by more serious effects. Proper exercise and a suitable diet, including fruits, large amounts of water, and much coarse food will aid greatly in preventing clogging of the intestines.

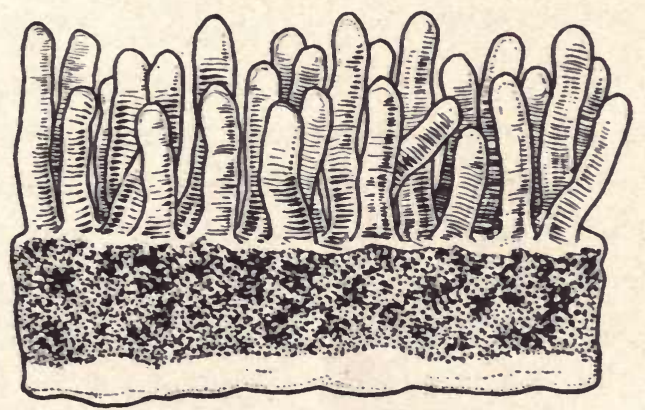

Fig. 155. A small portion of the wall of the small intestine magnified to show the villi.

Absorption. As we have stated before, the chief purpose of the process of digestion is to prepare the food so that it will diffuse. This process of diffusion 
in the alimentary canal is commonly known as absorption. By means of folds and finger-like projections, villi, the lining of the small intestine is

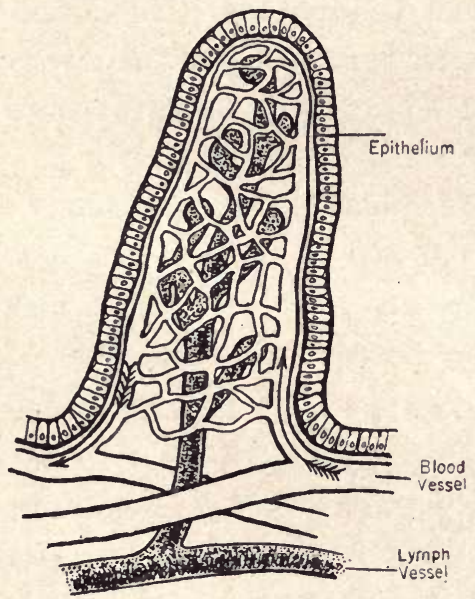

Fig. 156. Section of a villus, highly magnifled. especially adapted for absorption. In each villus there are two sets of small vessels. One set contains blood, the other contains a watery fluid called lymph.

The sugars and nitrogenous foods pass into the blood vessels and are then carried into larger vessels through the liver, and from there to the heart. In passing through the liver some of the sugar is left behind and stored in the form of glycogen or "liver starch." Fats pass into the lymph vessels. These enter larger vessels which finally empty into a vein in the neck. From there the fats enter the heart with the blood. From the heart all these foodstuffs are then distributed to all parts of the body.

\section{Questions}

1. Explain fully why it is necessary to have the food digested.

2. What is an enzyme? 
3. What changes, physical and chemical, take place in the food while it is in the mouth?

4. What is the digestive fluid in the stomach? What chemical change does it produce in the food?

5. Name the three digestive fluids in the small. intestine.

6. State definitely the action of each upon the food.

7. In what part of the alimentary canal does most food diffuse into the blood?

8. What is the structure of a villus?

9. Trace the path taken by fats from the intestine to the heart.

10. Trace sugars and proteins from the intestine to the heart.

11. Which foodstuff is stored in the liver?

12. How long does it take, from the time food is eaten, until it becomes a part of the body?

13. What is the function of the large intestine? 
CHAPTER XL

\section{NARCOTICS AND STIMULANTS}

Characteristics. Nareotics are substances which decrease the activity of the brain. If taken in large doses, they cause a person to fall into a kind of stupor or a deep sleep. The commonest narcotics are tobacco, morphine, laudanum, and opium.

Stimulants, on the other hand, increase the activity of the organs of the body. Commonly used stimulants are alcohol, tea, coffee, strychnine, and belladonna. Some of these, such as alcohol, act as stimulants in moderate doses and when first taken into the body. In large doses following this stimulating effect, they produce a stupor similar to that resulting from narcotics.

Neither narcotics nor stimulants are necessary in order that the body may perform its functions properly. Moreover, it is a well-known fact that persons who have become slaves to the use of either are not as successful and happy as those who do not use them.

Tobacco. Tobacco consists of the dried leaves of the tobacco plant grown extensively in many parts of the south as well as in other warm climates. The active substance in tobacco is nicotine, a deadly poison. Like 
other poisons, one may become so accustomed to its use by beginning with small doses, that finally even large doses produce little apparent effect. The nicotine is a mild narcotic. It dulls the sensibilities and weakens the nerves. In young boys who are habitual users of tobacco the nervous system does not develop properly. As a result, they fall behind in their school work. Less than $7 \%$ of the school children who smoke are able to keep up their work. They become dull and backward instead of keen and alert. They are not apt for school work. They are often rejected for athletics because they can not act and think quickly. In a similar way, later in life they are not fitted for such positions as demand good, clear, and rapid thinking.

Much of the nicotine is absorbed by the blood vessels and is then passed into the heart. It has very injurious effects upon this organ, especially in young people. The heart becomes enlarged and weakened sometimes to such an extent that a "tobacco heart" is produced. This frequently makes it necessary to reject boys from athletic contests and from occupations requiring a good physique.

Many business corporations demanding workers who are mentally, physically, and morally sound will not employ a person who is a smoker. This alone should be sufficient argument against the use of tobacco.

Opium and other narcotics. Opium is made from the milky juice which is found in the green seed-pod of the poppy. Morphine and laudanum are made from opium. 
They are all dangerous drugs and should not be taken except by the advice of a physician. In medicine these drugs are all valuable, Because they benumb the senses they are frequently used to give temporary relief to those who are suffering intense pain. Persons sometimes begin the use of these drugs to relieve them of pain or to produce sleep. In a short time they are unable to stop taking them. Like other narcotics they create an unnatural appetite which is only satisfied by increasingly larger doses of the drug itself. The effect upon the body is so great that the victim finally becomes a moral and physical wreck.

Alcohol. The alcohol used in drinks is always produced by the growth of yeast in some liquid containing sugar. Yeast is a plant. It grows rapidly and produces a chemical action called fermentation, by which sugar is changed to alcohol and carbon dioxide. The alcoholic liquors used are prepared by different processes, but all depend for their stimulating effect upon the presence of alcohol.

You are already familiar with the fact that many persons who at first use alcoholic liquors in moderation later become slaves to their use. There is nothing more deplorable than the sight of a person who has taken such large quantities of alcohol that the activities of the brain and muscles are impaired and weakened. He does and says things of which, in his sober hours, he is ashamed. There is no doubt of the injurious effects of alcohol upon the body. Its effects are very wide- 
spread. Excessive use of alcohol affects the liver, kidneys, heart, blood vessels, and nervous system. More than any other drug, it is responsible for the general break down of the whole body.

Alcohol not only ruins the health, but it also results in much poverty and crime. A constant drinker spends a large proportion of his income for liquors, and at the same time he renders himself unfit to earn more money. Wide and accurate scientific investigations have proved, beyond a doubt, that alcohol is responsible for a large percentage of crime. It not only wrecks the mind, but it wrecks the character. The cost of the care of the many, who, through intemperance, help to fill up our reformatories, prisons, and insane asylums has been estimated at $\$ 100,000,000$ annually.

Conclusion. After showing the terrible results which come from the excessive use of narcotics and stimulants, Mr. Blount* says: "We squander our materials, waste our energies, and benumb our powers in that which harms but does not satisfy. And yet the world is full of great things to do. There are barren lands to clothe with forest and field, marshes to drain, canals to dig, works of art to make, magnificent cities to build, founded not on the bones of the weak and oppressed, but firmly grounded in equality and justice. This work cannot be done by people whose delight is in tickling their senses with drugs. It is a labor for

${ }^{*}$ R. E. Blount, Physiology and Hygiene. Row, Peterson and Company. 
strong men and women. We are summoned to mighty deeds. We must employ every resource we have, use every ounce of energy we possess, to respond to the call. We must go into training, as an athlete for a contest, nourish our bodies with the most wholesome food, discarding that which is harmful or questionable, and make us strong for the conflict. The day of heroes is not past. Choose a worthy object for your life work, put yourself in training for it, and you will have nothing to fear from stimulants and narcotics."

\section{Questions}

1. What is a narcotic? Name the more commonly used narcotics.

2. How do stimulants differ from narcotics?

3. What is the name of the active substance in tobacco?

4. State the principal reasons why boys who smoke are often rejected for athletics.

5. Are business corporations justified in not employing men who are habitual smokers? State the reasons for your answer.

6. For what purposes are morphine and laudanum valuable?

7. Name the organs of the body upon which alcohol has an injurious effect.

8. Does any relation exist between poverty and the use of alcohol?

9. To what extent does alcohol contribute to crime?

10. What is the estimated annual cost of the care 
of those who through intemperance become criminals or become insane?

11. In how many states is the sale of alcoholic liquors now prohibited?

12. What are the principal arguments in favor of prohibition? Against it? How do the two compare in number and in value?

13. Name some of the things which you. would like to accomplish during your life. Will the use of tobacco and alcohol assist, or hinder, you in the fulfillment of these ambitions?

14. What federal law do we have to regulate the sale of morphine, cocaine, and similar drugs? 


\section{CHAPTER XLI \\ CIRCULATORY SYSTEM}

Introduction. In plants we learned that there were tubes through which liquids passed from one part of the plant to another. In our bodies there are also tubes through which liquids are forced. These liquids have two very important functions. First, they carry food from the alimentary canal and oxygen from the lungs to all parts of the body, so that each part receives what it needs. Second, they carry waste materials from all parts of the body to the organs from which they can be removed.

The set of organs which performs these two functions is the circulatory system. This system consists of three parts:

1. Blood and lymph, liquids which flow through tubes.

2. The heart, a pump for forcing the blood around.

3. Blood and lymph vessels.

Blood. The liquid which flows through the blood vessels we call blood. It consists of a watery fluid called plasma. Floating in this are very small cells called corpuscles. There are three kinds of these cells: red corpuscles, white corpuscles, and blood plates. The last 
of these disintegrate so rapidly when blood is removed from the body that very little is known of their structure. The plasma of the blood is largely water and is almost colorless. The red color of the blood is due to the red corpuscles which float in it. It contains, however, all the food and waste products which are soluble. This food is carried to all the cells of the body, and the waste products are taken to the excretory organs. The composition of the plasma thus varies greatly in different parts of the body. The plasma diffuses readily through the walls of the blood vessels and thus comes directly in contact with the body cells. As soon as the plasma has left the blood vessels it is called lymph.

Lymph. Lymph is blood plasma, minus the red corpuscles. It is a colorless liquid in which all the tissues are bathed. The watery fluid which collects in a water blister is lymph. From this lymph the body cells take such food substances as they need. In exchange they return to the lymph waste products formed as a result of the action of the cells. Part of this lymph filled with waste products again diffuses directly into the blood. The rest is collected into lymph vessels, which we have learned finally enter the blood vessels.

Red corpuscles. When a drop of blood is examined under a microscope, the red corpuscles appear as small disk-shaped cells of a reddish yellow color. A corpuscle is round and flat like a coin, but thinner in the middle than near the edge. They are all about the same size, about $1 / 3,500$ of an inch in diameter. They are so 
numerous that between four and five million are present in one cubic millimeter of blood. Like other cells they are composed of protoplasm. They likewise wear out

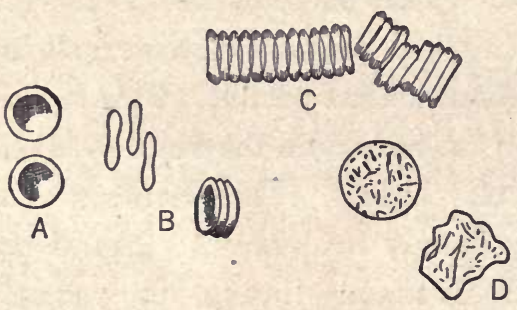

Fig. 157. Blood corpuscles; $A$, red corpuscles from above; $B$, from the side; $C$, in chains ; $D$, white corpuscles.

and must be replaced. $\mathrm{Som} \mathrm{e}$ are produced by the cells in the red marrow of bones. The color of the corpuscles is due to the presence of a substance known as hemoglobin. By means of this the corpuscle can perform its important function of -carrying oxygen.

When the blood passes through the small blood vessels into the lungs, oxygen from the air in the lungs is diffused into it. The hemoglobin then combines chemically with the oxygen and forms an oxide of hemoglobin. As the blood circulates through the body, the oxygen is given up to the cells of the body where it is needed. At the same time the blood loses its bright red color, which had been due to the presence of the oxide of hemoglobin.

White corpuscles. The white bodies are not as numerous as the red. There is one white to about every six hundred red. They are larger, colorless, and irregular, and change their shape rapidly. They are not, as the red, restricted to the blood vessels. By their movements they can get through the walls and flow 
out into the tissues. They are always found in large numbers in the region of wounds. Here they may aid in repairing the injured part, but they are most useful in destroying the many bacteria which collect about wounds. This they do by flowing around the bacteria and then by digesting them.

Coagulation. When blood escapes from the blood vessels into the tissues, or when a vessel is ruptured and it escapes from the body, it soon coagulates or clots. This process is the result of the action of an enzyme. The function of clotting is to plug up the wound and so prevent excessive bleeding.

Amount of blood. The blood constitutes about onethirteenth of the weight of the body. The distribution of this to the parts of the body varies at different times. Just after a meal more blood is needed in the digestive organs. During exercise more blood is sent to the working muscles.

The amount of blood going to all parts of the body depends upon the rate of the heart beat. The amount sent to each organ, however, can not be regulated by the heart. This regulation is brought about by a change in the diameter of the blood vessels leading to or from the organ in question. If more blood is needed in the stomach, for example, the diameter of the blood vessel going to the stomach is enlarged. This is the result of the action of the muscles in its wall, which is controlled in turn by the nervous system. There is less resistance to the flow of blood 
in a large vessel than there is in a small one, consequently more blood enters it.

The heart structure. The heart is a conical shaped organ about the size of a man's fist. It lies in the chest cavity just above the diaphragm and directly back of the lower two-thirds of the breast bone. The apex is below and slightly to the left of the breast bone, where

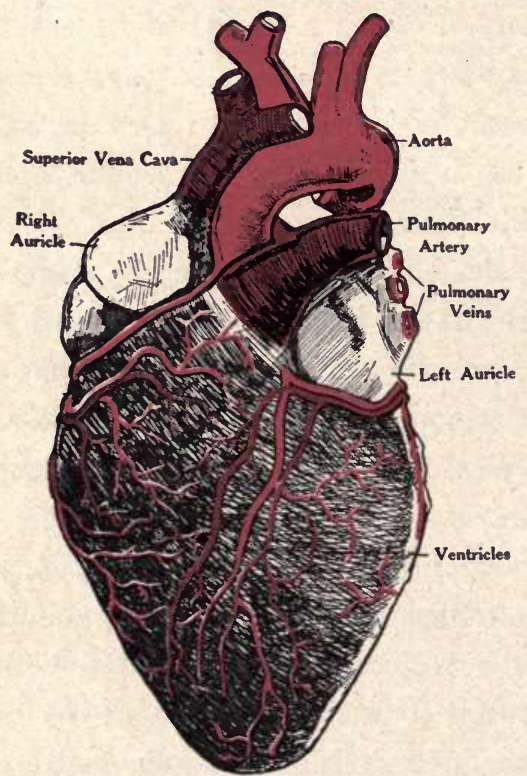

its beat can easily be felt between the ribs. The heart is enclosed in a sac called the pericardium. Between this and the heart there is a fluid which lessens the friction caused by the beating of the heart.

Since the heart is a pump, we naturally expect that it is made of muscle. Internally the heart is Fig. 158. External view of the heart. divided into four cavities; the upper two called the auricles, the lower two the ventricles. The ventricles are larger than the auricles and have much thicker walls. There are no openings between the left and the right sides of the heart, but there is an opening between the left 
auricle and ventricle and between the right auricle and ventricle. Each of these openings is guarded by a valve. These are so arranged that when they are closed no blood can pass from the ventricles back into the auricles.

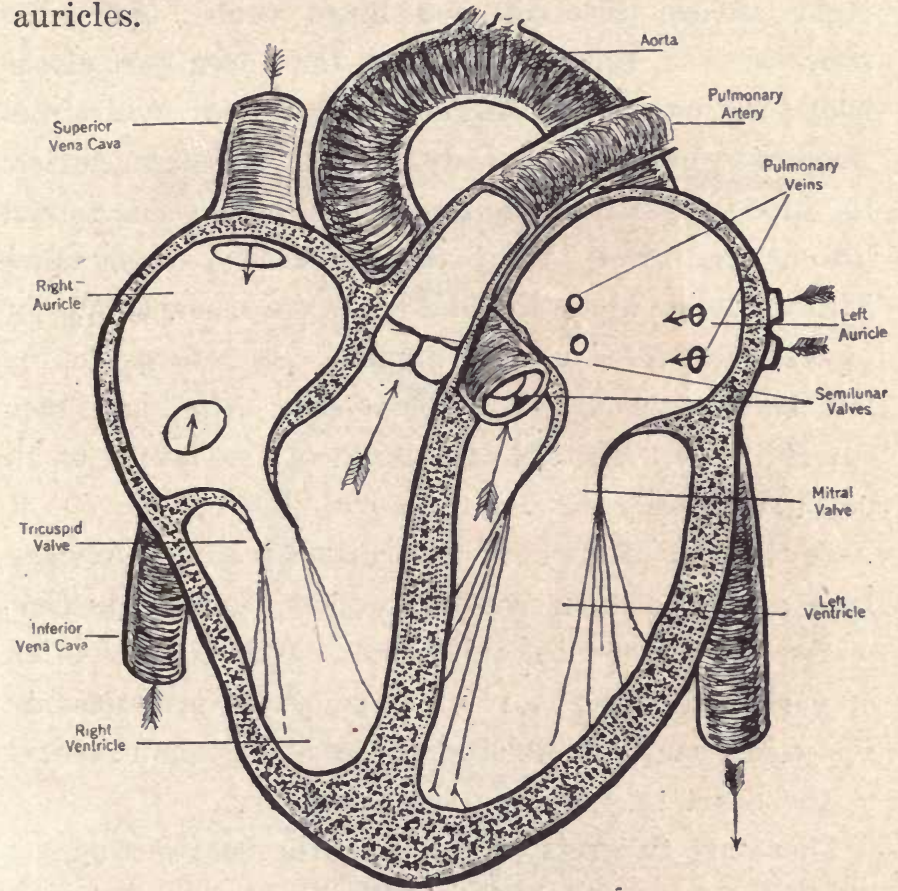

Fig. 159. Diagram to show the internal structure of the heart.

Connected with the heart are tubes called blood vessels. The tubes which carry blood to the heart enter the auricles and are known as veins. Those vessels through which blood leaves the heart from the ventricles are called arteries. 
Action of heart. The left and right sides of the heart work in unison. However, for convenience, we will follow the flow of the blood through one side of the heart and then through the other. Blood enters the right auricle through two large veins. Qne, the superior vena, brings blood from the upper part of the body; the other, the inferior vena, carries blood from the lower part of the body. From the right auricle the blood enters the right ventricle. Then it is forced into a large artery, the pulmonary artery, which takes it to the lungs where the blood receives a new supply of oxygen and loses carbon dioxide. It returns to the left auricle through four pulmonary veins, and then enters the left ventricle from which it is forced to all parts of the body through the aorta.

To the cells of the body it furnishes food and oxygen. Into it they return waste products, carbon dioxide, water, and nitrogenous substances. With the exception of carbon dioxide, most of these waste products are removed from the veins before the blood again returns to the heart through the vena cavas.

There are two sets of valves in the heart. One set, already referred to, prevents the blood from the ventricles returning to the auricles. The other valves are found one in each artery. These prevent the blood in the arteries from returning to the ventricles.

Beat. A beat of the heart is the contraction of the walls of the auricles and of the ventricles. The two auricles contract at the same time; then the two ven- 
tricles; and then there is a pause. This is followed immediately by another contraction of the auricles. The heart beats in an adult about seventy two times a minute, but its rate varies in different individuals.

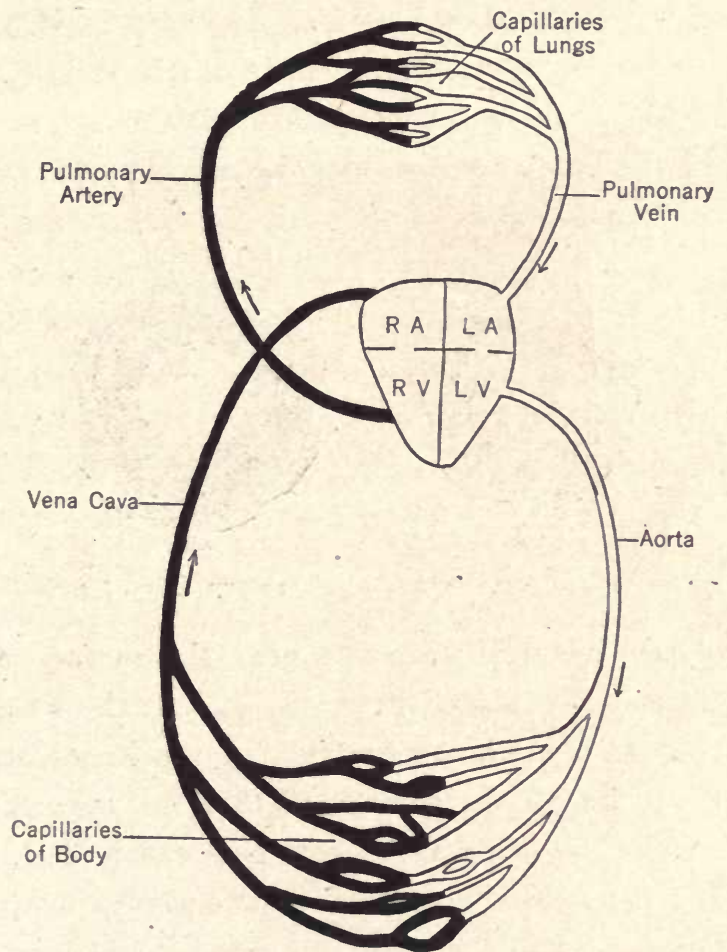

Fig. 160. Diagrammatic representation of the circulation of the blood.

The structure of the heart is such that the blood passes into the ventricles. The thick walls of the ventricles then contract and force the blood out into the arteries. While the ventricles are contracting 
they can not receive more blood. During this time blood is entering the auricles which serve as reservoirs.

Blood and lymph vessels. When the heart beats, the blood is forced with considerable pressure into vessels which we have called arteries. In order to withstand this pressure, arteries must have thick, elastic walls. After the blood has passed through the arteries and before the heart beats again, the arteries spring back to their normal size.
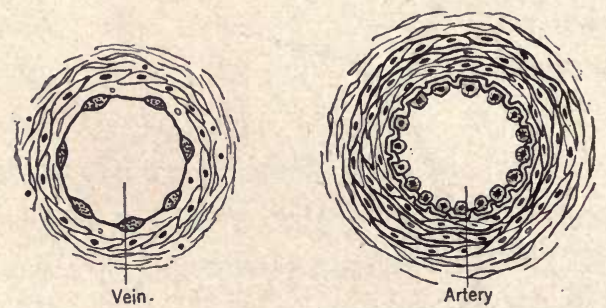

Fig. 161. Cross section of an artery and of a vein.

Arteries generally are not near the surface of the body. In a few places, however, such as the wrist, the temples, and on the under side of the knees arteries are near enough the surface so that the expansion of their walls following each heart beat can be felt. This we call the pulse. If we trace the arteries away from the heart, we find that each one divides and subdivides a great many times so that gradually the branches beeome smaller and smaller. At the same time the walls become thinner. Finally very small tubes with very thin walls are left, called capillaries. We can not prick any spot on the skin with a needle without causing 
bleeding. Evidently the skin is filled with these small capillaries, so small that they can not be seen with the naked eye. The estimated diameter of these vessels is $1 / 3,000$ of an inch.

If we continue to trace the capillaries, we notice that gradually they unite to form larger tubes with thicker walls. These tubes become successively larger and finally form the large veins which enter the heart. The walls of veins are thinner than those of the arteries, but they will not, like arteries, remain distended when there is no blood in them. The blood pressure in veins is low. In order to prevent the backward flow of blood many of the veins are supplied with pocket-like valves. These valves open and thus close the vein if the blood tends to flow back toward the capillaries.

Lymph vessels. The veins are assisted in returning the blood to the heart by a set of tubes known as the lymph vessels. These vessels originate in the (lymph) intercellular spaces in the tissues. They gradually run together to form larger vessels and finally empty their contents into the veins at the sides of the neck. .

\section{Questions}

1. State the chief uses of the circulatory system.

2. What are the three parts of this system?

3. What is the composition of blood plasma? Its use? 
4. Contrast the red and the white blood eorpuscles as to size, appearance, number, and use in the body.

5. What is hemoglobin?

6. How is the amount of blood which goes to each organ regulated?

7. Why is it difficult to study immediately after eating?

8. Describe the internal structure of the heart.

9. Locate and give the function of the superior vena cava, the inferior vena cava, the pulmonary artery, the pulmonary vein, and the aorta.

10. Trace a drop of blood from the left ventricle throughout the body and back to the left ventricle.

11. How many times does the heart beat per minute?

12. What is the advantage in having the walls of the left side of the heart thicker than those of the right?

13. What is the function of the perieardium, the auricles, and the ventricles?

14. What is the pulse? Locate three places in the body where a pulse may be felt.

15. Give three ways in which arteries differ from veins.

16. What are capillaries? Show by a diagram their relation to arteries and veins.

17. Give some first aid suggestions for the eare of a cut vein. For the care of a cut artery.

18. What is lymph? What is its function?

19. How does lymph get back into the blood circulation? 


\section{RESPIRATORY SYSTEM}

Need of air. We already know that we must have air in order to live. If a man is shut off from a supply of air for even a relatively short time he dies. Moreover, we constantly need a large amount of air. From fifteen to eighteen times every minute each one of us is taking in a new supply of air by a process which we call inhaling. Each time this is followed by exhaling, in which air is given off from the body. The rate at which we breathe varies. If we are exercising we breathe faster than we do when at rest.

Oxidation. The element in the air essential for our bodies is oxygen. This we know combines readily with other elements, and in so doing produces energy in the form of light or heat. It is precisely this property of oxygen which makes it so necessary to the cells in our body. In order to move, to think, and to. keep the body warm, we must have energy. This is produced by the oxidation of the cells of the body. As a result of oxidation, waste products, especially carbon dioxide, water, and nitrogenous waste in the form of urea, are formed. 
Internal and external respiration. The process in which the cells of the body take oxygen from the blood, use it for oxidation, and return to the blood waste products is the essential part of respiration and is known as internal respiration. This name distin-

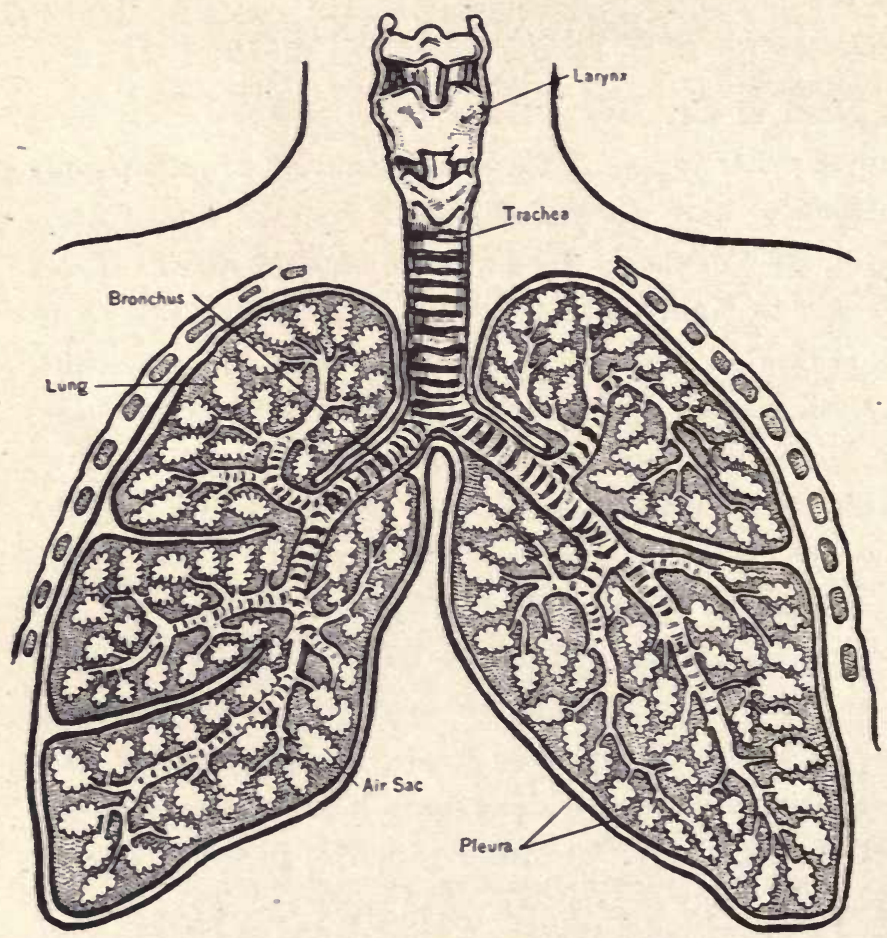

Fig. 162. The respiratory organs.

guishes it from external respiration, which is purely a mechanical process by means of which air is taken into and given off from the body. 
Organs of respiration. In the digestive system food is taken into the alimentary canal and from-there is carried to all parts of the body by the blood. In a similar manner, in the respiratory system air is taken

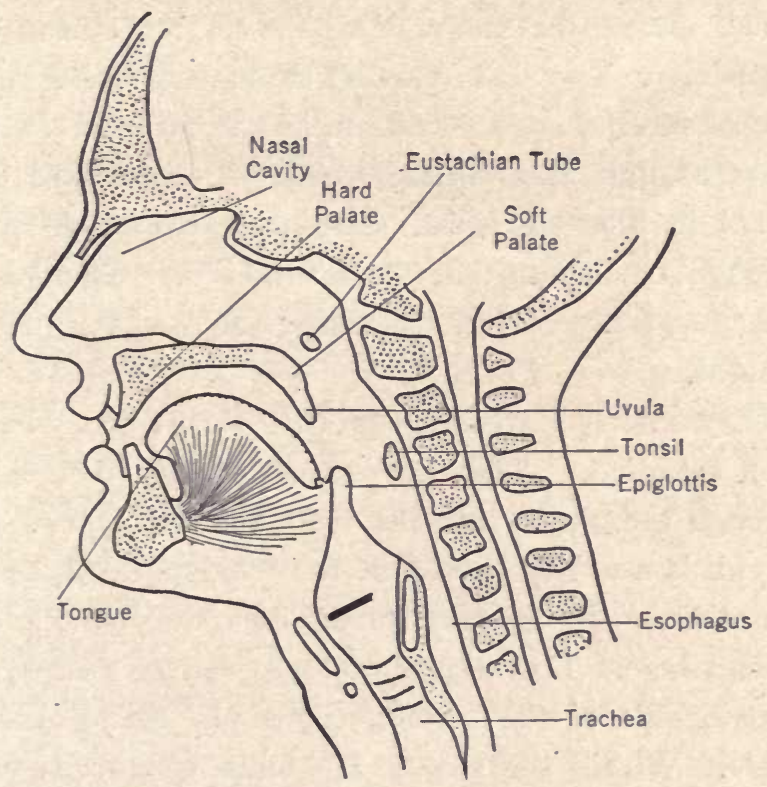

Fig. 163. Median section through the head showing the relation of the mouth and nasal cavities to the esophagus.

into the organs, called the lungs, and from there it is carried by the blood to all parts of the body.

Air enters the body through the two nostrils. It then passes backward into the throat, from which it enters the wind pipe, or trachea, through a slit-like opening, the glottis. Just above the level of the heart the trachea 
divides into two tubes, the right and the left bronchus, each of which supplies one lung.

Nose cavity. The nose eavity is an irregular-shaped passage lined with a mucous membrane. This secretes mucus which aids in catching any dust and germs which escape the many fine hairs at the entrance of the cavity. The air in passing through the nose undergoes several changes; first, it is partly freed of particles of dust and germs; second, it is warmed; and third, it becomes moist. Air may reach the lungs through the mouth, but the mouth is not adapted for the purpose. Mouth breathing is a habit to be avoided.

Larynx. The structure of the throat has already been studied. The air passes from the throat through the glottis into the voice box, or larynx. The larynx is a cavity on top of the wind pipe. Its walls are stiffened by movable pieces of a substance known as cartilage. The largest of these can be felt on the ventral side of the larynx, commonly called Adam's apple. Within the larynx are folds of mucous membrane. These folds form the vocal cords. When these are drawn close together and air passes over them, they vibrate and produce sound. The glottis can be closed by the epiglottis, as we have previously mentioned. This must be closed during swallowing. If particles of food enter the larynx, choking results.

Trachea. The trachea, or wind pipe, is immediately below the larynx. It and its branches are kept open 
by incomplete rings of cartilage. These can be easily felt on the ventral side of the neck. Attention has already been called to the fact that the trachea divides at the base of the lungs into a right and a left bronchus.

The lungs. Each bronchus divides and subdivides a great many times. As these bronchial tubes become smaller, their walls become thinner, each tube ending finally in a branching air sac with extremely thin walls of elastic tissue. The walls of these sacs are richly filled with blood capillaries. The bronchial tubes and air saes are all bound together with a soft, pink, elastic tissue. Over the whole is stretched an elastic membrane known as the pleura.

The pleura. This membrane covers both lungs. At the point where the bronchi enter the lungs the pleura is turned back and lines the interior of the chest cavity. This is another membrane which secretes a fluid to reduce friction. When the lungs are filled with air the two layers of pleura rub against each other.

Mechanism of breathing. We are all familiar with the fact that certain movements of the body accompany breathing. As a result of those movements the chest cavity is enlarged. This causes the air in the lungs to expand; in this way the pressure is reduced. The greater atmospheric pressure outside of the body then forces more air into the lungs. Usually about one pint of air is taken in at each inhalation. In exhaling, the chest again becomes smaller. This pressure upon the lungs, 


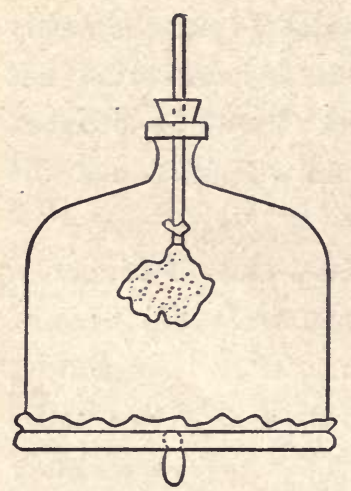

Fig. 164. Experiment to illustrate the effect upon the lungs of the movements of the diaphragm. The belljar corresponds to the walls of the thorax; the rubber balloon to the lungs: the glass tube to the trachea : and the sheet of rubber tied over the bottom of the belljar to the diaphragm. As the diaphragm is lowered air flows down the tube and inflates the balloon.

together with the elasticity of their walls, is sufficient to force out about one pint of air.

The chest is enlarged by the movements of the diaphragm and of the ribs. Muscles in the diaphragm eause it to lower. As a result, what happens to the abdomen?. Muscles between the ribs, and between the ribs and shoulders, pull the ribs up and this movement pushes the breast bone forward. These movements are controlled by nerves. With effort we can increase their extent and so inhale more air, and wa can

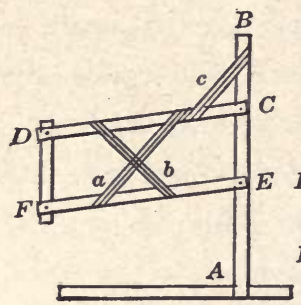

I

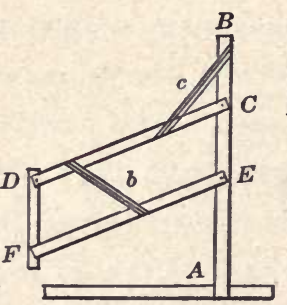

II

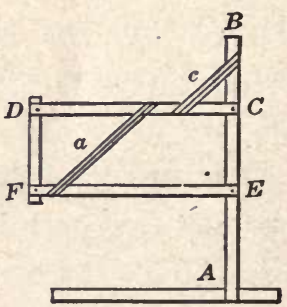

III

Fig. 165. Experiment showing movements of ribs in breathing ; $A B$, vertebral column; $C D$, and $E F$, ribs; $D F$, breast bone; $a, b$, external and internal intercostal muscles; $c$, neck muscles. If these muscles contract, the ribs and breast bone are drawn upward. This movement widens the thorax from front to back and from side to side.

also forcibly exhale more than the usual amount of air. It is impossible, however, to empty the lungs. The 
presence of some air in the lungs all the time makes it possible for the exchange of gases in the blood to take place continually instead of at intervals.
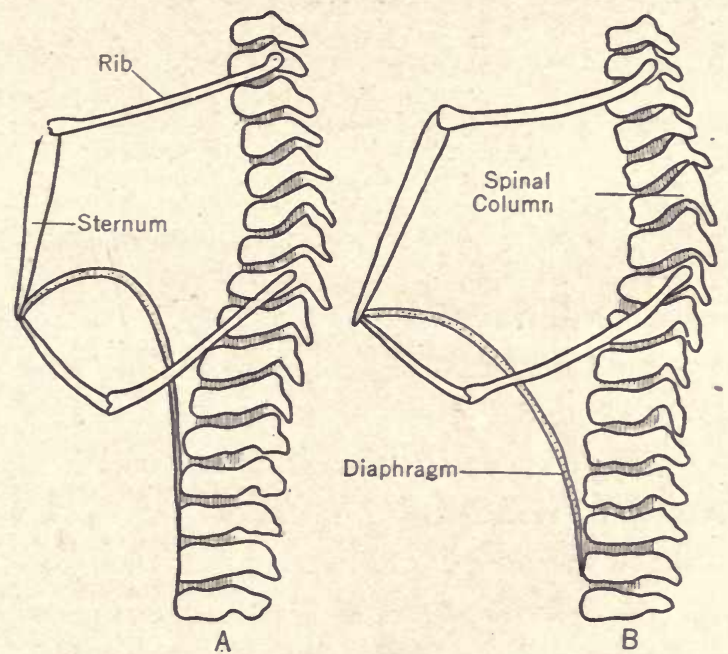

B

Fig. 166. Diagram showing the position of the ribs and diaphragm in $A$, expiration; $B$, inspiration.

Comparison of inhaled and exhaled air. The oxygen of the air which is inhaled diffuses through the thin walls of the air sacs and eapillaries in the lungs and enters the blood. Most of it combines with the hemoglobin in the red corpuscles and is thus carried to the different cells of the body, where it is given up again. As a result of the oxidation which then takes place the energy which we need is produced, and also, as in any burning, waste products are formed. Of these waste products the principal one removed by the lungs is carbon dioxide. 
A comparison of inhaled and exhaled air is most readily appreciated when tabulated.

\section{IXHALED}

Approximately

Nitrogen $78 \%$

Oxygen $21 \%$

Carbon dioxide $.03 \%$

Dust, variable

Dust, rariable

Temperature, variable About $98^{\circ} \mathrm{F}$.
ExhaLed

Approximately

Nitrogen $78 \%$

Oxygen $16 \%$

Carbon dioxide

$4.38 \%$

Dust, almost none

More
Chaxge

None

Loss $25 \%$

Increased over 100 times

Decreased

Greatly inereased

Increased usually

In addition to the above changes, there are added to the air while in the body small quantities of ill-smelling, poisonous, organic matter. It is the latter which gives the bad odor to a poorly ventilated room.

Necessity of ventilation. We know that it is necessary to have the air in a room changed. If this is not done the room becomes "close." We soon become very restless, feel sleepy and stupid, and frequently headaches result. Experiments seem to indicate that these results are not brought about by a lack of oxygen or by an over abundance of carbon dioxide. They seem rather to be the result of the presence of the organic matter before referred to. Much discomfort also results from air which is too hot and too dry.

Methods of ventilation. In order to ventilate it is necessary not only to remove foul air, but also to bring in fresh air. According to some authorities, a room is not well ventilated unless it supplies each person with about eighteen hundred eubic feet of air an hour.

In dwelling houses the amount of space for each per- 
son is large, and a good deal of air enters through the cracks around the windows and the doors. But even so, out-of-door air is far superior to the air in houses. Unfortunately in most dwellings little provision has been made for proper ventilation. Most of us depend entirely upon open windows. If one window is opened at the bottom to let fresh air in, and another at the top to admit of the escape of the warm foul air, this method works pretty well. It does, however, often produce drafts, and as a rule cools the air too much. Fresh air does not necessarily mean cold air.

In tenement buildings, public halls, and work shops much more attention should be given to ventilation. Certainly each of us has had the experience of being made very uncomfortable because of poor air. Air itself will not circulate very rapidly. Consequently in large buildings it is necessary to have it forced into the rooms by large fans in the basements. It is best to have fresh air brought in from the out-of-doors, have it washed to remove the dust, then heated, moisture added, and fanned around to the rooms. It is well to have this warm air enter at the top of the room. Then as it cools and becomes foul it settles to the lower part of the room from which it should be removed.

Diseases of the respiratory organs. There are many diseases which attack one or more parts of the organs used in breathing. Many of these are the so-called "impure" air diseases, while others have a different origin. 
Adenoids. This is the name given to certain growths which appear in the upper part of the throat just behind the nasal opening. They often occur in growing children. Sometimes they become so large that they close the nasal openings, and hence make mouth breathing necessary. By closing the Eustachian tubes they may be the cause of deafness. Adenoids in themselves are not dangerous. They may shrink and disappear. However, they are often the indirect cause of much harm and should then be removed.

Tonsils. In the throat are the tonsils, which we know often cause much annoyance. If they become repeatedly inflamed, they should be removed.

Pleurisy. In pleurisy the pleural membranes become inflamed and oftentimes secrete an abnormal amount of fluid. This fluid takes up space which the lungs should occupy.

Contagious diseases. The so-called impure air diseases are all contagious. Since air is the medium through which the germs are carried, it is evident that these diseases are very readily spread. The most common of these diseases are colds, tonsilitis, diphtheria, bronchitis, pneumonia, and tuberculosis. With most of these we are already so familiar that they need little explanation. If we all become impressed with the fact that they are contagious diseases and put forth every effort to prevent their spread, we have gone a long way toward eradicating them. We know what causes them and we know how to prevent their 
carriage. They are all preventable diseases. The duty of preventing their spread rests with each one of us.

Vaccination for smallpox was discovered by Jenner in 1796. Since that time the public has gradually become convinced of the advantages of this, as well as other methods of protection against that one-time terrible disease. In the following table notice the effect this has had upon the prevalence of the disease. Compare with this the death rate due to impure air diseases and it will be evident that we are facing a great problem, but one which each of us can share in solving.

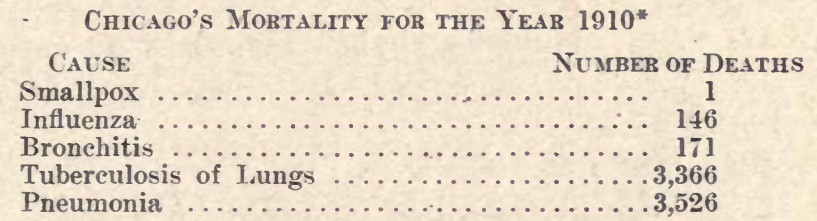

\section{Questions}

1. Why do all living things need air?

2. What is meant by internal respiration? By external respiration?

3. Name the parts of the respiratory tract beginning with the nasal passages. Briefly describe the structure of each.

4. Why should we avoid mouth breathing?

5. What are the chief features of the larynx?

6. How is sound produced?

7. What is the pleura? What are its functions?

8. Explain how the thorax is enlarged.

${ }^{*}$ From Report of the Department of Health of the City of Chicago for the years 1907-1910. 
9. What causes the air to rush into the lungs?

10. How is the thorax decreased in size? What effect does this have on the amount of air in the lungs?

11. State some facts concerning the capacity of the lungs.

12. Of what use are the air sacs?

13. What changes take place in the air while it is in the lungs?

14. How can you account for these changes?

15. Describe foul air and its effect on health.

16. Explain fully how to ventilate a room.

17. How much pure air is required for each person per hour?

18. Why should the air in a room be kept moist?

19. What are adenoids? How may they interfere with the health?

20. Locate the tonsils.

21. Name five so-called impure air diseases.

22. Are they preventable diseases?

23. Why should colds not be neglected?

24. What was the death rate from tuberculosis in Chicago in 1910 ?

25. How does this compare with the number of deaths from smallpox?

26. How can you account for this difference?

27. Why is tuberculosis called the white plague?

28. How may tuberculosis be spread? Suggest methods for preventing its spread.

29. Is tuberculosis hereditary?

30. What can you personally do to guard against contracting tuberculosis?

31. What can you do to help to decrease the amount of tuberculosis? 


\section{CHAPTER XLIII}

\section{EXCRETORY SYSTEM}

General. A furnace must not only be supplied with fuel and air, but from it must constantly be removed smoke and ashes. Every boy, at least, appreciates the amount of ashes formed and the importance of their removal.

We already know how our bodies are supplied with food and oxygen. We also know that in the process of living, parts of the body are constantly being oxidized and other parts are being worn out. As a result of these destructive processes, waste products are formed. Chief among these are carbon dioxide, water, and urea.

The organs used in the elimination of these wastes are the lungs, the skin, the kidneys, and to some extent, the liver. These are known as excretory organs. Which of the waste products are removed by the lungs?

The kidneys. The kidneys are organs through which urea (nitrogenous waste) and water are removed from the blood. In addition to these the kidneys excrete some carbon dioxide, salts, and small quantities of other substanees. On each side of the backbone in the abdominal cavity lie two bodies about five inches long. These are the kidneys. In the figure notice the shape 
and the exact location of them. From each of the kidneys a tube, the ureter, passes to the bladder. The

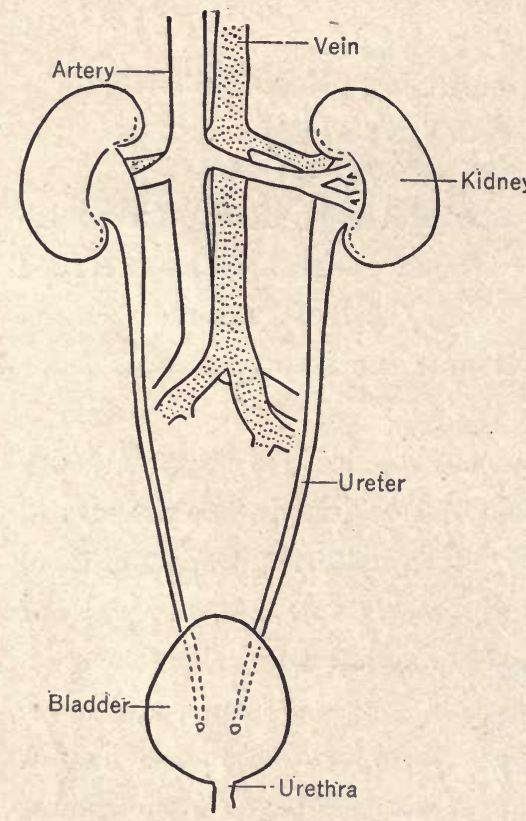

Fig. 167. The kidneys and their connections.

latter is a muscular sac situated in the lower part of the abdominal cavity. From it a tube, the urethra, carries the urine to the external urinary opening.

Each kidney is composed of an enormous number of complieated tubes. Around these tubes are many blood capillaries. From the blood, while it is in the kidneys, there is removed, by means of secreting cells in the tubes,

large quantities of water holding in solution urea and the other excretions from the kidneys. This waste material is called urine. From these tubes the urine passes into a cavity in the kidney from which it is poured through the ureter to the bladder. When a sufficient amount has collected in the bladder, the muscular walls contract and it is expelled. It will thus be seen that the kidneys do not make the waste 
products which they excrete, but only remove them from the blood.

Sometimes extra waste products are sent to the kidneys for removal. They become overw or k e d, poisonous substances c oll e et, and severe illness ensues. Unless the defect is remedied death may result, for the work of the kidneys is indispensable to the body.

Theskin. The whole outer surface of our bodies is cov-

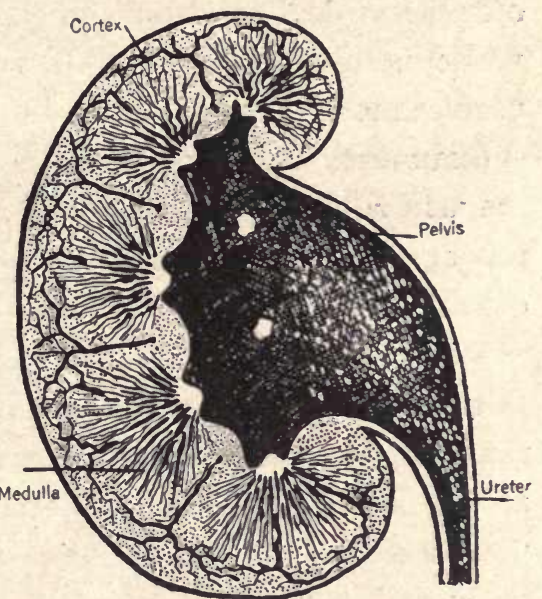

Fig. 168. Longitudinal section of a ered with a flexible, elastic tissue, the skin. This varies in thickness and in texture. On the palm of the hand and the sole of the foot it is thick and tough; the covering of the lips is extremely thin. The hair and nails are modifications of it.

Ordinarily we do not appreciate the great importance of the skin. It has at least four important uses. First, its most obvious use is that of protection for the muscles and other organs which lie beneath it. It keeps them from drying; prevents the irritation which would result from contact with clothing; and also keeps bacteria from entering the body. Second, it contains 
a countless number of organs at the ends of nerves by means of which we receive messages of temperature and touch. Third, by means of perspiration it throws off a great deal of water and small quantities of other waste materials. Fourth, it is the chief means of regulating the temperature of the body.

Structure. As we might infer from all of these uses, the skin is a complex organ. It consists of two layers; the outer is called the epidermis, and the inner the dermis.

The epidermis is formed of layers of cells. It contains no blood vessels and hence it is possible to prick this layer without causing bleeding. The growing cells are at the bottom of the epidermis, where they absorb nourishment from the dermis beneath. As these cells grow and increase in numbers they crowd the cells above away from the source of supply and they become thinner and drier until they become hard scales. These scales are constantly being worn and washed away. Scattered among the lower cells of the epidermis are some cells which contain pigment, or coloring matter. An abundance of these cells gives the black color to the skin of the negro.

The dermis is composed mainly of a loose network of fibrous tissue. In this are embedded numerous blood vessels, nerves, sweat and oil glands, and the roots of the hair. In the deeper parts of the dermis are groups of fat cells. These fill up the inequalities left by the tissues below the skin and make it smooth and plump. 
Sweat glands. If the outer surface of the skin is examined with a hand lens, many minute pores, or openings, will be seen. These are the openings of the sweat glands which lie embedded in the lower part of the dermis. Around each sweat gland is a network of blood vessels. As the blood flows through these capillaries, the glands take from it a fluid from which they produce sweat or perspiration. This is over $99 \%$ water, dissolved in which are some salts and nitrogenous waste. Perspiration is an excretion, but its chief function, as we shall see later, is to regulate the temperature of the body.

The hair. The hair is an outgrowth from the epidermis. Each hair is situated in a tube-like sac called the follicle, formed by the epidermis dipping down into the dermis. At the bottom of the follicle is a little bulb made of capillaries and nerves. It is from this bulb that the hair grows in length, and from this a new hair grows to replace an old one. A hair is a slender tube of hard dry cells, the interior of which is filled with cells containing coloring matter. Opening into the hair follicle are the ducts from the oil glands. The secretion from these glands keeps the skin moist and also makes the hair soft and more pliable. The glands may be made more active by massaging and vigorous brushing. If the hair is kept properly oiled, it does not become so brittle, and consequently is less liable to break or to split.

The condition of the hair depends upon the healthful- 
ness of the scalp. The falling out of hair is usually due to a lack of nourishment at its root. If the bulbs of the hair are dead, no substance will make it grow.

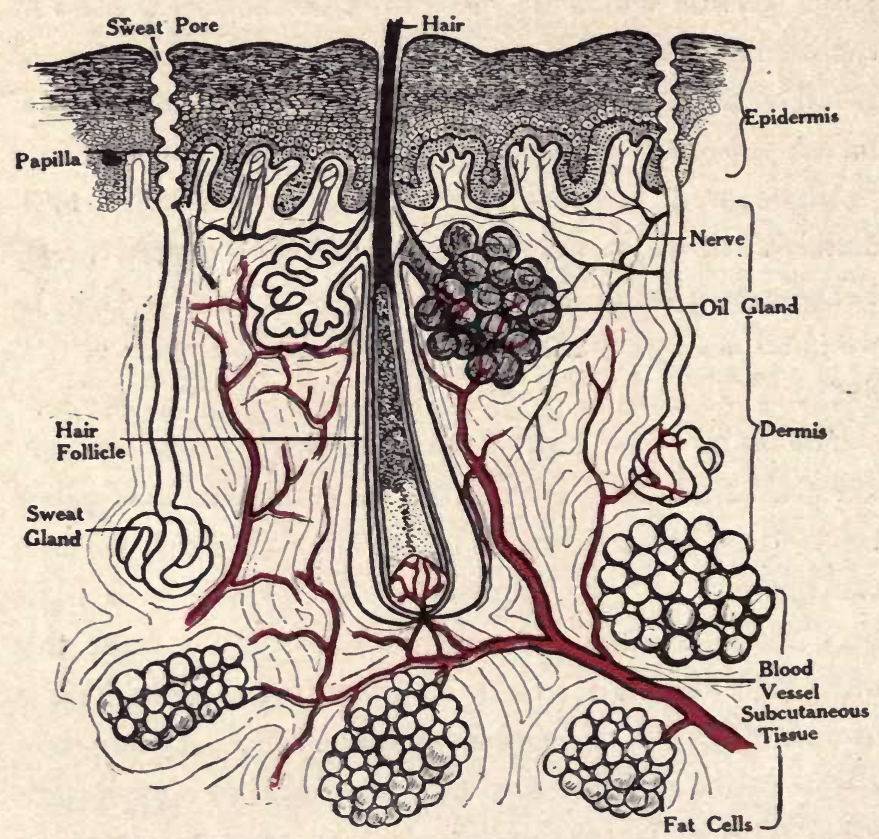

Fig. 169. A section of the skin highly magnified.

Therefore, no attention should be paid to the advertisements of hair tonics claiming that they will make hair grow on bald heads. Hair may be invigorated by massaging the scalp daily, but aside from that, its growth cannot be increased by any home remedies.

Fright, anxiety, or great care may turn the hair gray in a very short time, but usually the color dis- 
appears gradually after the age of forty. Little by little the system fails to supply the coloring matter for the central part of the hair. Its place is taken by air. There is no way of preventing this change.

The nails. The nails are hardened epidermis. They grow from the root which is underneath the skin and are gradually pushed forward. Their function is to protect the ends of the fingers and toes. They should be kept trimmed even with the tip of the finger. The skin at the base of the nail should be rubbed back to keep it from adhering to the nail.

Temperature of the body. Our bodies are usually warmer than the things around us, but the interesting fact is that our temperature is always the same, about $98.5^{\circ} \mathrm{F}$. The body is thus as warm on a cold day as it is on a hot day. If the temperature of the body does not change, the amount of heat produced must be equal to the amount of heat lost. If a greater amount of heat is produced, a greater amount must be lost and vice versa. We will now consider how heat is produced in the body, and how it is lost.

Source of heat. The source of heat in the body is the result of the process of slow oxidation, which is constantly taking place. Since the muscles form so large a portion of the body they contribute the most of the heat. The heat produced in different parts of the body is distributed by the blood. In passing through an organ producing heat the blood becomes warmer, and then as it circulates through different parts of the body, this 
heat is given up to the cooler parts. Heat also travels by conduction from the warmer to the colder parts.

Cooling the body. Usually too much heat is produced. The body is then brought to the proper temperature by cooling, a process which is brought about through the skin. If the body is too warm, the blood vessels in the skin enlarge and the blood supply to the skin is greatly increased. As a result the skin becomes very warm. It is then cooled by radiation, conduction, and by the evaporation of perspiration.

We can easily feel the heat given off by the skin through radiation and conduction. If too much heat is being lost in this way, the blood vessels in the skin contract and less blood flows through it. Perspiration is being produced nearly all the time. If the body is not warm, the amount of perspiration is small and dries up as soon as it is produced. , If, however, the body becomes very warm because of increased activity in work or play, or if the surrounding temperature is very high, more perspiration is produced. The body becomes covered with a layer of water. In order to evaporate this, heat is taken from the skin; in this way, the temperature is lowered.

By radiation and conduction it would be impossible to cool the body if the temperature of the atmosphere was over $98.5^{\circ} \mathrm{F}$. By the evaporation of perspiration, however, the temperature can be lowered even in the torrid regions.

All of this fine adjustment between the amount of 
heat produced and the amount lost is brought about and regulated through the action of the nervous system.

Clothing. In cold climates clothing helps to keep the body warm by checking radiation and by keeping off currents of air which would carry heat away. For this purpose our clothing should be made of materials which are poor conductors of heat, such as silk and wool. Linen and cotton, on the other hand, are good conductors of heat. Under what conditions should they be worn?

Care of skin. The various excretions from the skin are constantly collecting on its surface. These together with the dirt from the air around us must be removed, otherwise they would soon clog the ducts from the pores and so interfere with the work of the skin.

Warm baths are.necessary for cleansing. To aid in removing the oily secretions from the skin a good soap should be used. In addition to cleansing, the warm bath opens the pores, causes the blood vessels in the skin to dilate, and this increases the amount of perspiration. Warm baths should be taken before going to bed.

Cold baths should be taken as a stimulus. The best time for such a bath is immediately on rising in the morning. It should last but a few minutes and should be followed by vigorous rubbing. The cold bath is not advisable for all persons; for some it is beneficial, for others it is too severe and should not be taken. 
Paints, powders, and other external applications for beautifying the complexion not only do not beautify it but are often injurious. They always clog the pores and sometimes they contain poisonous substances. Anything which will tend to improve the health of the body such as good exercise, plenty of fresh air, and the proper food will improve the skin and make it far more beautiful than any artificial applications.

\section{Questions}

1. Name the principal waste products in the body.

2. By means of what organ is each removed from the body?

3. Why is it important that these waste materials should be removed?

4. Where are the kidneys located in the body?

5. Describe the structure of the kidneys.

6. How do the kidneys work?

7. Name four functions of the skin.

8. What is the structure of the epidermis?

9. Name the parts found in the dermis.

10. Describe the sweat glands. State definitely their functions.

11. What is the best treatment for keeping the hair in a good condition?

12. Explain fully the source of heat in the body, how this heat is distributed, and how the temperature of the body is regulated.

13. How may the complexion be improved?

14. What are the best methods for taking eare of the skin? 


\section{CHAPTER XLIV}

\section{DUCTLESS GLANDS}

Introduction. In different parts of the body there are a number of organs which do not seem to belong to any of the general systems. These organs are glands. We have already learned that the cells of the glands take from the blood fluids, some of which they change chemically and then excrete them into another cavity. For instance, the salivary glands make saliva from the fluid which they take from the blood. This saliva is then poured into a small tube, or duct, from which it is emptied into the mouth.

There are, however, some glands which do not empty their secretions into any duct or cavity. Whatever substances they form are poured directly into the blood. Such glands are known as the ductless glands, and their secretions are called internal secretions. It is very difficult to determine the functions of these glands. We still know very little about many of them.

Lymph glands. Scattered along the course of the lymph vessels there are small rounded masses of tissue called lymph glands. These are especially numerous around the hip and shoulder joints; their function 
is not fully known. Some white corpuscles are produced in them. To some extent they also act as filters, for the lymph, after passing through them, has had most of the bacteria removed from it. These are probably destroyed in the lymph glands.

Adrenal bodies. Just in front of each kidney there is a small gland, called the adrenal body. The substance which it secretes influences the muscles in the walls of the arteries. As a result they contract and reduce the size of the artery. The secretion from these bodies helps to regulate the size of the blood vessels and consequently to regulate the blood pressure. An extract, adrenalin, is made from the adrenal bodies of sheep. This is used to check hemorrhages.

Thyroid glands. The thyroid glands are located on the ventral side (front) of the neck just a little below the larynx. The secretion from these glands seems necessary for the proper nourishment and development of the body. Without them both the body and mind are not fully developed, a condition known as cretinism. Sometimes the glands become enlarged and produce a goiter. In that case they produce too much secretion and the activities of the cells become greatly increased. A very rapid pulse, headaches, and sometimes insanity may result. Goiters should not be neglected. As soon as any enlargement of these glands appears a physician should be consulted.

An extract is made from the thyroid glands of sheep, which is used in cases where the thyroid glands 
are lacking or where they do not produce enough secretion.

The spleen. At the left of the stomach is a reddish brown organ, the spleen, held in position by folds of the mesentery. It is of considerable importance, but its exact functions are not known. Like the lymph glands, it produces white blood corpuscles. Some authorities think that it is also used to disintegrate the dead red blood corpuscles.

The pancreas. Not only does the pancreas furnish digestive juices, but it also produces other important substances which enter the blood. These substances seem to regulate the amount of sugar which is present in the blood. If the blood contains too much sugar, it is carried to the kidneys and results in the disease known as diabetes. In many cases, this is supposed to result from the failure of the pancreas to do its work properly.

\section{Questions}

1. What is meant by internal secretions?

2. Name the chief ductless glands.

3. Discuss the function of each of these glands.

4. What is the cause of goiter? Explain why goiters should not be neglected.

5. Define cretinism. 


\section{SKELETAL SYSTEM.}

General. You are all familiar with animals which have no hard matter in their bodies at all, such as the jelly-fishes and worms. Other animals such as insects, crayfishes, and clams, have a hard outer covering. This outside skeleton is preferable to none because it gives the animal some rigidity and some protection. It is very inconvenient, however, for in most cases it does not permit of any growth. As a result it must frequently be shed, and then for a short period the animal is left with only a soft outer covering.

In the higher animals there is a well developed inner framework of bones. In the human body this skeleton is composed of over two hundred separate bones. These are joined and serve several purposes: 1 . They give shape and rigidity to the body. 2. They protect the delicate organs of the body. 3. They provide places for the attachment of muscles, and serve as levers upon which the muscles may act.

Regions of the skeleton. For convenience the bones of the skeleton may be divided into three groups, namely : 
1. The bones of the head.

2. The bones of the neck and trunk.

3. The bones of the arms and of the legs together with those of the shoulders and the hips.

The head. The bones of the skull, except that of the lower jaw, are united firmly together. They are divided into two regions, the cranium, or brain case, and the face. The bones of the cranium are large and flat, while those of the face are irregular in shape.

The trunk. The trunk consists of the following parts:

1. A main axis, the spinal or vertebral column. .

2. The ribs.

3. The breast bone.

The vertebral column consists of a number of separate bones, called vertebrae, placed one upon another. It is divided into regions as follows :

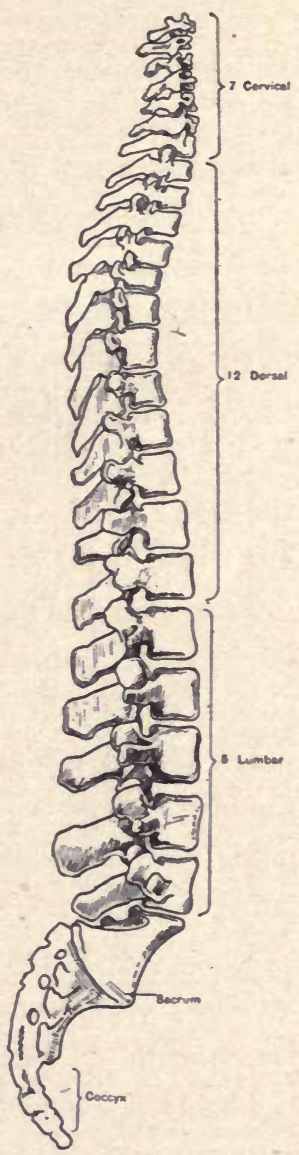

Fig. 170. Side view of spinal column.

1. The cervical, or neck region, consisting of seven vertebrae.

2. The dorsal region, or region of the back, consisting of twelve vertebrae to which the ribs are attached. 
3. The lumbar region, or region of the loins, consisting of five vertebrae.

4. The sacral region, consisting of five vertebrae united to form a single bone, the sacrum.

5. The coccygeal region, four small vertebrae united to form one bone, the $\operatorname{coc} c y x$.

In the diagram locate these regions. To which vertebrae are the ribs attached? Compare the vertebrae in size. What advantage is this difference in size?

Passing through the vertebral column is a canal through which the spinal cord extends and connects with the brain at the base of the skull.

Ribs and sternum. There are twelve pairs of slender curved bones called the ribs. We have already observed their attachment at the back. The first seven pairs are joined at the front by means of cartilage to the breast bone, or sternum; the eighth, ninth, and tenth pairs are attached to the cartilage of the seventh pair; the last two pairs are free or floating ribs.

Bones of limbs. The upper limbs, or arms, are attached to the shoulder blades and collar bones. The lower limbs, or legs, are attached to the hip bones. The hip bones are large and firmly united to the sacrum. Of what advantage is this?

The bones of the arms and those of the legs are arranged on the same plan. Locate the following bones in Figure 171.

Arm-humerus

Wrist -8 carpals

Forearm-radius and ulna Hand-5 metacarpals 
Fingers-14 phalanges, 3 Kneecap-patella in each finger and 2 in Ankle-7 tarsals

the thumb

Leg-tibia and fibula Thigh-femur

\section{Composition} of bone. If we place a rib in a bottle of dilute hydrochloric acid and let it stand a few days, we shall find that it has changed. The shape remains the same, but the bone becomes soft and elastic. It ean easily be cut with a knife, and it will be found to be so flexible that it can be tied in a knot. The substance of which it is now composed is animal matter, or cartilage.

By burning a bone

\section{Foot-5 metatarsals} each toe, except the big toe, which has two

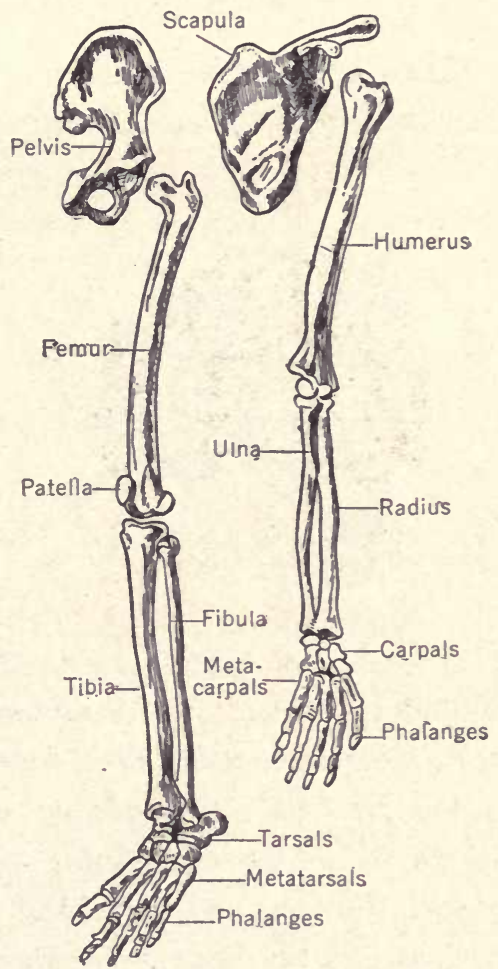

Fig. 171. Bones of the leg and the arm. in a fire this animal matter ean be removed. Again the form of the bone does not change. After this process, however, the bone is left white and brittle. The sub- 
stance now left is mineral matter, chiefly calcium carbonate and calcium phosphate.

In an adult about two-thirds of the bone is mineral matter. In a child there is much less. As a result, the bones of a child are much more flexible than those of an adult.

Growth of bone. Bone is not a solid compact mass, as one might be led to suppose from its appearance.
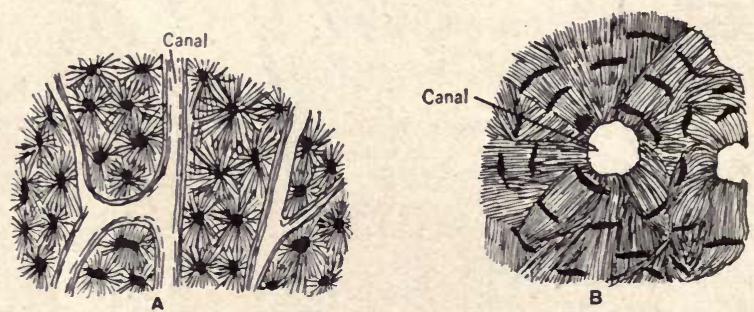

Fig. 172. Sections through bone highly magnifled; $A$, longitudinal section; $B$, cross section.

If a section of a bone is examined with a microscope, it will be found to be composed of a series of canals and irregular cavities. These canals contain blood which passes through smaller canals to the bone cells which lie in the irregular cavities. These bone cells absorb the food and transform it into bone material.

Covering the bone everywhere except at the joints is a tough membrane called the periosteum. This membrane is of great importance in the growth of the bone, because the new bone is formed by the cells of the periosteum. If a bone is broken, or if a piece is taken 


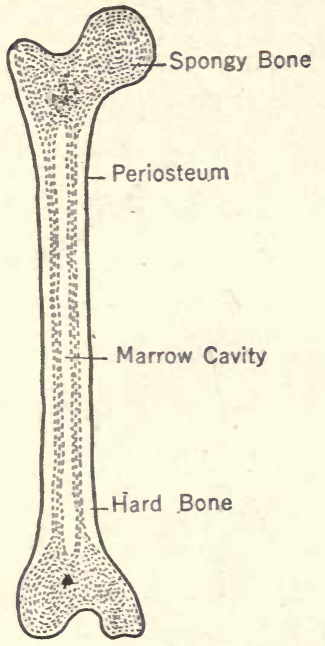

Fig. 173. A long bone cut lengthwise.

firmly fastened together that little or no movement is possible. In other cases, they move easily, one on the other.

out, the periosteum adds new cells which become bone tissue and repair the injury.

Joints. Where two bones come together they form a joint. Sometimes the bones are so

In joints, like the hip, the bones are held together by bands of tough material called ligaments. They are further held together by a covering of connective tissue and by the muscles.

Hygiene of the skeleton. Since the bones of children are soft and flexible, it is very easy for them to become distorted. Bowlegs, for example, are often the result of allowing children to walk too soon. The bones 
have not become sufficiently stiffened to resist the pressure of the weight of the body. Round shoulders often result from a careless position of the body.

Some germ diseases also attack the bones, among them tuberculosis, which sometimes causes a deformity. A common cause of deformity of the bones in small children is lack of the proper kind of nourishment. Lime salts are necessary for stiffening the bones, and a
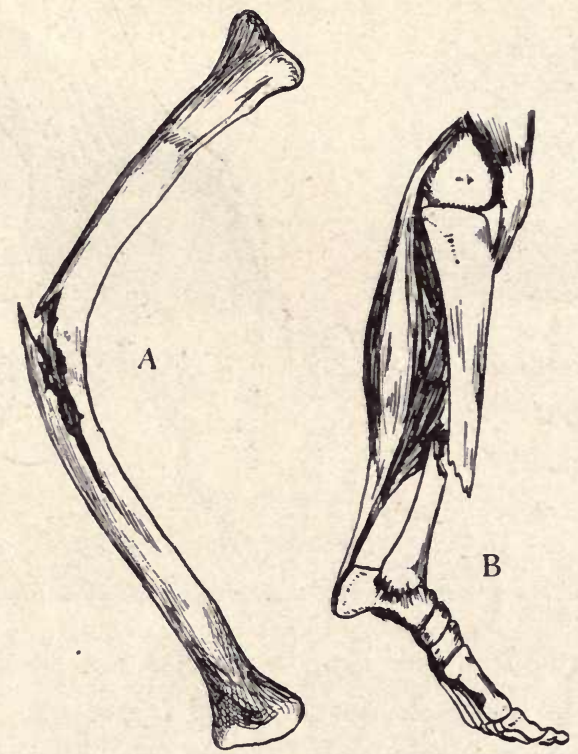

From Blount, Physiology and Hygiene, Row, Peterson \& Co. Fig. 175. Fractures; $A$, a "green stick" fracture of the radius; $B$, a fracture of the tibia.

lack of these salts in the food results in a disease called the rickets, which causes weak and crooked bones.

In a fracture the bone is broken. To treat a fracture, 
the pieces of bone must be brought back into position (this is called "setting" the bone), and must be held there by splints until the ends have become firmly knitted together. It is essential that the bone be kept quiet until the ends have "knitted."

Sometimes a bone in moving slips out of place. This is a dislocation. Parts of the ligaments are sometimes torn, and the bone may or may not be dislocated. Such an accident is a sprain. This is often very painful, slow to heal, and should be treated with care.

\section{Questions}

1. Of what use are the bones?

2. What are the three parts of the skeleton?

3. On your head locate the two parts of the skull.

4. Describe the structure of the vertebral column.

5. How many ribs are there? To what are they attached?

6. Name the bones in the upper limb. In the lower limb.

7. How does the arrangement of the bones in the arm differ from that in the leg?

8. Give the composition of bone.

9. Discuss the growth of bone.

10. Describe a joint.

11. Why should not a heavy strain be put upon the bones of children?

12. What is meant by : rickets, fracture, dislocation, sprain? 


\section{MUSCULAR SYSTEM}

Importance. The muscles of our body constitute about one-half of its weight. By means of these muscles all the movements of the body and of its organs are produced. Not only do they bring about the more obvious motions of the legs and the arms, but also to their action are due the contractions of the heart, of the stomach, and of the other internal organs.

Structure. In this study we will consider only the larger muscles which are attached to the skeleton. Muscles are of various shapes, but they are usually larger in the middle than at either end. They are attached at both ends to bones, usually by a tough, white, inelastic cord, or tendon.

If a complete muscle is examined, it will be found to be covered with a thin sheet of connective tissue. When this is removed, the muscles can readily be divided longitudinally into bundles. These can be split into smaller bundles, which in turn can be divided into a number of long fibers. These fibers have the power to contract and thus to become shorter and thicker. When they shorten, they pull on the bone to which they are fastened and move it. Their force is always 
the result of a contraction, and hence is due always to a pull and never to a push.

Tendons are useful because they permit the thick contracting part of the muscle to be at some distance from the part to be moved. This avoids bulkiness, especially at the joints. The muscles which move the finger, for example, are located in the forearm. Tendons, which can easily be traced on the back of the hand, extend from these muscles to the finger bones. It is evident that this arrangement makes the hand smaller and more graceful and permits of greater ease and delicacy in its movements.

Blood and nerve supply. Muscles are well supplied with blood. Fresh meat is always deep red in color due to the presence of a great quantity of blood. Nerves are also very numerous in muscles; in fact, some muscles are altogether under the control of the nervous system, and are known as voluntary muscles. Most of the muscles fastened to the bones are of this type. Other muscles, such as those in the walls of the stomach, in the walls of the blood vessels, or in the heart are perhaps not completely under nerve control. At any rate, we can not control them and they are called involuntary muscles.

Action of muscles. The action of a muscle can best be understood by a consideration of the arm muscles. The forearm is bent or flexed by the action of a large muscle on the front of the arm, known as the biceps muscle. This is attached by two tendons to the 
shoulder blade. The muscle then passes over the front of the humerus. Just below the elbow joint it is attached by a tendon to the radius. When the biceps

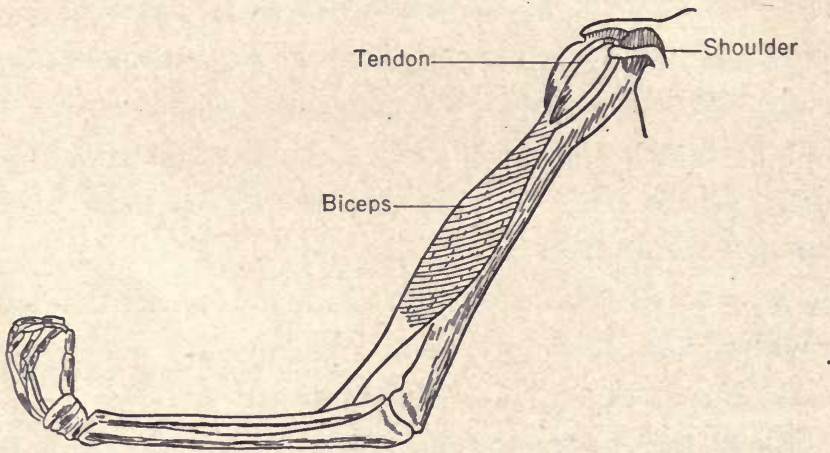

Fig. 176. The arm showing the attachments of the biceps muscle. If the muscle contracts slightly the forearm will be lifted over a great distance.

contracts the distance between the forearm and the shoulder is shortened. As a result, the forearm is bent on the arm. If the biceps is decreased only a few inches in length, the hand is moved through a much greater distance.

Situated on the back of the arm is the large triceps muscle. By its contraction the forearm is straightened, or extended. Where must its attachments be in order to produce this action?

Results of muscular action. The results of muscular action are familiar to all of us. We know that motion, heat, and energy are produced. To produce these, oxidation is necessary, as a result of which both nerves and muscles are being worn out and waste products are 
being formed. The chief ones of these products are carbon dioxide, water, and nitrogenous wastes.

Frequently we become fatigued. This is probably not because the muscles and nerves are being overworked, but because the waste products are not being removed fast enough. A good blood circulation is necessary to remove these wastes and to carry food and oxygen for rebuilding the tissues which are being used.

Exercise. A certain amount of vigorous exercise each day is essential to keep the body in the best physical condition, for, as everyone knows, if the muscles are not used for a time they become weak and flabby. Regularity in exercise is as important as regularity in eating. The kind and amount of exercise should vary with the individual. It should be vigorous enough so that one feels fatigued but not exhausted. The ideal exercise involves the action of the greatest number of muscles.

Exercise taken in the spirit of play is most beneficial, because it not only results in free and varied activity, but it also rests the mind. As a result of exercise the whole body is improved, respiration and circulation are increased, the muscles are developed, and the mind is made more alert and active.

\section{Questions}

1. What part of the body by weight is muscle?

2. Of what use to the body are the muscles?

3. What special property is possessed by muscle? 
4. Describe a typical muscle.

5. What is the appearance of muscle as seen on the cut end of a piece of meat?

6. What are tendons? What is their use?

7. How are muscles made to act?

8. Explain fully how the arm is flexed and extended by the action of the biceps and triceps muscles.

9. What is meant by the term voluntary. muscle? Involuntary muscle?

10. Name two voluntary muscles and also two involuntary ones.

11. What is probably the cause of fatigue?

12. Explain how and why the muscles should be exercised.

13. Why are games a beneficial form of exercise? 


\section{CHAPTER XLVII}

\section{NERVOUS SYSTEM}

Introduction. In the preceding chapters we have learned that the body is composed of many organs, each of which has its special function. The human body, however, is not simply a collection of working organs, but it is a complete organism with its many parts working together harmoniously.

Even in very simple operations, the coördinated action of many parts of the body is involved. In moving the arm, for example, the muscles contract and relax and as a result, motion is produced. In this process, however, they have consumed food and oxygen and given off waste products. This increases the activity of the digestive, respiratory, circulatory, and excretory systems. Obviously it would be utterly impossible for all of these organs to work together for the common good, unless there was some means of communicating the needs of one organ to the others. There must also exist some central system that controls the action of each of the organs in our body, and brings about coöperation among them.

Not only must the parts of our body be correlated with each other, but also they must be adjusted to the 
outside world. Parts of our body must. receive impressions from the outside world, and then these must be communicated from them to other parts. This adjustment and regulation of the parts of the body to each other and to the outside world is the work of the nervous system.

Parts of nervous system. The nervous system con-

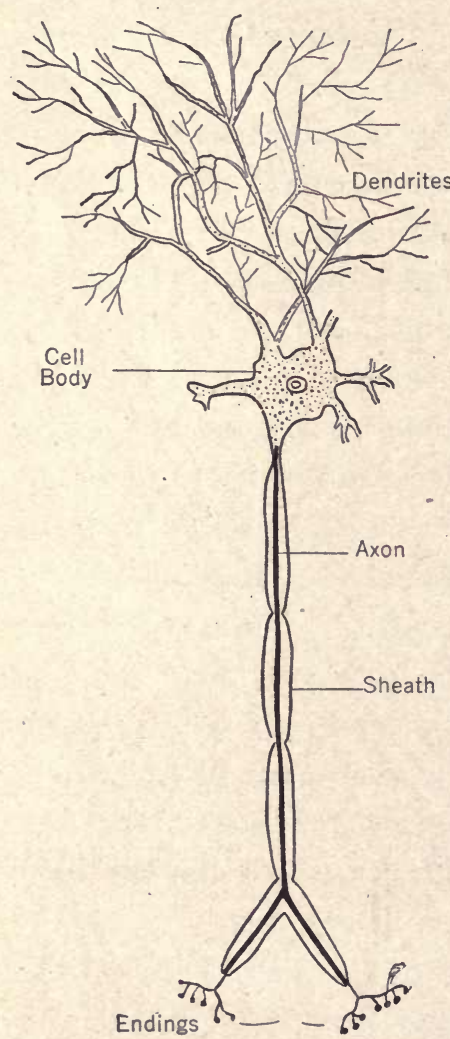

sists of nerve centers and nerves. The nerve centers are the brain, the spinal cord, and smaller centers called ganglia seattered in different parts of the body. From these nerve centers nerves arise. These divide a great many times and their branches penetrate all the organs and tissues of the body.

The nerve cell. The unit of structure in the nervous system is the nerve cell, or neuron. This is not so simple in structure as many of the other cells in the body. It consists of a large cell from which there are $\mathrm{m}$ a ny projections called Fig. 177. Diagram to show the dendrites. One of these structure of a neuron. 
projections is greatly elongated and forms a nerve fiber which may be only a fraction of an inch in length or it may be two or three feet. Near the end, a fiber may branch abundantly, sometimes having very complex endings as in the eye or in the ear. Along its course the fiber is protected by two coverings. Nerve cells are found only in nerve centers.

Nerves. Bundles of nerve fibers, together with blood vessels and connective tissue, form nerves. A nerve is like a telegraph cable. It consists of many fibers, each insulated from the others. Fibers separate from the main group and form a branch of the nerve, each having a particular use. Some carry messages only to the brain and spinal cord; these are known as sensory nerves. Others carry messages from the brain and the spinal cord to the organs; these are motor nerves.

The brain. Most of the organs of our body are in some way protected. None, however, is any better protected than the brain. The human brain is an exceedingly delicate mechanism and would be subject to frequent injury if not properly protected. It is protected by the hair, the loose, tough scalp, and by the bones of the cranium. The arched instep and the curved spinal column give some "spring" to the body and hence tend to keep the brain from being jarred. Finally, the brain itself is enclosed in two membranes.

The brain is the largest part of the nervous system. It weighs about three pounds. and consists of a mass of nerve cells and many connecting fibers. It may be 
divided into three regions : fore brain, mid brain, and hind brain. The latter is continuous with the spinal cord.

The fore brain is called the cerebrum. It is enormously developed, forming about three-fourths of the

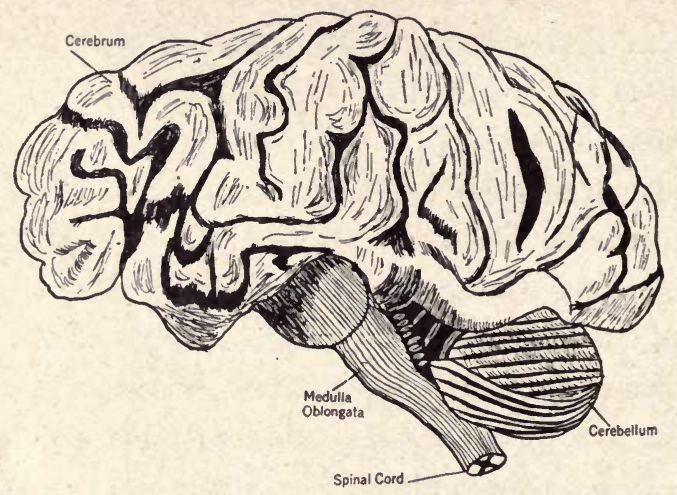

Fig. 178. Side view of the brain.

entire brain, and is divided by a deep fissure into a left and right hemisphere. Many folds and ridges, called convolutions, greatly increase its surface.

The mid brain is an isthmus connecting the fore and hind brains.

The hind brain consists of the cerebellum, the pons varolii, and the medulla oblongata. The cerebellum has a wrinkled surface, but is somewhat different in appearance from the folded cerebrum. It is the largest part of the hind brain and is partly covered at the back by the cerebrum.

The medulla oblongata lies in the cranium, but it is 
really the enlarged upper portion of the spinal cord. It forms a connection between the spinal cord and the brain.

The pons consists of broad bands of nerve tissue that pass around the ventral side of the medulla and connect the two halves of the cerebellum.

Twelve pairs of nerves, called cranial nerves, arise from the brain. These are distributed to different parts of the head and to the body.

Functions of brain. The functions of the parts of the brain are as follows:

The cerebrum is the seat of all sensations, of intelligence, of memory, of emotions, and of will. Through it we receive all sensations such as sight, touch, and taste, and in it originate all impulses which produce voluntary movements.

The cerebellum does not start voluntary motion but it coördinates these movements and makes them definite. If the cerebellum is removed from a pigeon, for example, the pigeon can still move but it cannot walk or fly. The various pairs of muscles do not work together; those of the right side do not work with those of the left. Consequently the pigeon flutters about, but it can make no definite movements.

The medulla is a passageway for impulses between the brain and the spinal cord.

Spinal cord. The large nerve which passes down through the backbone, or spinal column, is called the spinal cord. It tapers somewhat at the lower end, but 
its average diameter is about three-fourths of an inch. A number of large nerves, thirty-one pairs, arise from the spinal cord. Their branches pass to all parts of

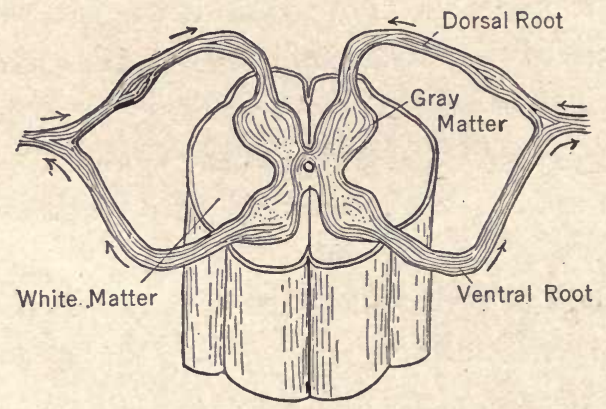

Fig. 179. Section of the spinal cord showing the method of origin of the spinal nerves by two roots. The arrows indicate the direction in which the nerve impulses pass through these roots.

the body. Each of these nerves has two roots. The ventral root is composed of fibers which carry currents out to the muscles and is, therefore, called the motor root. The dorsal root carries currents from the organs to the spinal cord. Consequently, we would assume that if dorsal roots are in any way injured, a person would lose the sensation of feeling in the part from which these nerves led. Similarly, if the ventral roots are disabled the power of motion would be lost. Experiments on lower animals or observations in human beings in which the cord has been injured, or diseased, confirm these assumptions.

The spinal cord is of great importance; first, because it relieves the brain of a great deal of work; second, because it is a passageway for conducting messages of 
importance to and from the brain; and third, it controls to a great extent the digestive and the circulatory systems.

Sympathetic nervous system. A chain of ganglia on each side of the spinal column together with three large ganglia and a network of nerves, situated in the middle line of the body, form what is often called the sympathetic nervous system. It is not a distinct system at all, but is closely connected with the brain and the spinal cord. Nerves from these centers pass to many of the internal organs, to the skin, to the glands, and to the muscles. This system also relieves the brain, for through its centers many of the involuntary activities are controlled. One of these centers, located just behind the pit of the stomach, is the so-called "solar plexus." A blow in the region of the stomach paralyzes many parts, and may even result in instant death.

Action of nervous system. Even the simplest motions which we perform involve the action of many nerves and nerve centers. If the finger is accidentally pricked by a pin, a touch organ in the skin is stimulated. From this currents, or impulses, are sent over several nerve fibers through the dorsal root into the spinal cord. As a result of changes which this produces in cells in the spinal cord, currents are sent to motor cells in the cord. From these motor cells currents are sent over fibers in the motor root to a muscle in the arm. This causes a contraction of the muscle which produces a motion, the response, as a result of which the hand is 
drawn away from the pin. In such an action the current is carried to the spinal cord, or to some ganglion, and from there currents are sent out which stimulate the muscles. This is called a reflex action.

Reflex actions. These actions are produced without the consent of any conscious center of the brain. The impulse may go to the brain, but not to cells where conscious activity occurs. Reflex actions, such as the movements of the internal organs, the heart, stomach, or the glands, are involuntary. These are due to internal stimuli. Many of our responses to external stimuli are also reflex: the winking of the eyelids, walking, removing the hand from a hot object, and many others. These actions are performed quickly, and they also relieve the brain of a great deal of work. All of our time would be needed to attend to only the simplest activities necessary for life, if they were all done consciously.

Voluntary action. We have just learned that the peculiarity of a reflex movement is that it is performed without the action of the conscious center, the cerebrum. All actions which do come from the use of the cerebrum and which are thus under the control of the will are voluntary.

If food is placed before us, impulses are sent from the eye to the visual center of the cerebrum. From there messages may be sent to motor centers in the brain, from which in turn impulses may go to the muscles of the arm causing us to pick up some of the 
food. It is not necessary, however, for us to eat the food after it is in the mouth, or even to pick it up. We may decide to leave it. In voluntary actions, the mind controls the stimuli which are sent out.

When we are awake countless nerve impulses keep pouring into our brains. Of some of these we are conscious, and we may see, hear, or taste. The impressions which they produce are more or less lasting. Some are retained for only. a few minutes, but others may be retained for years. In some way these impressions are stored away in our brains and constitute our memory.

There is much about the activity of the nervous system which at present no one seems to know. For example, we can not explain exactly how nerve currents pass along the nerves, or from one cell to another. We often compare nerve currents with electric currents. They are, however, not the same. Nerve currents travel only about one hundred feet per second; electric currents travel thousands of times more rapidly. Nerve currents wear out the nerve tissue; electricity seems to have no permanent effect on the wire over which it passes. We likewise do not know just how impressions are formed in our brains, or how they can be retained there.

Habits. When we first attempt to do a thing, we do it slowly and awkwardly. Each time we repeat the same thing we do it more rapidly and more accurately. The first time a nerve current passes over a certain set of nerves and through certain centers it does so slowly. 
At each repetition of the same act the currents move more rapidly. For this reason practice makes perfect. We learn to write, to walk, to read, to think, to feel slowly but surely as the nerve routes become established. Finally such acts, thoughts, or feelings require little attention, and we speak of them as habits.

Habits, too, save the brain much time and effort. At first the mind must direct each impulse necessary to produce the movements in learning to write, for example. Later on these impulses reflexly go over the proper nerves and make the proper connections.

It requires considerable effort, when habits are once formed, to break them. Certain impulses readily pass over certain nerves, through certain centers, and produce definite, fixed responses. Only with great and repeated effort is it possible to make these impulses travel over new routes. It is just as difficult to break a good habit as it is to break a bad one. The older we grow the more fixed our habits become, and consequently the more difficult to change.

It is wise to form only such habits of thought and action as will make us most useful to ourselves and to our fellow-men. The importance of this is most forcibly expressed by Professor James:

"The hell to be endured hereafter," says Professor James," "of which theulogy tells, is no worse than the hell we make for ourselves in this world by habitually fashioning our characters in the wrong way. Could

*Professor James, Psychology. Henry Holt \& Co. 
the young but realize how soon they will become mere walking bundles of habits, they would give more heed to their conduct while in the plastic state. We are spinning our own fates, good or evil, and never to be undone. Every smallest stroke of virtue or of vice leaves its never-so-little scar. The drunken Rip Van Winkle, in Jefferson's play, excuses himself for every fresh dereliction by saying, 'I won't count this time!' Well! he may not count it, and a kind Heaven may not count it; but it is being counted none the less. Down among his nerve cells and fibers the molecules are counting it, registering and storing it up to be used against him when the next temptation comes. Nothing we ever do is, in strict scientific literalness, wiped out. Of course this has its good side as well as bad one. As we become permanent drunkards by so many separate drinks, so we become saints in the moral, and, authorities in the practical and scientific spheres by so many separate acts and hours of work. Let no) youth have any anxiety about the upshot of his education, whatever the line of it may be. If he keep faithfully busy each hour of the working day, he may safely leave the final result to itself. He can with perfect certainty count on waking up some fine morning, to find himself one of the competent ones of his generation, in whatever pursuit he may have singled out."

Education. As civilization advances success and achievement in life depend more and more upon the 
ability of each individual to use his brain, but in order that the mind may act quickly and easily it must be trained. Education gives this training. Through it the brain not only obtains information, but it learns how to act and grow stronger by use just as the muscles do. Because we appreciate how important this training of the mind is, each generation spends yearly millions of dollars to educate the young people who will make the men and women of the next generation.

Care of nervous system. Mens sano in corpore sano, a sound mind in a sound body, is just as true to-day as it was hundreds of years ago when the Greeks and Romans excelled in physical and in mental development. Everything which goes to build up a sound body also builds up a sound mind. Plenty of exercise, fresh air, work, rest, and sleep are all necessary for an active brain.

The great demands made upon our nervous systems and the consequent need of care are well expressed in the following quotation. Mr. Blount says:

"The superiority of man to the lower animals is most conspicuous in his nerve system. It is precisely where civilized man is most developed that he breaks down most easily. We live in what has been called an age of nervous prostration. The speculator watching the market, the society woman madly pursuing a program, and the scholar striving for honors or promotion, all are the frequent victims to the disease of the age. We should learn to relax, to rest. Some time each day 
should be given to quiet and meditation. The various sorts of mental healing often produce good only because they establish nerve quiet, and direct the thoughts away from self. One can live under good conditions of physical hygiene, and yet become a nervous wreck, if he is the subject of constant nervous irritation. Great minds cultivate poise and equanimity. We are wont to magnify the small ills of life, if there are no large objects to occupy us. One engaged in thoughts of science, government, or philosophy is not so worried over his own petty affairs of life. The dignified pursuit of a worthy object in life gives tone and poise to the nerve system." '*

\section{Questions}

1. Why would it be impossible for us to live without a nervous system?

2. What is the structure of a nerve cell? Of a nerve?

3. How does a motor nerve differ from a sensory nerve?

4. Give the parts of the brain.

5. Why is it so essential that the brain be protected?

6. Describe the cerebrum and state its functions.

7. How does the cerebellum differ from the cerebrum in appearance and in size? What is its function?

8. How is the brain connected with the spinal cord?

*Blount, Physiology and Hygiene. Row, Peterson \& Co. 
9. What is the function of the medulla?

10. Give the size and location of the spinal cord.

11. Explain how a spinal nerve is attached to the spinal cord.

12. What is the difference in the use of the sensory root and the motor root?

13. What is the sympathetic nervous system?

14. Trace the path of a nerve impulse in a reflex action.

15. What are the principal advantages in reflex actions?

16. In what respects do voluntary actions differ from reflex ones?

17. What is the physiological reason why practice makes perfect?

18. Why is it an advantage in early life to form many good habits?

19. Point out the error in thinking that we can perform a certain act and then not count it.

20. Why do we have schools?

21. Learn how much your education for a year costs the community in which you live. Also, determine how much it costs your parents to keep you in school for a year.

22. Is the education which you are receiving worth that amount of money to you?

23. Do you think that the returns which your parents and the community are receiving are adequate, considering the amount of money which they have invested in your education?

24. What rest and care do you give your nervous system? 


\section{CHAPTER XLVIII}

\section{THE SPECIAL SENSES}

General. It is quite essential that we receive some very definite information in regard to the world outside of ourselves. For this we depend upon the soealled special senses. Originally there were thought to be just five of these, feeling, tasting, smelling, seeing, and hearing. To these, however, we must add some others, especially the sense of temperature and of pain. For the purpose of receiving impressions from the outside world and then of converting them into nerve currents we have highly specialized organs, such as the eye and the ear.

Touch. The sense of touch is the most widely distributed of the special senses, for all parts of the skin, the tongue, and the mucous membrane of the mouth and nose are sensitive to touch. In the dermis of the skin there are many minute elevations called papillae. In some of these there are modified structures containing the ends of nerves of touch, ealled touch corpuscles.

In some parts of the body these corpuscles are very close together so that the sense of touch is keen. In other parts they are far apart so that the sense of touch is dull. The degree of sensitiveness of the various parts 
of the body can be determined by the use of a compass. If the person operated upon has his eyes closed and the compass is placed on the back of the neck with the points three inches apart, he will get a distinct impression of each. If, however, the points are placed from one and a half inches to two inches apart, he will feel only a single point. On the tip of the tongue the two points ean be distinguished when separated only one twenty-fourth of an inch. The lips and finger tips are also very keen. When an object touches the skin the pressure upon the touch corpuscles stimulates the nerve endings and an impulse is sent to the brain.

Temperature. It seems safe to assume that the nerves which receive the impression of heat and cold are not the same as those used for touch. When the skin is touched with a cold object, certain areas all over the body give us a sensation of cold. Other areas when touched with a warm object give the sensation of warmth. The body seems to be mapped out into irregular "cold and warm" spots.

Taste. The nerves of taste end in taste buds which are in papillae scattered over the upper surface and sides of the tongue, the pharynx, and in parts of the soft palate. Hair-like processes project from the taste cells through cavities in the taste buds. These processes come in contact with the food which must be in solution to be tasted.

There are four different kinds of tastes : sweet, sour, bitter, and salt. All parts of the tongue are not equally 
sensitive to each of them. The bitter taste is most developed at the back of the tongue, the sour at the sides, the sweet at the tip, and the salt taste is nearly equally distributed. Many of our tastes are combinations of these four primary ones together with smell.

Smell. The sense of taste and smell at the beginning of the digestive tract and the sense of smell at the beginning of the respiratory tract also will at once suggest a

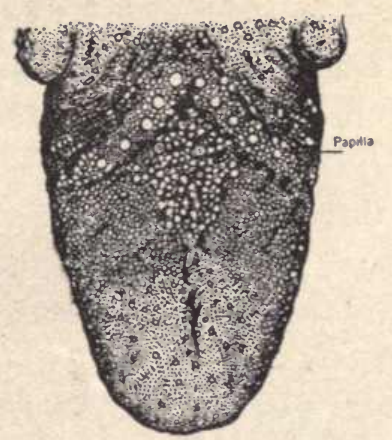

Fig. 180. The tongue. possible function for these two senses. They are undoubtedly of some use in helping us to detect unfit food and air.

The nerves of smell, the olfactory nerves, have their endings in the mucous membrane of the upper part of the nasal cavity. Substances which stimulate these nerves give off small particles which are then carried into the nose by currents of air. The sense of smell is not so keen in man as it is in dogs, or in some other lower animals. Even in man it is very acute, but it becomes exhausted rather quickly.

Eye. The eyes are delicate, complex, nearly spherical bodies which fit into sockets formed by the facial bones. They are further protected by folds of skin. the eyelids. They are freed of dust and kept moist by mucus and by tears secreted by the tear glands. 
A tear gland is located on the outer and upper side of each eye. The fluid secreted by this gland passes over the eye and is carried away by a duct, of which one branch opens on the inner angle of the lower eyelid, and another opens in the upper eyelid. The other end of this duct opens into the nasal passage.

The eyeball is held in place and moved by six muscles. One end of these muscles is attached to the eyeball, and the other end at the back part of the bony socket into which the eye fits. One set of these muscles turns the eye toward or away from the nose. A second set turns the eyeball upward or downward. The third set of oblique muscles rotates the eyeball.

Structure. The eye is made up of three layers or coats. The outer coat is opaque and white, forming the "white of the eye." It is known as the sclerotic layer. It is a tough strong coat filled with blood vessels. At the front this layer becomes transparent and forms the cornea.

Inside of the sclerotic layer is the choroid coat, which is colored black. In front it is usually brown or blue and forms the iris. In the center of the iris is an opening, the pupil. This is controlled by muscles which open or close it.

The innermost coat, the retina, covers the back portion of the choroid coat. It is a very complex membrane, and in it are the endings of the optic nerve which enters the eye at the back.

Just back of the pupil is the crystalline lens. Between 
it and the cornea is a space filled with a transparent watery fluid, the aqueous humor. The entire cavity of the eyeball back of the lens is filled with a jelly-like mass, the vitreous humor.

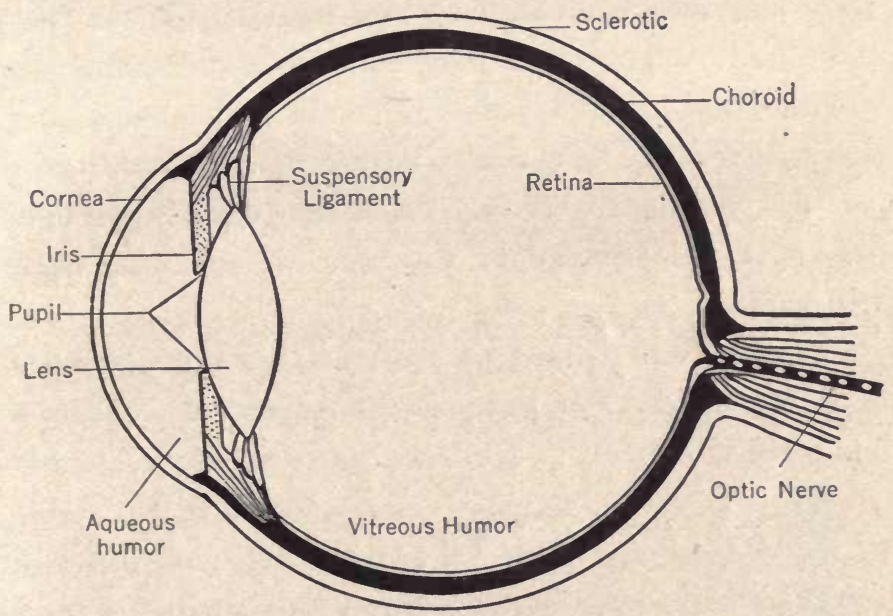

Fig. 181. Section of the eye.

Light. The nerve endings in the retina when stimulated by light start impulses to the brain which produce sensations of sight. The source of this light varies. It may be the sun, an electric light, or it may be light reflected by objects.

We can not give a definite answer to the question, "What is light?" We do know how to produce it, and we do know many things about its behavior. It is supposed that vibrations, or light waves, are given off in all directions by luminous bodies. These waves travel in straight lines; a single line of light is called a 
ray. Light travels at a velocity of about one hundred and eighty-six thousand miles per second.

When light rays strike a body, one of three things happens to them: they may enter the body and stop, they may strike its surface and bound back, or they may go through it. If they stop in the substance we say they are absorbed; if they bound back we say they are reflected. If light passes through one substance from another, the light waves are often bent out of a straight line. To this change of direction we give the name refraction.

Lenses. When light passes from air through glass it is refracted. For purposes of refraction a piece of glass with one or two curved surfaces is frequently

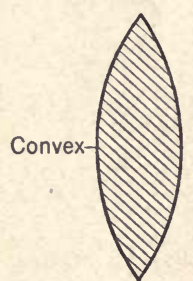

Fig. 182. A biconvex and a used. This is called a lens. Lenses are of different forms as shown in Figure 182. When rays of light pass through a concave lens, they spread away from each other. When they pass through a convex lens, they are brought toward each other and meet at a point called the focus.

In the eye the cornea and the lens have convex surfaces. When an object is seen, rays of light pass from every point of it through the cornea and the lens, and are brought to a focus on the retina where an image of the object is formed, 
Images. When a lens is used to form an image, it is always desired that a distinct image be formed on a

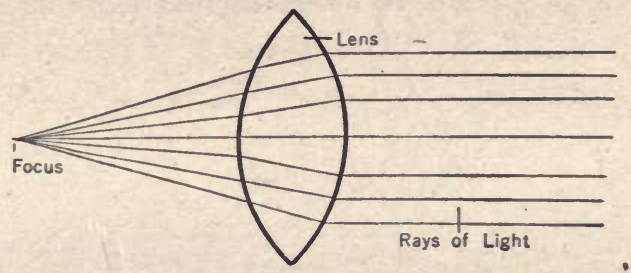

Fig. 183. A biconvex lens bending the rays of light so as to bring them to a point, the focus.

given surface. If a candle is placed in front of a convex lens, and a screen is placed back of the lens and moved back and forth, a place will be found at which a sharp but inverted image of the candle is thrown upon the screen.

Focusing. In the experiment above, it is evident that the screen must be placed

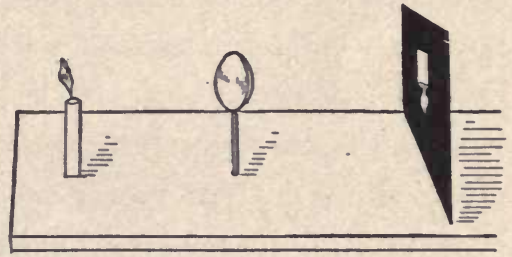

Fig. 184. Diagram showing the method of the formation of an image by a lens. in a certain position if a distinct image is produced. In a camera the image of the object falls upon the sensitive plate or film. To secure this for any given object, the lens in the camera must be moved backward and forward until the converging rays are brought to a focus on the plate.

In the eye, the distance between the lens and the retina can not be changed, consequently the focusing 
must be done in a different way. It is brought about by a change in the shape of the lens. The lens is elastic, and if left to itself it tends to become more convex. It is fastened to the choroid coat by a ligament, known

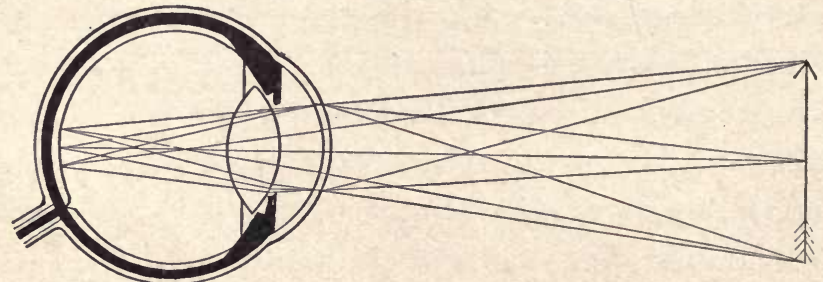

Fig. 185. Diagram of the eye showing the convex lens forming an image by converging the rays on the retina.

as the suspensory ligament. This is ordinarily stretched tight and exerts a constant pull on the lens, tending to make it thinner. By means of ciliary muscles the choroid coat can be drawn forward. This loosens the suspensory ligament and the lens becomes more convex. This power of the eye to change the curvature of the lens is called accommodation.

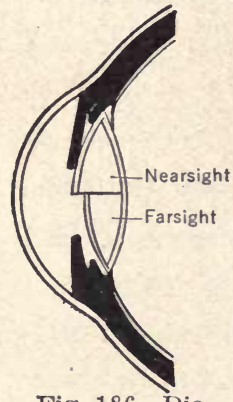

Fig. 186. Diagram to illustrate changes of the lens in accommodation.

The more convex the lens is, the more it bends the rays of light. When an object is near, the light rays from any point of it spread out or diverge rapidly. To bring these to a focus they must be bent very decidedly. This can be done when the lens is convex. Light from a distant object comes to us almost parallel and hence a flattened lens can bring it to a focus. 
Defects of the eye. There are several defects of the eye which are common: short sightedness, far sightedness, and astigmatism. Spectacles are worn to compensate for these defects. In a near sighted eye, objects can be seen distinctly only when not more than about ten inches away. If an object is at a greater distance, the focus is formed in front of the retina. To remedy this defect concave lenses are used. These will throw the image farther back upon the retina.

If the eye is far sighted, the image will fall behind the retina unless the object is more than ten inches away. To correct this convex glasses are used. These will bring the focus farther forward.

Astigmatism is a very common defect in the eye. This is due to an irregular curvature in the surfaces of the cornea or lens, or in both. The result is that only a part of the rays focus on the retina at once. This produces a blurred image. The eye muscles become strained in trying to adjust the lens to secure a clear image. As a result headaches are frequently produced.

Care of the eyes. Too much care can not be taken of the eye; first, because the eye is a very delicate instrument, and second, because it is so very useful to us. Frequently defects of the eye escape the attention. This is especially true in children. Nervousness and headaches are often caused by defective vision. If glasses, properly fitted by a competent oculist, are worn, these troubles may be relieved. The light by 
which we read should be good, but not too bright; it should come from above or from one side. Care should be taken to avoid having bright lights shine directly into the eyes, or having it reflected into them from the page. A flickering light is very tiresome. Reading in the cars is extremely taxing because the eye is strained in trying to follow the book which is constantly being moved by the jarring of the car. The distance at which a book should be held will vary somewhat, but twelve to fifteen inches is the best distance for steady reading.

The eyes should not be rubbed, for they might become infected by germs on the fingers. Dust is also bad for the eyes. It sometimes contains harmful germs, and it always irritates them. A saturated solution of boracic acid is best for washing inflamed eyes.

The ear. If a bell is struck, it is made to vibrate. This causes the air in all directions around the bell to vibrate, and waves of sound are produced. Some of these waves of sound enter the ear, are conducted through the ear, and finally stimulate the ends of the auditory nerve from which nerve currents are sent to the brain.

Structure of the ear. The ear is divided into three parts : the external, the middle, and the internal ear.

1. The external ear consists of the oval, more or less flattened structure at the side of the head. It is composed of cartilage and skin. It collects sound waves and helps to converge them into the auditory canal which is the tube leading to the middle ear. 
Across the inner end of this tube is stretched a thin membrane known as the ear drum.

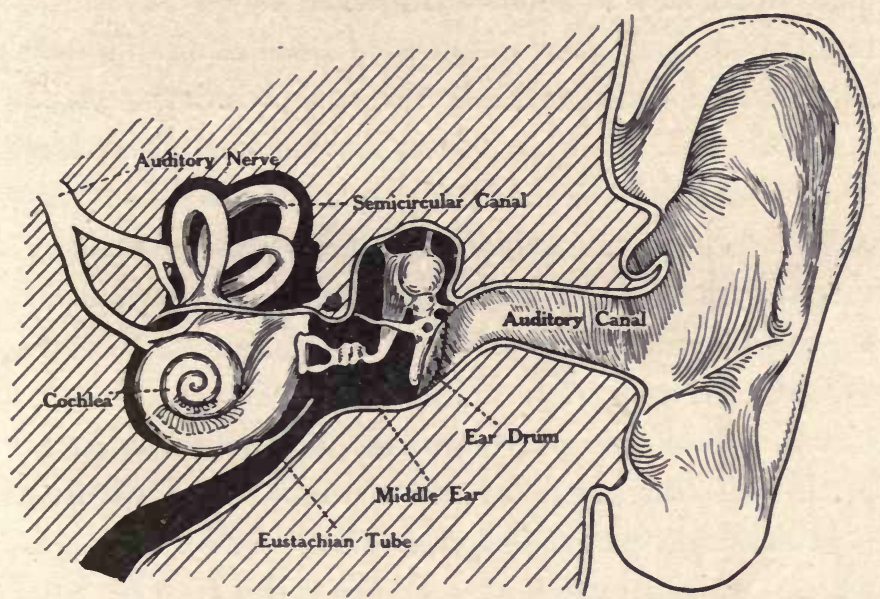

Fig. 187. Diagram to illustrate the structure of the ear.

2. Beyond the ear drum is a small cavity in the temporal bone. This is the middle ear. It is connected with the pharynx by the Eustachian tube. Through this, air enters the middle ear and presses on the inside of the ear drum, balancing the pressure of the air on the outside of the drum. A sudden very loud noise might otherwise burst the ear drum because of the great pressure outside. There are three bones in the middle ear; the hammer, the anvil, and the stirrup. These small bones are arranged in a chain across the cavity of the middle ear. The first is connected with the ear drum and the third is fastened to a membrane over an opening into the internal ear. 
3. The internal ear is far more complex than the other parts. It is an irregular cavity in the temporal bone lined with a membranous sac. Lying next to the middle ear is a tube coiled like a snail shell and called the cochlea. Next to this there is a central portion back of which there are three semicircular canals lying in three planes and placed perpendicular to each other. All of these tubes are filled with a watery fluid. In the cochlea is a thin membrane in which the auditory nerves terminate.

Action of ear. The external ear gathers the sound waves so that they pass down the auditory eanal to the ear drum. This then starts to vibrate. These vibrations pass through the three bones of the middle ear to the membrane separating it from the internal ear. From this membrane the liquids in the middle ear are set in motion. They in turn cause the membrane in the cochlea to vibrate and thus stimulate the nerves from which impulses are sent to the brain.

It is generally supposed that different parts of this membrane respond to different rates of vibration and this makes it possible for us to distinguish between different pitches. The range of hearing is very great. We can hear sounds corresponding to vibrations from about 30 to about 40,000 per second. Between these limits as many as 6,000 variations of pitch can be perceived.

The semicircular canals are not used for hearing. They are used in maintaining the balance, or equilib- 
rium, of the body. Through them we know in what position the body. is. Even with our eyes closed, we know in what direction the body is leaning and how to move to balance it.

Care of ears. Since the middle and inner ears are enclosed in bone there is very little danger of injuring them. By attempting to remove the ear wax from the external ear injury is sometimes done to the ear drum. This wax is a protection against insects entering the ear. It should not be removed except with clean warm water.

In severe colds the ear may become infected by germs passing up through the Eustachian tubes. This sometimes causes very serious infeetions in the ear; in the porous bones around the head; and, in extreme eases, it may extend to the brain. In any such infection a physician's services are necessary.

\section{Questions}

1. Name seven senses.

2. Of what use are the sense organs?

3. Name the senses having organs located in the skin.

4. Are all parts of the skin equally sensitive to touch?

5. Describe the sense organs of taste.

6. Where is the sense of smell located?

7. If you have a cold why is it difficult to taste some substanees? 
8. How is the eyeball protected?

9. Name and describe the parts of the eye.

10. What is the nature of light?

11. Explain how the rays of light are bent in passing through a convex lens.

12. What is an image? Where must the image fall in the eye if the object is seen?

13. Explain what is meant by accommodation.

14. How may shortsightedness and farsightedness be remedied?

15. What is astigmatism?

16. Give some points in reference to the care of the eyes.

17. What is the structure of the external ear? The middle ear? The internal ear?

18. What is the nature of sound?

19. How are sound waves transmitted through the ear to the auditory nerve?

20. Of what use are the semicircular canals?

21. Why do colds sometimes affect the ear? 


\section{HEALTH AND DISEASE}

Importance of health. Physical health is essential to the greatest success and happiness of any individual. Likewise, the prosperity of any community depends upon the health of the community, which is the combined health of its individuals. The preservation of health, both individual and public, is an important duty. In order to fulfill this duty, imposed upon each one of us, it is necessary to understand the conditions which make for disease as well as those which make for health. The science of keeping the body in good health is called hygiene.

Health and disease. We already know that each organ in the body has a special work to do. It is also true that each tissue and even each cell, has certain functions to perform. If the various activities of all of the cells are being properly performed, we are in good health. If anything, however, interferes with the functions of these cells so that they are not properly performed disease results.

Cause of disease. Diseases are due to many causes, some of which are known, and some of which are still unknown. The causes of some diseases are very evident; for example, an accident may deprive a man of 
his arm or injure some internal organ. Parasites, such as the tapeworm, or trichina, may infest organs and thus interfere with their working.

In many diseases the causes are not so evident, but we now know that they are the result of the action of very small plants and animals. They are commonly called bacteria, germs, micro-organisms, or microbes. These small organisms either act directly upon the tissues, or they produce poisons, called toxins, which destroy the tissues or in some other way prevent their normal activity.

The more common plant germs, we have already learned, are bacteria. Diseases of which we know they are the cause are diphtheria, measles, tuberculosis, pneumonia, mumps, scarlet fever, tetanus (lock jaw), cholera, plague, and spinal meningitis. Small onecelled animals, protozoa, are likewise responsible for some diseases, the best known of which are malaria, smallpox, and yellow fever. All diseases which are caused by germs are "catching" or contagious.

How germs enter the body. Germs are found everywhere about us, in the air, in the water, in our food, and on our clothing. Fortunately, not all of them succeed in entering the body, and even if some of them do get in they do not always find conditions there favorable to growth.

Germs must enter the body through the digestive tract, the respiratory organs, or the skin. Those which enter the digestive tract are taken in with our food 
and water, or they can enter the mouth through the air. Many enter this way, chief of which cause typhoid fever, cholera, and dysentery.

The respiratory organs afford the best entrance to the body for germs. This is primarily because germs are so easily carried by air. In spite of the many adaptations of the respiratory organs for the removal of dust and germs, the long irregular passageways are good lodging places for them. Tuberculosis, pneumonia, colds, influenza, tonsilitis, bronchitis, and many other diseases enter the body in this way.

Fortunately the skin is a very effective covering of the body, and it consequently prevents the entrance of foreign material. If the skin is removed in any way, as in cuts or other injuries, germs can then enter. Those which produce blood poisoning enter the body in this manner. Diseases such as malaria, yellow fever, or bubanic plague are communicated to man by the bites of insects and thus enter the body through the skin.

Growth of germs. When germs have entered the body, they sometimes find there conditions favorable for their growth; plenty of food and moisture, and a warm temperature. A few will grow any place in the body, but most of them show some choice in their selection of these favorable conditions. Some will grow only in the respiratory tract, others in the alimentary canal, and still others only in the blood or skin. 
A number of days elapse from the time the germs enter the body until they exist in sufficient numbers for the disease to appear. This time is known as the incubation period. The length of this period varies with the kind of disease. For measles it is nine days, scarlet fever two to four days, typhoid fever two weeks, and grippe from one to five days.

How the body destroys germs. In spite of these innumerable and active enemies, the body is generally well able to defend itself. It has at least three means of destroying germs; by the white blood corpuscles, by substances called germicides, and by other .substances called antitoxins.

1. White corpuscles. We have already referred to the method by which the white blood corpuscles destroy germs. They are present not only in the blood, but also in all parts of the body. If bacteria are present, they surround and-destroy them. They are always present in great numbers around a wound.

2. Germicides. In the blood there are certain unknown substances formed which destroy germs. They are called germicides. If these substances are present in sufficient quantities in the blood, they kill the disease germs and consequently protect the body from disease.

3. Antitoxins. The injurious effects of disease are sometimes the result of poisons, toxins, which the germs produce. There is sometimes produced in the body a substance called antitoxin (anti, against). This 
counteracts, or acts against, the toxin so as to render it harmless. Each disease probably has its own antitoxin. If this is produced rapidly and abundantly enough, the toxin of any disease is destroyed, the corpuscles then dispose of the germs, and there is immediate recovery from the disease.

If the body is kept in good healthy condition by the proper food, exercise, and plenty of fresh air and sleep, there is usually an abundance of white corpuscles to defend it against germs. It is also in the proper condition to produce the right germicides or antitoxins, and thus render it less subject to infectious diseases.

Treatment of disease. To cure an infectious disease it is necessary to destroy the germs which produce it. The power to do this lies mostly in the body itself. If it becomes impossible for the body to accomplish this, however, other means must be resorted to. Chief of these are serums, vaceines, and drugs which we call medicines.

Serums are obtained from the blood of an animal, usually a horse. They are prepared in the following manner: dead or weakened germs, or the toxins of the diseases to be cured, are injected into the blood of the horse. We still have much to learn in regard to the substances which these then produce in the blood of the animal. Extracts, called serums, are made from the blood drawn from an animal treated in this way. We do know, however, that if such serums are injected into a person, substances are produced which result 
in the destruction of the disease germs in the person.

One of the most recent and valuable discoveries in medicine is the method of production and the use of serums called antitoxins which normally are produced in the blood of a person who has an infectious disease. The immediate stimulus for their production is the presence of toxins. Sometimes these are not produced rapidly enough and the disease cannot be checked. For a few diseases, such as diphtheria and lock jaw, it has been found possible to produce artificial antitoxins to inject into the human body. The method for producing the antitoxin for diphtheria is as follows: Bacteria which produce diphtheria are grown in blood serum in the laboratory. These bacteria produce toxins, which are then separated from the live germs. A number of doses of this toxin are then injected into the blood of a horse. This is done at intervals for several months, during which time large quantities of antitoxin are being produced in the horse's blood. Finally blood is taken from the horse and from it antitoxin is extracted. This is injected into the body of a person who has diphtheria and often causes a cure. If it is injected into the body of a person who has been exposed to the disease, it prevents its development.

Vaccines. The term vaccine is familiar to most of us because of its long use in connection with vaccination for smallpox. In order to stimulate the body to produce substances to destroy a disease, dead or weak- 
ened germs of that disease are sometimes injected into the body.

Vaccination (vacca, cow) was discovered in 1796 by Jenner. He found at that time that if pus from sores found on cows, suffering from the disease cowpox, was injected into the human body, the person was protected from smallpox.

The methods at first employed in securing this pus, or vaccine, were very crude and the results from its use were sometimes disastrous. It is now secured by injecting into a healthy young cow germs which give the cow the disease known as cowpox. This results in the formation of sores from which pus is taken. It is preserved in small tubes and is injected into the skin when a person is vaccinated. If this "takes," the person has a mild disease which produces in the blood germicides for the smallpox germ. Vaccination is now being successfully carried out against typhoid fever. This is done in cases of epidemics in cities, and also in armies.

Medicines. Very few drugs can be used to destroy germs. Those which are successful are in most cases also destructive to the tissues. Physicians give medicines to aid the body in the destruction of the germs, the substances for which must come from the body itself. In some cases medicines are administered to produce immediate, but only temporary, relief. This does not cure the disease, but it is often an advantage. To accomplish such relief drugs are sometimes used to 
benumb the nerves; hot or cold applications, or electricity may also be used.

In a few instances, it is possible to destroy the germs directly. This is true for germs in the throat, nose, and skin where they can be reached and destroyed by antiseptics.

It is most essential that every one realize the necessity of putting a sick person into the hands of a competent physician. Home remedies are seldom beneficial, and they are often harmful. Discretion is necessary in the selection of a physician, for he must be honest as well as skillful and well-trained. We may always be certain that a physician who advertises is not reliable. Many efforts have been made in the past few years to protect the public against "quack" doctors who profess to have some secret cure for diseases. However, there are still thousands of these incompetent practitioners operating all over the country. By foul means and under false pretenses they get their patients' money.

In the same class with "quack" doctors must be placed many patent medicines. Some of these medicines are good, and especially so when taken under the direction of a physician. Many, however, are not only useless, but they are also harmful, frequently containing alcohol and other harmful drugs. Headache tablets, in particular, often contain opiates. Death sometimes results from their use. The alcohol in patent medicines 
produces a temporary exhilaration which is often mistaken for some beneficial effect.

Immunity. In some cases'germs may enter the body of an individual and yet have no effect on him. He is said to be immune to that disease. This immunity, undoubtedly, depends upon the presence of substances in the body which can destroy the germs. We already know that certain diseases, such as mumps, smallpox, and whooping cough, we do not have a second time. On the other hand, some diseases recur time and again. It is not definitely known just why this difference exists. Evidently the antitoxin, germicide, or other substance which was produced to cure a given disease remains in the body for a more or less definite'period of time. In some diseases this is for life.

\section{Questions}

1. Why should we know something about hygiene?

2. What are the principal causes of disease?

3. Name eight diseases caused by germs.

4. How do germs enter the body?

5. Explain the incubation period of a disease.

6. What are the ways in which the body defends itself against the attack of germs?

7. How are serums obtained?

8. Of what value are antitoxins? How are they produced?

9. Why has it been possible to reduce the death rate of smallpox? 
10. Why should we place no confidence in physicians who advertise?

11. Discuss the value of patent medicines.

12. What do you understand by the term immunity?

13. It has been estimated that a typhoid fever germ may travel about 2,000 times its own length in one hour. A cholera germ may attain a speed that is 45 times as great as that of the typhoid bacillus. If a man should travel as many times his own length as the typhoid bacillus or cholera spirillum, how far would he travel in one hour?*

*From Bergen and Caldwell, Practical Botany, Ginn and Company. 
CHAPTER I

\section{SANITATION}

Importance. Sanitation is a study of the conditions which make for the health of a community. The greatest prosperity ean not come to any community until every precaution is taken to promote and to establish public health. It is much more important that we should prevent diseases than it is that we should cure them. Many times as much money is now spent in attempting to cure diseases than there is in preventing their spread. It is only recently that the public has begun to realize the advantages in prevention and methods of eontrol. There is still an annual loss from infectious diseases of millions of dollars, and the death of hundreds of thousands of persons in our communities, conditions which produce untold suffering and sorrow.

Preventable diseases. All infectious or contagious diseases are preventable diseases. By that we mean that their spread can be prevented. The preventive methods used depend upon the way in which the germs ean be destroyed and the way in which they are carried.

Destruction of germs. There are many methods of destroying germs and still more methods of preventing 
their rapid growth if they are not destroyed. The simplest and one of the most effective measures for killing germs is heat. Fortunately germs can not withstand a boiling temperature, and if dry heat or boiling water is applied for about an hour, they will be destroyed. Ordinary cold temperatures do not kill germs, but they do prevent their rapid multiplication. Drying is destructive to many. Light, espeeially bright sunshine, kills most microbes in a few hours. Many poisons known as antiseptics and disinfectants are also used.

Disinfection. The process of destroying germs is ealled disinfection. People do not generally realize the necessity of careful disinfection during and after disease. Because disinfection is so frequently neglected preventable diseases continue to attack mankind. A little more care in this direction would save many lives.

The simplest methods for disinfection are boiling and airing clothing and bedding in the bright sunlight. Most methods, however, depend upon the use of poisons. The method used generally depends upon the nature of the particular disease. For example, in tuberculosis, pneumonia, or colds, the sputum should be burned. Handkerchiefs or any clothing containing discharges from the nose or throat should be thoroughly soaked in an antiseptic or boiled, and should not be put in with the common laundry before this is done. In diseases, such as typhoid fever or cholera, 
all discharges from the intestines should be disinfected. Dishes used by persons having an infectious disease should always be scalded.

Many different poisons are used for killing germs though they are not all suited for the same disease. One of the most frequently used of these disinfectants is mercury bichloride (corrosive sublimate). Carbolic acid, lysol, alcohol, formalin, boracic acid, and chloride of lime all serve this purpose. If it becomes necessary to disinfect a house, or even a room, a gaseous disinfectant must be used. This process of destroying germs by fumes or poisonous vapors is fumigation.

Fumigation. The two most common agents used in this process are formalin and burning sulphur. The room should be tightly closed, bedding and clothing should be spread out. Formalin can then be introduced into the room as a vapor; as an easier method of getting the gas into the room, formalin may be spread on a sheet and allowed to evaporate.

Sulphur dioxide is made by the burning of sulphur "candles." A better and safer way is to obtain liquid sulphur dioxide. If this is poured out into dishes, it will soon evaporate and fill the room with the sulphur dioxide fumes. For thorough fumigation a room should be kept closed for several hours. This will destroy all vermin as well as germs.

Quarantine. We prevent the spread of the most infectious diseases by keeping people suffering from such diseases away from other people; that is, we 
isolate or quarantine them. If a house is quarantined, persons ean not go into or out of it for fear that they may earry the germs to others. We now maintain strict quarantine for such diseases as smallpox, diphtheria, and scarlet fever.

Quarantine frequently causes great personal inconvenience, but we should all be public spirited enough to be willing-to make whatsoever sacrifices are necessary to keep from spreading diseases to those around us.

Food. It is impossible for us to supervise personally the production or even the preparation of all of our food. The food which we eat has in most cases passed through the hands of many individuals, and in some instances through many processes before it is taken into our bodies. The possibility of germs entering the food is thus very great. In our homes we can protect ourselves from infection by being careful in its preparation. Cooking sterilizes food. If eaten raw, foods should be carefully washed. In purchasing our table supplies, it is advisable to patronize only those markets, bakeries, and fruit stores which are kept clean. Our only means of protection from infection in restaurants or hotels is to select those which are clean and sanitary.

Insects and disease. We now know that many diseases are earried by insects, the most common of which is the eommon house fly. To this little inseet with its filthy habits may be traced the spread of 
many diseases, especially typhoid fever. The mosquito carries malaria and yellow fever germs. Sleeping sickness, common in the low lands of Africa, is spread by the tse-tse fly. The flea is responsible for carrying bubonic plague.

The fly lays her eggs in all sorts of decaying matter, manure, garbage, dead animals, etc. In a very short time these hatch and develop into mature insects. The body covered with hairs and spines, and most of its habits, particularly adapt the fly for collecting and distributing germs. It feeds in all manner of dirty places, and in so doing, eats many germs and gets its feet covered with many more. These it may deposit upon our food either by shaking them off its feet as it walks over the food or

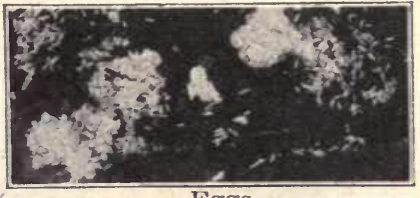

Eggs.

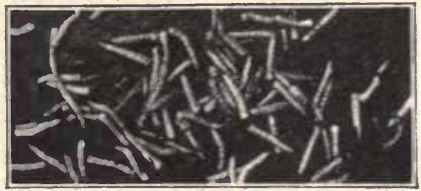

Larvae.

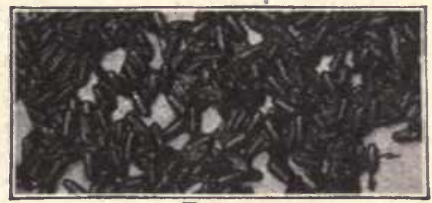

Pupae.

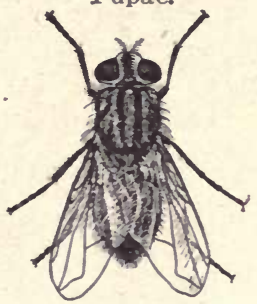

Adult.

Permission of $U$. S. Dept. of Agriculture.

Fig. 188. Life history of house fly. dishes, or in its "specks" which always contain many germs. If by chance the fly has visited a sick room 
before it reaches our kitchen, we may be certain it is bringing with it hundreds of disease producing germs. Until we get rid of flies, it is very important that by screening we keep them away from our food and away from the sick room.

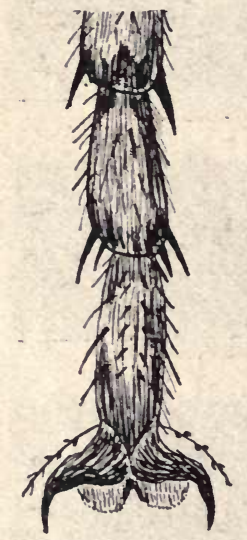

Fig. 189. Foot of a fly, showing hooks, hairs, and pads to whi ch germs easily adhere.

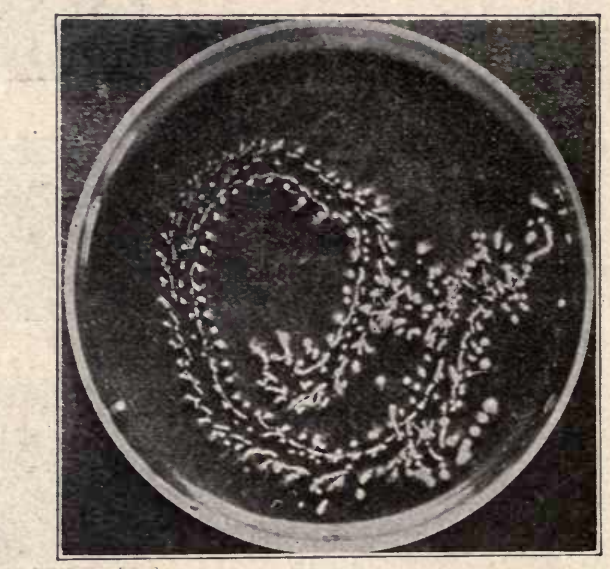

Permission U. S. Dept. of Agriculture. Fig. 190. Gelatine plate showing bacteria in fly foot prints.

The most effective way of abolishing this pest is to prevent it from breeding. This can be done by removing the dirty places in which it breeds. Manure and garbage should be kept in ciosed cans or boxes, and frequently removed and destroyed. The neighborhood should be kept clean and sanitary so that the fly can not find a place in which to lay her eggs. Any campaign against the fly must be directed against filth as well as against the adult fly. 
The mosquito is responsible to a large extent for the spread of two diseases, malaria and yellow ferer. When it pierces the skin of a sick person, germs are taken into its body. These may then later be injected into the body of a well person.

The eggs of the mosquito are laid on the water. These soon hatch into "wrigglers," which later develop

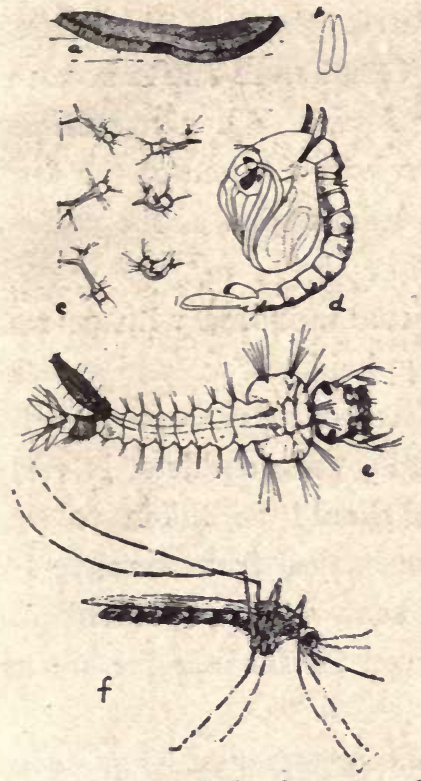

Fig: 191. Life history of common mosquito. $A, B$, eggs; $C, E$, larvae; $D$, pupa; $F$, adult.' After 'Howard.

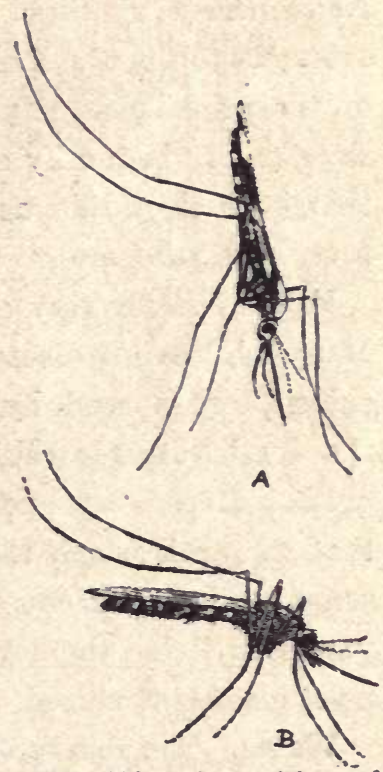

Fig. 192. A, position of malaria mosquito (Anopheles) when at rest. $B$, position of common house mosquito (Culex) when at rest. After Howard.

into the adult mosquito. The wriggler lives in the water, but it must frequently come to the surface to get air. To get rid of the mosquito we must destroy 
its breeding places. Swamps and ditches must be drained; rain barrels, open wells or any receptacles holding water should be carefully screened. The wrigglers can be destroyed by a film of oil on the water. This enters the breathing pores and readily kills the larvae.

Yellow fever has practically been stamped out of New Orleans by these measures. Some of the earlier attempts to dig the Panama Canal were futile because of the prevalence of yellow fever. When operations were finally begun by our government, one of the first things which it did was to rid the region of the yellow fever mosquito.

Milk. Milk is very easily contaminated with germs. Many children's diseases, typhoid fever, and tuberculosis, are spread by infected milk. Consequently the death rate for babies and young children is very great. Every care possible should be taken to see that the milk which they use is free from germs. In summer the milk must be kept cool to prevent its "spoiling," and the bottles used for feeding the babies must also be sterilized.

Water. The source of drinking water in large cities is very frequently from rivers or lakes. This makes it very liable to contamination from sewage, and sewage is almost certain to contain germs of typhoid and other diseases. City water should be frequently examined to see that it contains no germs. If it is known to be bad, or even suspected, it is wise to boil the water before 
using it. In smaller communities and in the country where wells are used, it is necessary to guard against contamination of the water from the barn yard, privy, or cess pool.

The Board of Health. Since cities were first organized people have recognized the need of some kind of protection. Accordingly, laws have been made for governing the people, for protecting property, and in fact for protecting individuals from attack and murder.

Only recently, however, have we come to recognize the necessity of having laws and regulations for protecting the public health. It is almost as important to prevent your neighbor from giving you the smallpox as it is to prevent him from injuring or possibly killing you in some other way. Nearly every community now has a Board of Health, the duty of which is to protect the health of the people. Persons appointed from the community constitute this board. One of the number, the health officer, is required to see that certain laws are enforced to prevent the spread of contagious diseases. It is his duty to placard houses in which are contagious diseases. Before the quarantine is removed he must disinfect the house.

It is the duty of the health board to inspect all milk; to prevent the sale of unhealthful milk; to see that all garbage and sewage are properly disposed of; and to provide a pure supply of water. All persons should obey the instructions of the Board of Health. This board needs the assistance of each individual in the community. 
The carelessness of just one individual may be the cause of much sickness and many deaths.

\section{Questions}

1. Name ten preventable diseases.

2. To what extent is a community responsible for the spread of such diseases?

3. State six methods of destroying germs.

4. What is a disinfectant? Name five disinfectants.

5. How should a room be fumigated?

6. What should be our attitude toward quarantine? Why?

7. How can we guard against infection from foods?

8. Discuss the relation between insects and diseases.

9. How may milk become contaminated? What diseases may be spread by milk?

10. Are there any objections to running sewage into bodies of water from which the water supply for the city is obtained?

11. Are there better methods for disposing of sewage?

12. When should one use only boiled water?

13. Learn what you can of the work done by the Board of Health in your city. 


\section{INDEX}

Abdomen, 317

Absorption of food, $278,32.5$

Accommodation of eye, 404

Acids, 105

characteristics of, 106

Adaptation of animals, 252

of plants, 222

Adenoids, 354

Adrenal bodies, 368

Adrenalin, 368

Adult, 262, 267, 374

Adulteration of food, 307

Agassiz, Alexander, 130

Age of man, 295

Air, as matter, 2

comparison of inhaled and exhaled, 351, 352

composition of, 121

importance to plants and animals, 345

sac, 349

storage by plants, 216

Alcohol as a stimulant, 330

Alimentary canal, of animals. 276

of $\operatorname{man}, 310$

Ameba, 272, 279, 280, 282

Amphibians, 261

Anatomy, definition of, 296

Anchorage of plants, 222

Animal life dependent upon water, 115

Animals, adaptation of, 252

change due to new conditions, 252 classification of, $254 \mathrm{ff}$.

distribution of, $249 \mathrm{ff}$.

life processes in, $272 \mathrm{ff}$.

relation to man, $286 \mathrm{ff}$.

unable to maintain their ground, 251

Anther, 234

Anticyelone, 142

Antiseptics, 422

Antitoxin, 414, 416

Aorta, 340

Appendix, 318

Argon, 121

Arm, bones of, 372,373

muscles of, 379

Arteries, 339, 340, 342, 368

Arthropods, 264

Astigmatism, 405

Atmosphere, composition of, 121

effect on earth's surface, 164 importance of, 120 moisture in, 124ff. pressure of, $129 \mathrm{ff}$. properties and uses of, 121 variations in, 120

Auditory canal, 406

Auricles, 338

Bacteria, 243

b. and disease, 245

conditions for growth of, 245

decay due to, 246

for diphtheria, 416

in lymph glands, 368 
in waste products, 325

skin as a protection against, 359

useful b., 103, $24 \overline{7}$

Bacteriology, definition of, 243

Barometer, 134

Bases, 106

Bile, 319,324

Birds, 257

Bladder, 258

Blade, 200

Blizzards, 142

Blood, 334

amount of, 337

coagulation of, 337

supply in muscles, 379

vessels, 334,342

Board of Health, 429

Boiling points, 27, 40, 42

Bones, cells of, 374

composition of, 72,373

diseases of, 375

division of, 371

fracture of, 376

growth of, 374

of limbs, 372

purpose of, 370

Botany, 1, 193ff.

Brains, of animals, 281

of man, $384,38 \tilde{3}, 386,387$

Bread-making, 70

Breathing, mechanism of, 349

Breezes, land and sea, 140

Bronchus, 348

Burning, 94

Butterfly, development of, 266

Calorie, definition, 31, 44 of heat in food, 305

Calyx, 233
Canal, alimentary, 310 of ear, 406, 408

Capillaries, 342

Carbohydrates, 203, 204, 301

Carbon, kinds of, $60 \mathrm{ff}$.

Carbon dioxide, 66, 93, 204

balance maintained, 68 commercial uses of, 68,123 in air, 66, 68, 121, 123, 351 in blood, 357

test for, 67

Carpal, 372, 373

Cartilage, 373

Cast iron, 87, 88

Cell, egg and sperm, 283

of a plant, 196

of animals, 275

nerve, 384

- wall, 195

Cerebellum, 386

Cerebrum, 386

Charcoal, 61

Chemical, affinity, 58

analysis, 57

changes, 52

compounds, 53, 54

properties, 53

synthesis, 57

Chemistry, 2, $51 \mathrm{ff}$.

Chlorophyll, 202, 203, 204, 301

Choroid, 400

Chrysalis, 266

Circulatory system, 334ff.

Circulation in animals, 279

Clay, 190

Climate, 149, 150

Clothing, animals supplying. 288

use of, 365

Clouds, 126

Coagulation, 337 
Coal, formation of, $62,63,64$

Cochlea, 408

Coelenterates, 269

Coke, 64, 65

Complex animals, 274

Condensation, 46

Conduction, 20, 22

Continents, 160, 162

Convection, 22, 138, 139

Cooking, 307

Corals, 198, 269

Corolla, 233

Corpuscles, destroying germs, 414

red, 335

touch, 397

white, 336, 368, 414

Cortex, 227. 228

Crayfish, 264

Cretinism, 368

Crops, animals injurious to, 289 rotation of, 222

value in U. S., 206

Crustacea, 264

Crystalline lens, 400

Cyclones, 141

Darwin, Charles, 236

Day, 151

Decay, due to bacteria, 246,30s

Dendrites, 384

Dermis, 360

Dew, 125

$$
\text { point, } 125
$$

Diabetes, 369

Diamond, 65

Diaphragm, 317

Diffusion, 6, 9, 10, 11, 221, 322, $323,324,325$

Digestion, absorption, 325

in animals, 276 in intestine, 324

in mouth, 322

in plants, 207

in stomach, 323

large intestine, 324

necessity of, 312

Digestive system, $310 \mathrm{ff}$.

Disease, cause of, 411

contagious, 354

due to bacteria, 245

due to insects, 424

due to worms, 308

germs, 412, 413, 414, 421

health and d., $411 \mathrm{ff}$.

immunity from, 419

medicines, 417

of bones, 375

of glands, 368, 369

of respiratory organs, 353

of the ear, 409

of the eye, 405

preventable, 421

produced and carried by animals, 289

some methods of prevention, $422,423,424$

treatment of, 415,416

Disinfection, 422

Dislocation of bone, 377

Distillation, 41

Dust, 121, 124, 164

Ear, drum, 407 structure, 406

Earth, orbit of, 152,153 surface of, $160 \mathrm{ff}$.

Echinoderms, 268

Education, 394

Eggs, development of, 283

fertilized, 235, 262, 283

Electrolysis, 110 
Elements, 53, 55

carbon as, 60

hydrogen as, 97

in food, 298

iron as, 85

nitrogen as, 101

number of, 56

oxygen as, 90

phosphorus as, 72

sulphur as, 77

Enzymes, 322, 323, 324

Epidermis, 360

of leaf, 201

Epiglottis, 348

Esophagus, 310, 317

Eustachian tube, 317,407

Evaporation, 44, 124, 208, 209, 213,364

Evans, Dr. W. A., 117

Excretion in animals, 280

in $\operatorname{man}, 357 \mathrm{ff}$.

in plants, 221, 222

Excretory system, $357 \mathrm{ff}$.

Exercise, necessity of, 381

Eyes, of animals, 281

of man, 399

care of, 405

defects of, 405

structure, 400

Fatigue, 381

Fats, 302, 323, 324, 326

test for, 302

Fauna, definition of, 249

Femur, 373

Fertilization, 235

Fibula, 373

Fire extinguisher, 69

Fireless cookers, 21

Fishes, 263

Flowers, 232
Fly, abolishment of, 426

development of, 425

Focus, 402, 403

Fog and clouds, 126

Food, absorption of by animals, 278

adulteration, 307

composition of, $304 \mathrm{ff}$.

cooking of, 307

diffusion of, 322,325

digestion of by animals, 276 , 277

elements in, 298

manufactured by plants, 203 , 206

protection against infection, 424

quantity and kind of, 306 selection of, 306

storage of, 205

stuffs, $299 \mathrm{ff} .-326$

supplying animals, 287

uses of, 198, 207, 298, 305

Frost, 125

Fumigation, 423

Fungi, 243

Furnace, blast, 86

phosphorus, 73

Ganglia, 384

Gases, boiling points of, 40,42 change from liquid to g., 35 change in volume, 47

effect of temperature upon, 18 molecules in, 10

Gastric juice, 323

Germicides, 414

Germs, 412, 413, 414, 421

Glands, adrenal, 268

definition of, 277

digestive, 310,311 
ductless, $367 \mathrm{ff}$.

gastric, 311, 318, 323

intestinal, 311,324

liver, 311,319

lymph, 367

pancreas, 369

salivary, 316

spleen, 369

sweat, 361

thyroid, 368

Glottis, 347

Glycogen, 326

Goiter, 368

Graphite, 65

Habitat, 211

Habits, 391

Hail, 126

Hair, 361

Head, 371

Health, 117, 316, 325, 331, 355, $365,381,405,409,411 \mathrm{ff}$., $421 \mathrm{ff}$.

Board of, 429

Heart, $334 \mathrm{ff}$.

action of, 340

beat, 340

structure, 338

Heat, effect of, on liquids, 15, 44

effect of, on solids, 13

given off in condensation, 46

necessary to change ice to water, 37

necessary to change water to steam, 44

necessary to dissolve a substance, 38

source of in the body, 363 , 380 transfer of, conduction, 20,22 convection, 22

through air, 124

unit of h. measure, 31

withdrawn in evaporation of liquids, 44

Heating, effect of unequal, 139

Hemoglobin, 336, 351

Hemorrhages, 368

Host, 243

Humerus, 372, 373

Humidity, 124

Humor, aqueous and vitreous, 401

Hydrochloric acid, 98

Hydrogen, $97 \mathrm{ff}$.

Hygiene, definition of, 296

of the skeleton, 375

Ice, $38,39,45,47$

Images, 402, 403

Insects, 264, 265, $424 \mathrm{ff}$.

Intestine, 310, 311, 318, 324

Invertebrates, 255

Involuntary action, 389, 390

Iris, 400

Iron, $84 \mathrm{ff}$.

oxide of, 94,168

sulphide, 54,55

Irrigation, 144

Isobar, 155, 156

Isotherm, 156, 158

James, Professor, 392

Jenner, 355, 417

Joints, 227, 375

Kahlenberg, 121

Kidneys, 357

Lampblack, 62

Larva, 266, 428 
Larynx, 348

Leaves, bloom of, 214 chlorophyll, 202, 203, 204, 301

excretion, 280

food-making power, 203

food storage, 205

motion, 280

protection against loss of

water, 213

relation to water supply, 211

respiration, 215

structure of, 200

transpiration, 208

Lens, 402

Ligaments, 375

sprain of, 377

Light, 401, 402

Lightning, 143

Lime water, 53, 68

Limbs, bones of, 372

Liquids, boiling points of, 40 , 42

change from solids, 35

change in volume, 47

change to gas, 35

effect of heat on, $15,16,44$

entering plants, 230

heat given off when 1 . be-

come solids, 38

heat withdrawn in evapora-

tion of, 44

melting points of, 39

molecules in, 9

Litmus, 106, 107

Liver, 311, 319, 326

Loess beds, 164

Lungs, 347, 348, 349

Lymph, 334, 335

glands, 367

vessels, 334, 342,343
Mammals, 255

Man, age and races of, 295

body of, 296

classification of, 294

difference between $\mathrm{m}$. and other primates, 294

relation of animals to, 286

Manganese dioxide, 92

Matches, 74, 75, 76

Matter, classification of, 53

constitution of, 6

definition of, 2 .

effect of heat on, 13

molecular theory of, 7

physical and chemical

changes, 51

three forms of, 3,34

Mechanical mixtures, 53

Medicines, 417

patent, 418

Medulla oblongata, 386

Melting points, 27, 39, 81

Mercury, boiling point, 40

melting point, 40

use in barometer, 134

use in thermometer, 27

Mercuric oxide, 92

Mesentery, 319

Metacarpals, 372, 373

Metatarsals, 373

Milk, action of rennin on, 323 composition of, 300

contamination of, 428

pasteurization of, 308

Molecular theory, 7

Molecules, 8, 9, 10, 11, 24, 4S

Mollusks, 267

Mortality list for Chicaco. 1910,355

Mosquito, development of, $42 \%$ protection against, $\mathbf{4 2 8}$ 
relation to disease, 427

Motion of animals, 280

Mountains, 162

Mouth, digestion in, 322

of animals, 276

of $\operatorname{man}, 310,312$

Mucous membrane, 312, 316, 318,348

Mucus, 312, 316, 322

Muscles, eiliary, 404 in walls of arteries, 368 protection of, 359

Muscular system, $378 \mathrm{ff}$.

Nails, 363

Narcotics, 328ff.

Natural science, 1

Nerves, auditory, 408

cranial, 387

motor, 385

of animals, 281

olfactory, 399

sensory, 385

supply of in muscles, 379

Nervous system, $383 \mathrm{ff}$.

Nervousness due to eyes, 40.5

Neurons, 384

Neutral substarces, 107

Neutralization, 107

Nicotine, 328

Night, 151

Nitric acid, 106, 108

Nitrogen, in air, 101, 102, 103, 121,122

Nose cavity, 348

Nostrils, 347

Nucleus, 196

Nutrition, 207

Oceans, 160

Oils, 302, 323

test for, 302
Olfactory nerves, 399

Opium, 329

Orbit of earth, 152, 153

Organs, coördination of, 383

definition of, 275

in body cavity, 311

Oxidation, 345,380

definition of, 93,94

Oxides, 58, 66, 82, 85, 92, 93,

94, 102, 106, 168

Oxygen, 90ff.

attack on rocks, 168

given off by plants, 204

in air, 68, 90, 95, 121, 122,

351

uses of, 94, 121, 122

Ovary, 234

Ovule, 234

Oysters, 267

Palate, hard and soft, 312

Pancreas, 311, 319, 369 juice from, 324

Papillae, 397, 398

Parasites, 243

Paramoecium, 274

Pasteurization, $30 \mathrm{~s}$

Peat, 64

Pepsin, 323

Periosteum, 374

Peritoneum, 319

Perspiration, 360

Petal, 233, 234

Petiole, 200

Phalanges, 373

Pharynx, 317

Phosphorus, 72ff.

Physical changes, 51 geography, 2, $120 \mathrm{ff}$.

properties, 53 
Science, 1

Physiology, definition of, 296

Pistil, 234

Pith, 227, 228

Plains, 163

Plant life dependent upon water, $115,198,211$

Plants, air storage of, 216 comparison with animals, 197 composition of, $195 \mathrm{ff}$.

food, 198, 206

importance of, 193, $205242 \mathrm{ff}$.

leaves, $200 \mathrm{ff}$.

reproduction of, $232 \mathrm{ff}$.

respiration of, 215

roots, $219 \mathrm{ff}$.

stems, $225 \mathrm{ff}$.

transpiration of, 208

protection against loss of water, 213

waste products of, 216,221

Plasma, 334, 335

Plateaus, 163

Pleura, 349

Pleurisy, 354

Pollen, 234

Pollination, 236

Pons varolli, 386,387

Porifera, 269

Potassium chlorate, 92

Potassium hydroxide, 106

Pressure, atmospheric, 129

column of mercury held by, 133

effect of change on boiling point, 42

regions of high and low, 142 variations in $p$. due to elevation, 134

Priestley, Joseph, 92

Primates, 294
Proteins, 206, 299, 323, 324 test for, 300

Protoplasm, 195, 196, 197, 272, 305

composition of, 196

Protozoa, 270, 412

Ptomaines, 308

Pulse, 342

Pupa, 266

Quarantine, 423

Radius, 372,373

Rain, 126

amount of in U. S., 146

distribution of, 172

effect of winds on, 144

work of r. in causing relicf, 169

Rainbow, 143

Reflex action, 390

Refraction, 402

Rennin, 323

Reproduction, definition of, 282 of animals, 281

of plants, 232, 234, 235, 236 , 238

Reptiles, 260

Respiration, external and internal, 346

of animals, 278

of plants, 216

organs of, 347

Respiratory system, $345 \mathrm{ff}$.

Ribs, 372

Rickets, 376

Rind, 228

Rocks, 186, 189

chemical effect on, 168

effect of change of temperature on, 167 
Roots, absorption through, 220 anchorage, 222 definition of, 219 excretion through, 221 structure of, 220

Rust, 94, 168

Saliva, 316, 322, 323

Salts, 107, 302, 357

Sand, 165, 190 dunes, 165

Sanitation, $421 \mathrm{ff}$.

Saprophyte, 243

Saturation of atmosphere, 125

Science, definition of, 1

Seasons, 152

Secretions, in the mouth, 316 internal, 367,368

Seed dispersal, 238

Seeds, formation of, 234

Senses, the special, $397 \mathrm{ff}$.

Sensitiveness, of animals, 281 of $\operatorname{man}, 399$

Sepal, 233

Serums, 415

Skeletal system, $370 \mathrm{ff}$.

Skin, care of, $\mathbf{3 6 5}$ structure of, 360 uses of, 359

Smell, 399

Snow, 126

Sodium hydroxide, 106, 108

Soil, kinds of, 190, 191, 192

Dryer's classification of, 192 origin of, 186

Solar plexus, 389

Solids, change in volume, 47 change to liquids, 35,37 effect of heat on, 13 heat giren off when liquids become s., 38 heat necessary to dissolve, 38 melting points, 39 molecules in, 8

Solutes, 187, 188, 206, 219, 220, 302,322

Spiders, 264, 267

Spinal cord, 384,387

Spleen, 369

Sponges, 198, 269

Sprain, 377

Stamen, 234

Starch, digestion of, 324

formation of in plants, 204, 301

test for, 301

Steel, 87, 88

Stems, functions of, 225

kinds of, 225

structure of, 227

Sun as a source of heat, 124, 150

Sterilize, 245, 247, 308, 428

Sternum, 372

Stimulants, $328 \mathrm{ff}$.

Stomach, 310, 317, 323

Stomate, 201, 202, 214, 215

Storms, $137 \mathrm{ff}$.

definition, 141

kinds of, 142

Streams, effect on human ac-

tivities, 182

development, 175, 178, 179, 181

erosion, 172

Sugar, 301, 324, 326, 369

test for, 301

Sulphur, $77 \mathrm{ff}$.

dioxide, 94

Talus, 168

Tarsals, 373 
Taste, 398

Teeth, 312, 314

care of, 315

structure of, 314

Temperature, boiling points, 40, 42

condensation, 46

effect of on gases, 18

effect of on rocks, 167

effect of heat on liquids, 15 , 16,44

effect of heat on solids, 13

effect of $t$. on climate, 150

measurement of, 26

melting points, 39

regulation of $360,363,364$, 398

Tendon, 378, 379

Thermometer, Air, 26

centigrade, $27,28,29,30$

Fahrenheit, 27, 29, 30

determination of fixed points, 28

Galileo's, 26

range of mercury t., 31

Thermos bottle, 21, 24

Thorax, 317

Throat eavity, 310,317

Thunder, 143

Thunderstorms, 142

Tibia, 373

Tissues, definition of, 196, 275

Tobacco, 328

Tongue, 316, 398

Tonsils, 317, 354

Tornadoes, 142, 144

Touch, 397

Trachea, 347, 348

Trade winds, 140

Transpiration, 208, 209

Trichina, 308
Trunk, 371

Tuberculosis 354,376

Typhoid and flies, 425,428

Urea, 357

Ureter, 358

Urethra, 358

Urine, 358

Uvula, 312

Vaccination, 355, 417

Vaccines, 416

Valves in heart, 340

Vascular bundle, 228, 229

Veins, 200, 339, 340

Ventilation, 352

Ventricles, 338

Vertebrae, 371

Vertebrates, 254

Vessels, blood, 324, 342, 368 lymph, 324, 342, 343

Villi, 326

Vocal cords, 348

Volume, changes in, 47

Voluntary action, 390

Water, $110 \mathrm{ff}$.

absorbed by roots, 220

composition of, 110

contamination of, 428

dangers in, 116

factor in soil formation, 187

factor in starch formation, 204

falls, $177,179,181,183$

filtering of, 117

hard, 114

in the human body, 302, 257

plant and animal life depend-

ent upon, 115, 198, 211

properties and uses of, 111 
protection against loss of $w$. by plants, 213

quantity of on earth, 110, 221 soft, 114

spouts, 144

vapor in air, 121

Waste products, of plants, 216, 221

in the body, 325, 340, 351, $357,359,380$

Weather Bureau, 154, 155

definition of, 149 forecast, 154

maps, 154, 156, 157

explanation of maps, 155 , 158

Weathering, $164 ; 187,190$

Winds, $137 \mathrm{ff}$.

Worms, 268

in food, 308

Yeast, 70

Zoology, 1, $249 \mathrm{ff}$. 


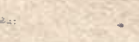



UNIVERSITY OF CALIFORNIA LIBRARY BERKELEY

THIS BOOK IS DUE ON THE LAST DATE STAMPED BELOW

Books not returned on time are subject to a fine of $50 \mathrm{c}$ per volume after the third day overdue, increasing to $\$ 1.00$ per volume after the sixth day. Books not in demand may be renewed if application is made before expiration of loan period.

\section{DEC 91918}

MIAYY 61919

\section{JUN 11 19\%}

RAE 9923

DEC $18:: ?$

APค $16 \quad 1926$

gNov' $111 \%$

MAR 27'69-8 AM

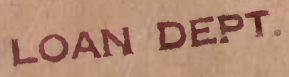

APR 16 1968

LOAN DEPT. 
TKes.

$\frac{1,9.2}{23.8} \frac{245}{18}$

\section{YC 22533}

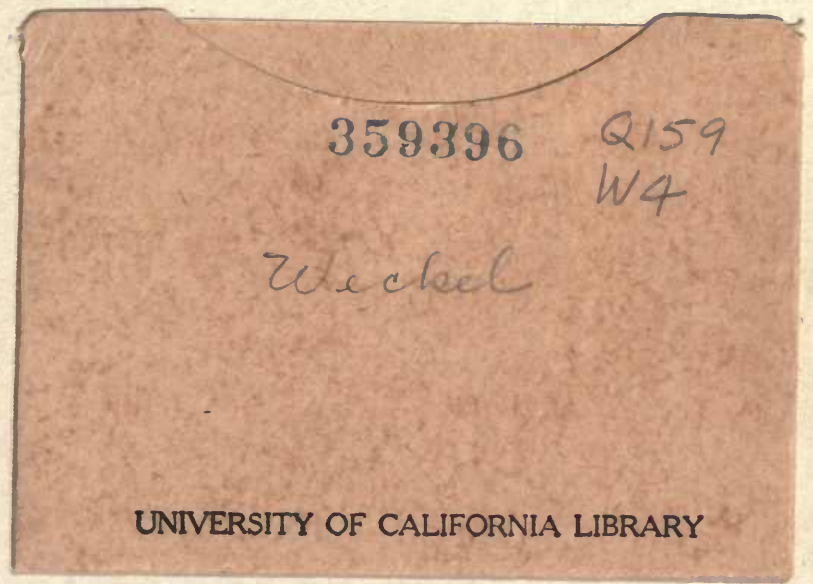

\section{UNIVERSITY OF CALIFORNIA LIBRARY}



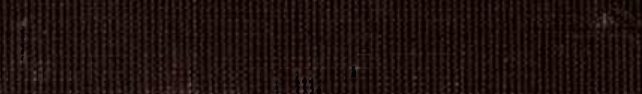

II

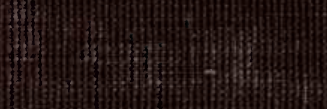

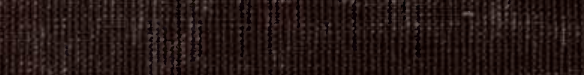

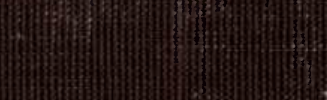

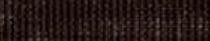

